\author{
Universidade de São Paulo \\ Instituto de Física
}

\title{
Estudo de Propriedades Eletrônicas e Estruturais de Complexos de Cobre
}

\author{
Marcos Brown Gonçalves \\ Orientadora: Dra. Helena Maria Petrilli
}

Tese de doutoramento apresentada ao

Instituto de Física para a obtenção do

título de Doutor em Ciências

Comissão examinadora:

Profa. Dra. Helena Maria Petrilli (orientadora) IFUSP

Prof. Dr. Armando Corbani Ferraz IFUSP

Prof. Dr. Henrique Eisi Toma IQUSP

Prof. Dr. Márcio Henrique F. Bettega UFPR

Prof. Dr. Wendel Andrade Alves UFABC

São Paulo 2010 


\section{FICHA CATALOGRÁFICA}

Preparada pelo Serviço de Biblioteca e Informação do Instituto de Física da Universidade de São Paulo

Gonçalves, Marcos Brown

Estudo de Propriedades Eletrônicas e Estruturais de Complexos de Cobre. São Paulo, 2010.

Tese (Doutorado) - Universidade de São Paulo. Instituto de Física - Depto. de Física dos Materiais e Mecânica

Orientador: Profa. Dra. Helena Maria Petrilli Área de Concentração: Física

Unitermos: 1. Estrutura eletrônica; 2. Física Computacional; 3. Cobre; 4. Química inorgânica.

USP/IF/SBI-083/2010 


\section{Resumo}

Neste trabalho estudamos propriedades estruturais, magnéticas e eletrônicas de complexos de cobre em duas classes de ligantes semelhantes com potenciais aplicações nas áreas de nanotecnologia e farmacologia. A primeira classe de ligantes é do tipo bases de Schiff, conhecidas por sua vasta gama de aplicações em química e biologia, aqui estudadas como miméticos de sítios de proteínas e também como potenciais metalo-fármacos. Procuramos investigar as características estruturais e eletrônicas buscando correlacionar as informações obtidas experimentalmente com as obtidas através de cálculos de estrutura eletrônica. Em especial, no estudo da competição pelo íon $C u$ entre as bases de Schiff e a proteína albumina, mostramos a influência de diversos fatores como, por exemplo, a geometria dos ligantes e a sua estrutura eletrônica. A segunda classe estudada é constituída de bases modificadas de DNA com a habilidade de complexar metais (espécie [M-DNA]) e formar estruturas com acoplamento ferromagnético. Observamos para as espécies [M-DNA] que o acoplamento ferromagnético é estabilizado através de dois efeitos: a) diferentes estados de carga que podem gerar distorções na coordenação quadrado planar; b) a adição do backbone do DNA. Utilizamos neste estudo o método Projector Augmented Wave (PAW) e também bases locais dentro da Teoria do Funcional da Densidade, através dos códigos computacionais CP-PAW e Gaussian03. 


\section{Abstract}

We studied structural, electronic and magnetic properties of copper complexes with two similar classes of ligands with potential applications in nanotechnology or pharmacology. The first class of compounds consists of Schiff bases and corresponding copper complexes. We investigated structural and electronic properties of these complexes searching for correlations among the information obtained experimentally and by electronic structure calculations. In special, in the study of the competition for the $\mathrm{Cu}$ ion between Schiff bases and the albumin protein, we show the influence of different factors such as the geometry of the ligands and their electronic structure. The second class of ligands focused in our studies are modified DNA bases coordinated to copper, where EPR studies have shown ferromagnetic interactions among the metal centers. We studied in this case the influence of the charge state and of the backbone in the magnetization of the $\mathrm{Cu}$ chain. In all cases presented here, we used ab-initio electronic structure calculations in the framework of the Density Functional Theory (DFT). This has been done using the CP-PAW code and the Gaussian03 code. 


\section{Agradecimentos}

Aos meus pais Claudio e Leslie pelo apoio e amor. Aos meus irmãos Ricardo, Sérgio e Cinthia. À minha Eliane pelo incentivo, amor, companheirismo e paciência desde o mestrado e ao Lord Braga Brown.

Agradeço em especial à Profa. Helena Petrilli por todos os ensinamentos, amizade e motivação. Agradeço à Profa. Ana Maria Ferreira pela oportunidade de estudar os complexos metálicos. À Profa. Vera Constantino, ao Prof. Giovanni Caramori pela ajuda 'química' e à profa. Marília Caldas por me receber no grupo Nanomol. Aos colegas do IF, IQ e do grupo Nanomol pelas discussões e amizade e também para a Sandra e à Rosana. À CNPq pelo auxílio financeiro Às facilidades computacionais do LCCA USP e CENAPAD SP. Às redes IMMP, INEO e Nanobiomed. 
Estrutura dos complexos de Cobre com bases de Schiff

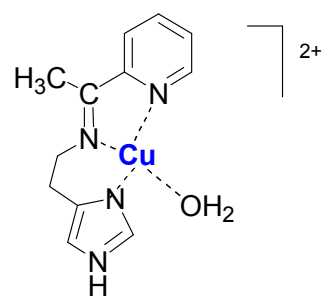

$\left[\mathrm{Cu}(\text { apyhist }) \mathrm{H}_{2} \mathrm{O}\right]^{2+}$ Tri-1

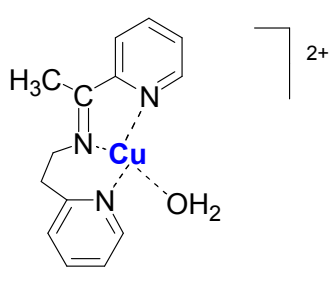

$\left[\mathrm{Cu}(\text { apyepy }) \mathrm{H}_{2} \mathrm{O}\right]^{2+}$ Tri-2

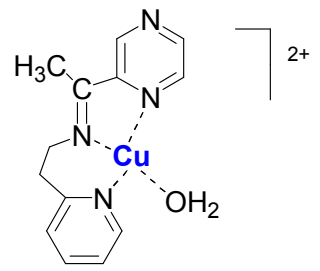

$\left[\mathrm{Cu}\left(\text { apzepy) } \mathrm{H}_{2} \mathrm{O}\right]^{2+}\right.$ Tri-3

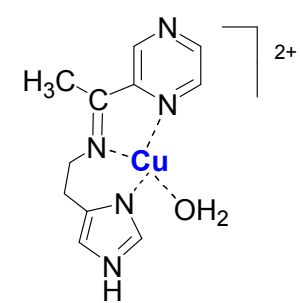

[Cu(apzhist) $\left.\mathrm{H}_{2} \mathrm{O}\right]^{2+}$ Tri-4

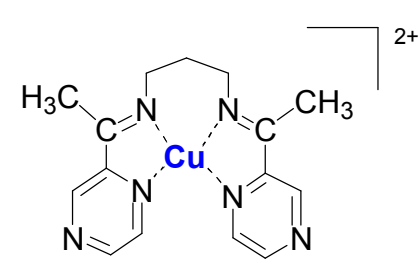

$[\mathrm{Cu}(\mathrm{apzpn})]^{2+}$ tetra-1

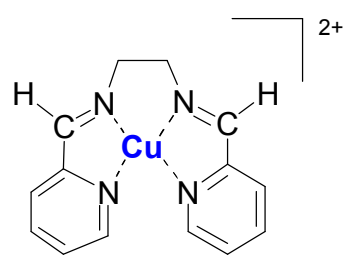

$[\mathrm{Cu}(\text { pyalen })]^{2+}$ tetra-2<smiles></smiles>

$[\text { Cu(pyen) }]^{2+}$ tetra-3

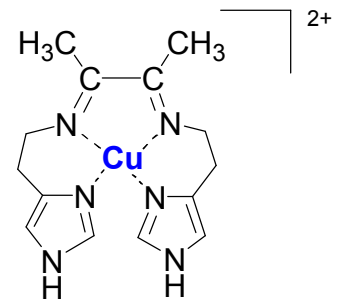

$[\mathrm{Cu}(\text { dachist })]^{2+}$ tetra-4
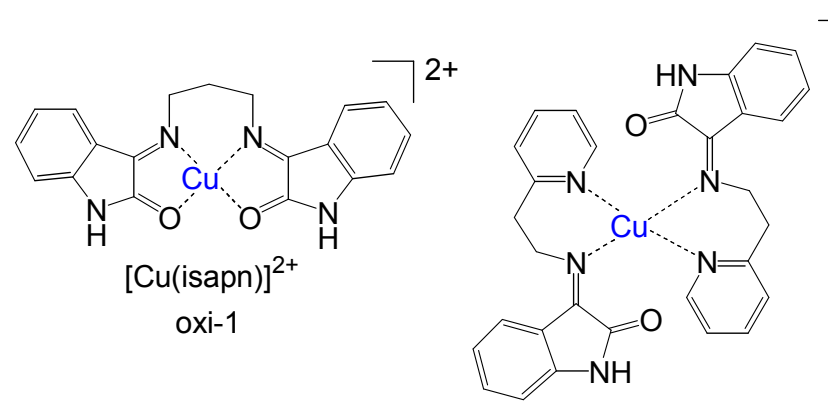

$2+$

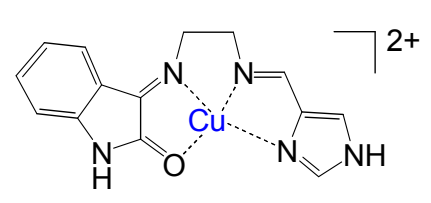

$\left[\mathrm{Cu}(\text { isaenim) }]^{2+}\right.$ oxi3

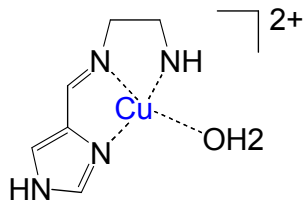

$\left[\mathrm{Cu}(\text { enim }) \mathrm{H}_{2} \mathrm{O}\right]^{2+}$ oxi-4

$\left[\mathrm{Cu}(\text { isaepy })_{2}\right]^{2+}$ oxi-2 


\section{Sumário}

1 Introdução $\quad 2$

1.1 Complexos metálicos . . . . . . . . . . . . . . . . . 2

1.1.1 Bases de Schiff . . . . . . . . . . . . . . . . . . . . 4

1.2 Proteína Albumina de Soro Humano e Bovino . . . . . . . . . . . . . . . . . 8

1.3 Bases Modificadas de DNA . . . . . . . . . . . . . . . 16

1.3 .1 A Estrutura do DNA . . . . . . . . . . . . . . 17

1.3.2 DNA como dispositivo biomolecular . . . . . . . . . . . . . . . . . 17

1.3 .3 Metal-DNA . . . . . . . . . . . . . . . . 19

2 Abordagem Teórica e Metodologia Computacional 25

2.1 Teoria do Funcional da Densidade . . . . . . . . . . . . . . . . . 26

2.2 Funções de Base . . . . . . . . . . . . . . . . . . . . . . . . . . . . . . . 29

2.3 O Método PAW . . . . . . . . . . . . . . . . . . . . . . . . 29

2.3.1 Valores Esperados . . . . . . . . . . . . . . 33

2.4 Bases Locais do tipo Gaussianas . . . . . . . . . . . . . . . . . . . . . . . 35

2.5 Dinâmica Molecular Ab initio de Car e Parrinello . . . . . . . . . . . . . . . 35

3 Complexos de Cobre com Bases de Schiff $\quad 39$

3.1 Estruturas precursoras .......................... 40

3.2 Série das piridinas, pirazinas e histaminas tridentadas . . . . . . . . . . . . . 42

3.2.1 Comparação entre os complexos e considerações sobre energia . . . . 49 
3.2.2 Estrutura eletrônica dos complexos . . . . . . . . . . . . 54

3.3 Série das piridinas, pirazinas e histaminas tetradentadas . . . . . . . . . 58

3.3.1 Estruturas dos complexos (oxidado e reduzido) . . . . . . . . . . 59

3.3.2 Estrutura eletrônica dos complexos . . . . . . . . . . . . 62

3.3.3 Energia de Ligação . . . . . . . . . . . . . . . . . . . . . . . . . . . . 74

3.4 Série Oxindol . . . . . . . . . . . . . . . . . . . . 76

3.4.1 Estrutura dos complexos . . . . . . . . . . . . 76

3.4 .2 Estrutura Eletrônica . . . . . . . . . . . . . . . . . 77

3.4.3 Considerações sobre energia . . . . . . . . . . . . . . . 78

3.5 Estudo da proteína albumina . . . . . . . . . . . . . . . 84

3.5.1 Sítio N-terminal da BSA e da HSA . . . . . . . . . . . . . . . 84

3.6 Comparação entre os complexos . . . . . . . . . . . . . . . . 85

4 Estudo de bases modificadas de DNA $\quad 96$

4.1 Sistemas Estudados . . . . . . . . . . . . . . . . . . . 96

4.1.1 Estudo para diferentes estados de carga . . . . . . . . . . . . 101

4.1.2 Estudo do M-DNA com o backbone . . . . . . . . . . . . . . . 106

5 Conclusões

A Gradiente de Campo Elétrico no Núcleo 112

A.1 Cálculo do Gradiente de Campo Elétrico (GCE) no núcleo . . . . . . . . . . 114

B

B.1 Testes de Convergência . . . . . . . . . . . . . . . . . . 120

B.2 Estudo dos complexos $\left[\mathrm{Cu}\left(\mathrm{H}_{2} \mathrm{O}\right)_{n}\right]^{2+} \ldots \ldots \ldots \ldots \ldots \ldots$

B.3 Lista dos Aminoácidos . . . . . . . . . . . . . . . . . . . . . . . . . . . . 124 


\section{Capítulo 1}

\section{Introdução}

\subsection{Complexos metálicos}

Um composto de coordenação é formado por um ou mais centros metálicos ligados a um ou mais ligantes que podem ser átomos, íons ou moléculas. Essas espécies são denominadas complexos metálicos. Originalmente este termo designava a associação reversível destas espécies através de ligações fracas. Entretanto, atualmente este conceito se modificou visto que há complexos metálicos muito estáveis sendo que a ligação pode ser irreversível (alguns compostos de coordenação podem até ser volatilizados em altas temperaturas) [1]. Classicamente um ligante é uma base de Lewis (espécie que possui átomos doadores de elétrons) e o metal é um ácido de Lewis (espécie receptora de elétrons) ${ }^{1}$ [3]. Os ligantes podem ser doadores com caráter $\sigma$ como, por exemplo, o nitrogênio e o oxigênio nas moléculas de $\mathrm{NH}_{3}$ e $\mathrm{H}_{2} \mathrm{O}$, ou caráter $\pi$ como os ligantes $\mathrm{CO}$ e $\mathrm{NO}$. Desta forma, dependendo das características dos átomos doadores e da estrutura dos ligantes, estes modificam os orbitais dos metais modulando as suas propriedades, além do fato de que o metal provoca distorções nos ligantes.

\footnotetext{
${ }^{1}$ Este conceito é mais amplo porque pode haver a chamada 'retrodoação' na qual um doador $\sigma$ de elétrons, ou base de Lewis, também pode receber elétrons através da interação com orbitais antiligantes sendo também um receptor $\pi$, ou ácido de Lewis [2].
} 
Neste trabalho estudaremos uma série de ligantes contendo sítios de $N$ e $O$ coordenados ao íon cobre.

\section{O Cobre em meio biológico}

O cobre é um dos metais de transição essenciais ao ser humano, sendo o terceiro íon mais abundante com composição média de $0.11 \mathrm{~g}$ em um homem de $70 \mathrm{~kg}$, enquanto que o zinco apresenta $2.3 \mathrm{~g}$ e o ferro aproximadamente $4.2 \mathrm{~g}$ [4]. O cobre está envolvido em inúmeros processos biológicos vitais, tais como a fotossíntese, a respiração, a inativação de radicais livres, o metabolismo do $F e$ e também em funções neurológicas [4-6]. Sua importância vem da capacidade de realizar reações de óxidorredução em um intervalo específico de potenciais necessários para a ativação e inativação de determinados processos biológicos [4]. Acreditase que a utilização do $C u$ em seres aeróbicos data da utilização do $O_{2}$ [4]. Com o uso de $\mathrm{O}_{2}$, tornou-se necessário enzimas com um potencial redox mais alto entre 0 a $0.8 \mathrm{~V}$. Desta forma as enzimas e proteínas dos organismos aeróbicos com potenciais redox mais altos aproveitaram o poder oxidante do $\mathrm{O}_{2}$ para tais tarefas [4]. Por outro lado, o excesso de cobre no organismo também é responsável pela geração de danos oxidativos em processos com provável participação de radicais livres através de reações do tipo-Fenton [7], que pode culminar em inúmeras doenças e levar à morte celular.

O cobre apresenta dois estados de oxidação mais usuais. O chamado $C u^{+}$ou $\mathrm{Cu}(\mathrm{I})$, com a carga formal $1+e$ (configuração eletrônica $d^{10}$ com camada fechada), apresenta preferencial coordenação tetraédrica, mas também é encontrado na coordenação linear [3]. Já o $C u^{2+}$ ou $\mathrm{Cu}(\mathrm{II})$, com carga formal $+2 e$ (configuração eletrônica $d^{9}$ ), pode apresentar número de coordenação 4 ou 5 e configuração geométrica que dependerá da natureza dos ligantes: quadrado piramidal, trigonal bipiramidal ou quadrado planar através de distorção tetragonal devido ao elétron desemparelhado (efeito Jahn-Teller)². A interação entre os diferentes

\footnotetext{
${ }^{2}$ É importante salientar que a visão iônica dos metais com carga $\mathrm{Cu}(\mathrm{I})$ ou $\mathrm{Cu}(\mathrm{II})$ é apenas pictórica já que nem sempre é possível atribuir a que sítio os elétrons de valência pertencem, devido a sua deslocalização eletrônica. Entretanto utilizaremos a nomenclatura empregada na área que é designar os diferentes estados
} 
ligantes orgânicos e o $C u$ é diferente dependendo do seu estado de oxidação. A teoria HSAB (Hard and Soft Lewis Acids and Bases) [9] utiliza a idéia de que a densidade eletrônica mais polarizável dos metais tende a interagir com a densidade eletrônica mais polarizável dos ligantes, apresentando um caráter mais covalente de ligação. Estes, ligantes e metais, são chamados de ácidos ou bases soft ou moles. Para compostos com caráter mais iônico, metais em estado de oxidação mais positivo e ligantes com menor polarizabilidade são chamados de hard ou duros. Em geral o $\mathrm{Cu}^{1+}$ tem preferência por ligantes com nuvens eletrônicas mais polarizáveis, como no caso de ligantes contendo enxofre $(S)$ ou ligantes com caráter $\pi$ receptor. Já o $\mathrm{Cu}^{2+}$ é considerado um ácido de caráter intermediário, uma vez que forma complexos mais estáveis com ligantes de menor polarizabilidade como a carbonila $(C=O)$, o $N(-N=)$ das iminas e também ligantes com caráter $\pi$, como o imidazol e a piridina. Os ligantes estudados neste trabalho são considerados entre intermediários e duros, possuindo sítios de coordenação de $N$ e $O$.

\subsubsection{Bases de Schiff}

O estudo de sistemas biológicos metalados é bastante complexo, e por este motivo, a criação de modelos, tanto empíricos como teóricos, visa tornar possível o estudo de características pontuais destas macromoléculas. As bases de Schiff têm desempenhado este papel pois formam facilmente complexos de coordenação estáveis com a maioria dos metais de transição [10]. A estabilidade térmica e a habilidade de formar complexos metálicos em diferentes estados de oxidação possibilitam o seu uso em diversos processos catalíticos (como por exemplo em reações com o oxigênio molecular) [11] e também em estudos de miméticos de proteínas contendo sítios metálicos ${ }^{3}$ (Fig. 1.2) [4]. As bases de Schiff são uma classe de compostos que possuem o grupo imina formado pela condensação do grupo amina $\left(-N H_{2}\right)$ primário de

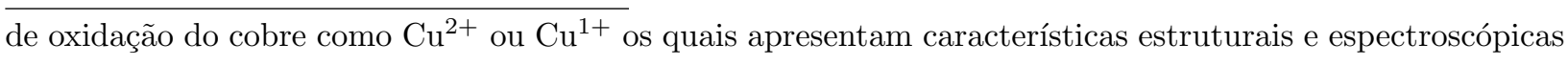
peculiares [8].

${ }^{3}$ Os miméticos são estruturas modelo simplificadas de sítios de proteínas, com propriedades similares como, por exemplo, a afinidade de ligação por determinado íon. 
uma molécula com o grupo aldeído ou cetona de uma segunda molécula [10]. A síntese da imina é reversível, envolvendo um intermediário carbinolamina e a eliminação de moléculas de água (Fig. 1.1) [10].

O interesse nos complexos com bases de Schiff está associado à modulação ${ }^{4}$ da ligação com o metal, que por vezes tem como função mimetizar o comportamento de sítios ativos em metaloproteínas ou de sítios coordenantes de metais em biomoléculas, mas, com maior simplicidade estrutural, e sem perder as características originais, como a geometria de coordenação. Esta modulação imposta pelo ligante ao metal pode repercutir na atividade biológica, como por exemplo, no grau de dano oxidativo gerado a uma biomolécula (Fig. 1.2) $[12,13]$. Essa reatividade modulada torna possível a potencial utilização destes compostos como metalo-fármacos. Os complexos formados por íons de $C u$ são de particular interesse uma vez que, sendo um elemento essencial, em princípio, teria os mecanismos naturais de absorção, distribuição e eliminação conhecidos [14].

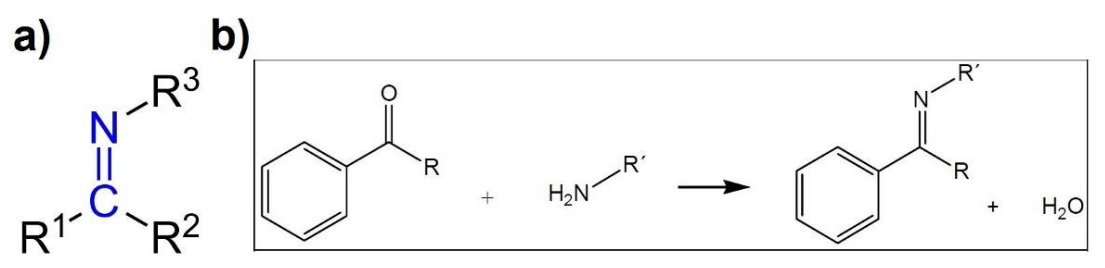

Figura 1.1: a) Representação esquemática da estrutura básica das bases de Schiff. b) Exemplo da reação de um aldeído (ou cetona) e uma amina primária formando uma base de Schiff ou imina (figura reproduzida da referência [10]).

Os complexos de cobre com bases de Schiff estudados no presente trabalho foram sintetizados, caracterizados e tiveram suas atividades biológicas analisadas nos laboratórios da Profa. Ana Maria da Costa Ferreira, do Instituto de Química da USP (IQUSP). Estes

\footnotetext{
${ }^{4}$ Diz-se que o ligante 'modula' as propriedades do complexo impondo certas restrições à esfera de coordenação do metal gerando características estruturais e eletrônicas particulares. Além disso, as características externas do ligante também irão repercutir nas medidas.
} 
Complexos de Cobre com Ligantes Bases de Schiff

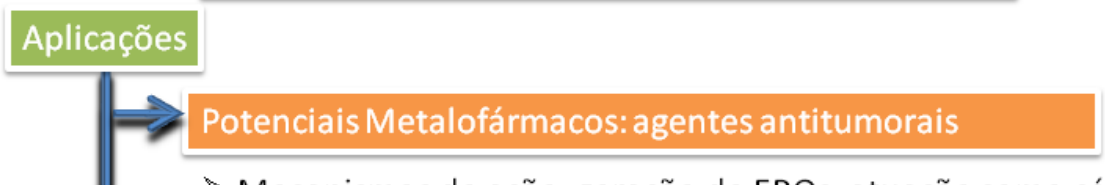

Mecanismos de ação: geração de EROs, atuação como cátions lipofílicos, indução de apoptose, ativação/inibição de kinases

Ação oxidativa no DNA e na mitocôndria

Ligantes competitivos por

cobre em meio biológico

Presentes no sítio ativo de inúmeras proteínas (resíduos de histidina)

Catalisadores

Catalisadores eficientes de processos oxidativos

Miméticos de sítios ativos

de metaloproteínas

Atividade SOD: Antioxidante

$>$ Atividade tirosinase ou catecol oxidase: pró-oxidante

Complexos multinucleares:

Propriedades magnéticas e catalíticas peculiares

Figura 1.2: Esquema das potenciais aplicações dos complexos de cobre estudados. Potenciais metalofármacos $[12,15]$; Ligantes competitivos por $\mathrm{Cu}$ em meio biológico [16, 17]; Catalisadores [18, 19]; Miméticos de sítios ativos de metaloproteínas [20,21]; Complexos multinucleares com propriedades magnéticas e catlíticas [19,22].

complexos foram investigados com diversas técnicas espectroscópicas, tais como a espectroscopia UV-visível (UV/VIS), espectroscopia vibracional no infravermelho (IR), Dicroísmo Circular (DC ou CD) e ressonância paramagnética eletrônica (EPR). Para a análise das reatividades utilizou-se técnicas eletroquímicas, através da investigação dos potenciais redox, por voltametria cíclica, de suas propriedades antioxidante e pró-oxidante, como a dismutação (desproporcionamento) ou a formação de radicais livres e consequentemente a geração de da- 


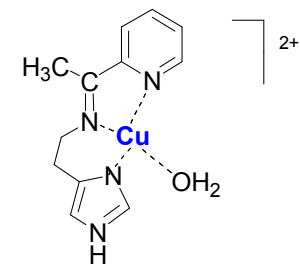

$\left[\mathrm{Cu}(\text { apyhist }) \mathrm{H}_{2} \mathrm{O}\right]^{2+}$

Tri-1

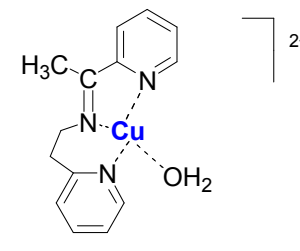

$\left[\mathrm{Cu}(\text { apyepy }) \mathrm{H}_{2} \mathrm{O}\right]^{2+}$ Tri-2

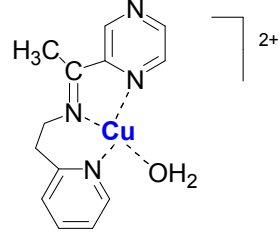

$\left[\mathrm{Cu}(\text { apzepy }) \mathrm{H}_{2} \mathrm{O}\right]^{2+}$ Tri-3

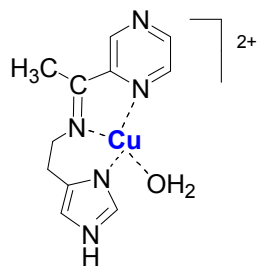

$\left[\mathrm{Cu}(\text { apzhist }) \mathrm{H}_{2} \mathrm{O}\right]^{2+}$ Tri-4

Figura 1.3: Representação esquemática dos complexos de cobre da série das piridinas, pirazinas e histaminas tridentadas estudadas neste trabalho utilizando a mesma nomenclatura para designar os complexos e os ligantes (entre parênteses) introduzida na Ref. [10]. Na linha abaixo a nomenclatura simplificada empregada neste trabalho.
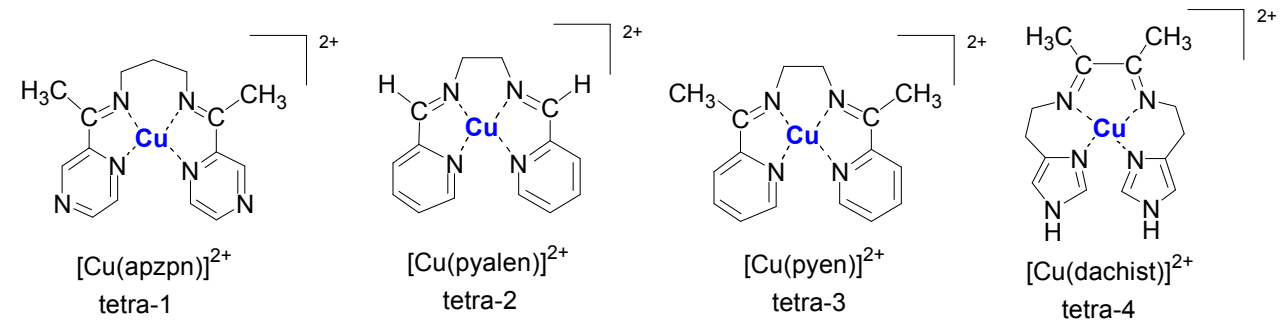

Figura 1.4: Representação esquemática dos complexos de cobre da série das piridinas, pirazinas e histaminas tetradentadas estudadas neste trabalho utilizando a mesma nomenclatura para designar os complexos e os ligantes (entre parênteses) introduzida na Ref. [17]. Na linha abaixo a nomenclatura simplificada empregada neste trabalho.

nos oxidativos em biomoléculas, como proteínas, DNA, lipídios e açúcares [12,17,23]. Estes ligantes foram classificados em duas séries: a) a série das piridinas, pirazinas e histaminas tridentadas (Fig. 1.3) e tetradentadas (Fig. 1.4); b) a série dos oxindóis (Fig. 1.5). Notamos que existem na literatura dados cristalográficos apenas para o complexo de cobre com o ligante apyhist e espécies correlatas (Fig. 1.3) [19,24]. Uma das contribuições do presente trabalho é preencher esta lacuna estudando as possíveis conformações de equilíbrio para os 


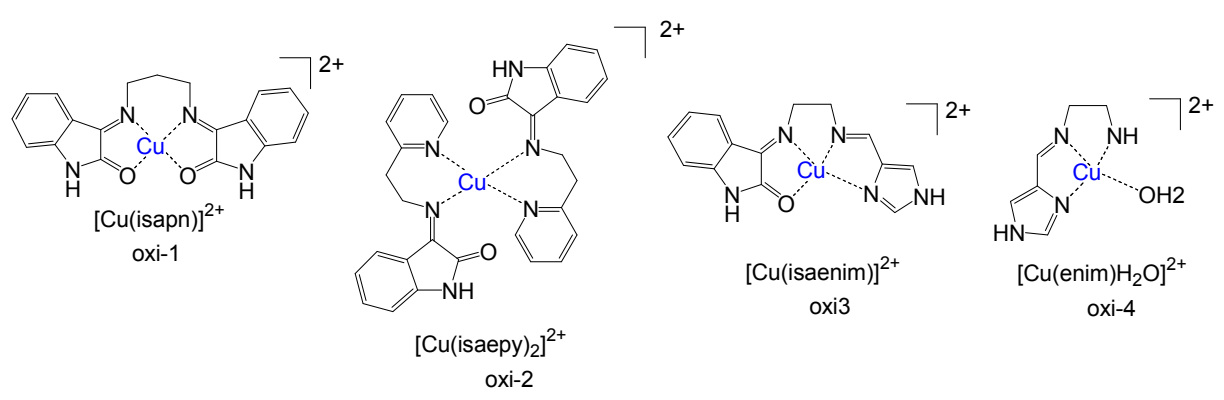

Figura 1.5: Representação esquemática dos complexos de cobre da série dos oxindóis estudados neste trabalho utilizando a mesma nomenclatura para designar os complexos e os ligantes (entre parênteses) introduzida na Ref. [16]. Na linha abaixo a nomenclatura simplificada empregada neste trabalho.

demais complexos.

Alguns destes complexos são capazes de atravessar a membrana celular e induzir a apoptose celular, tendo como alvos principais a mitocôndria e o DNA (Fig. 1.2) [12, 15]. O mecanismo de ação, neste caso, envolve a formação de espécies reativas de oxigênio (EROs - radicais livres), em presença de $\mathrm{H}_{2} \mathrm{O}_{2}$ causando danos às biomoléculas [12,13]. No DNA, estes complexos induzem a clivagem da fita simples ou dupla [12], enquanto na mitocôndria diminuem o potencial de membrana e desacoplam a síntese do ATP (atuam como agente desacoplador), induzindo apoptose [15].

\subsection{Proteína Albumina de Soro Humano e Bovino}

A albumina humana (human serum albumin ou HSA, Fig. 1.6) é a proteína mais abundante no plasma com concentração de $600 \mu M[25,26]$. Aproximadamente $80 \%$ da pressão osmótica do sangue é mantida pela albumina cuja massa molecular é de $66 \mathrm{kDa}^{5}$ [27]. A albumina tem a função de transporte de diversas moléculas e íons endógenos e exógenos [27] como o Cu,

\footnotetext{
${ }^{5} 1 \mathrm{Da}=1 \mathrm{u} . \mathrm{m} . \mathrm{a} .=1.66054 .10^{-27} \mathrm{Kg}$.
} 
$Z n, C d, N i, A u$ e $H g$ [26]. A HSA é constituída por uma única cadeia polipeptídica com 585 aminoácidos $(\mathrm{AA})^{6}$ sendo 9 alças, 17 pontes disulfídicas e uma cisteína livre [28]. Sua alta solubilidade é devida aos resíduos polares na sua superfície e é atribuída a carga formal de -18 e distribuídos de forma não uniforme [28]. Na região da HSA com a maior quantidade de resíduos negativamente carregados estão os dois principais sítios de coordenação para cátions metálicos: o sítio N-terminal e o sítio do aminoácido cisteína, contendo o grupo SH (sulfidril), na posição 34 (cis-34). O sítio N-terminal é representado através dos três primeiros aminoácidos da sequência da HSA: Asp1 (ácido aspártico), Ala2 (alanina), His3 (histidina) e do nitrogênio N-terminal (Fig. 1.6). O N-terminal da albumina de soro bovino (BSA) se diferencia da HSA por apresentar a Thr2 (treonina) ao invés do Ala2 [29]. O sítio N-terminal é a região da proteína preferencial para a interação com os íons $C u^{2+}[30]$. A segunda região usual de ligação de íons metálicos é o sítio da cis-34 que não é específico e pode coordenar íons $\mathrm{Au}^{+}, \mathrm{Ag}^{+}, \mathrm{Hg}^{2+}, \mathrm{Cd}^{2+}$ e $\mathrm{Cu}^{2+}$ [28].

Desde 1948 já havia evidências da forte ligação do íon cobre com a albumina [26] e acreditavam que o sítio N-terminal estava envolvido nesta ligação. Em 1974 Sarkar et al [31] sintetizaram miméticos do sítio N-terminal da HSA. Em 1984 espectros de ressonância magnética nuclear (NMR) revelaram com maior detalhe a estrutura do sítio N-terminal da HSA quando complexado com $\mathrm{Cu}^{2+}$ e $\mathrm{Ni}^{2+}[32]$. É importante ressaltar que nesta época ainda não haviam dados conclusivos de cristalografia para a HSA, sendo conhecida apenas sua estrutura primária [32]. Com base no experimento de NMR, comprovou-se a coordenação quadrado planar com o $\mathrm{Cu}^{2+}$ como já sugerido na literatura. Em 1989 Perutz obteve a estrutura cristalográfica da HSA [33] publicada no site: www.rcsb.org/PDB sob o código 1N5U, mas nós desconhecemos qualquer publicação referente à estrutura cristalográfica da BSA. Nas investigações realizadas nos laboratórios do IQ-USP, foi sintetizado o mimético do sítio N-terminal da HSA [16]. Por este motivo realizamos, no presente trabalho, estudos computacionais para o tripeptídeo terminal da HSA e da BSA.

\footnotetext{
${ }^{6}$ No apêndice B.3 apresentamos a estrutura química dos vinte aminoácidos principais.
} 


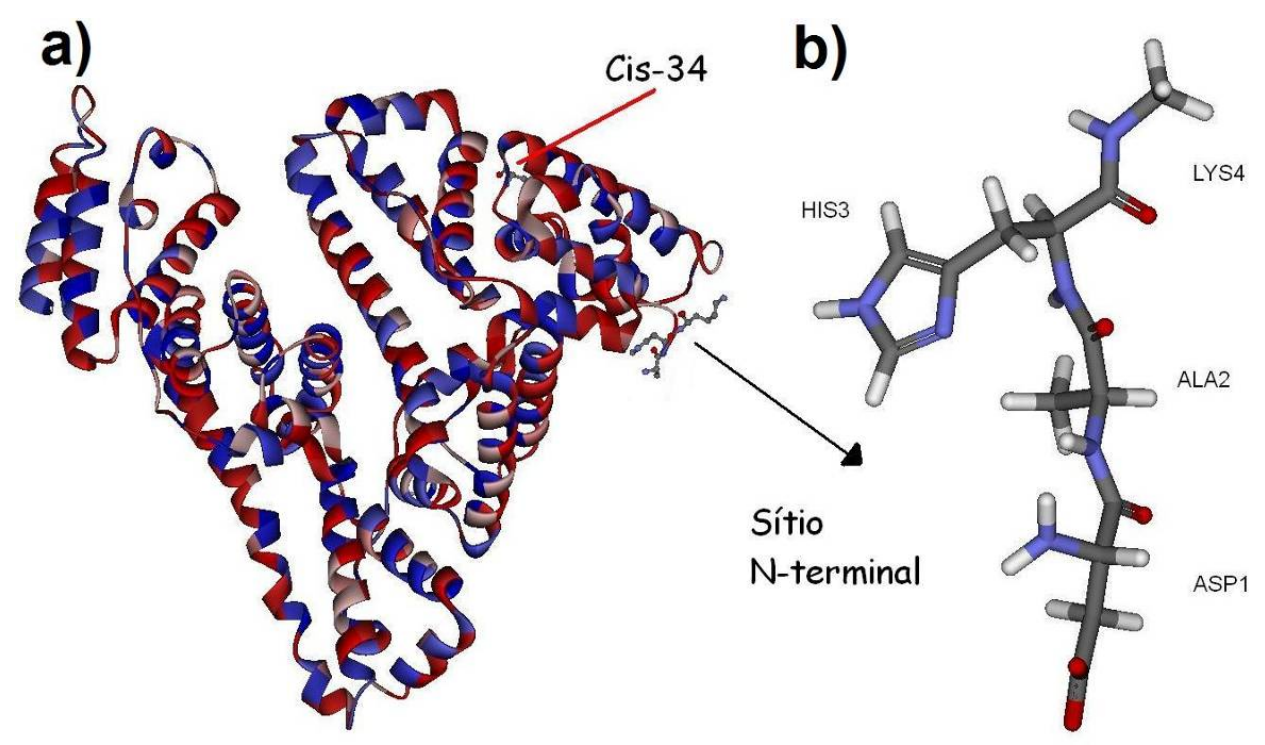

Figura 1.6: a) Representação artística da HSA (código PDB:1N5U) com o destaque das regiões do aminoácido cis-34 e dos aminoácidos do sítio N-terminal. b) Representação do sítio N-terminal constituído pelos três primeiros aminoácidos ASP1, ALA2 e HIS3 e parte do quarto resíduo (LYS4) da sequência polipeptídica.

Existem na literatura poucos estudos computacionais sobre a coordenação do íon $C u$ no sítio N-terminal da HSA [34-37]. Utilizando a abordagem de dinâmica molecular clássica e também métodos semi empíricos (ZINDO) destacamos o trabalho de Silva et al [35] onde estudaram a afinidade do sítio N-terminal por diferentes íons e as variações da afinidade ao alterar certos aminoácidos do sítio N-terminal. O estudo mais relevante com relação ao nosso trabalho é o trabalho de Kima et al de 2008 [36], onde cinco diferentes conformações do oligopeptídeo mimético do N-terminal são analisados, em pH maior que o fisiológico, em relação à estabilidade no vácuo e em solvente contínuo. Entretanto a estrutura mais estável encontrada foi aquela em que não há ligação do $C u$ com o $N$ da His3 indicando uma configuração diferente daquela observada por diversas técnicas experimentais [32,37].

Além do sítio N-terminal, a cis-34 (Fig. 1.7) é outro sítio conhecido de interação com metais [38]. A cis-34 é a única cisteína que não faz ligação disulfídica na albumina e, por- 

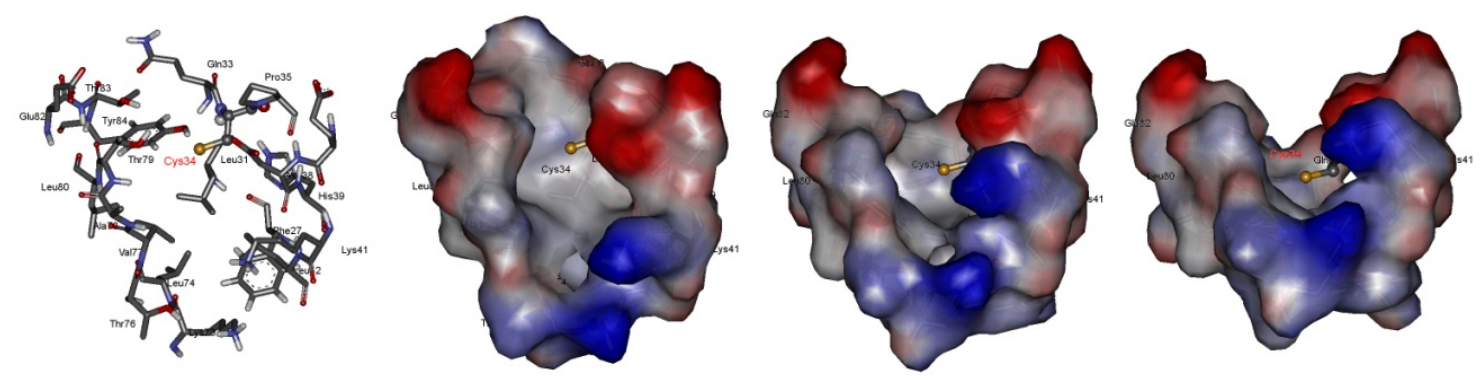

Figura 1.7: Representação dos aminoácidos constituintes da cavidade que permite o acesso ao aminoácido cis-34 da HSA (código pdb 1N5U). Representação artística da superfície de potencial eletrostático em três perspectivas diferentes da cavidade da cis-34.

tanto, está disponível para realizar ligações. Seu grupo sulfidril realiza ligação com diversas moléculas do plasma sanguíneo [39]. Não é do nosso conhecimento a existência de estudos computacionais sobre a interação de íons $C u$ com a cis-34. O que se sabe é que este possui alta constante de afinidade por íons 'macios' como $\mathrm{Au}^{+}, \mathrm{Ag}^{+}, \mathrm{Hg}^{2+}$ e $\mathrm{Cd}^{2+}$ [28]. Em relação ao $C u$ há indícios de que coordene em geometria tetraédrica com dois sítios de $O$ e dois sítios de $N$ [40], mas não se sabe, ao menos, se um dos ligantes é uma molécula de $\mathrm{H}_{2} \mathrm{O}$.

\section{Resultados experimentais para a competição entre ligantes por cobre}

Através de técnicas como o CD pode-se estudar a estabilidade termodinâmica relativa entre os complexos e ligantes biológicos do plasma humano, como a HSA, além de obter informações sobre as modificações na proteína geradas pelos complexos. A literatura mostra que no experimento de titulação ${ }^{7}$ ao se adicionar íons cobre na forma de aqua complexo, até a relação molar HSA:Cu igual a 1:1, verifica-se a inserção do íon $C u$ no sítio N-terminal [16]. Com o excesso de $C u$ este se insere na região da cis-34. Esta tendência já foi confirmada em

\footnotetext{
${ }^{7}$ Titulação é uma técnica de química analítica em que se adiciona um reagente $A$ em pequenas porções ao reagente $B$, até a proporção estequiométrica (ou maior). No presente caso é inferido a quantidade de produto formado através nas mudanças espectroscópicas observadas nas técnicas UV-VIS e CD.
} 
diversos trabalhos experimentais [30,41-44], através de técnicas como UV-/VIS, EPR, CD entre outras. Nestes casos o íon está coordenado à moléculas de $\mathrm{H}_{2} \mathrm{O}$ que são bastante lábeis e facilmente trocadas pela proteína. Esta substituição é favorável não só entalpicamente, através da maior afinidade do ligante N-terminal, como também entropicamente, por exemplo, através do efeito quelato, favorecendo a interação com o N-terminal [3].

Um dos objetivos das investigações experimentais nesta área $[12,45]$ é estudar a competitividade pelo cobre entre as bases de Schiff e a albumina, isto é, se os complexos são estáveis frente a uma proteína do soro humano com alta afinidade por cobre, como é a HSA . Como já mencionamos anteriormente, a albumina possui dois sítios principais de coordenação com o cobre (Fig. 1.6): o N-terminal com alta afinidade por cobre e o sítio multimetal cis-34 com menor afinidade por $C u$. O cobre complexado a diferentes bases de Schiff comporta-se de maneira diferente no equilíbrio de transferência do íon metálico (ou todo o complexo) à HSA. Na maioria dos casos os complexos se mantém estáveis frente à albumina, apresentando tendências semelhantes de compartilhar o íon $C u$ com a albumina. As constantes de estabilidade determinadas (Tabela 1.1) são de ordem semelhante a aquelas das espécies $[\mathrm{Cu}(\mathrm{HSA})]$ e $[\mathrm{Cu}(\mathrm{BSA})]$.

Os equilíbrios competitivos entre a albumina e as diferentes bases de Schiff pelo íon $C u$ podem ser estudados através de espectros de EPR e de CD. Na Fig. 1.8 apresentamos os resultados obtidos por CD extraídos das Refs. [16,17,45]. A banda na região de $564 \mathrm{~nm}$ indica a coordenação do cobre no sítio N-terminal e a banda na região de $370 \mathrm{~nm}$ no sítio da cis-34 [10]. A banda ao redor de 470/570 nm, está associada a transições eletrônicas $d$ - $d$ do íon neste sítio [43] (Fig. 1.8 (a) e (b)). Este comportamento é característico para a grande maioria dos complexos estudados, inclusive para o $\left[\mathrm{Cu}\left(\mathrm{H}_{2} \mathrm{O}\right)_{4}\right]^{2+}[16,17]$. A figura 1.8 (c) mostra o caso do complexo $\left[\mathrm{Cu}(\text { apzhist }) \mathrm{H}_{2} \mathrm{O}\right]^{2+}$ (tri-4 - Fig. $\left.1.3(\mathrm{~d})\right)$ no qual o excesso o íon $C u$ é inserido no sítio da cis-34 dando origem a uma banda ao redor de 370/470 nm.

A exceção ocorre para o composto $\left[\mathrm{Cu}(\text { apyhist }) \mathrm{H}_{2} \mathrm{O}\right]^{2+}$ (tri-1 - Figs. 1.3 e 1.8 (e)) onde logo no início da titulação ocorre a inserção do íon no sítio da cis-34. A fim de verificar se 

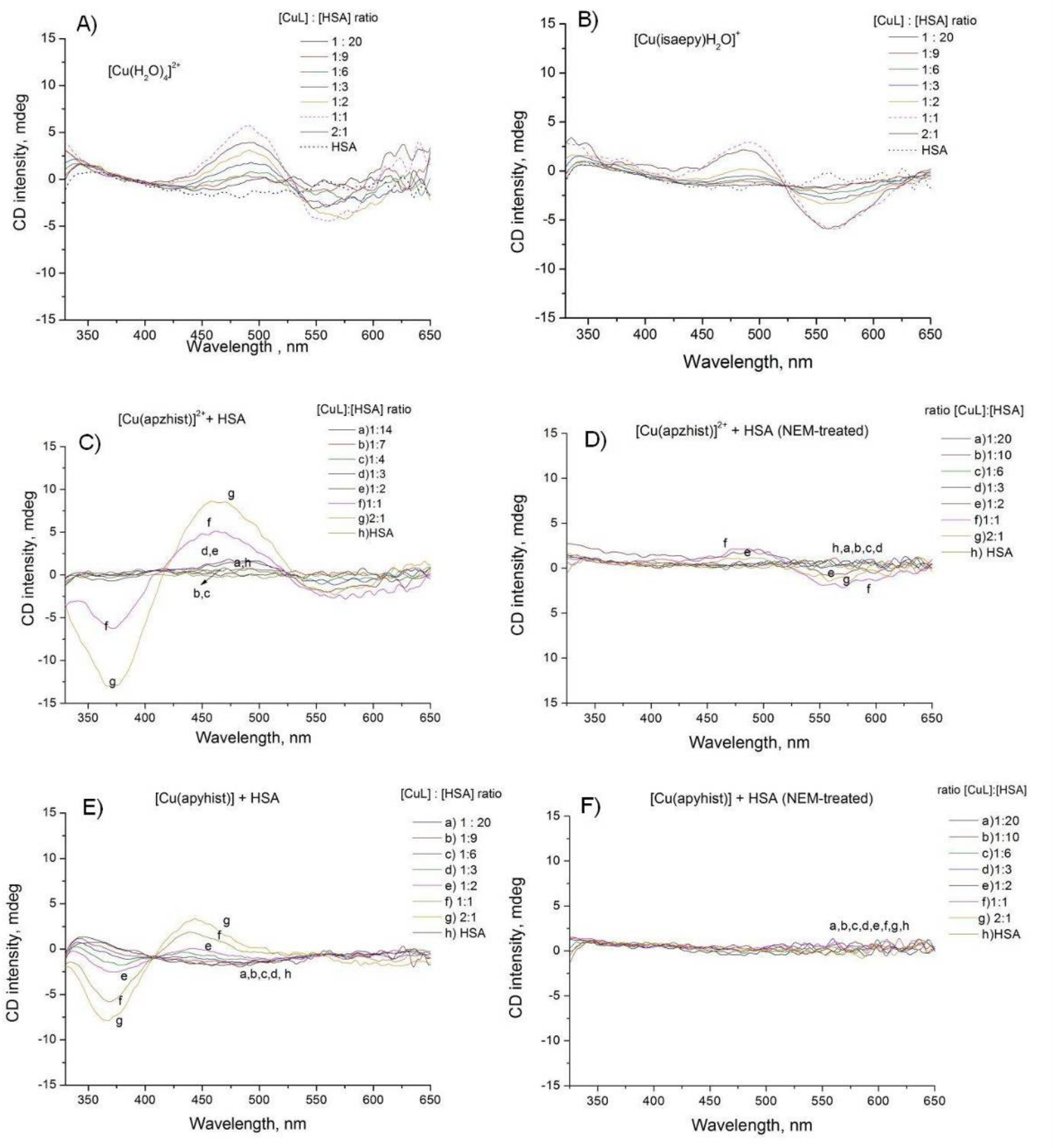

Figura 1.8: Espectros de CD da titulação de HSA com os complexos: A) $\left[\mathrm{Cu}\left(\mathrm{H}_{2} \mathrm{O}\right)\right]^{2+}$; B) $\left[\mathrm{Cu}(\text { isaepy })_{2}\right]^{2+}$ (oxi-2); C) $\left[\mathrm{Cu}(\text { apzhist }) \mathrm{H}_{2} \mathrm{O}\right]^{2+}$ (tri-4); D) $\left[\mathrm{Cu}(\text { apzhist }) \mathrm{H}_{2} \mathrm{O}\right]^{2+}$ (tri-4) + NEM; E) $\left[\mathrm{Cu}(\text { apyhist }) \mathrm{H}_{2} \mathrm{O}\right]^{2+}\left(\right.$ tri-1); F) $\left[\mathrm{Cu}(\text { apyhist }) \mathrm{H}_{2} \mathrm{O}\right]^{2+}($ tri-1) $+\mathrm{NEM}[16,45]$. 
o $C u$ estava sendo transferido realmente na cis-34, foi utilizado um composto para bloquear a cis-34, o N-etilmaleimida (NEM) [46] e assim verificar se o íon $C u$ do tri-1 seria inserido no sítio de alta afinidade por $C u$ (o sítio N-terminal). As figuras 1.8 (d) e (f) mostram o espectro CD da HSA com o agente bloqueador da cis-34 com os complexos. Para o tri-4, o Cu é inserido no N-terminal, como esperado, mas para o tri-1 não ocorre essa inserção, indicando que por algum motivo não há a interação com o N-terminal e a interação realmente ocorre apenas na cis-34 [45]. A tabela 1.1 mostra as constantes de estabilidade obtidas por CD para os diferentes complexos ${ }^{8}$ (Constantes estas obtidas através dos espectros de CD da Fig. 1.8).

Em paralelo aos estudos de CD, também foram realizados pelos pesquisadores do IQ-USP estudos de EPR a fim de verificar distorções na esfera de coordenação do íon $C u^{2+}$. Estes estudos indicam que o $\left[\mathrm{Cu}\left(\mathrm{H}_{2} \mathrm{O}\right)_{4}\right]^{2+}$ apresenta valores característicos de $\mathrm{A} / /$ (definidos no anexo I) de 125 G (Gauss). Ao interagir com a proteína, o íon é inserido completamente no sítio N-terminal e apresenta $\mathrm{A} / /=205 \mathrm{G}$, que é o valor característico para o $C u^{2+}$ na coordenação quadrado planar com quatro ligantes $\mathrm{N}$ do sítio N-terminal [32]. Por outro lado, para o $C u$ complexado com os diversos ligantes imínicos, estes valores estão entre 178 a 196 G (vide tabela 4 do anexo I). Ao comparar a competição entre os complexos e a proteína, nota-se que a proteína é capaz de subtrair o íon do complexo e em alguns casos há indícios de que o complexo se ligou a proteína. Por exemplo, para o complexo $\left[\mathrm{Cu}(\text { isaepy })_{2}\right]^{2+}$ (oxi-2) há três sinais característicos da localização do $C u$ : este se distribui entre o sítio Nterminal, outro sítio não bem definido e também se mantém na forma original ligado ao próprio ligante. Por outro lado, o sinal de EPR indica que o $[\mathrm{Cu}(\text { isaenim })]^{2+}$ (oxi-3) retém o íon não o disponibilizando para a proteína.

Este comportamento não esperado verificado através de duas técnicas espectroscópicas (CD e EPR) se apresentou como motivação para o presente trabalho teórico onde procuramos investigar as diferenças e semelhanças entre estes compostos visando explicar as dife-

\footnotetext{
${ }^{8}$ Os valores apresentados nesta tabela indicam que há um equilíbrio químico no qual parte do $C u$ do complexo é transferido para a proteína.
} 
Tabela 1.1: Medidas das constantes de estabilidade relativa $\left(\mathrm{K}_{C u L}\right)$ dos complexos listados na coluna 1 frente à albumina obtidas por $\mathrm{CD}[10,16]$. A banda na região de $\lambda=564 \mathrm{~nm}$ indica a coordenação do íon $C u$ no sítio N-terminal. O erro experimental é \pm 1 . [38].

\begin{tabular}{|c|c|c|}
\hline Complexos & $\begin{array}{l}\log \mathrm{K}_{C u L} \\
(564 \mathrm{~nm})\end{array}$ & $\begin{array}{l}\log \mathrm{K}_{C u L} \\
(564 \mathrm{~nm})\end{array}$ \\
\hline & BSA & HSA \\
\hline tri-1 & - & \\
\hline tri-2 & 13.9 & \\
\hline tri-3 & 12.6 & \\
\hline tri-4 & 14.0 & \\
\hline tetra-2 & 13.1 & \\
\hline tetra-4 & 13.6 & \\
\hline$[\mathrm{Cu}(\mathrm{BSA})]$ & 12.9 & \\
\hline oxi-2 & & 15.7 \\
\hline oxi-4 & & 16.2 \\
\hline oxi-3 & & 16.7 \\
\hline oxi-1 & & 18.1 \\
\hline$[\mathrm{Cu}(\mathrm{HSA})]$ & & 16.2 \\
\hline
\end{tabular}


renças verificadas nas suas reatividades. Nesta avaliação consideramos os seguintes aspectos mencionados a seguir:(1) Propriedades estruturais: estruturas de equilíbrio e conformações de mínimos locais, possibilidade de polimerização ou formação de estruturas cíclicas, coordenação com o $C u$, distâncias $C u$-ligante, ângulo de torção, ângulo de 'abertura' do ligante. Procuramos ainda investigar as espécies no estado reduzido a fim de verificar maior estabilidade do tri-1 nesta conformação. (2) Propriedade energética: energia de ligação. Estrutura eletrônica: característica dos orbitais, densidade de estados, momento de dipolo e características de polaridade dos ligantes. (4) Além do estudo dos complexos isolados estudamos o mimético do sítio N-terminal da HSA/BSA e também o sítio da cis-34.

Em resumo, no presente trabalho realizamos estudos de propriedades estruturais, eletrônicas e hiperfinas para as bases de Schiff complexadas com o íon $C u$ e também para os sítios de ligação com metal nas proteína HSA e BSA, buscando correlações entre os resultados experimentais e os obtidos através de cálculo ab-initio de estrutura eletrônica.

\subsection{Bases Modificadas de DNA}

Os avanços em bioquímica e biologia molecular apresentam novas perspectivas uma vez que proteínas, enzimas, ácidos nucleicos e uma infinidade de moléculas trabalham em sincronia mantendo o bom funcionamento dos seres vivos. Estas "nanomáquinas"com propriedades elétricas, mecânicas e químicas nos levam a pergunta: porque não utilizá-las em novas ferramentas tecnológicas? Conhecendo o funcionamento destas biomoléculas, podemos utilizá-las em dispositivos e sensores biológicos além de melhorar o relógio biológico protegendo o ser humano de vírus, bactérias, câncer, etc.

Dentre as características deste mundo biomolecular com potenciais aplicações tecnológicas destacamos a seletividade, reconhecimento, automontagem e armazenamento. O ácido desoxirribonucléico (DNA) apresenta estas características e pode adequar seu uso em determinadas aplicações. Este trabalho busca entender o funcionamento de uma bases modificada de DNA com potenciais aplicações em nanobiotecnologia. 


\subsubsection{A Estrutura do DNA}

O DNA (Fig. 1.9a) possui uma estrutura helicoidal formada por pequenas unidades chamadas de nucleotídeos. Cada nucleotídeo é composto por três partes: grupo fosfato, açúcar (2-desoxi-D-ribose) e base nitrogenada. O DNA é constituído por uma sequência de nucleotídeos formando o polinucleotídeo. A estabilidade da dupla hélice é dada pelas ligações de $\mathrm{H}$ que se formam entre as bases, o empilhamento entre as bases e o efeito hidrofóbico no interior da dupla hélice. A estrutura externa do DNA (backbone) é formada pela ligação fosfodiéster e pelo açúcar 2-desoxi-D-ribose (Fig. 1.9a-c). Internamente ao backbone estão as bases nitrogenadas constituídas de duas famílias: as pirimidinas representadas pelas bases citosina $(\mathrm{C})$ e timina $(\mathrm{T})$ e as purinas representadas pelas bases adenina $(\mathrm{A})$ e guanina $(\mathrm{G})$ (Fig. 1.9b). Estas bases nitrogenadas se combinam de maneira única C-G e A-T (Fig. 1.9 a) através de ligações de hidrogênio.

O DNA apresenta algumas conformações características. A forma mais comum encontrada em meio biológico é a forma $B$ que tem o diâmetro de $26 \AA$ e a distância entre planos de base de $3.4 \AA$. As cadeias estão rotacionadas entre si, se repetindo a uma sequência de 10.5 bases. A forma $A$ ocorre em situações de baixa concentração iônica do meio. O diâmetro é

também de $26 \AA$, a distância entre planos é $2.6 \AA$, se repetindo a cada 11 planos de bases. As pesquisas ainda não evidenciaram a forma $A$ em vivo mas é bastante comum quando o DNA é cristalizado [47]. A forma $Z$ é menos usual, sendo que a cadeia se enovela no sentido contrário àquela das formas $A$ e $B$ e é mais alongada, com diâmetro de $18 \AA, 12$ bases por giro com a distância de $3.7 \AA$ entre planos de base.

\subsubsection{DNA como dispositivo biomolecular}

O interesse no uso do DNA em nanodispositivos originou-se de três características: a) a automontagem na qual os filamentos se interligam sem a necessidade de catalisadores ou outros processos; b) a alta seletividade entre bases; c) a capacidade da formação do código genético ou seja o armazenamento de informações [48]. Além disso, as técnicas de sequenciamento, 
(a)
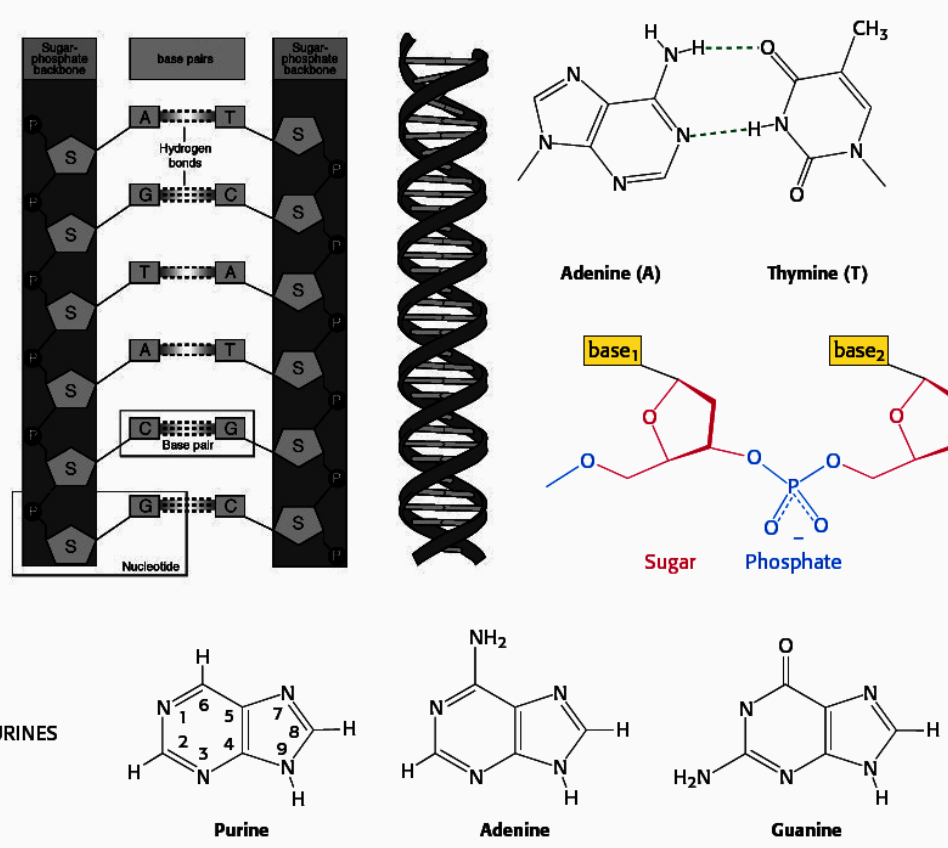

(c)
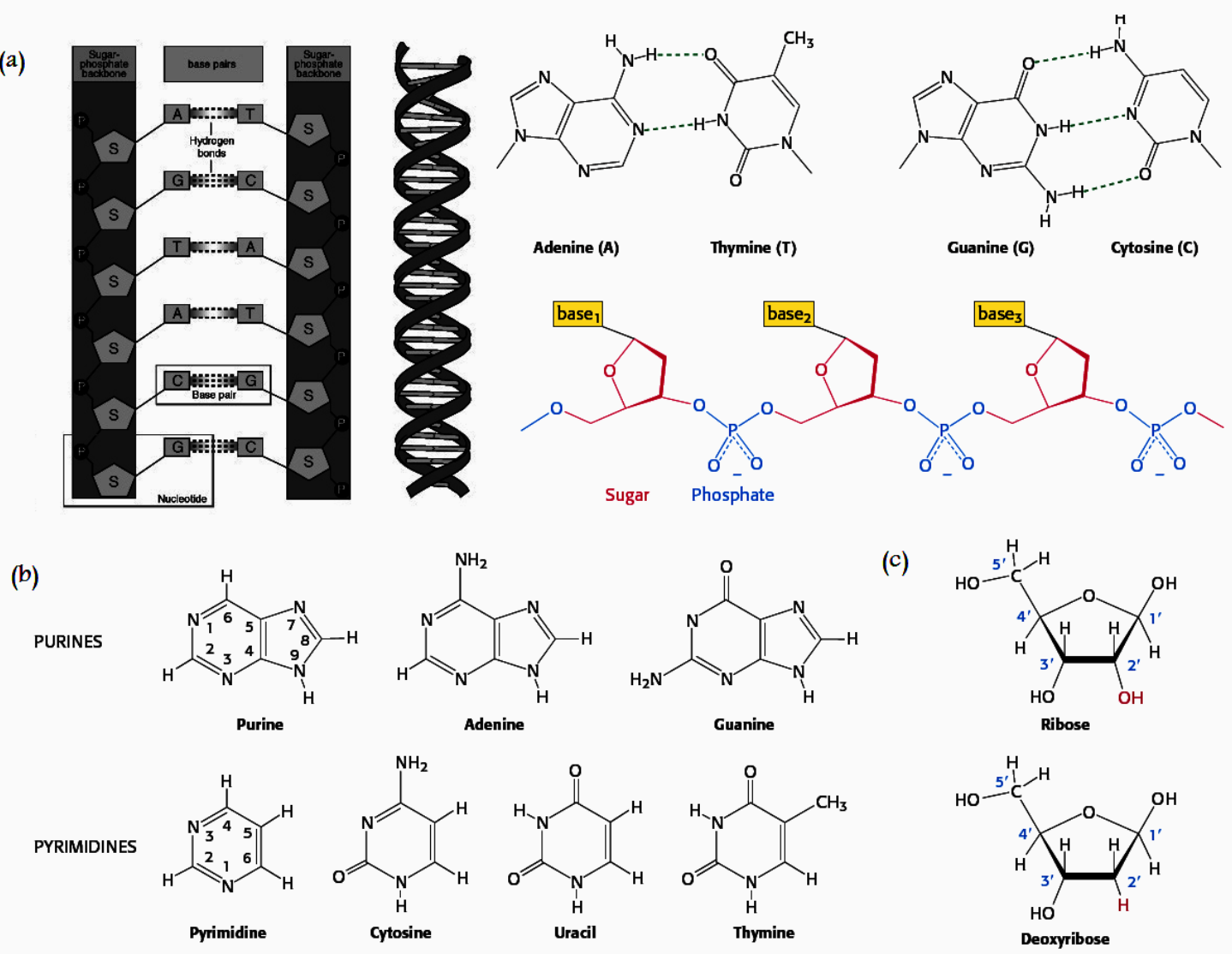

Figura 1.9: (a) Representação esquemática da estrutura do DNA e seus nucleotídeos: em destaque as ligações de hidrogênio entre as bases nitrogenadas adenina e timina (A-T) e guanina e citosina (G-C); detalhe da ligação fosfodiéster com o açúcar. (b) Bases nitrogenadas do DNA e do ácido ribonucleico (RNA) da família das purinas e das pirimidinas. (c) Detalhe do açúcar ribose (RNA) e deoxiribose (DNA). Numeração padronizada para o backbone onde a ligação fosfodiéster ocorre entre os carbonos $3^{\prime}$ e $5^{\prime}$. Figura reproduzida da referência [47]. 
duplicação e clivagem em sequências específicas de bases já estão bastante desenvolvidos [48].

Em 1962, Eley e Spivery [49] sugeriram a possibilidade de condução eletrônica através do DNA. A partir de 1997 diversos estudos experimentais apontaram o DNA como uma estrutura isolante, semicondutora ou mesmo condutora [50]. Técnicas experimentais como a Microscopia de Força Atômica (AFM) e a Microscopia de Varredura (STM) permitiram a investigação na escala atômica e já se sabe hoje que, dependendo da arquitetura do experimento, o DNA pode conduzir eletricidade mas apenas em sequências pequenas [48]. Entretanto não há ainda consenso sobre qual processo físico origina a condução eletrônica. Entre os processos mais prováveis estão, por exemplo, a sobreposição dos orbitais $\pi$ de fronteira, processos de hopping ou por intermédio dos contra-íons [50].

Em paralelo à pesquisa do uso do DNA natural, outra frente de investigação iniciou-se com o objetivo de otimizar ou funcionalizar o DNA. Estes estudos visavam modificações nas bases nitrogenadas [51] ou na estrutura externa da dupla hélice com o intuito de suprir ou aprimorar características não desejadas do DNA. Estas modificações visavam a melhoria na condução eletrônica diminuindo a interação DNA-substrato, ou mesmo o aumento da rigidez do backbone e o aumento da sobreposição (overlap) $\pi-\pi$ entre as bases ${ }^{9}$. Dentre estas modificações no DNA podemos citar o GNA [52], no qual o backbone é apresenta uma estrutura mais simplificada que a do DNA natural e também a inserção de íons metálicos entre as bases também chamado de Metal-DNA [M-DNA] [53,54].

\subsubsection{Metal-DNA}

A inserção de metais nas bases modificadas é uma promissora alternativa dentro deste imenso campo de pesquisa. A literatura apresenta estudos da interação de DNA com sais de metais desde 1924 [55] mas, há indícios que a síntese do complexo tenha ocorrido somente na década de 60 [48]. O primeiro experimento medindo corrente elétrica em um [M-DNA] foi publicado em 2001 [48]. Com a criação de bases modificadas, um metal poderia ser complexado com

\footnotetext{
${ }^{9} \mathrm{O}$ aumento do overlap é proporcional a redução do ângulo de rotação entre as bases.
} 
maior especificidade. A proposta inicial consistia no aumento do overlap $\pi-\pi$ criando um canal de condutância, entretanto, não se sabia precisamente a posição em que o íon iria intercalar no DNA: a ligação poderia ocorrer no backbone, entre duas bases naturais, ou mesmo entre dois pares de bases. Um dos primeiros trabalhos a apresentar esta configuração com um DNA natural foi o de Rakitin et al [56] de 2001, onde um átomo de $Z n$ ionizando um íon $H$ da guanina ou da timina e se inseriu entre as bases A-T ou C-G. Entretanto, artigos mais recentes afirmam que "nenhum outro laboratório conseguiu reproduzir estes resultados" $[57,58]$. Além disso, cálculos de estrutura eletrônica mostram que o íon $Z n$ não hibridiza nem com o orbital molecular mais alto ocupado (highest occupied molecular orbital - HOMO) nem com o orbital molecular mais baixo desocupado (lowest unoccupied molecular orbital - LUMO), indicando que a condutância verificada no experimento de Rakitin não vinha da inserção do íon $Z n[57,58]$. Em um outro trabalho teórico da literatura ao invés do $Z n$ adicionou-se $C u$ que apresentou hibridização com os orbitais de fronteira [58].

Há diversos trabalhos que afirmam a incorporação do metal em uma base modificada de DNA. Em 1999 o grupo de Tanaka e Shionoya [59] publicaram o que eles denominaram de "o primeiro estudo da incorporação de metal em um plano de bases modificadas". Os pesquisadores sintetizaram uma modificação do DNA natural em uma base complexada com um íon metálico $\left(\mathrm{Pd}^{2+}, \mathrm{Pt}^{2+}, \mathrm{Cu}^{2+}\right.$ e $\left.\mathrm{Ni}^{2+}\right)$ e propuseram a coordenação quadrado planar (apresentada na figura 1.10), que poderia complexar íons sem alterar a estrutura planar das demais bases naturais. Em 2002, Tanaka et al [54] sintetizaram uma nova base chamada de hidroxipiridona (Hy) que complexaria com um íon cobre (Fig. 1.11). Em 2003 [60] o mesmo grupo apresentou resultados de medidas onde até 5 íons $C u^{2+}$ se alinhavam ferromagneticamente (Fig. 1.12). Experimentos de CW-EPR (Continuous-wave electron paramagnetic ressonance) exibiram a estrutura fina do acoplamento magnético estimando a distância $C u$-Cu em $3.7 \pm 0.1 \AA$. A possibilidade de modificar as bases naturais pra formar ligantes específicos de íons metálicos que não alterassem as características helicoidais do DNA natural gerou grande interesse na comunidade científica [61-63]. 


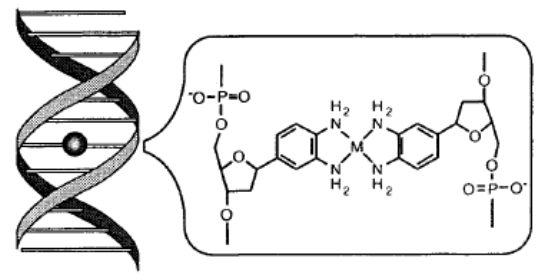

Figura 1.10: Representação esquemática de uma base modificada de DNA complexada com metal em uma sequência natural de DNA [59].

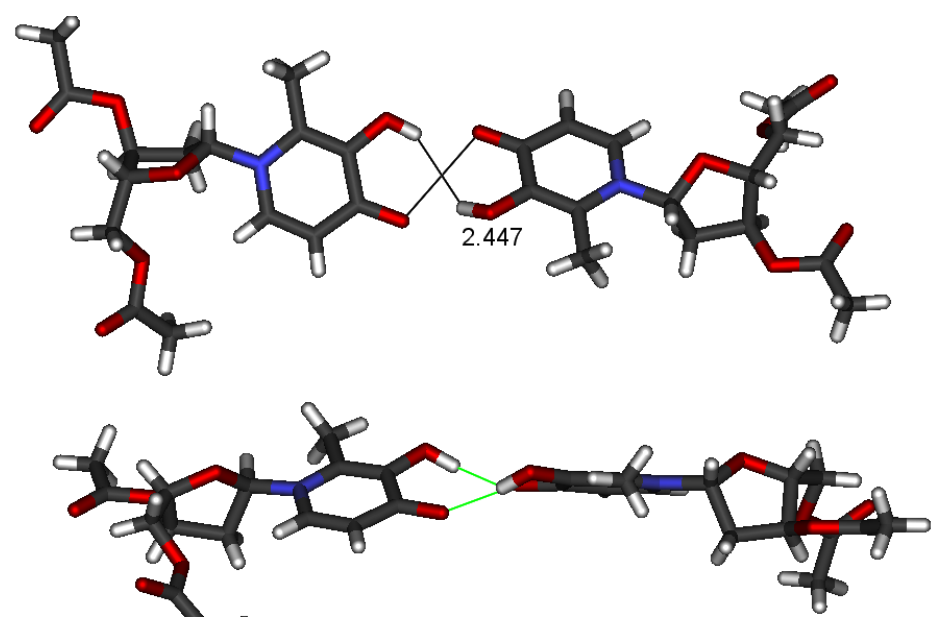

Figura 1.11: Representação da base modificada de hidroxipiridona (Hy) ligada ao açúcar deoxiribose determinada por difração de raios-X [54]; a distância $O-O$ é de $3.187 \AA$ e a $H$ - $H$ de $2.447 \AA$.

A existência de ferromagnetismo para os íons $C u$ neste experimento indicou a possibilidade do uso do DNA em spintrônica. Alguns estudos teóricos foram realizados com o objetivo de investigar maior estabilidade ferromagnética frente a antiferromagnética [64-67]. No trabalho de Zhang et al [64] foram estudados bases isoladas (sem a presença do backbone) formando uma cadeia infinita (Fig. 1.13), com o argumento que a adição do backbone não altera os estados próximos ao HOMO nem a amplitude ou mesmo as características destes níveis [68]. O interesse neste trabalho é que as energias obtidas para as configurações ferro- 

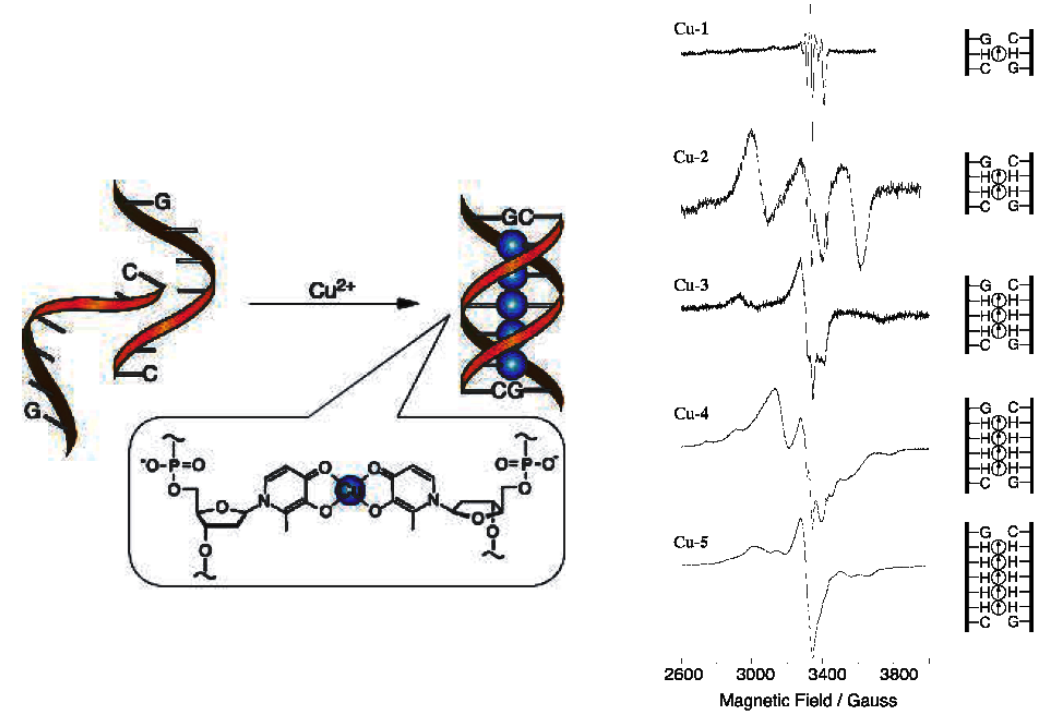

Figura 1.12: (esquerda) Representação esquemática do experimento da complexação de cinco íons $\mathrm{Cu}^{2+}$ na estrutura de hidroxipiridona $[\mathrm{Hy}-\mathrm{Cu}-\mathrm{Hy}]_{5}$. (direita) Espectro de EPR indicando as modificações a cada inserção de $\mathrm{Cu}^{2+}$. Figura reproduzida da referência [60].

magnética e antiferromagnética se mostraram degeneradas e a diferença entre a densidade de spin $\left(\Delta \rho=\rho_{u p^{-}} \rho_{\text {down }}\right)$, que reflete a localização do spin desemparelhado, se concentrava entre os sítios de $\mathrm{O}$ e o $\mathrm{Cu}$. Assim, cada base se comporta de forma independente do ponto de vista de estrutura eletrônica. O orbital de mais alta energia ocupado (HOMO) apresenta característica $\pi$, sendo que o orbital que contribui para o spin desemparelhado estava 0.3 eV abaixo do HOMO e o orbital que possivelmente contribuiria para a condução eletrônica (provavelmente o orbital $\mathrm{d}_{z^{2}}$ do $\mathrm{Cu}$ ) estava $1.2 \mathrm{eV}$ abaixo do HOMO. De acordo com estes resultados, os autores sugerem que esta localização mais profunda dos orbitais eletrônicos reduz a forte interação eletrostática entre os íons mantendo a cadeia estável.

Mallajosyula et al publicaram em 2007 e 2009 estudos teóricos para estruturas de [MDNA], entre estas, a estruturas de hidroxipiridona complexada com $\mathrm{Cu}^{2+}[65,69]$. Neste trabalho o backbone do DNA foi acrescentado com a abordagem QM/MM para o arranjo de 
cinco bases de $[\mathrm{Hy}-\mathrm{Cu}-\mathrm{Hy}]_{5}$ intercaladas nas extremidades com bases nitrogenadas naturais e o alinhamento ferromagnético foi obtido com uma diferença de energia de $0.15 \mathrm{eV}$. O arranjo apresentou coordenação quadrado planar distorcida como já havia sido especulado no trabalho de Zhang [64]. A diferença entre as densidades de spin up/down apresentaram grande contribuição no orbital $\mathrm{d}_{x^{2}-y^{2}}$ do $C u$ no plano e pequena contribuição dos orbitais com caráter $\pi$ (fora do plano). Outros trabalhos foram publicados apresentando a importância da interação de van der Waals para estabilizar as bases empilhadas [66] e também um estudo do acoplamento magnético em função do ângulo de rotação entre as bases e a distância $\mathrm{Cu}-\mathrm{Cu}$ [67]. Estes dois estudos indicam que o acoplamento ferromagnético é degenerado em relação a antiferromagnético.

O trabalho experimental de Tanaka [60] e o teórico de Zhang ${ }^{10}$ [64] foram os motivadores do estudo que aqui realizamos. Os estudos teóricos publicados até a presente data apontam que a diferença na densidade de spin está nos planos das bases [64] mas existe uma pequena contribuição fora do plano [65]. Nosso trabalho procura interpretar estes resultados experimentais através do estudo de diferentes estados de carga nas bases metaladas e também o estudo da presença do backbone através de cálculos ab - initio.

\footnotetext{
${ }^{10}$ Note-se que no início do presente trabalho apenas este estudo teórico havia sido publicado.
} 
a

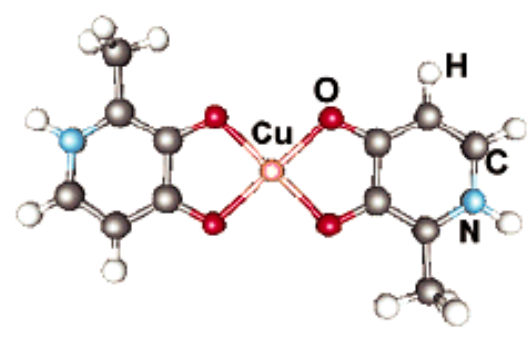

\section{b}

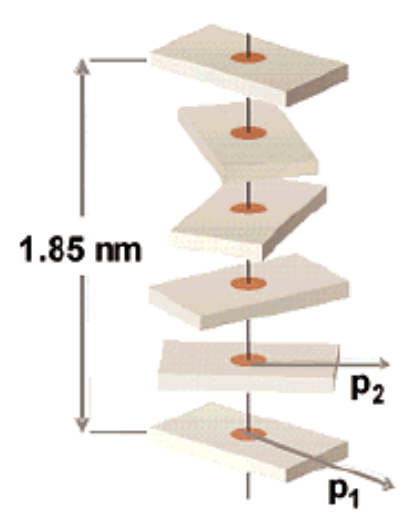

c

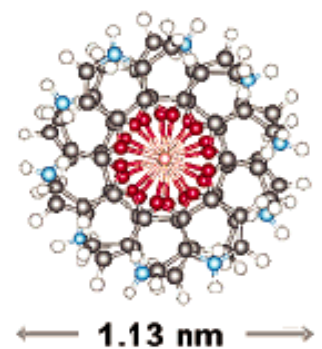

d

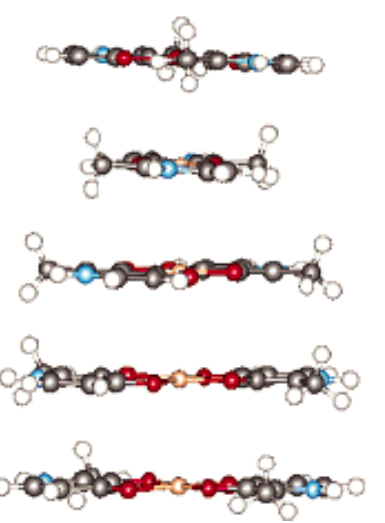

Figura 1.13: Representação esquemática da estrutura de bases modificadas de DNA complexada com cobre. a) monômero b) arranjo espacial separado a $3.7 \AA$ e $36^{\circ}$ de rotação entre os planos adjacentes c) Vista superior do pentâmero d) vista lateral do pentâmero. Figura reproduzida da Ref. [64]. 


\section{Capítulo 2}

\section{Abordagem Teórica e Metodologia}

\section{Computacional}

Neste capítulo vamos descrever alguns tópicos da abordagem teórica utilizada neste trabalho. Iniciamos com a Teoria do Funcional da Densidade (DFT) [70], dentro do esquema de KohnSham que é utilizada no código computacional CP-PAW [71] como no Gaussian03 (G03) [72]. A função de onda no método Projector Augmented Waves (PAW) é constituída por uma base mista composta por ondas parciais (funções de onda localizadas) e ondas planas numa abordagem all-electron (AE). No PAW as equações de Kohn-Sham são resolvidas através da abordagem de Car-Parrinello [73], que transforma o problema de obtenção da estrutura eletrônica e geometria de equilíbrio em um único problema que é tratado através das equações de movimento de Newton [73].

O cálculo de estrutura eletrônica independente do tempo consiste em resolver a Equação de Schrödinger (ES) independente do tempo

$$
\hat{H}\left|\Psi_{n}(\mathbf{r}, \mathbf{R})\right\rangle=E_{n}\left|\Psi_{n}(\mathbf{r}, \mathbf{R})\right\rangle
$$

onde $\Psi_{n}$ é a função de onda para $n$ estados eletrônicos do sistema que depende das coordenadas eletrônicas $(\mathbf{r})$ e nucleares $(\mathbf{R})$. O Hamiltoniano é dado por 


$$
\hat{H}=\hat{T}_{e}+\hat{T}_{n u}+\hat{V}_{e-e}+\hat{V}_{e-n u}+\hat{V}_{n u-n u}
$$

onde $\hat{T}_{e}$ e $\hat{T}_{n u}$ são as energias cinéticas dos elétrons e dos núcleos, $\hat{V}_{e-e}$ a interação entre os elétrons, $\hat{V}_{e-n u}$ a interação entre elétrons e núcleos e $V_{n u-n u}$ a interação entre núcleos.

Este problema necessita simplificações e se faz, usualmente, através da aproximação de Born-Oppenheimer [74], que devido à grande diferença entre as massas nucleares e eletrônicas, separa a equação de Schödinger em uma equação eletrônica e uma equação para o movimento nuclear.

$$
\hat{H}_{e l}\left|\psi_{n}(\mathbf{r} ; \mathbf{R})\right\rangle=E_{n(e l)}\left|\psi_{n}(\mathbf{r} ; \mathbf{R})\right\rangle
$$

onde $\hat{H}_{e l}$ é dado por $\hat{T}_{e}+\hat{V}_{e-e}+\hat{V}_{e-n u}, \psi$ é a função de onda eletrônica que depende parametricamente do movimento nuclear.

\subsection{Teoria do Funcional da Densidade}

Pierre Hohenberg e Walter Kohn em 1964 [75] e Walter Kohn e Lu J. Sham em 1965 [76] apresentaram uma formulação para o problema da estrutura eletrônica, utilizando a densidade eletrônica $(n(\mathbf{r}))$ ao invés da função de onda. As aproximações propõem a transformação de um problema de $\mathrm{N}$ partículas interagentes (3N variáveis) em $\mathrm{N}$ problemas de uma partícula (3 variáveis, por partícula), para um potencial efetivo $\left(v_{K S}\right)$.

Na formulação de Kohn e Sham (KS) temos de resolver as equações de KS (em unidades atômicas - Hartree)

$$
H_{K S} \psi_{i}(\mathbf{r})=\left(-\frac{1}{2} \nabla^{2}+v_{K S}([n(\mathbf{r}))]\right) \psi_{i}(\mathbf{r})=\varepsilon_{i}(\mathbf{r}) \cdot \psi_{i}(\mathbf{r})
$$

onde $\psi_{i}$ são chamados de orbitais de $\mathrm{KS}$, sendo $n(r)=\sum_{i=1}^{N}|\psi|_{i}^{2}$ e admitimos que não haja variação do número total de partículas $N=\int n(\mathbf{r}) d^{3} r$. As Equações (2.4) formam um 
conjunto de equações do tipo Schrödinger para uma única partícula, com o potencial $v_{K S}$ dado por $v_{K S}[n(\mathbf{r})]=v(\mathbf{r})+v_{H}(\mathbf{r})+v_{x c}[n(\mathbf{r})]$ onde $v(\mathbf{r})$ é o potencial externo (interação entre elétrons $\mathbf{r}$ e íons $\mathbf{R}), v_{H}(\mathbf{r})$ é o potencial de Hartree para interação elétron-elétron e $v_{x c}[n(r)]=\delta E_{x c}[n] / \delta n$ é o potencial de troca e correlação.

A energia total de KS é dada por

$$
E_{K S}[n]=-1 / 2 \sum_{i=1}^{N} \int \psi_{i}^{*} \nabla^{2} \psi_{i} d^{3} r+1 / 2 \iint \frac{n(\mathbf{r}) n\left(\mathbf{r}^{\prime}\right)}{\left|\mathbf{r}-\mathbf{r}^{\prime}\right|} d^{3} r d^{3} r^{\prime}+E_{x c}[n]+\int v(\mathbf{r}) n(\mathbf{r}) d^{3} r
$$

o primeiro termo é a energia cinética para os elétrons não interagentes, o segundo a energia de Hartree, o terceiro o funcional energia de troca e correlação e o último a energia dada pelo potencial externo. A minimização do funcional (2.5) em relação a $n(\mathbf{r})$ para um número fixo de elétrons gera as equações de $\mathrm{KS}(2.4)$ [70,77].

Através de um processo autoconsistente as soluções das Equações (2.4) podem ser obtidas. Com o potencial de KS podemos calcular os autovalores e autovetores de (2.4); com a autofunção, recalculamos a densidade e assim continuamos o cálculo até a autoconsistência, ou seja, até que a densidade/potencial de entrada seja igual ao de saída dentro de uma certa tolerância e assim obtemos os autovalores e as autofunções de KS.

\section{Funcionais de troca e correlação}

A DFT é uma metodologia que tem sido bastante empregada no estudo de complexos metálicos [78]. Grande parte do sucesso em tratar estes sistemas vem da chamada "revolução computacional" observada nas últimas décadas que permite o tratamento de sistemas cada vez mais complicados. Entretanto a escolha do funcional de troca e correlação ainda se coloca como um desafio dependendo das características do sistema em estudo e das propriedades que se pretende obter [78,79]. Esta é uma área de corrente e intensa pesquisa [77]

Há diversas abordagens na literatura para tratar o funcional de troca e correlação, que carrega toda a informação da interação eletrônica de muitos corpos. Entre elas destacamos 
a aproximação de densidade local ou LDA (Local Density Approximation) que mapeia a densidade a partir de uma densidade eletrônica de um gás de elétrons homogêneo [70]. A aproximação de gradiente generalizado GGA (Generalized Gradient Approximation) utiliza a densidade eletrônica e o gradiente da densidade de carga [77]. A combinação do termo de correlação GGA e de 'misturas' do termo de troca exato do Hartree Fock (HF) e do termo de troca do funcional DFT introduziu os chamados funcionais híbridos [77]. Esta abordagem procura reduzir o conhecido efeito da auto interação existente na DFT onde um elétron interage com a sua própria densidade eletrônica ${ }^{1}[78]$.

Há diversos estudos na literatura que realizam 'misturas' do termo de troca exato do HF para otimizar determinada propriedade. Podemos citar três exemplos: a) Medidas de parâmetros hiperfinos para o complexo de cobre $\left[\mathrm{Cu}(\mathrm{Cl})_{4}\right]^{2-}$ indicam melhor concordância em relação ao experimental [83] utilizando $38 \%$ do termo de troca exato HF em combinação com o funcional de troca $B$ [84] e o funcional de correlação PW91 [85]; b) O cálculo do potencial redox para uma série de complexos metálicos [86] apresenta boa concordância com o experimental ao adicionar 15\% do termo de troca exato HF no funcional B3LYP; c) Já o estudo do estado fundamental do complexo $\left[\mathrm{Cu}\left(\mathrm{H}_{2} \mathrm{O}\right)\right]^{2+}$ em fase gasosa apresenta melhores resultados com a 'mistura' entre $40 \%$ a $50 \%$ do termo de troca exato do HF [87]. Desta forma, o uso indiscriminado deste artifício pode gerar uma estrutura eletrônica incorreta mesmo que determinada propriedade apresente melhores resultados.

No código CP-PAW utilizamos o funcional de troca e correlação GGA desenvolvido por Perdew, Burke e Ernzerhof (PBE) [88]. No código G03 utilizamos os funcionais GGA PBE e o PB86 [84], onde o ' $B$ ' representa o funcional de troca publicado em 1988 por Becke [84] e o "P86" representa o funcional correlação publicado em 1986 por o Perdew [89].

\footnotetext{
${ }^{1}$ Há outras abordagens que procuram reduzir este efeito como a correção de auto interação (Self Interaction Correction - SIC) [80] ou através da abordagem $\mathrm{LDA}+\mathrm{U}$, onde $U$ é o fator de Hubbard [81]. Nestes casos há parâmetros que devem ser ajustados empiricamente a fim de corrigir os efeitos de autointeração eletrônica [82].
} 


\subsection{Funções de Base}

Nesta seção vamos introduzir as funções de base PAW conforme utilizadas no método CPPAW e também, de forma resumida, as funções de base gaussianas utilizadas no código Gaussian03.

\subsection{O Método PAW}

Utilizamos dentro da DFT o método Projector Augmented Waves (PAW) [71]. Esta é a mesma metodologia utilizada na Ref. [90] que seguiremos nesta seção. O formalismo do PAW está nos métodos iniciados pelo Augmented Plane Waves (APW) [91] e seus sucessores lineares como o Linearized Augmented Plane Waves (LAPW) [91]. No formalismo APW, o espaço é dividido em duas regiões como mostra a Figura 2.1. A região $\Omega$, próxima a um dado núcleo, é chamada de região de augmentation, onde a função de onda oscila fortemente pela presença do núcleo. Para descrever esta característica nodal é utilizada bases localizadas do tipo atômicas, tais como ondas parciais (produto de uma função radial por harmônicos esféricos). Na região onde ocorrem mais efetivamente as ligações químicas, chamada de intersticial, as funções de onda variam mais suavemente. Nesta região, qualquer alteração no ambiente químico irá deformar as funções de onda e é utilizado uma expansão em ondas planas.

No estudo de sistemas periódicos, o potencial tem a característica $\mathrm{V}(\mathbf{r})=\mathrm{V}(\mathbf{r}+\mathbf{R})$, onde r é um vetor dentro da célula unitária e $\mathbf{R}$ um vetor de translação da rede [92]. As soluções das equações de KS (Equação 2.4) para este potencial são ondas planas, uma vez que ondas planas formam um conjunto completo ortonormal (e que a utilização desta base está fundamentalmente ligada à geração de periodicidade [93]). Desta forma, o uso de ondas planas em um sistema periódico é bastante eficiente, entretanto, próximo aos núcleos, o número de ondas planas necessárias para reproduzir as oscilações das funções de onda inviabiliza, em geral, a utilização desta base. Assim, o "método do pseudopotencial" (PP) [94] foi introdu- 


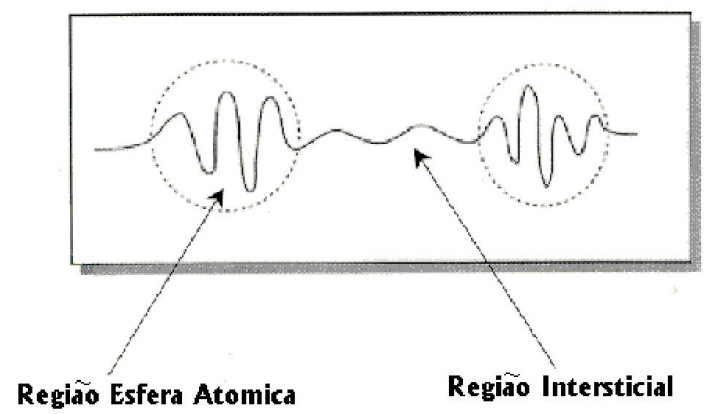

Figura 2.1: Representação esquemática de uma molécula diatômica. As regiões no interior das esferas $\Omega$ são chamadas de regiões 'aumentadas' augmentation, onde, devido ao forte potencial nuclear, a função de onda varia rapidamente. Fora das esferas temos a região intersticial com funções de onda mais suaves.

zido, na literatura, com o objetivo de simplificar o problema, ao substituir as funções de onda nas regiões próximas aos núcleos, por funções suaves sem nós, soluções obtidas utilizando um potencial efetivo ao invés do abrupto potencial real. O principal ganho do uso do PP é a redução do custo computacional uma vez que o grande número de ondas planas, necessárias para descrever as funções, do tipo atômicas na região que corresponde à região de $\Omega$ no contexto das abordagens APW não é calculada. Os métodos PP são muito eficientes computacionalmente, mas podem falhar quando necessitam de informações da região próxima ao núcleo, já que esta foi suprimida pelo pseudopotencial.

A correta escolha do $\Omega_{R}$ (raio da região de augmentation) depende do casamento contínuo e diferenciável das funções de onda dentro e fora de $\Omega$ [91]. No PP este casamento acontece por construção, entretanto nos métodos APW o casamento de funções tão distintas como orbitais atômicos e ondas planas, na fronteira de $\Omega$, é bastante custoso computacionalmente. Esta combinação no raio de $\Omega$ no PAW, se dá através de funções projetoras que serão apresentadas na próxima seção [71].

O PAW combina as vantagens das abordagens AW, que utilizam ondas parciais dentro de $\Omega$ e ondas planas na região intersticial, e a abordagem do PP, através de suas pseudo 
funções (funções auxiliares). Aqui as funções são calculadas durante o ciclo autoconsistente, e os projetores e as ondas parciais, uma vez calculados, não variam mais no decorrer do cálculo [71].

\section{Funções de Base PAW}

O PAW é um método ab-initio dentro do esquema de Kohn-Sham da DFT que descreve todos os elétrons do sistema, isto é, elétrons de valência e elétrons de caroço ${ }^{2}$ (que são tratados em separado com toda a sua característica nodal).

A função AE no método PAW é dada por

$$
\left|\psi_{n}\right\rangle=\left|\tilde{\psi}_{n}\right\rangle+\sum_{i}\left\langle\tilde{p}_{i} \mid \tilde{\psi}_{n}\right\rangle\left(\left|\phi_{i}\right\rangle-\left|\tilde{\phi}_{i}\right\rangle\right)
$$

que é uma função de onda de KS designada pelo índice $n$. O índice $i$ se extende sobre os sítios atômicos $R$, os índices $l$ e $m$ de momento angular por sítio e o número de ondas parciais por momento angular por sítio. O índice $n$ será omitido nas expressões que seguem.

O primeiro termo, chamado de função de onda auxiliar $|\tilde{\psi}\rangle$, é idêntico à função de onda AE fora de $\Omega$ (Figura 2.2)

$$
|\psi\rangle=|\tilde{\psi}\rangle \quad \text { (Fora de } \Omega)
$$

O segundo termo de (2.6) é constituído por funções de ondas parciais $\left|\phi_{i}\right\rangle$, soluções da Equação de Schrödinger para o átomo isolado, dado por uma função radial multiplicada por harmônicos esféricos $\left|\phi_{i}\right\rangle=R_{n l}(\mathbf{r}) Y_{l m}$; funções projetoras (projetores), $\left|\tilde{p}_{i}\right\rangle$, dentro de $\Omega$ e que diferem para cada sítio atômico $R$. Este segundo termo é idêntico à função AE dentro de $\Omega$ (Figura 2.2)

\footnotetext{
${ }^{2} \mathrm{O}$ código CP-PAW implementa a aproximação de "caroço congelado".
} 


$$
|\psi\rangle=\sum_{i}\left|\phi_{i}\right\rangle\left\langle\tilde{p}_{i} \mid \tilde{\psi}\right\rangle \quad(\text { Dentro de } \Omega)
$$

O terceiro termo, por construção, cancela a função auxiliar $(|\tilde{\psi}\rangle)$ dentro de $\Omega$ e a contribuição das ondas parciais $\left(\left|\phi_{i}\right\rangle\right)$ fora de $\Omega$ (Figura 2.2).

A base PAW é dada nestas três contribuições e a maneira como as funções se combinam na fronteira de $\Omega$ trás um relevante ganho computacional em relação aos demais métodos APW sem a perda de informações [95].

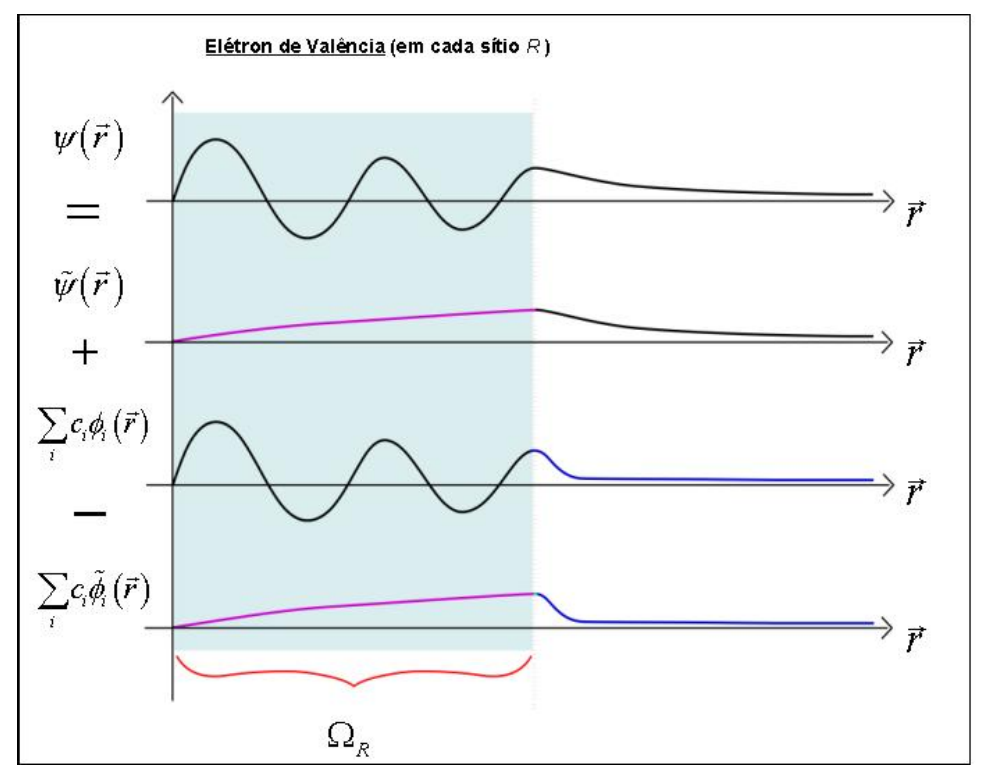

Figura 2.2: Representação esquemática das três contribuições para a função total (AE) de um elétron. De cima para baixo: Função de onda AE, função de onda auxiliar, função de onda parcial e função de onda parcial auxiliar. A função de onda auxiliar é idêntica a total fora de $\Omega$, e a função de onda parcial é idêntica a total dentro de $\Omega$ (Figura retirada da referência [96]). 


\section{Operador de Transformação}

Utilizando o operador de transformação (Eq. 2.9) o PAW obtém a função de onda AE $\psi$ para um elétron que é computacionalmente mais adequada ao cálculo

$$
T=1+\sum_{i}\left(\left|\phi_{i}\right\rangle-\left|\tilde{\phi}_{i}\right\rangle\right)\left\langle\tilde{p}_{i}\right|
$$

Uma descrição mais detalhada para a obtenção das funções AE, das funções parciais e das funções projetoras do método PAW pode ser encontrada nas Refs. [71] e [95]. Aqui, apresentamos de uma forma simplificada as propriedades básicas da construção da função de base dos elétrons de valência no PAW.

\subsubsection{Valores Esperados}

Utilizando a Equação (2.6) para obter o valor esperado de um operador $A$.

$$
\langle A\rangle=\sum_{n} f_{n}\left\langle\psi_{n}|A| \psi_{n}\right\rangle
$$

onde $f_{n}$ é a ocupação para os $n$ estados.

Podemos obter o operador auxiliar $\tilde{A}=T^{t} A T$, onde $T^{t}$ é o transposto de $T$, e a partir da função de onda auxiliar, podemos calcular $\langle A\rangle$ como

$$
\langle A\rangle=\sum_{n} f_{n}\left\langle\tilde{\psi}_{n}\left|T^{t} A T\right| \tilde{\psi}_{n}\right\rangle
$$

Modificando a notação do segundo e do terceiro termos da Eq. 2.6, temos dentro de $\Omega$ 


$$
\begin{aligned}
& \left|\psi_{R}^{1}\right\rangle=\sum_{i}\left|\phi_{i}\right\rangle\left\langle\tilde{p}_{i} \mid \tilde{\psi}\right\rangle \\
& \left|\tilde{\psi}_{R}^{1}\right\rangle=\sum_{i}\left|\tilde{\phi}_{i}\right\rangle\left\langle\tilde{p}_{i} \mid \tilde{\psi}\right\rangle
\end{aligned}
$$

Substituindo as equações (2.12) em (2.10) obteremos

$$
\langle\psi|A| \psi\rangle=\left\langle\tilde{\psi}+\sum_{R}\left(\psi_{R}^{1}-\tilde{\psi}_{R}^{1}\right)|A| \tilde{\psi}+\sum_{R}\left(\psi_{R}^{\prime 1}-\tilde{\psi}_{R}^{\prime 1}\right)\right\rangle
$$

O resultado desta equação não é calculado por inteiro porque na prática há o truncamento da série [71].

Desenvolvendo a equação (2.13)

$$
\langle\psi|A| \psi\rangle=\langle\tilde{\psi}|A| \tilde{\psi}\rangle+\sum_{R}\left(\left\langle\psi_{R}^{1}|A| \psi_{R}^{1}\right\rangle-\left\langle\tilde{\psi}_{R}^{1}|A| \tilde{\psi}_{R}^{1}\right\rangle\right)+\sum_{R=R^{\prime}}(\ldots)+\sum_{R \neq R^{\prime}}(\ldots)
$$

os termos dos somatórios com $\mathrm{R}=\mathrm{R}$ ' e $\mathrm{R} \neq \mathrm{R}$ ' se anulam para operadores locais e 'quaselocais', quando a função de onda converge [71].

A equação (2.14) pode ser representada simplificadamente como

$$
A=\tilde{A}+A^{1}-\tilde{A}^{1}
$$

E incluindo os elétrons de caroço teremos

$$
A=\tilde{A}+A^{1}-\tilde{A}^{1}+A^{c}
$$

onde, explicitamente, a equação para o cálculo dos valores esperados no PAW é dada por 


$$
\langle A\rangle=\sum_{n} f_{n}\left[\langle\tilde{\psi}|A| \tilde{\psi}\rangle+\sum_{R}\left(\left\langle\psi_{R}^{1}|A| \psi_{R}^{1}\right\rangle-\left\langle\tilde{\psi}_{R}^{1}|A| \tilde{\psi}_{R}^{1}\right\rangle\right)\right]+\sum_{n=1}^{N_{c}}\left\langle\phi_{n}^{c}|A| \phi_{n}^{c}\right\rangle
$$

O cálculo dos observáveis se dá pela equação (2.17) como por exemplo, os resultados para a densidade de carga.

\subsection{Bases Locais do tipo Gaussianas}

O código computacional Gaussian03 [72] utiliza funções de bases do tipo gaussianas centradas nos sítios atômicos. O conjunto de base gaussiana pode ser construído como a combinação linear de diversas gaussianas primitivas [97, 98]. Há diversos textos na literatura sobre a construção e o uso de funções de onda gaussianas [98-101] e no presente trabalho utilizamos a base Alrich's all-electron 3- $\zeta$ de valência polarizada (TZVP - triple zeta valence polarization) $[102,103]$. Esta base triplica o número de funções primitivas de valência e adiciona funções de polarização responsáveis pelo acréscimo de orbitais de maior momento angular $l$ além dos estados ocupados do estado fundamental [102]. Este conjunto de base tem sido empregado em trabalhos contendo complexos metálicos $[16,104,105]$ na literatura.

\subsection{Dinâmica Molecular Ab initio de Car e Parrinello}

A abordagem sugerida por Car e Parrinello (CP) [73] encontra a solução para as Equações de KS evitando a custosa diagonalização de matrizes e trata a função de onda eletrônica e a dinâmica nuclear da mesma forma, o que previne erros de convergência na determinação das forças [73]. Na Dinâmica Molecular de Car e Parrinelo (DMCP) é utilizado um artifício que consiste em tratar o problema quântico dentro de um formalismo da mecânica clássica, onde as funções de onda eletrônicas e os núcleos são coordenadas generalizadas da 
Lagrangeana do sistema. Os métodos usuais de dinâmica molecular tratam os átomos como partículas clássicas [106] e a novidade introduzida por CP foi tratar as funções de onda como coordenadas generalizadas.

Conforme mencionado na Eq. 2.3 a aproximação de Born-Oppenheimer (BO), separa o movimento nuclear do eletrônico. Assim a função de onda é dada pelo produto de uma função puramente nuclear, e outra eletrônica $(\Psi(\mathbf{r}, \mathbf{R})=\psi(\mathbf{r} ; \mathbf{R}) \cdot \phi(\mathbf{R}))$, dependendo parametricamente da coordenada nuclear: a cada movimento (lento) dos núcleos, a função eletrônica deve se rearranjar rapidamente, sendo que a diferença na escala temporal entre o movimento dos núcleos e elétrons deve ser grande o suficiente para que a aproximação de BO (aproximação adiabática) seja válida [74].

A dinâmica de CP adiciona uma 'energia cinética fictícia' aos elétrons e escreve a lagrangeana $\left(L=E_{c}-V\right)$ na forma

$$
L_{C P}=\underbrace{\sum_{i} m_{\psi_{i}} f_{i}\left\langle\dot{\psi}_{i} \mid \dot{\psi}_{i}\right\rangle}_{E_{c} \text { eletronica }}+\underbrace{\sum_{A} \frac{M_{A}}{2} \dot{\mathbf{R}}_{\mathbf{A}}{ }^{2}}_{E_{c} \text { nucleos }}-\underbrace{E\left[\left\{\psi_{i}\right\},\left\{\mathbf{R}_{\mathbf{A}}\right\}\right]}_{\text {Potencial }}
$$

onde $m_{\psi}$ é a massa fictícia eletrônica que deve ser muito menor do que $M_{A}$ (massa dos núcleos) para que a aproximação de $\mathrm{BO}$ seja satisfeita [73], $f_{i}$ é a ocupação dos orbitais e $E=E_{K S}+E_{n u-n u}$. A energia de interação entre os núcleos é dada por $E_{n u-n u}$, e a energia $E_{K S}$ é a energia eletrônica calculada anteriormente (Eq. 2.5) para os núcleos nas posições $R_{A}$.

Para a DMCP é necessário incluir um vínculo de ortogonalidade para funções de onda $\left\langle\psi_{i} \mid \psi_{j}\right\rangle=\delta_{i j}$ e a equação (2.18) torna-se

$$
L_{C P}=\underbrace{\sum_{i} m_{\psi_{i}} f_{i}\left\langle\dot{\psi}_{i} \mid \dot{\psi}_{i}\right\rangle}_{E_{c} \text { eletronica }}+\underbrace{\sum_{A} \frac{M_{A}}{2} \mathbf{R}_{\mathbf{A}}{ }^{2}}_{E_{c} \text { nucleos }}-\underbrace{E\left[\left\{\psi_{i}\right\},\left\{\mathbf{R}_{\mathbf{A}}\right\}\right]}_{\text {Potencial }}+\underbrace{\sum_{i j} \Lambda_{j i}\left(\left\langle\psi_{i} \mid \psi_{j}\right\rangle-\delta_{i j}\right)}_{\text {Vinculo de ortogonalidade }}
$$


onde $\Lambda_{j i}$ é o multiplicador de Lagrange para esta condição de vínculo.

A validade da DMCP depende que as partes nuclear e eletrônica do sistema não troquem energia. Os orbitais eletrônicos devem permanecer muito próximos do estado fundamental para que o sistema fique na vizinhança da superfície de BO (Potential Energy Surface - PES), antes de iniciar a dinâmica dos núcleos [73]. Podemos imaginar os elétrons e os núcleos do sistema como dois sistemas termodinâmicos em temperaturas diferentes relacionadas às suas energias internas: a energia eletrônica próxima do estado fundamental com temperatura $\mathrm{T} \rightarrow 0$ e com freqüência de vibração alta, e o outro sistema termodinâmico com alta energia cinética, com baixa freqüência e com as posições dos núcleos ainda não otimizadas. Se os espectros vibracionais dos elétrons e dos íons forem bem separados, os íons nessas condições não irão transferir energia para o sistema mais frio (elétrons), e é válida a aproximação adiabática. Quantitativamente, dizemos que a freqüência máxima dos graus de liberdade nucleares deve ser menor que a frequência mínima dos graus de liberdade eletrônicos para que haja o desacoplamento adiabático $\left(\omega_{A}^{\max }<\omega_{\psi}^{\min }\right)$ [107]. A massa fictícia $m_{\psi}$ é um parâmetro de ajuste [107], ou seja, quanto menor for a $\mathrm{m}_{\psi}$, maior será o distanciamento entre as frequências nucleares e eletrônicas. Entretanto, esta redução implica na redução do passo de cada iteração e retarda a velocidade do cálculo [73].

A partir da lagrangeana (equação 2.19), utiliza-se o princípio de ação mínima

$$
\frac{d}{d t}\left(\frac{\delta L}{\delta\left\langle\dot{\psi_{i}}\right|}\right)-\frac{\delta L}{\delta\left\langle\psi_{i}\right|}=0 \quad \frac{d}{d t} \frac{\partial L}{\partial \dot{\mathbf{R}_{\mathbf{A}}}}-\frac{\partial L}{\partial \mathbf{R}_{\mathbf{A}}}=0
$$

assim pode-se obter, como solução, um conjunto de equações de Newton [73]

$$
m_{\psi}\left|\ddot{\psi}_{i}\right\rangle=-\frac{\delta E}{\delta\left\langle\psi_{i}\right|}+\frac{1}{f_{i}} \sum_{j} \Lambda_{j i}\left|\psi_{j}\right\rangle
$$


e

$$
M_{A} \ddot{\mathbf{R}_{\mathbf{A}}}=-\frac{\partial E}{\partial \mathbf{R}_{\mathbf{A}}}
$$

Através da técnica de recozimento simulado [73] pode-se resolver as equações (2.21) e (2.22) reduzindo a energia cinética fictícia dos elétrons até chegar ao mínimo de energia definido pela PES. Para tanto, utiliza-se um coeficiente de fricção tanto na equação eletrônica como na nuclear

$$
m_{\psi}\left|\ddot{\psi}_{i}\right\rangle=-\frac{\delta E}{\delta\left\langle\psi_{i}\right|}+\frac{1}{f_{i}} \sum_{j} \Lambda_{j i}\left|\psi_{j}\right\rangle-\alpha_{\psi} \cdot m_{\psi}\left|\dot{\psi}_{i}\right\rangle
$$

e

$$
M_{A}\left|\ddot{\mathbf{R}_{\mathbf{A}}}\right\rangle=-\frac{\partial E}{\partial \mathbf{R}_{\mathbf{A}}}-\alpha \cdot M_{A} \ddot{R}_{A}
$$

onde $\alpha_{\psi}$ é a fricção para os orbitais eletrônicos e $\alpha$ para é a fricção para os núcleos. Ao adicionar atrito ao processo, obtemos $\left|\ddot{\psi}_{i}\right\rangle \rightarrow 0\left(F_{A}=0\right)$. Para a fricção também tendendo a zero, a equação (2.23) torna-se (a menos de uma transformação unitária) a equação de KS

$$
\frac{\delta E}{\delta\left\langle\psi_{i}\right|}=\frac{1}{f_{i}} \sum_{j} \Lambda_{j i}\left|\psi_{j}\right\rangle=H_{K S}\left|\psi_{i}\right\rangle
$$

Para uma geometria de equilíbrio, onde a força entre os átomos é zero, a Lagrangiana fictícia de CP fornece um resultado físico, e os multiplicadores de Lagrange são os auto valores de $\mathrm{KS}\left(\Lambda_{j i}=E_{K S}\right)[73]$. 


\section{Capítulo 3}

\section{Complexos de Cobre com Bases de}

\section{Schiff}

Neste capítulo apresentaremos os resultados utilizando o código computacional PAW com o funcional de troca e correlação PBE. Em algumas seções utilizamos também o código computacional Gaussian e será mencionado na seção em que este for utilizado. Este complexos de cobre foram sintetizados no grupo da Profa. Ana Maria Ferreira do IQUSP. Faremos um estudo das propriedades eletrônicas e estruturais a fim de correlacionar com medidas de estabilidade termodinâmica relativa e de propriedades pró-oxidante e antioxidante dos complexos de cobre $[16,17,108]$. Conforme mencionado na introdução, estes são classificados nas séries: das piridinas, pirazinas e histaminas tridentadas (Fig. 1.3) e tetradentadas (Fig. 1.4) e na série das isatinas (oxindóis) (Fig. 1.5) ${ }^{1}$. Os compostos chamados de tridentados/tetradentados são aqueles em que o ligante, possui três/quatro pontos de coordenação para se ligar ao metal. Estes ligantes são chamados de bases de Lewis por possuírem grupos doadores $\sigma$ apresentando pares isolados de elétrons que podem se coordenar a íons

\footnotetext{
${ }^{1}$ Nos complexos preparados em laboratório, o íon $C u$ é adicionado através do sal perclorato de cobre(II), $\mathrm{Cu}\left(\mathrm{ClO}_{4}\right)_{2}$, que em solução é dissociado em íons $\mathrm{Cu}^{2+}$ e $\mathrm{ClO}_{4}^{-}$e assim inserido no ligante. Após a complexação o contraíon $\left(\mathrm{ClO}_{4}^{-}\right)$mantém a espécie neutra, como observado nos cristais obtidos em laboratório [22]. Não consideramos o contraíon em nossos resultados.
} 
metálicos [109]. Neste trabalho os ligantes possuem grupos funcionais contendo $N$ e $O$.

\subsection{Estruturas precursoras}

Vamos agora descrever de forma sucinta as características estruturais das estruturas precursoras que foram utilizadas na síntese dos complexos de cobre ${ }^{2}$. Utilizaram-se oito precursores [10,23,110] (Fig. 3.1): a) hidrocloreto de histamina (hist); b) 2-amino-1-etilpiridina (epy); c) 2-acetilpiridina (apy) ; d) 2-acetilpirazina (apz); e) 3-indolin-2-ona ou isatina (isa); f) 1-2-etilenodiamina (en); g) 1-3-diaminopropano (pn); h) 1,2-dimetilglioxol ou diacetil (dac).

a)

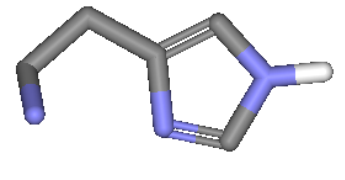

e)

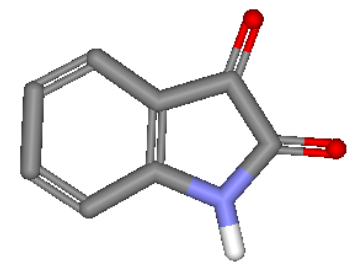

b)

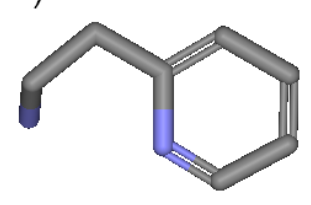

f)

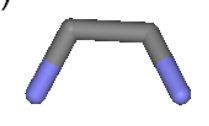

c)

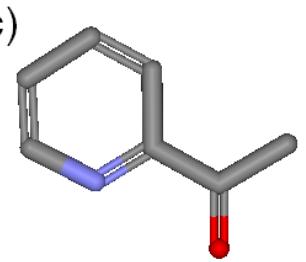

g)

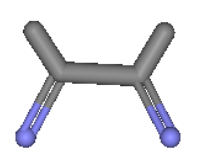

d)

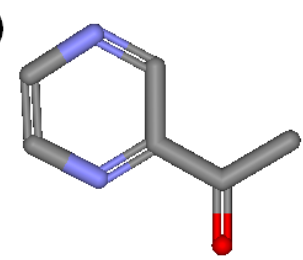

h)

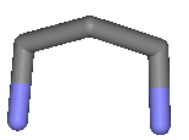

Figura 3.1: Representação das estruturas precursoras: a) hist, possuindo o heterocíclo imidazol ou imid; b) epy, possuindo o heterocíclo piridina ou py; c) apy, possuindo o heterocíclo piridina ou py; d) apz, possuindo o heterocíclo pirazina ou pz; e) isa; f) en; g) dac; h) pn. Alguns átomos de $\mathrm{H}$ foram removidos para melhor visualização. Representação das cores: carbono (cinza), nitrogênio (azul), oxigênio (vermelho) e hidrogênio (branco).

Ao formar os respectivos ligantes as estruturas hist (Fig. 3.1 a) e epy (Fig. 3.1 b)

\footnotetext{
${ }^{2}$ Denominaremos os complexos na forma oxidada através da nomenclatura simplificada conforme figuras 1.3,1.4 e 1.5. Na forma reduzida, ou quando designarmos apenas os ligantes isolados, chamaremos pelo nome por extenso, por exemplo: $\left[\mathrm{Cu}(\text { apyhist }) \mathrm{H}_{2} \mathrm{O}\right]^{+}$ou apyhist.
} 
possuem grande flexibilidade, devido ao grupo (N-C-C-), já o apy (Fig. 3.1 c) e o apz (Fig. 3.1 d) são mais rígidos e formarão a região com a ligação dupla do ligante (Fig. 3.1). Os ligantes de "conexão" são o en (Fig. 3.1 f), o dac (Fig. 3.1 g) e o pn (Fig. 3.1 h). O grupamento pn (N-C-C-C-N) possibilita maior flexibilidade aos ligantes enquanto o en (NC-C-N), com um carbono a menos, tem menor flexibilidade. No primeiro caso ( $p n$ ) haverá formação de um anel de seis membros ao se coordenar ao íon $C u^{2+}$ enquanto no segundo caso (en) o anel formado será de cinco membros. O grupamento isa (Fig. 3.1 e) contendo dois anéis condensados apresenta estrutura mais planar. Os anéis heterocíclicos piridina (py - Fig. 3.1b e c) e pirazina ( $p z$ - Fig. 3.1 d) são mais volumosos que o imidazol (imid - Figs. 3.1 a) o que irá repercutir na distância de ligação metal-ligante(conforme discutiremos na seção 3.2.1).

Os ligantes heterocíclicos são anéis aromáticos contendo cinco ou seis átomos. O imid possui cinco átomos no anel, e por consequência é menor que a $p y$ e a $p z$ que possuem seis átomos. Com relação à polaridade, à py, com um grupo imina, é mais apolar que o imid ${ }^{3}$ que possui dois $N$ de grupos funcionais diferentes: um amino, com característica de ácido fraco e um imino, com característica de base forte que se liga ao metal [109]. A pz apresenta dois grupos imina: sendo, no complexo, um deles disponível para a ligação com o íon $C u$ e outro 'par isolado' disponível não ligante.

\footnotetext{
${ }^{3}$ Momento de dipolo experimentais: $i m i d=3.6$ D e $p y=2.19 \mathrm{D}$ [111].
} 


\subsection{Série das piridinas, pirazinas e histaminas triden- tadas}

Nesta seção analisamos os complexos de cobre da série das piridinas, pirazinas e histaminas tridentadas ${ }^{4}$. Estes ligantes são obtidos em duas etapas [10]: 1) formação do ligante através de reação de condensação entre um precursor contendo grupo carbonila com outro grupo contendo amina; 2) metalação da imina ou diimina formada, usando perclorato de cobre. O quarto ligante é uma molécula de $\mathrm{H}_{2} \mathrm{O}$ (ligante aqua) ou $\mathrm{OH}^{-}$(ligante hidroxila) ${ }^{5}$. Estudamos as distâncias de ligação, os ângulos de torção e as coordenações entre os vários ligantes e o cobre, assim como as possíveis conformações de mínimo energético. A relaxação estrutural foi realizada considerando algumas possíveis configurações estruturais iniciais. Observa-se que a estrutura dos ligantes para as bases de Schiff desta série são semelhantes diferenciando-se apenas em relação ao heterociclo (Fig. 1.3). A ligação entre o $N 1-C 3$ Fig.3.2 (a), assume característica de ligação dupla, "mais rígida", já as ligações $C 1-C 2$ e $C 2-N 1$ por apresentarem característica de ligação simples, adquirem maior flexibilidade. Desta forma, realizamos alguns testes de geometrias iniciais, levando-se em conta esta flexibilidade. Também realizamos estudos onde consideramos dois estados de carga: o estado oxidado $\left(\mathrm{Cu}^{2+}\right)$ e o estado reduzido $\left(\mathrm{Cu}^{+}\right)$segundo a nomenclatura para os estados formais de carga [3].

Em todos os cálculos realizados com o método PAW utilizamos o corte em energia para ondas planas em 40 Ry e 160 Ry para a densidade de carga. Os compostos foram isolados das demais células periódicas em no mínimo 7 Å. No estudo das energias de ligação mantivemos o mesmo tamanho da célula unitária tanto para o complexo como para o ligante e para o íon.

\footnotetext{
${ }^{4}$ Chama-se ligante n-dentado aquele que possui $n$ átomos contendo pares de elétrons com caráter de base de Lewis (nucleófilo). Estes ligantes apresentam afinidade por ácidos de Lewis(eletrófilos) que, neste caso, é o metal.

${ }^{5} \mathrm{Os}$ complexos com o ligante $\mathrm{OH}^{-}$ou $\mathrm{H}_{2} \mathrm{O}$ são obtidos em função do pH utilizado em sua síntese [10].
} 


\section{Complexos de Cobre com Base de Schiff: tri-1}

O complexo tri-1 é apresentado na Fig. 3.2 e é formado pelas estruturas precursoras apy (Fig. $3.1 \mathrm{c}$ ) e hist (Fig. $3.1 \mathrm{a}$ ), com os grupos piridina (py) e imidazol (imid) respectivamente. Conforme mencionado na introdução, no equilíbrio competitivo pelo íon $C u$ entre os complexos e a proteína albumina, o tri-1 apresenta a característica diferenciada de transferir o íon $C u$ apenas para o sítio do aminoácido cis-34 de menor afinidade por $C u$. Por este motivo e também pelo fato de que é o único ligante que possui estrutura cristalográfica [19, 22, 24].

As Figuras 3.2 (b) e (c) representam duas possíveis conformações do ligante no complexo ${ }^{6}$ que denominamos respectivamente conformação para baixo (cb) e conformação 'para cima' (cc) (Fig. 3.3 a e b respectivamente).

Após a relaxação estrutural encontramos a conformação em que o ligante $\mathrm{H}_{2} \mathrm{O}$ se mantém coplanar (coordenação quadrado planar) com os demais sítios ligantes do apyhist (Fig. 3.2 d) e também 'abaixo' deste plano (coordenação quadrado planar distorcida - Fig. 3.2 c). A conformação de mais baixa energia foi a (cb) com a coordenação quadrado planar distorcida (Tabela 3.1). A diferença em energia entre as geometrias mais estáveis foi de apenas $0.7 \mathrm{kcal} / \mathrm{mol}$ ou $0.03 \mathrm{eV}$ (Tabela 3.1) ${ }^{7}$. Apesar de haver uma configuração de mais baixa energia, a diferença de $0.03 \mathrm{eV}$ é pequena se pensarmos que a energia de agitação térmica à temperatura ambiente é desta mesma ordem de grandeza $(\mathrm{kT}=0.026 \mathrm{eV})$, assim as duas conformações são energeticamente indistinguíveis. Assim podemos considerar que o complexo tri-1 possui diversos mínimos locais 'rasos', o íon $C u$ não se mantém fixo na geometria quadrado planar e os átomos C1-C2 e C2-N1 (Fig. 3.2) para cima e para baixo ${ }^{8}$.

Ao comparar as diferenças estruturais entre os mínimos energéticos observa-se que as distâncias de ligação entre os átomos ligantes de $N$ e o $C u$ permanecem pouco alteradas,

\footnotetext{
${ }^{6}$ Experimentalmente há ainda a conformação que não será considerada neste trabalho com a torção do anel imidazólico em $180^{\circ}$ onde é observada a formação de estruturas poliméricas e cíclicas [18].

${ }^{7}$ Fatores de conversão: $1 \mathrm{H}$ (Hartree $)=27.2107 \mathrm{eV}$ e $1 \mathrm{H}=627.5030 \mathrm{kcal} / \mathrm{mol}$.

${ }^{8}$ Estas estruturas de mínimo energético são encontradas experimentalmente e serão apresentadas na próxima seção.
} 


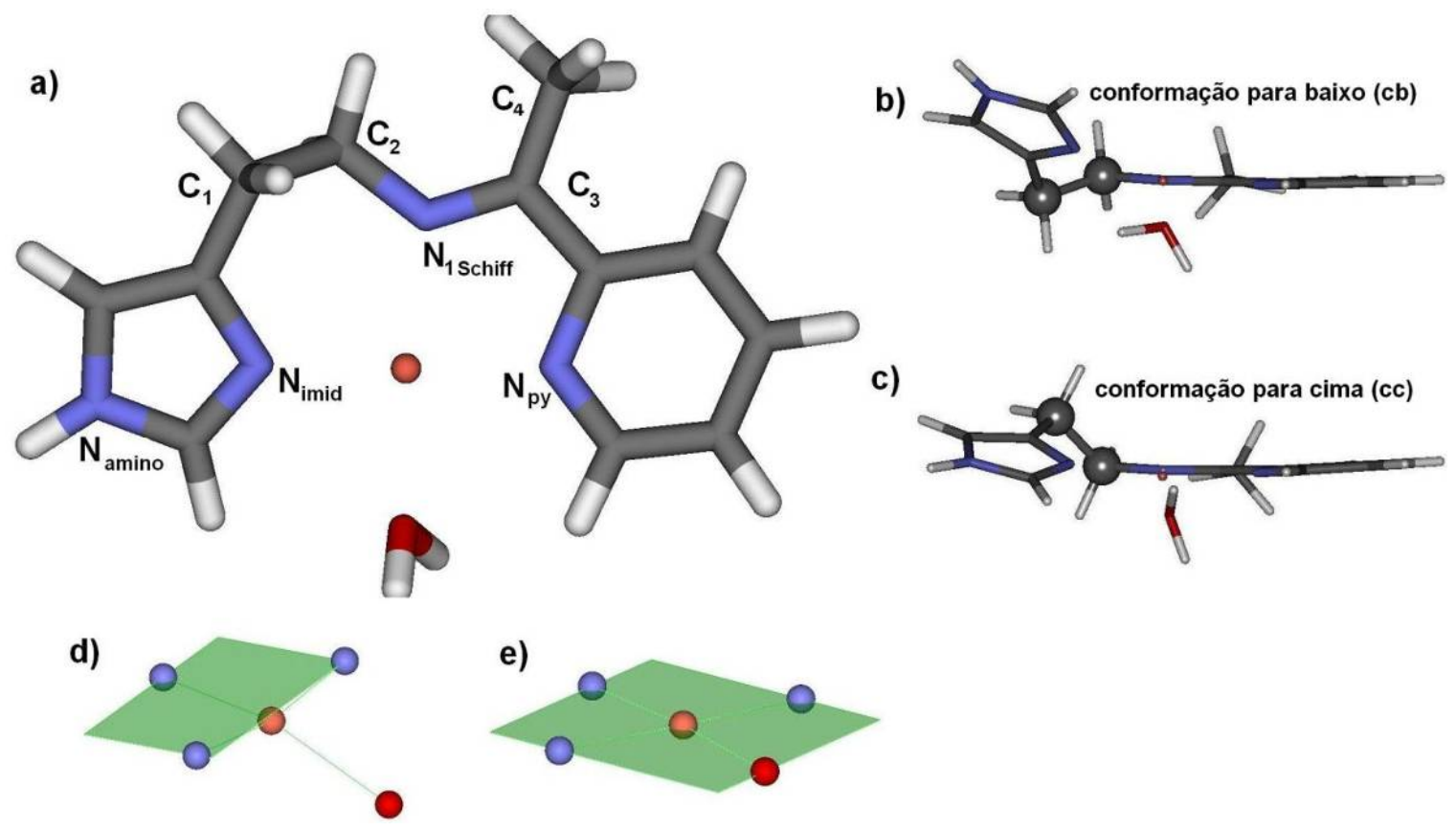

Figura 3.2: Representação do complexo tri-1 com as posições atômicas relaxadas para as duas conformações de mínimo estrutural encontradas. a) Nomenclatura para os átomos de $C$ e $N$; b) Representação da conformação 'para baixo' (cb); c) Representação da conformação 'para cima' (cc). d) Representação esquemática do plano que contém os átomos ligantes de $N$ com o sítio de $O$ (em vermelho) e o íon $C u$ abaixo deste plano (coordenação quadrado planar distorcida); e) Representação esquemática do plano que contém os átomos ligantes de $N$ com todos os sítios coplanares (coordenação quadrado planar). Representação das cores: carbono (cinza), nitrogênio (azul), oxigênio (vermelho), cobre (laranja) e hidrogênio (branco). 
Tabela 3.1: Energia total em Hartree (H) para as conformações (cb) e (cc) e coordenações do tri-1.

\begin{tabular}{|c|c|c|c|}
\hline \multirow{2}{*}{$\begin{array}{l}\text { Coordenação } \\
\qquad \mathrm{N}_{3} \mathrm{O}\end{array}$} & & \multicolumn{2}{|c|}{ Energia Total $(\mathrm{H})$} \\
\hline & & Quadrado planar & Quadrado planar distorcida \\
\hline & $(\mathrm{cb})$ & -185.8286 & -185.8297 \\
\hline & $(\mathrm{cc})$ & -185.8280 & -185.8280 \\
\hline
\end{tabular}

com variações menores que $1 \%$. Mesmo a distância entre o $C u$ e o sítio de $O$ da molécula de $\mathrm{H}_{2} \mathrm{O}$, com maior flexibilidade, varia no máximo $0.06 \AA$ entre as conformações.

Realizamos estudos modificando o posicionamento da molécula de $\mathrm{H}_{2} \mathrm{O}$ e do átomo de cobre a fim de encontrar uma configuração de mais baixa energia. Podemos citar, por exemplo, a inserção do ligante $\mathrm{H}_{2} \mathrm{O}$ perpendicular ao 'plano' do ligante e o distanciamento do átomo de $\mathrm{Cu}$ do plano entre os átomos de $N$. Em todos os estudos aqui realizados foram encontradas geometrias de mínimo em energia, como as apresentadas anteriormente. Desta forma, concluímos que as geometrias reais devem oscilar entre as posições médias apresentadas nesta seção.

\section{Comparação estrutural com resultados da literatura}

Comparamos as estruturas do tri-1 com duas estruturas diméricas obtidas por difratometria de raios- $\mathrm{x}$ dos cristais $\left[\mathrm{Cu}_{2}\right.$ (apyhist) $\left.{ }_{2} \mathrm{Cl}_{2}\right]\left(\mathrm{ClO}_{4}\right)_{2}[22],\left[\mathrm{Cu} \text { (apyhist) } \mathrm{N}_{3}\right]_{2}$ [24] e também para o cristal do complexo $[\mathrm{Cu}(2 \text { pymehist }) \mathrm{Cl}]^{+}$contendo o ligante pymehist derivado do apyhist [19]. Estes complexos apresentam propriedades catalíticas sendo bons miméticos da enzima superóxido dismutase (SOD), responsável pela dismutação de radicais superóxido $\left(O_{2}^{-}\right)$em oxigênio molecular e peróxido de hidrogênio [20,112]. Na Tabela 3.2 comparamos algumas propriedades estruturais mais relevantes nestes complexos, como as distâncias de ligação CuLigante $(\mathrm{Cu}-\mathrm{L})$, o 'ângulo de abertura' ${ }^{\text {9 }}$ do ligante e ângulo de torção entre os três $\mathrm{N}$ ligantes

\footnotetext{
${ }^{9} \mathrm{O}$ ângulo de abertura é muitas vezes chamado em inglês por bite angle [3].
} 

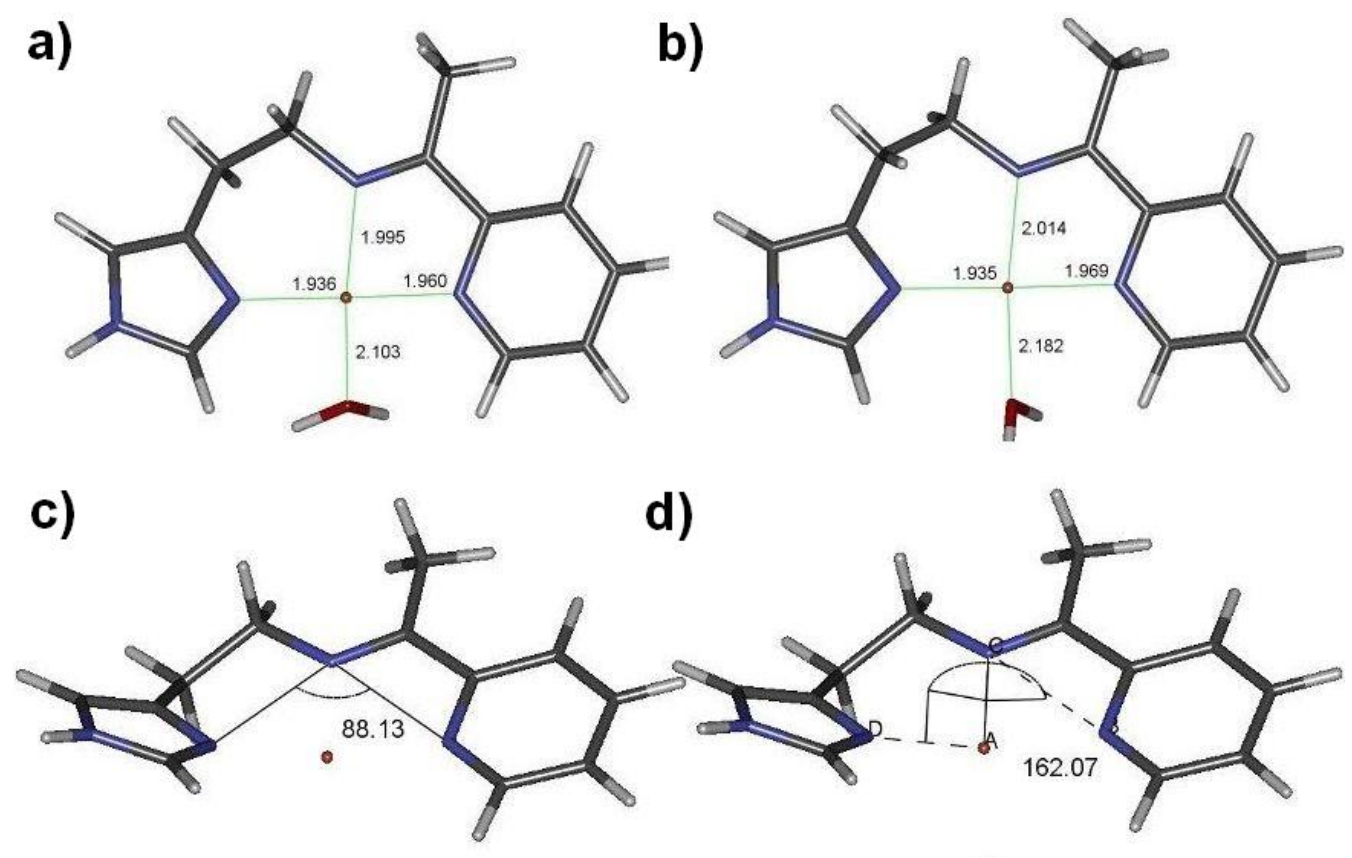

d)
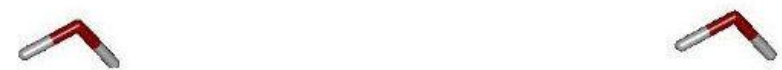

Figura 3.3: Representação dos resultados obtidos para o complexo tri-1 com a) conformação para baixo (cb); b) conformação para cima (cc); c) Ângulo de abertura entre N-N-N; d) Ângulo de torção entre N-N-Cu-N (direita). Distâncias de ligação em A.

e o metal. As estruturas cristalinas apresentam características semelhantes entre si sendo as diferenças nas distâncias de ligação de no máximo $2 \%$ e entre os ângulos de torção de $3.5 \%$. Observa-se que nas estruturas com os ligantes apyhist/pymehist há conformações nos dois mínimos locais (cb/cc). Tanto as estruturas calculadas com o ligante $\mathrm{H}_{2} \mathrm{O}$ como com o $\mathrm{OH}^{-}$, nas diversas conformações, apresentam ótima concordância com os dados de raio-x, menor que $4 \%$ para as distâncias e menor que $8 \%$ para o ângulo de torção. Entretanto os resultados com ligante $\mathrm{OH}$ são em geral mais próximos dos resultados experimentais (distâncias $\mathrm{Cu}-\mathrm{L}$ menores que $2 \%$ e ângulo de torção menor que $3.5 \%$ ). Isto é esperado já que o quarto ligante, nos cristais é um ânion. Em resumo, podemos concluir que as principais características estruturais do complexo metálico, como distância $\mathrm{Cu}-\mathrm{N}$, ângulo de torção e 
ângulo de abertura estão em excelente concordância com resultados de sistemas análogos, obtidos por raio-X. A distância $\mathrm{Cu}-\mathrm{N}$ varia de 1.933 a $2.016 \AA$ para os cristais enquanto que para os complexos calculados aqui encontramos distâncias $\mathrm{Cu}-\mathrm{N}$ entre 1.936 a $2.059 \AA$. A coordenação típica é a quadrado planar com alguma distorção tetraédrica conforme verificado em nossos cálculos e experimentalmente.

\section{Complexos com Bases de Schiff : tri-2 a tri-4}

O complexo tri-2 (Fig. 1.3) se diferencia do complexo tri-1 pelo uso do composto precursor epy substituindo o composto hist. Neste complexo foram realizados três estudos: o primeiro com o ligante $\mathrm{H}_{2} \mathrm{O}$ e o segundo e o terceiro partindo de duas geometrias iniciais diferentes com o ligante $\mathrm{OH}^{-}$. A estrutura obtida é semelhante ao tri-1 com a coordenação quadrado planar distorcida e distâncias de ligação de aproximadamente $2 \AA$. Nos dois estudos conformacionais obtivemos respectivamente as energias totais $\mathrm{E}=-187.6036 \mathrm{H}$ para a conformação (cc) e $\mathrm{E}=-187.6073 \mathrm{H}$ para a conformação $(\mathrm{cb})$. O valor $\Delta \mathrm{E}$ obtido de $2.27 \mathrm{kcal} / \mathrm{mol}$ é maior que o obtido para o complexo tri-1. Entretanto, este valor é apenas uma estimativa da diferença em energia entre as conformações de mínimo. O terceiro complexo estudado foi o tri-3 (Fig. 1.3) e este se diferencia do complexo tri-2 pela substituição da molécula de piridina pela pirazina. As distâncias de ligação são bastante semelhantes, em relação aos demais complexos, com distância entre os átomos ligantes e o $\mathrm{Cu}$ de aproximadamente $2 \AA$. Estudamos também as configurações (cb)/(cc) com o ligante $O H^{-}$a configuração (cc) com o ligante $\mathrm{H}_{2} \mathrm{O}$. A diferença de energia para as duas conformações foi de de $2.2 \mathrm{kcal} / \mathrm{mol}$ (0.1 eV) com $\mathrm{E}=-191.2765 \mathrm{H}$ (cc) e $\mathrm{E}=-191.2800 \mathrm{H}(\mathrm{cb})$. O quarto complexo desta série é o tri-4 (Fig. 1.3). Este se diferencia do complexo (tri-1) devido ao uso do composto precursor apz no lugar da apy. As distâncias de ligação $\mathrm{Cu}-\mathrm{N}$ são semelhantes, em torno de $2 \AA$, e $1.8 \AA$ para o $\mathrm{Cu}-\mathrm{OH}$. As energias totais encontradas para as configurações para cima e para baixo foram: $\mathrm{E}=-189.4930 \mathrm{H}(\mathrm{cc})$ e $\mathrm{E}=-189.4939 \mathrm{H}(\mathrm{cb})$ com a diferença em energia de $\mathrm{E}=0.6$ $\mathrm{kcal} / \mathrm{mol}(0.03 \mathrm{eV})$. 


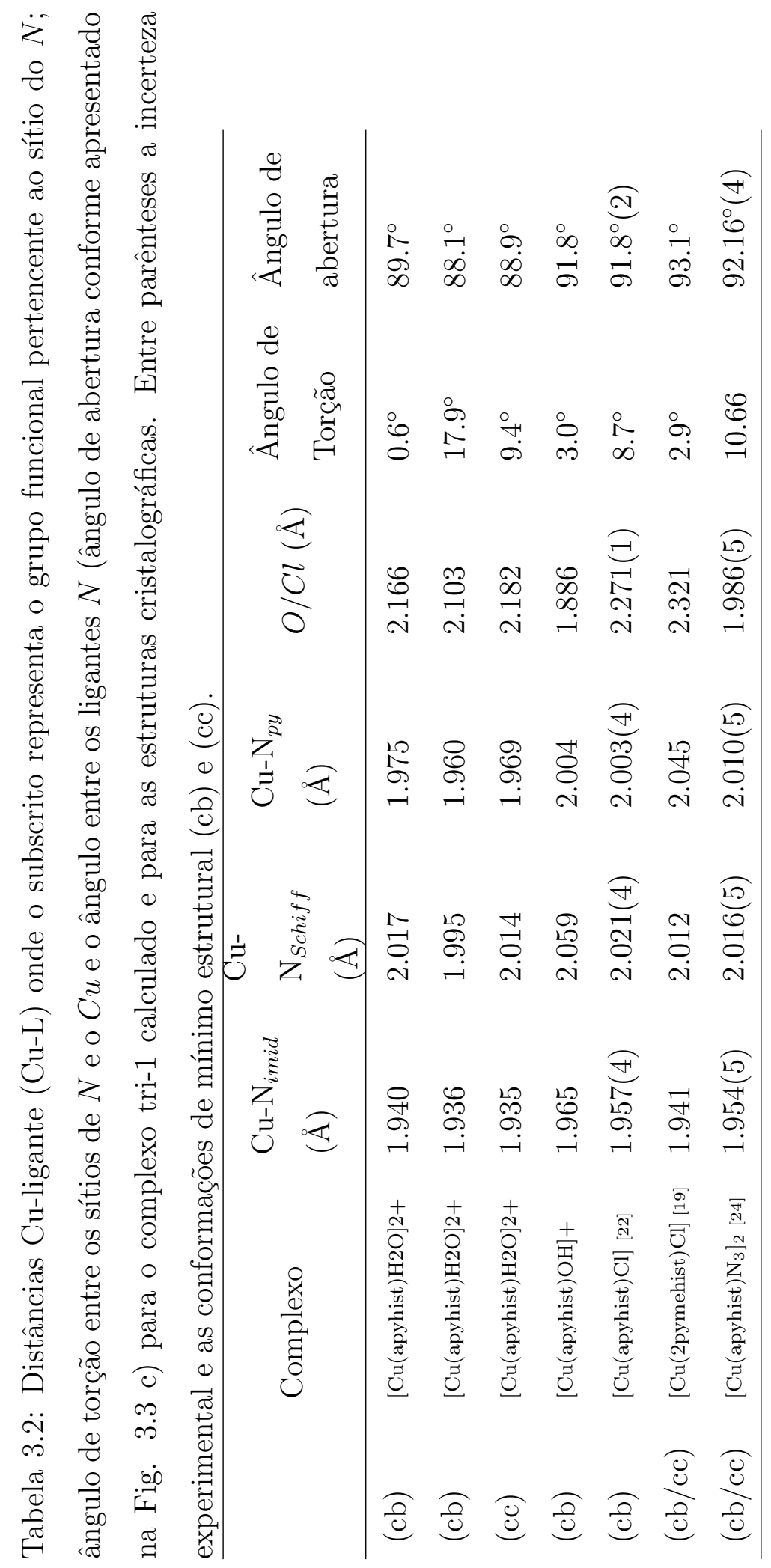




\section{Complexos no estado de oxidação reduzido}

Realizamos também o estudo dos complexos tridentados para o estado de oxidação reduzido. Pretendemos investigar se neste estado eletrônico o complexo tri-1 apresenta características estruturais ou eletrônicas diferenciadas dos demais complexos desta série. Nesta configuração eletrônica espera-se a coordenação $\mathrm{Cu}-\mathrm{L}$ mais tetraédrica devido ao preenchimento do nível $\mathrm{d}^{10}$ no íon $\mathrm{Cu}^{+}$. Assim, para um ligante neutro e considerando o cobre com carga formal +1 e, atribuímos a carga +1 e para o sistema. Apesar desta configuração eletrônica ser, em geral, menos estável que a oxidada em condições experimentais, o centro redox $C u$ pode 'ciclar' entre os dois estados de oxidação +1 e $+2 e$.

\subsubsection{Comparação entre os complexos e considerações sobre ener- gia}

As Tabelas 3.3 e 3.4 e a Fig. 3.4 apresentam um resumo das propriedades estruturais dos quatro complexos estudados. A partir das informações obtidas nas seções anteriores observamos que, mesmo com diferenças em energia muito pequenas, a configuração com o $C 1-C 2$ e $C 2-N 1$ para baixo (Fig. 3.2) apresenta maior estabilidade. Note-se que não estamos aqui investigando as transições entre as conformações de equilíbrio; assim, estes valores são apenas relativos às conformações iniciais de cálculo. Mesmo sendo pequenas as diferenças em energia para as duas conformações é interessante notar que há uma tendência para baixo (cb) que mantém a coordenação mais distorcida. Outro fato observado é que, dos três resultados cristalográficos para o ligante apyhist em nenhum deles há apenas a conformação (cc) enquanto em um caso [22] há apenas estruturas com a conformação (cb). Como esperado, o anel heterocíclico ligado à região mais flexível (com ligações simples) do ligante apresenta maior deformação. Entretanto, muito provavelmente, à temperatura ambiente estes complexos estão em constante movimento e oscilam entre as conformações de equilíbrio, isto é, entre a coordenação do íon $C u$ quadrado planar e quadrado planar distorcida (cc) e (cb) 
(Fig. 3.2). Para os complexos tri-1 e tri-4 a distância $\mathrm{Cu}-\mathrm{N}_{\text {imid }}$ não se modifica independente da posição mínimo conformacional (tabela 3.3). Já para as distâncias $\mathrm{Cu}-\mathrm{N}_{p y / p z}$ há pequenas diferenças enquanto que as distâncias, $\mathrm{Cu}-\mathrm{N}_{\text {Schiif }}$ aumentam na conformação (cc).
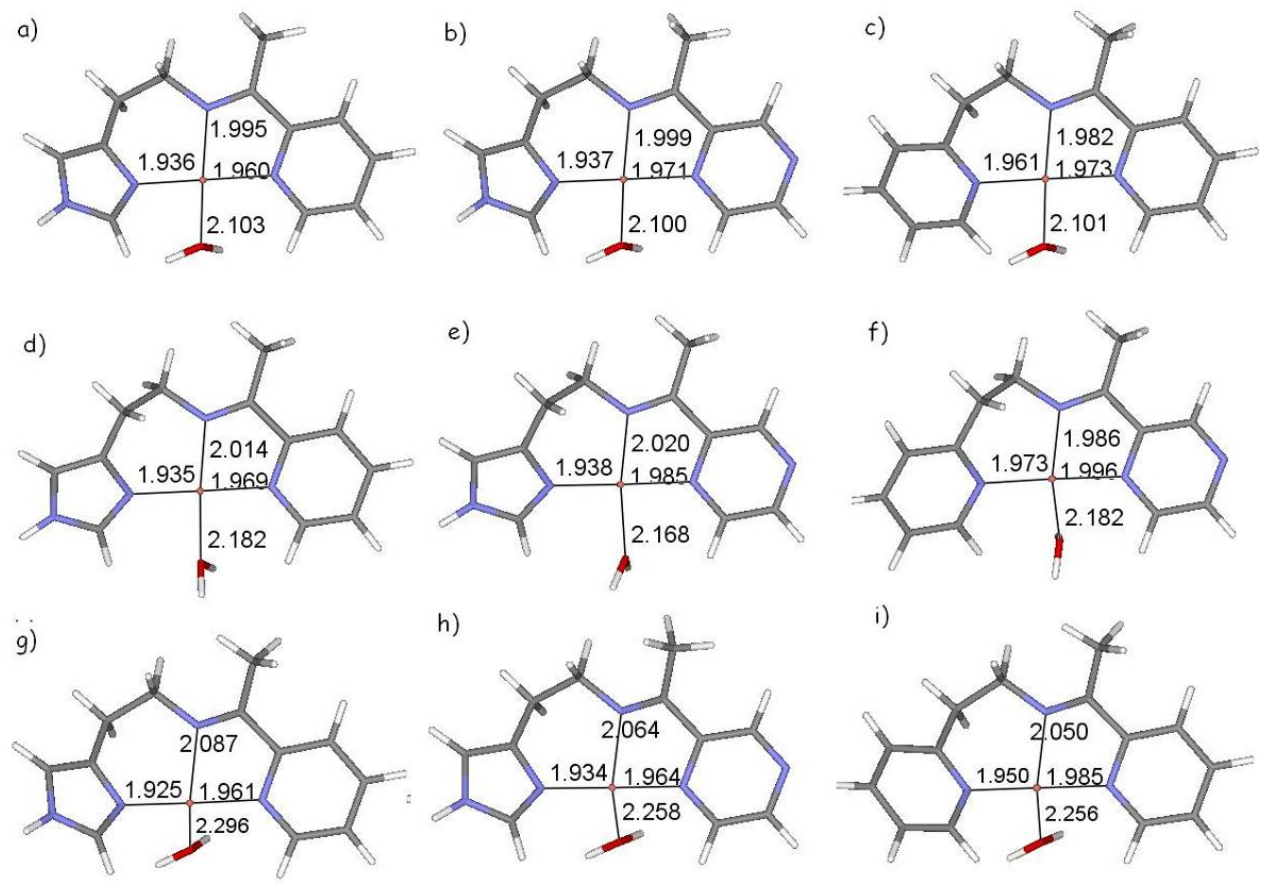

Figura 3.4: Distâncias de ligação para as estruturas relaxadas para dois mínimos conformacionais obtidas com o PAW para o estado oxidado a) $\left[\mathrm{Cu}(\text { apyhist }) \mathrm{H}_{2} \mathrm{O}\right]^{2+}$ (tri-1) b) $\left[\mathrm{Cu}(\text { apzhist }) \mathrm{H}_{2} \mathrm{O}\right]^{2+}\left(\right.$ tri-4) c) $\left[\mathrm{Cu} \text { (apyepy) } \mathrm{H}_{2} \mathrm{O}\right]^{2+}$ (tri-2) d) $\left[\mathrm{Cu}(\text { apyhist }) \mathrm{H}_{2} \mathrm{O}\right]^{2+}$ (tri-1) e) $\left[\mathrm{Cu}(\text { apzhist }) \mathrm{H}_{2} \mathrm{O}\right]^{2+}\left(\right.$ tri-4) f) $\left[\mathrm{Cu}(\text { apzepy }) \mathrm{H}_{2} \mathrm{O}\right]^{2+}$ (tri-3). Para o estado reduzido: g) $\left.\left.\left[\mathrm{Cu}(\text { apyhist }) \mathrm{H}_{2} \mathrm{O}\right]^{+} \mathrm{h}\right)\left[\mathrm{Cu}(\text { apzhist }) \mathrm{H}_{2} \mathrm{O}\right]^{+} \mathrm{i}\right)\left[\mathrm{Cu}(\text { apyepy }) \mathrm{H}_{2} \mathrm{O}\right]^{+}$.

Ao comparar as diferenças estruturais entre os dois estados de oxidação (Fig. 3.4) observamos que a única distância que se modifica é a $\mathrm{Cu}-\mathrm{N}_{\text {Schiff }}$ aumentando no estado reduzido em no máximo 4\%. Por outro lado, o ângulo de abertura diminui em $5 \%$ e o ângulo de torção aumenta de $7^{\circ}$ a $11.5^{\circ}$. Esta modificação do ângulo de torção é a mais característica do estado reduzido onde o complexo se mantém na configuração mais tetraédrica. A menor 


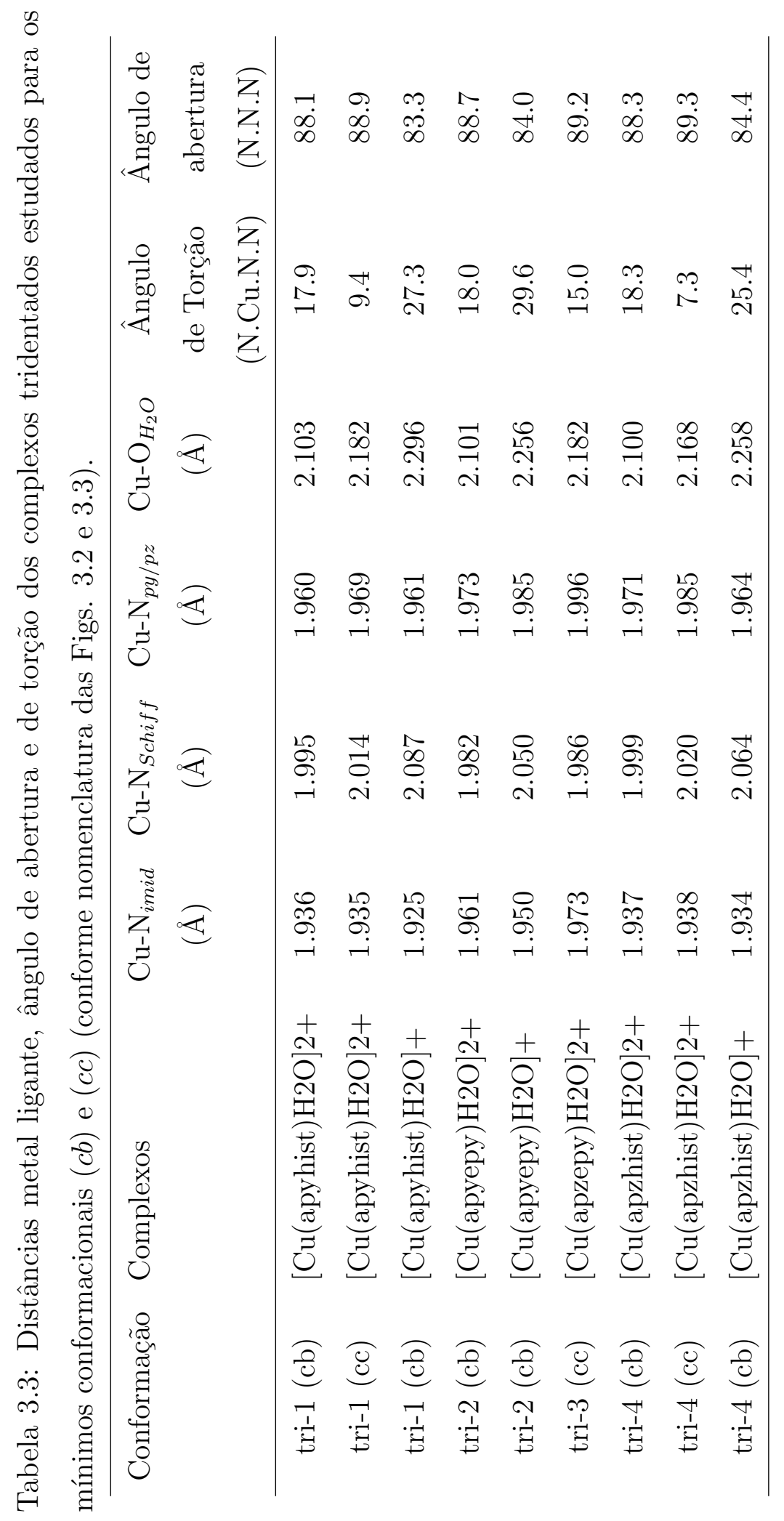


Tabela 3.4: Diferença em energia entre as conformações de mínimo local (cc) e (cb) para os dois mínimos locais e a energia de referência kT à temperatura ambiente.

\begin{tabular}{llll}
\hline Complexo & $\begin{array}{l}\Delta \mathrm{E}_{\text {total }} \\
\mathrm{kcal} / \mathrm{mol}\end{array}$ & Complexo & $\begin{array}{l}\Delta \mathrm{E}_{\text {total }} \\
\mathrm{kcal} / \mathrm{mol}\end{array}$ \\
\hline$[\mathrm{Cu}$ (apyhist $) \mathrm{OH}]^{+}$ & 0.3 & {$\left[\mathrm{Cu}(\text { apyhist }) \mathrm{H}_{2} \mathrm{O}\right]^{2+}$} & 0.7 \\
{$[\mathrm{Cu}(\text { apzhist }) \mathrm{OH}]^{+}$} & 1.4 & {$\left[\mathrm{Cu}(\text { apzhist }) \mathrm{H}_{2} \mathrm{O}\right]^{2+}$} & 0.6 \\
{$[\mathrm{Cu}(\text { apyepy }) \mathrm{OH}]^{+}$} & 2.3 & {$\left[\mathrm{Cu}(\text { apyepy }) \mathrm{H}_{2} \mathrm{O}\right]^{2+}$} & - \\
{$[\mathrm{Cu}(\text { apzepy }) \mathrm{OH}]^{+}$} & 2.2 & {$\left[\mathrm{Cu}(\text { apzepy }) \mathrm{H}_{2} \mathrm{O}\right]^{2+}$} & - \\
$\mathrm{kT}(\mathrm{T}=300 \mathrm{~K})$ & 0.577 & & \\
\hline
\end{tabular}

distância de ligação é sempre a $\mathrm{Cu}-N_{\text {hist }}$ já que o ligante imid apresenta menor dimensão.

\section{Energia de Ligação}

Estudamos a estabilidade dos complexos realizando o cálculo da energia de ligação $\left(\Delta \mathrm{E}_{\text {lig }}\right)$ dos ligantes com o $\mathrm{Cu}^{2+}$ que é dada pela energia total do complexo ( $\left.\mathrm{E}_{\text {complexo }}\right)$ subtraída a energia do íon $C u \mathrm{E}\left(\mathrm{Cu}^{2+}\right)$ e dos $n$ ligantes constituíntes do complexo após a relaxação das posições atômicas ${ }^{10}$

$$
\Delta E_{\text {lig }}=E_{\text {complexo }}-\left(E\left(C u^{2+}\right)+\sum_{i=1}^{n} E_{l i g(i)}\right)
$$

onde $\mathrm{E}_{\text {complexo }}$ é a energia do complexo subtraída da energia do íon $C u$ isolado e dos ligantes isolados, com a geometria otimizada. Definimos também a energia de deformação como o quanto o ligante necessita de energia para chegar à conformação de complexação com o metal:

\footnotetext{
${ }^{10}$ No cálculo para a expansão da base em ondas planas não há o erro de superposição de bases (BSSE) [113] como no cálculo de bases localizadas. O cuidado refere-se à utilização de células unitárias de mesma dimensão tanto para os cálculos do complexo como do íon e dos ligantes isolados.
} 


$$
\Delta E_{\text {def }}=\left(\sum_{i=1}^{n}\left(E_{\text {lig }(i)}^{\text {complexo }}-E_{\text {lig }(i)}^{o p t}\right)\right.
$$

onde o primeiro termo é a energia do ligante na conformação do complexo e o segundo termo é a energia do ligante otimizado.

Na Tabela 3.5 apresentamos as energias de ligação e deformação para os complexos tri-1 a tri-4 nos estados oxidado e reduzido respectivamente. Os complexos tri-1 e tri-2 são os mais estáveis (para os dois estados de oxidação). Em relação aos mais estáveis, o tri-3 é o menos estável em $18 \mathrm{kcal} / \mathrm{mol}(0.79 \mathrm{eV})$ e o tri-4 em aproximadamente $11 \mathrm{kcal} / \mathrm{mol}(0.48 \mathrm{eV})$. Esta diferença está provavelmente relacionada à maior localização eletrônica nos ligantes $N$ do tri1 e tri-2 e esta é refletida na maior compactação das ligações $\mathrm{Cu}-\mathrm{L}$. Nos outros dois complexos, há mais centros reativos externos à esfera de coordenação representados pelo heterociclo $p z$ gerando maior 'fragmentação' eletrônica. A energia de deformação do tri-2 é ligeiramente menor que a dos demais complexos (Tabela 3.5). Observe que o tri-2 apresenta uma menor deformação em relação aos demais, apenas rotacionando os anéis piridínicos (Fig. 3.5). Ao passo que os complexos tri-1 e tri-4 apresentam uma rotação de $180^{\circ}$ no anel imidazólico, além da deformação da estrutura do ligante. O complexo tri-3 também deforma o anel piridínico, que apresenta uma rotação de $90^{\circ}$, além da deformação da estrutura do ligante. Entretanto, como visto na seção anterior, estes complexos apresentam diversas configurações de mínimo local de energias e, dependendo da configuração, a energia de deformação pode variar. Em relação aos valores da energia de ligação no estado reduzido, conforme esperado, a estabilização é menor que nas espécies oxidadas, devido ao preenchimento do orbital do $C u$ com caráter $\mathrm{d}_{x}{ }^{2}-y^{2}$, como será mostrado na próxima seção. 

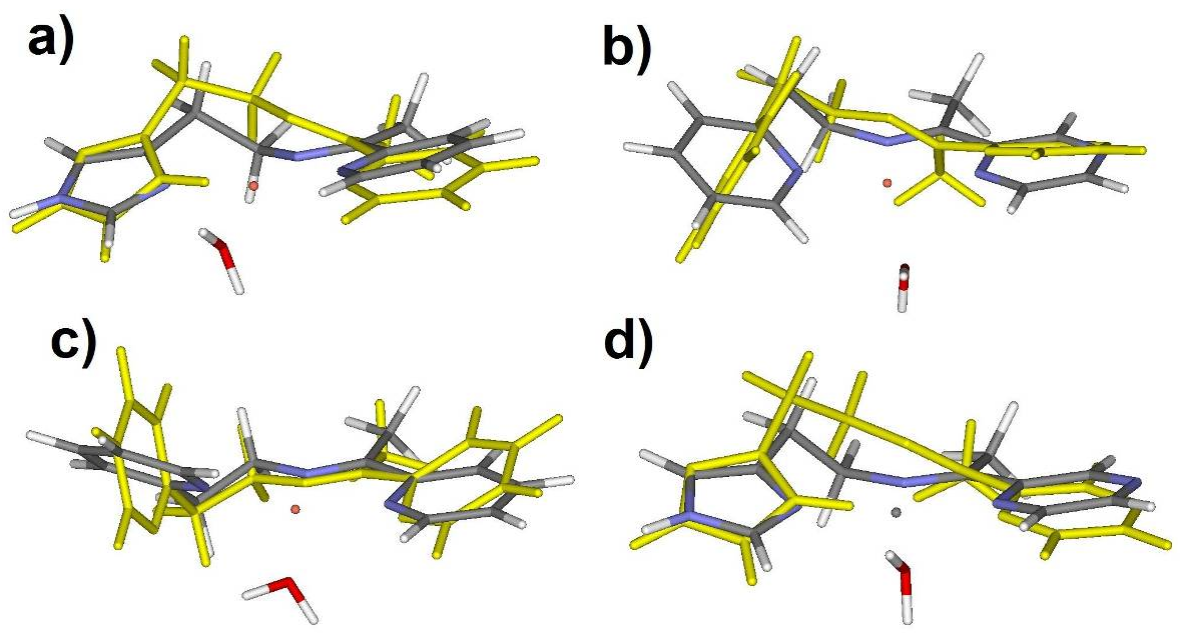

Figura 3.5: Representação dos complexos e seus ligantes isolados (em amarelo) após relaxação estrutural: a) tri-1; b) tri-2; c) tri-3; d) tri-4.

\subsubsection{Estrutura eletrônica dos complexos}

\section{Densidade de estados e análise dos orbitais}

Utilizaremos a densidade de estados (DOS) total e projetada (PDOS) nos ligantes e no $\mathrm{Cu}$ assim como os orbitais para analisar a estrutura eletrônica dos complexos. Nos concentramos na análise dos resultados de 'gap' de energia HOMO-LUMO ${ }^{11}$ e $\pi-\pi^{*}$, caráter dos orbitais de fronteira e hibridização com os demais grupos de orbitais, analisando também o posicionamento em energia dos grupos reativos como aqueles contendo a presença de pares isolados.

Nas Figuras 3.6 e 3.7 apresentamos as DOS para os complexos no estado oxidado. Os

\footnotetext{
${ }^{11} \mathrm{O}$ termo HOMO significa orbital molecular ocupado de mais alta energia (highest occupied molecular orbital) e LUMO significa orbital molecular desocupado de mais baixa energia (lowest unoccupied molecular orbital). Quando um orbital é ocupado por um elétron desemparelhado o designamos como orbital molecular unicamente ocupado (SOMO - singly occupied molecular orbital). Utilizamos o termo gap neste caso como um abuso de linguagem já que este termo é originalmente empregado em física do estado sólido como a região 'proibida' entre as bandas de energia ocupadas e desocupadas.
} 
Tabela 3.5: Energias de deformação $\left(\mathrm{E}_{\text {def }}\right)$ e energia de ligação $\left(\mathrm{E}_{\text {lig }}\right)$ para os complexos no estado oxidado e reduzido.

\begin{tabular}{llcc}
\hline Complexos & $\mathrm{E}_{\text {def }}$ & $\mathrm{E}_{\text {lig }}$ & \\
\hline tri-1 & $[\mathrm{Cu}$ (apyhist $\left.) \mathrm{H}_{2} \mathrm{O}\right]^{2+}$ & 13.60 & -440.94 \\
& $[\mathrm{Cu}$ (apyhist $\left.) \mathrm{H}_{2} \mathrm{O}\right]^{+}$ & 9.73 & -167.64 \\
tri-2 & {$\left[\mathrm{Cu} \text { (apyepy) } \mathrm{H}_{2} \mathrm{O}\right]^{2+}$} & 8.71 & -440.94 \\
& {$\left[\mathrm{Cu}(\text { apyepy }) \mathrm{H}_{2} \mathrm{O}\right]^{+}$} & 6.19 & -167.09 \\
tri-3 & {$\left[\mathrm{Cu}(\text { apzepy }) \mathrm{H}_{2} \mathrm{O}\right]^{+}$} & 11.93 & -422.72 \\
tri-4 & $[\mathrm{Cu}$ (apzhist $\left.) \mathrm{H}_{2} \mathrm{O}\right]^{2+}$ & 12.63 & -429.79 \\
& {$\left[\mathrm{Cu}(\text { apzhist }) \mathrm{H}_{2} \mathrm{O}\right]^{+}$} & 9.46 & -164.03 \\
\hline
\end{tabular}

complexos de $C u^{2+}$ na coordenação quadrado planar apresentam o orbital $\mathrm{d}_{x}{ }^{2}{ }_{-y}{ }^{2}$ ocupado com apenas um elétron e este orbital é também chamado de SOMO. Observamos este comportamento em todos os compostos estudados, diferindo em relação à maior ou menor hibridização com o orbital HOMO-1. Para o complexo tri-2 o HOMO está bem localizado nos ligantes e no $\mathrm{d}_{x}{ }^{2}-y^{2}$ (Fig. 3.7 b). Esta localização dos orbitais de fronteira, nesta série dos tridentados, parece estar relacionada à ausência de grupos reativos além daqueles que coordenam com o cobre ${ }^{12}$. Já para os demais complexos, o orbital $\mathrm{d}_{x}{ }^{2}-y{ }^{2}$ está hibridizado com o HOMO-1: com os orbitais $\pi$ do imid no tri-1 e no tri-4 e com o par isolado da pirazina no tri-3 e no tri-4. O LUMO apresenta caráter $\mathrm{d}_{x}{ }^{2}-y^{2}$ no $\mathrm{Cu}$ e ligantes nos quatro complexos sem hibridização de outros orbitais. Os valores de gap de energia HOMO-LUMO para os complexos são semelhantes: $0.68 \mathrm{eV}$ para os complexos tri-1 e tri-2 e 0.61 eV para os complexos tri-3 e tri-4. Estes últimos, apresentam o $\mathrm{HOMO}$ a $0.3 \mathrm{eV}$ mais estabilizado e possuem par isolado não ligado da pirazina. Os orbitais HOMO-1 e HOMO-2 possuem característica $\pi$ e contribuição do par isolado. Nos complexos com grupo imidazol, o orbital $\pi$ tem maior energia que o par isolado. Este orbital com característica $\pi$ está hibridizado

\footnotetext{
${ }^{12}$ Esta característica não ocorre nas outras duas séries de complexos estudadas.
} 
a)

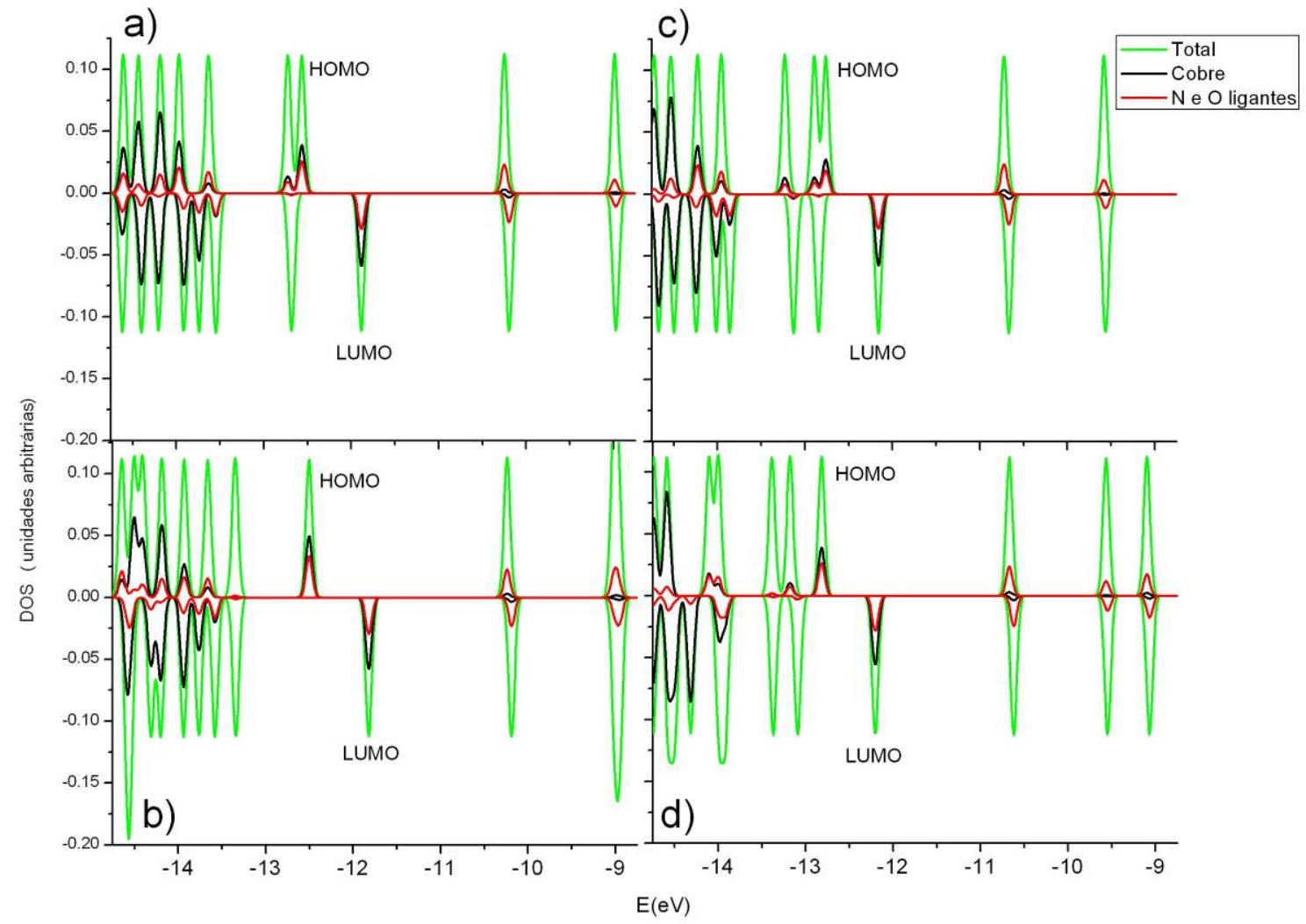

Figura 3.6: Densidade de estados (DOS) total e projetada nos sítios ligantes e no $C u$ para o complexos tridentados para os estados ocupados e desocupados de mais alta energia. a) tri-1, b) tri-2, c) tri-4 d) tri-3.

com o HOMO. No complexo tri-2 a separação do HOMO para o HOMO-1 é de 0.8 eV. Nos demais complexos esta diferença é menor que $0.25 \mathrm{eV}$. Nos complexos que possuem pares isolados não ligados há uma aproximação dos orbitais de fronteira. A correlação entre a estrutura eletrônica desta classe de complexos e a atividade biológica será retomada na seção 3.6 . 


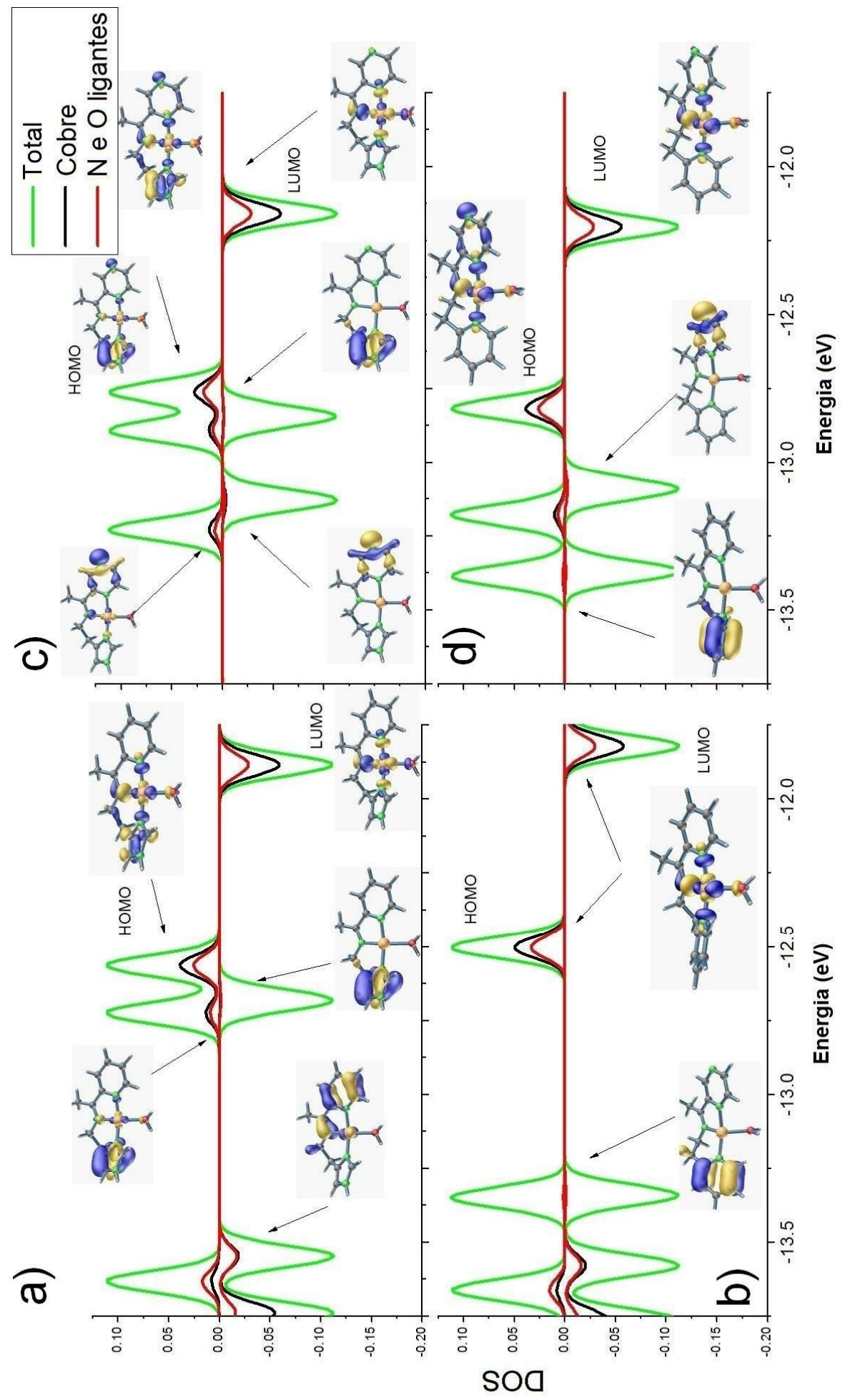

Figura 3.7: Densidade de estados (DOS) total e projetada nos sítios ligantes e no $C u$ para o complexos tridentados. Orbitais mais altos ocupados e o primeiro orbital desocupado (LUMO). a) tri-1, b) tri-2, c) tri-4 d) tri-3. 


\subsection{Série das piridinas, pirazinas e histaminas tetra- dentadas}

\section{Características estruturais dos ligantes}

Os compostos tridentados estudados na seção anterior possuem assimetria estrutural e três sítios de coordenação. A quarta posição está livre e assim pode-se formar espécies poliméricas ou cíclicas como com os ligantes apzhist e apyhist (Fig. 1.3) [18]. Já os ligantes tetradentados aqui estudados são simétricos e apresentam maior restrição estérica para interagir com outros ligantes. Apesar dos ligantes serem semelhantes, estes apresentam propriedades espectroscópicas, eletroquímicas e catalíticas peculiares $[108,114]$. Estes compostos possuem propriedades antioxidantes e pró-oxidantes e são bons catalisadores atuando como miméticos de sítios ativos de enzimas como a SOD e a tirosinase [17,21,115]. Foram também estudadas as suas propriedades quando intercalados em estruturas lamelares, procurando mimetizar o ambiente destes sítios ativos de enzimas [114,116] (vide anexo III). Esta classe de tetradentados é chamada muitas vezes de $\mathrm{N}_{4}$ por apresentar $4 \mathrm{~N}$ doadores $\sigma$. Na Fig. 1.4 apresentamos os complexos sintetizados nos laboratórios do IQ-USP pelo grupo da Profa. Ana Maria Ferreira. Estudamos também outros sistemas tetradentados com o objetivo de comparar as informações estruturais e/ou eletrônicas disponíveis na literatura(Fig. 3.8): $[\mathrm{Cu} \text { (pupy) }]^{2+}$ (tetra-5) [117], [Cu(ftalocianina)] (tetra-6 ) [3], [Cu(porfirina)] (tetra-7) [3], $\left[C u(p y)_{4}\right]^{2+}\left(\right.$ tetra-8) e $\left[C u(\text { imid })_{4}\right]^{2+}$ (tetra-9) $[118]$.

\section{Estruturas dos ligantes}

Primeiramente fizemos um estudo sobre os ligantes isolados e suas características estruturais que constituem dois grupos de ligantes: a) provenientes de heterociclos (imid, py e pz Figs. 3.1 a, c $e$ d); b) bidentados (en, dac e pn) (Figs. 3.1 f-h). Desta forma, a combinação entre o ligante bidentado e os heterocíclos deve permitir certa flexibilidade ao complexo nos diferentes estados de oxidação. 

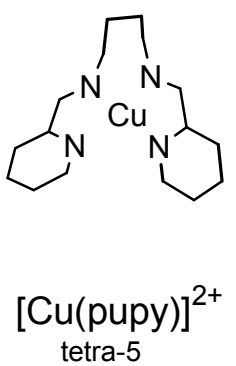

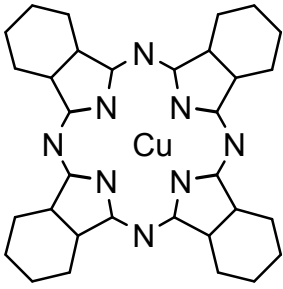

[Cu(ftalocianina)] tetra-6

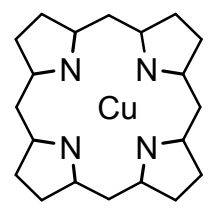

[Cu(porfirina) $]$ tetra-7

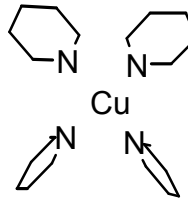

$\left[\mathrm{Cu}(\mathrm{py})_{4}\right]^{2+}$ tetra-8<smiles></smiles>

$\left[\mathrm{Cu}(\text { imid })_{4}\right]^{2+}$

tetra-9

Figura 3.8: Representação esquemática dos complexos de cobre estudados da literatura. Na linha abaixo a nomenclatura simplificada empregada neste trabalho.

A condensação entre os ligantes com heterociclos e os bidentados (Fig. 3.1) formam os ligantes sintetizados em laboratório. O ligante dachist ( $\mathrm{N}=\mathrm{C}-\mathrm{C}-\mathrm{hist})$ (Fig. 1.4) permite maior amplitude devido aos sítios de $C$ que fazem ligação simples. Já os ligantes pyalen, pyen e apzpn (Fig. 1.4) possuem uma estrutura mais compacta devido à presença de apenas um sítio de $C(\mathrm{~N}=\mathrm{C}$-heterocíclo). Os ligantes com estrutura otimizada apresentaram duas conformações $^{13}$ : 'aberta' e 'fechada' (Fig. 3.9). Para o ligante dachist duas configurações foram obtidas com maior estabilização $(3.28 \mathrm{kcal} / \mathrm{mol})$ para a conformação aberta (Fig. 3.9 b).

\subsubsection{Estruturas dos complexos (oxidado e reduzido)}

Abordaremos agora as diferenças estruturais encontradas para estes complexos nos estados oxidado e reduzido. A literatura indica que, em geral, estes complexos não são estáveis cineticamente na forma reduzida, sendo reoxidados pelo $O_{2}$ [21], entretanto em algumas situações, o composto pode permanecer no estado reduzido, como é o caso do $[\mathrm{Cu}(\text { pyalen })]^{+}$ (Fig. 1.4) intercalado em estruturas lamelares [114] (anexo III).

\footnotetext{
${ }^{13}$ Realizamos a relaxação estrutural dos ligantes sem o $C u$ sempre partindo da geometria do complexo. Desta forma não fizemos uma busca completa das estruturas a fim de obter o mínimo global energético. Observe que para o funcional de troca e correlação utilizado, PBE, não há correções de van der Waals.
} 


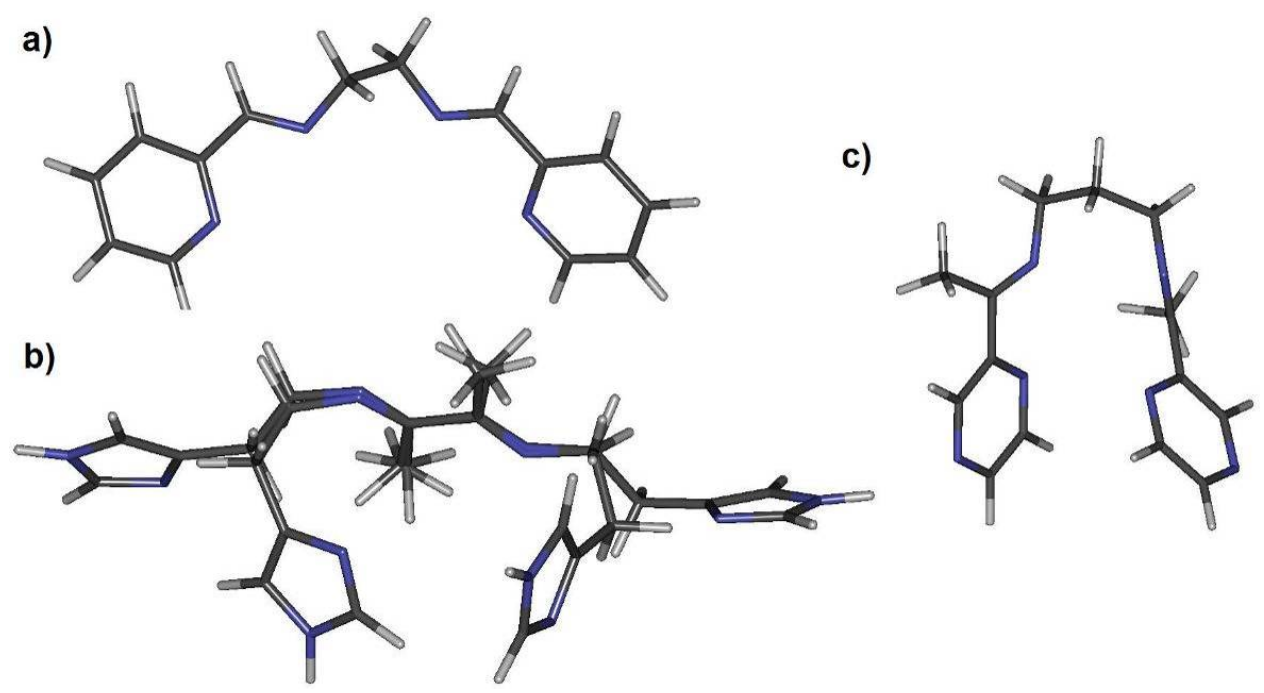

Figura 3.9: Representação dos ligantes isolados com as posições atômicas relaxadas. a) pyalen; b) dachist em dois mínimos estruturais sobrepostos para as estruturas 'aberta' e 'fechada'; c) apzpn.

A Tabela 3.6 exibe o ângulo de torção entre os sítios de $N$ ligantes (que indica o quanto a estrutura está distorcida em relação à coordenação planar), as distâncias $C u-N$ (Figs. $3.10 \mathrm{e}$ 3.11). Os compostos tetra-2, tetra-3 e tetra-1 apresentaram dois mínimos locais em energia, um plano e outro 'torcido' (Fig. 3.3.1). Os compostos torcidos mostraram-se mais estáveis, provavelmente por apresentarem menor repulsão entre os sítios de $H$ dos heterociclos.

Em relação ao ângulo de torção $N_{4}$ (Figs. 3.12 e 3.13) observa-se a seguinte tendência na conformação reduzida: tetra- $5>$ tetra- $4>$ tetra- 2 , tetra- $1>$ tetra-3. Na conformação oxidada temos: tetra- $5>$ tetra- $1>$ tetra- $4>$ tetra- $3>$ tetra- 2 . Conforme esperado, a configuração reduzida (com carga total $1+e$ ) tende a apresentar a geometria mais tetraédrica, isto é, as estruturas tornam-se mais distorcidas (ao redor de $40^{\circ}$, como se pode ver na Tabela 3.6) e a média entre as distâncias Cu-ligante tornam-se maiores. Observa-se que o complexo tetra-5 apresenta menor variação percentual no ângulo diedral entre o estado oxidado e o reduzido: $27 \%$ o que corresponde a $14^{\circ}$. O complexo com maior diferença percentual (59\%) 


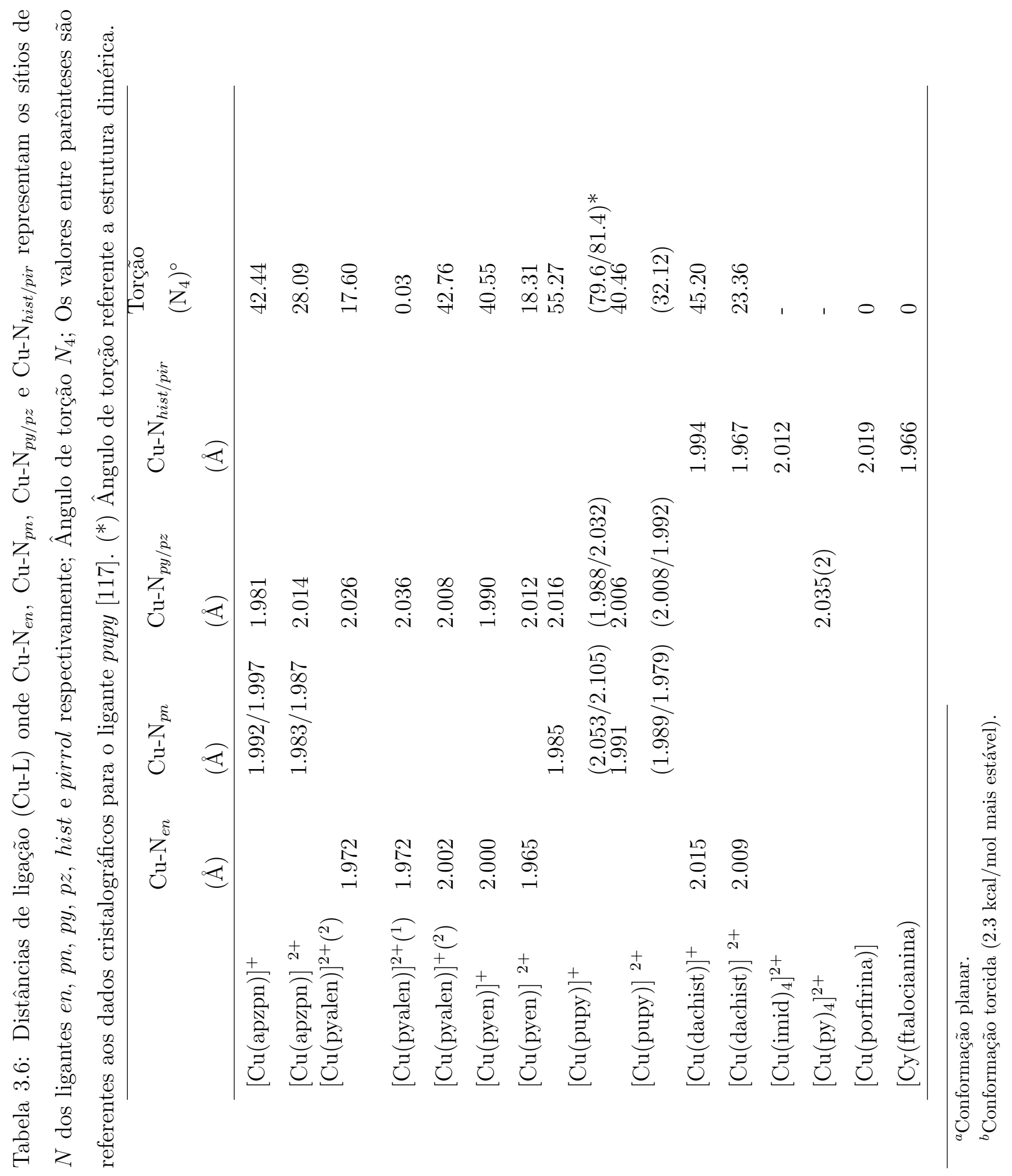


entre as formas oxidada e reduzida é o tetra- 2 o que corresponde a uma diferença de $25^{\circ}$. Desta forma o tetra-2 necessita de maior deformação enquanto que o tetra-5, já bastante distorcido, necessita de menor torção para se adequar as variações conformacionais dos estados oxidado e reduzido.
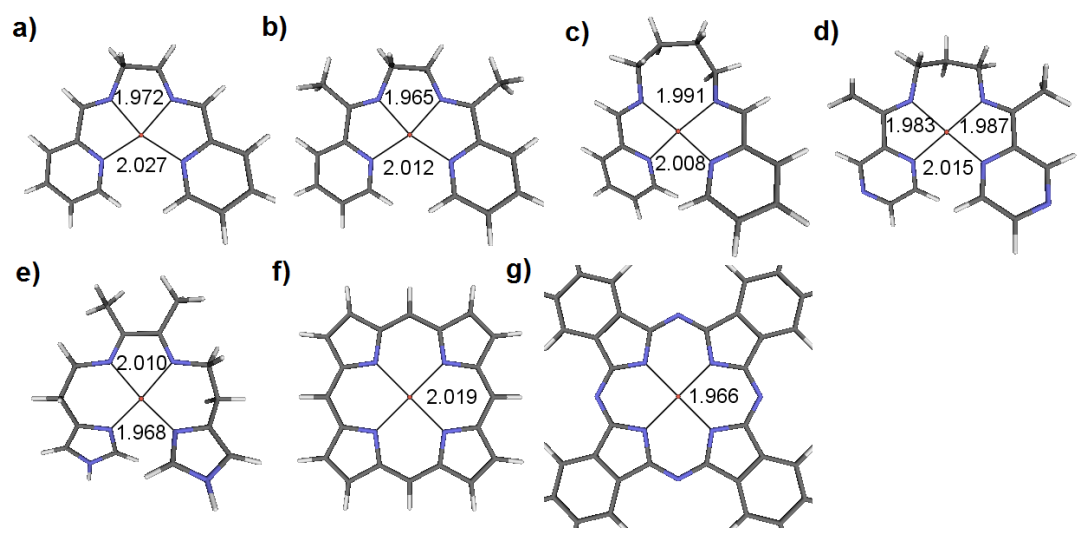

Figura 3.10: Representação esquemática para os complexos com as posições atômicas relaxadas no estado oxidado com as respectivas distâncias de ligação $\mathrm{Cu}-\mathrm{N}$ (em $\AA$ ): a) tetra-2 b) tetra-3 c) tetra-5 d) tetra-1 e) tetra-4 f) tetra-7 g) tetra-6.

\section{Estruturas com ligantes imidazólicos e piridínicos}

Realizamos outros dois estudos de complexos de cobre, um contendo quatro ligantes piridina $\left[\mathrm{Cu}(\mathrm{py})_{4}\right]^{2+}$ (tetra-8 - Fig. 3.8) e outro contendo quatro ligantes imidazol $\left[\mathrm{Cu}(\mathrm{imid})_{4}\right]^{2+}$ (tetra-9 - Fig. 3.8) nas simetrias $\mathrm{D}_{4 h}$ e $\mathrm{D}_{2 h}$ (Fig. 3.15). Observamos que os ligantes relaxam para um único mínimo local estrutural em todos os estudos realizados (Fig. 3.16). A distâncias de ligação $\mathrm{Cu}-\mathrm{N}$ para para o tetra-8 foi de $\approx 2.036$ Å $\approx 2.013$ Åpara o tetra-9.

\subsubsection{Estrutura eletrônica dos complexos}

Assim como fizemos com os complexos tridentados na seção 3.2 analisamos a estrutura eletrônica dos complexos utilizando as DOS total e projetadas nos sítios de $N$ ligantes e no 

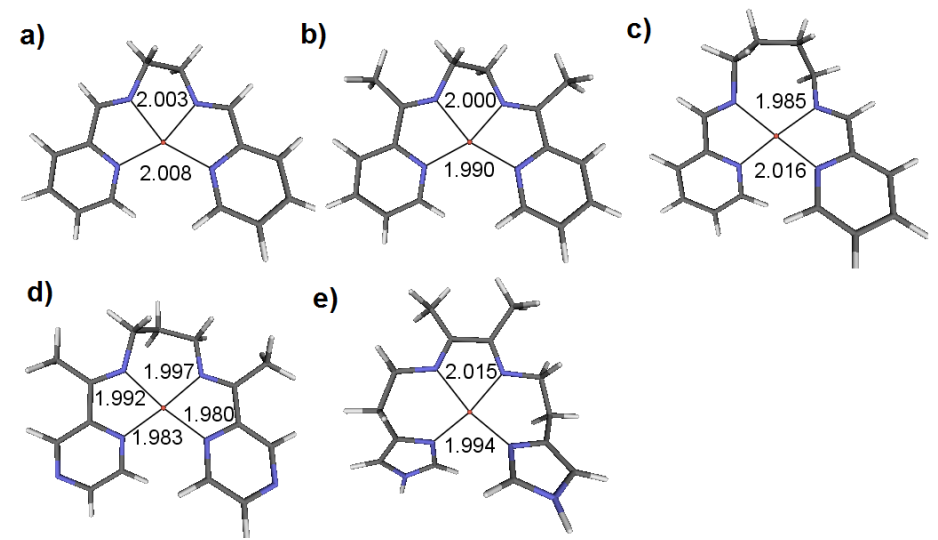

Figura 3.11: Representação esquemática para os complexos com as posições atômicas relaxadas com carga total $1+e$ (estado reduzido) com as respectivas distâncias de ligação $\mathrm{Cu}-\mathrm{N}$ (em $\AA$ ): a) tetra-2 b) tetra-3 c) tetra-5 d) tetra-1 e) tetra-4.
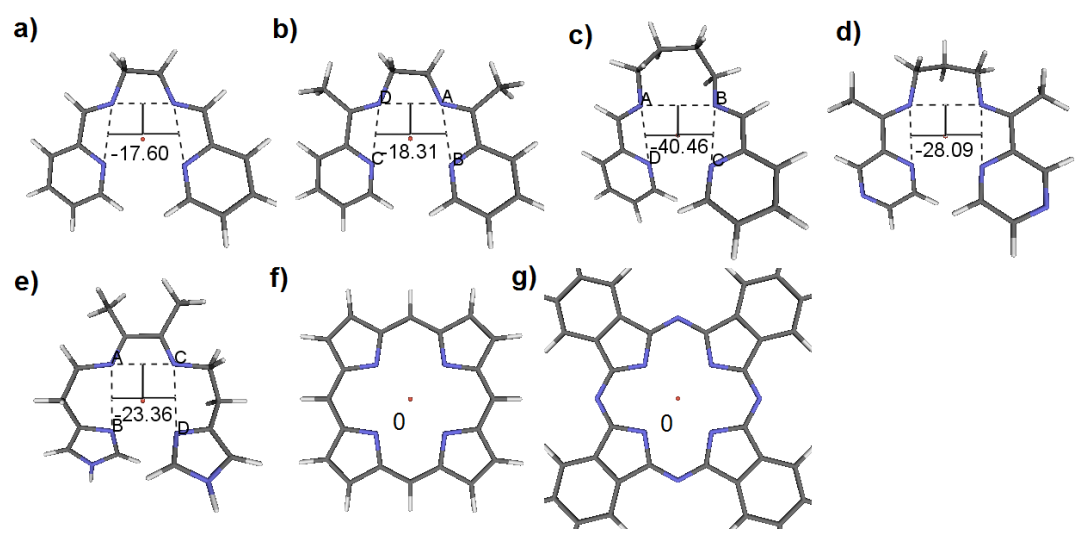

Figura 3.12: Representação esquemática para os complexos com as posições atômicas relaxadas no estado oxidado com os respectivos ângulos de torção $N_{4}$ (em graus): a) tetra-2 b) tetra-3 c) tetra- 5 d) tetra- 1 e) tetra- 4 f) tetra- $7: N_{4}=0^{\circ} \mathrm{g}$ ) tetra- $6: N_{4}=0^{\circ}$. 

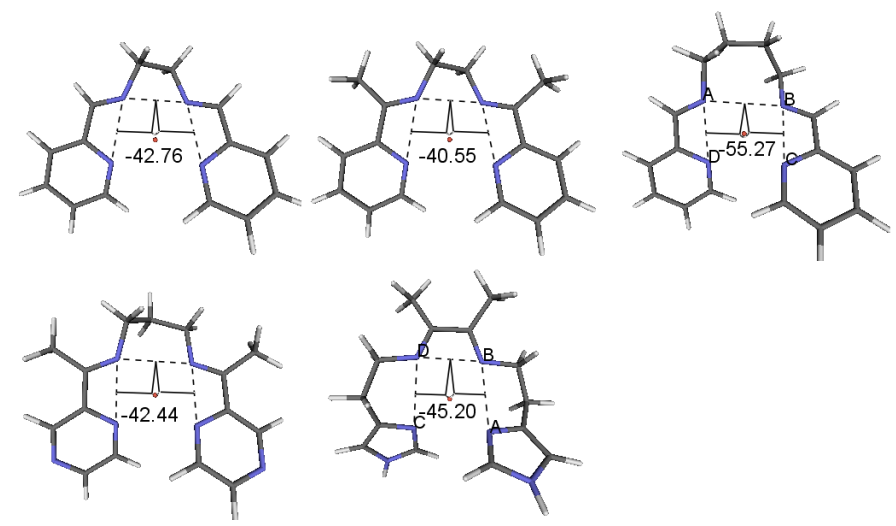

Figura 3.13: Representação esquemática para os complexos com as posições atômicas relaxadas com carga total 1+ (estado reduzido) com os respectivos ângulos de torção $N_{4}$ (em graus): a) tetra-2 b) tetra-3 c) tetra-5 d) tetra-1 e) tetra- 4 .
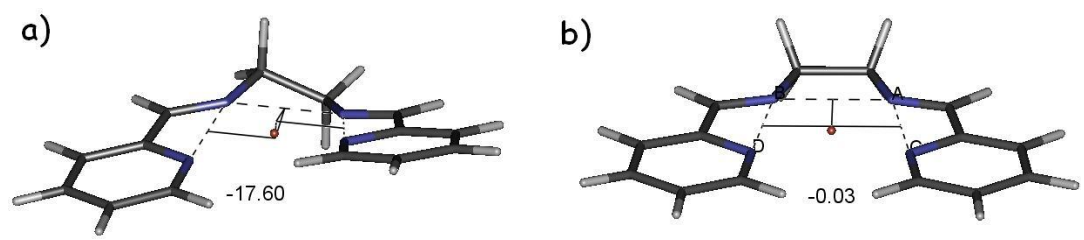

Figura 3.14: Representação do complexo tetra-2 em dois mínimos locais conformacionais.a) Torcido: ângulo de torção $N_{4}=17.60^{\circ}$. b) Plano: ângulo de torção $N_{4}=0.03^{\circ}$.

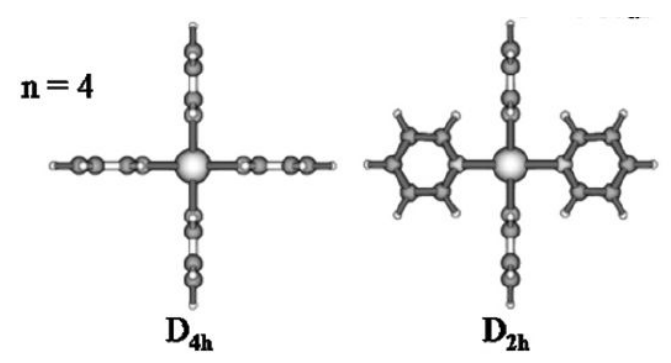

Figura 3.15: Representação esquemática para as simetrias $D_{4 h}$ e $D_{2 h}$ estudadas para os compostos tetra-8 $\left(\left[\mathrm{Cu}(\mathrm{py})_{4}\right]^{2+}\right)$ e tetra-9 $\left(\left[\mathrm{Cu}(\mathrm{imid})_{4}\right]^{2+}\right)$. 


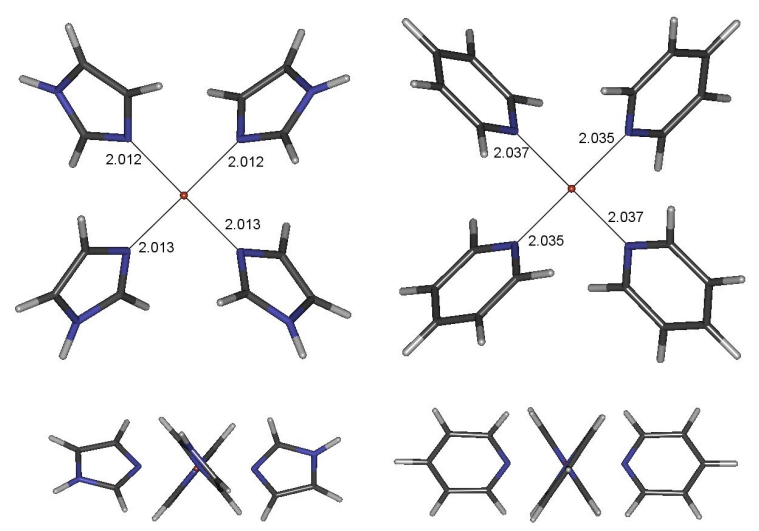

Figura 3.16: Representação das estruturas relaxadas para o $\left[\mathrm{Cu}(\mathrm{imid})_{4}\right]^{2+}$, tetra-9 (esquerda) e $\left[C u(p y)_{4}\right]^{2+}$, tetra-8 (direita) com as distâncias de ligação Cu-L em A.

íon $C u$, assim como os orbitais.

\section{$\mathrm{Cu}$ (porfirina) e $\mathrm{Cu}($ ftalocianina $)$}

Iniciamos com o estudo de sistemas já investigados na literatura como o [ $\mathrm{Cu}$ (ftalocianina) (tetra-8) e o [Cu(Porfirina)] (tetra-7) (Fig. 3.8) [119,120]. A porfirina e a ftalocianina são ligantes tetrapirrólicos com simetria $D_{4 h}$ e possuem uma cavidade acessível à ligação de íons metálicos como o $\mathrm{Fe}, \mathrm{Ni}$ e o $\mathrm{Cu}$. O ligante isolado é neutro, embora ao interagir com metais dois íons $H^{+}$sejam removidos para a inserção do metal. Estes complexos são bastante estudados tanto teoricamente como experimentalmente e pretendemos aqui comparar as suas propriedades estruturais e eletrônicas com os complexos acíclicos estudados neste trabalho. As ftalocianinas de cobre tem aplicações como dispositivos ópticos, sensores e corantes devido à intensa absorção na região do vermelho do espectro visível (600-700 nm ou 2.07-1.77 eV) [121] e assim emitindo coloração azul e/ou verde. Há muitos estudos teóricos díspares a respeito do estado fundamental dos sistemas metal-por firina/ftalocianina, tanto em relação aos níveis energéticos como em relação ao estado magnético [122,123]. Entretanto, estudos de microscopia de tunelamento (Scanning Tunneling Microscopy - STM) para 
[metal(ftalocianina)] adsorvidas em superfície de $\mathrm{Au}(111)$ indicam um caráter $\pi$ para os orbitais de fronteira (HOMO e LUMO) para o $[\mathrm{Cu}($ ftalocianina) $]$ e caráter $d$ para os orbitais de fronteira para a [Co(ftalocianina)] [119]. O mesmo resultado foi indicado através da espectroscopia de fotoelétrons excitados por ultravioleta (ultraviolet photoelectron spectra - UPS) [124]. O estudo teórico do grupo do pesquisador F. Evangelista [122], utilizando o funcional de troca e correlação B3LYP e base TZVP, apresenta o HOMO com caráter $d_{x^{2}-y^{2}}$ e os sítios de $N$ com caráter $\sigma$ e o LUMO apresenta caráter $\pi$. Já no trabalho de M. Liao et al [123] utilizado o funcional LDA combinado com correções GGA e utilizando a base 'triple- $\zeta$ ' apresenta a mesma simetria para o HOMO. Utilizando correções de auto interação (Self-Interaction Correction - SIC) L. Kronik et al [120] realizou um ajuste para reordenar os orbitais de fronteira com os de caráter $\pi$ conforme observado experimentalmente.

Utilizamos aqui dois códigos computacionais para realizar este estudo: o código CPPAW e o código Gaussian03 (G03) [72]. Observamos uma dependência do posicionamento do nível eletrônico $d$ do $C u$ com o tipo de funcional de troca e correlação $\left(\mathrm{E}_{x c}\right)$ embora a geometria se mantenha semelhante ${ }^{14}$. Com o G03 utilizamos alguns $\mathrm{E}_{x c}$ : funcionais GGA BP86 e PBEPBE e o funcional GGA híbrido B3LYP todos com a base TZVP. Com o CPPAW utilizamos apenas o funcional PBE. Como este deslocamento nos níveis do $C u$ está relacionado à escolha do termo de troca e correlação, os resultados tanto para o G03 como para o PAW são idênticos quando utilizamos o PBE. O funcional BP86 apresentou a mesma simetria que o PBE. O funcional B3LYP apresentou o HOMO com caráter $\pi$ e o LUMO com caráter $d_{x^{2}-y^{2}}$. Acrescentando porcentagens maiores que $30 \%$ do termo de troca exato do HF é possível obter o posicionamento do HOMO-LUMO observado experimentalmente. Entretanto, como o objetivo do presente trabalho é comparar diferentes complexos, optamos por uma abordagem "completamente ab-initio" dentro do esquema de Kohn-Sham para a DFT.

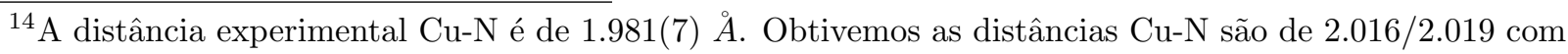
o CP-PAW/PBE e 2.006/2.025 com o TZVP/PBEPBE.
} 


\section{Densidade de Estados e orbitais}

Realizamos a análise da densidade de estados (DOS) e dos orbitais para os ligantes tetradentados acíclicos tetra- 1 ao tetra- 4 e também para os cíclicos $\mathrm{Cu}$ (ftalocianona) e $\mathrm{Cu}$ (porfirina) com o código computacional CP-PAW. Os ligantes pyen e pyalen possuem dois mínimos locais, um com a molécula plana e outra torcida (Fig. 3.14). Algumas tentativas de encontrar a geometria planar para o tetra-1 foram realizadas sem sucesso. Entretanto, para o tetra-4 não foi possível encontrar a geometria planar pelas características do ligante. Assim apresentamos a DOS para a geometria planar, torcida para o tetra-2 (Fig. 3.17 a e b). Os orbitais de fronteira para as duas conformações não se modificam, os níveis HOMO e LUMO e o gap de energia mantém-se inalterados. Os demais orbitais ocupados apresentam caráter $\pi$ nos $C$ da $p y$ e nos $N$ do en. Há também a contribuição do orbital com caráter $d_{z y}$ que não faz sobreposição direta com os sítios ligantes (diferente do que ocorre com os ligantes porfirina e a ftalocianina $)$. O ângulo $\mathrm{N}(\mathrm{Schiff})-\mathrm{Cu}-\mathrm{N}($ py) para o tetra-2 plano é de aproximadamente $17^{\circ}$ enquanto na porfirina este ângulo é zero.

\section{Estudo dos complexos tetra-8 $\left(\left[\mathrm{Cu}(\mathrm{py})_{4}\right]^{2+}\right)$ e tetra-9 $\left(\left[\mathrm{Cu}(\mathrm{imid})_{4}\right]^{2+}\right)$}

A figura 3.18 (a) e (c) mostra a DOS para os complexos tetra-8 e tetra-9 respectivamente e para os ligantes $(\mathrm{py})_{4}$ e (imid) 4 na geometria do complexo (Fig. 3.18 b e d). Observe que a ligação do metal nos ligantes não gera grandes alterações nos níveis energéticos. O metal hibridiza entre os níveis mais alto ocupados exceto aqueles que já pertenciam aos orbitais $\pi$ dos átomos de carbono do heterocíclo. O HOMO e o LUMO apresenta caráter $\mathrm{d}_{x^{2}-y^{2}}$ e caráter $\sigma$ nos sítios ligantes de $N$. O valor do gap HOMO-LUMO e gap $\pi-\pi *$ é de 0.767 e 4.7 eV para o tetra-9 e 0.678 e 4.5 eV para a tetra- 8 respectivamente. Observa-se também que os níveis $d$ do $C u$ no imid estão mais próximos dos orbitais $\pi$ ocupados enquanto no py estão no meio do gap $\pi-\pi *$. 


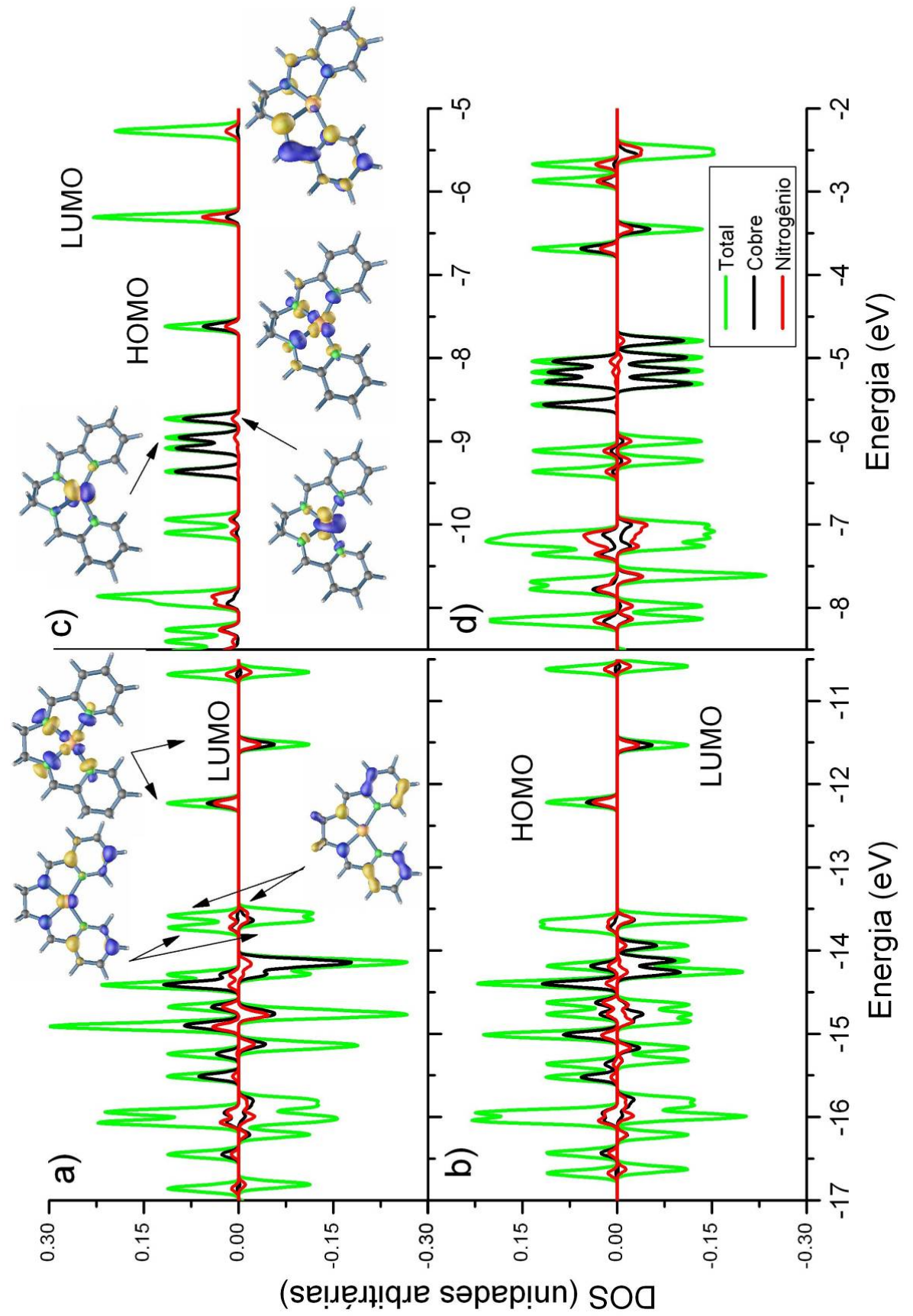

Figura 3.17: Densidade de estados (DOS) total e projetada nos ligantes $N$ e no íon $C u$ para o a) tetra-2 na conformação 'torcida' para o estado oxidado $[\mathrm{Cu}(\text { pyalen })]^{2+}$; b) conformação planar para o estado oxidado $[\mathrm{Cu}(\text { pyalen })]^{2+}$; c) conformação para o estado reduzido. $[\mathrm{Cu}(\text { pyalen })]^{+} ;$d) conformação para o estado sem carga $[\mathrm{Cu}($ pyalen $)]$. 


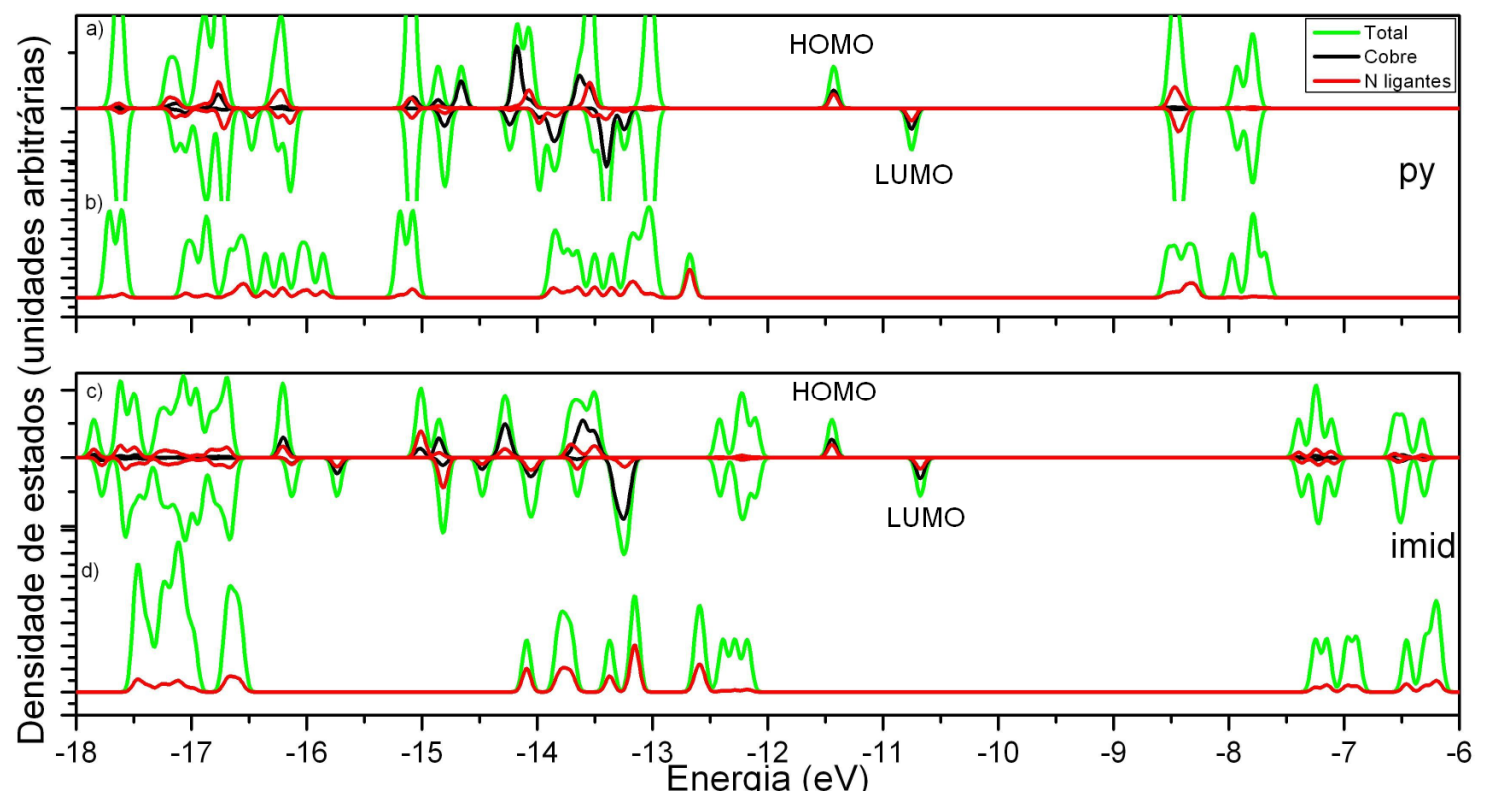

Figura 3.18: Densidade de estados (DOS) total e projetada nos sítios de $N$ ligantes e no íon $C u$ para a) o complexo $\left[C u(p y)_{4}\right]^{2+}$; b) o ligante $p y_{4}$ na conformação do complexo; c) o complexo $\left[\mathrm{Cu}(\mathrm{imid})_{4}\right]^{2+}$; d) o ligante $\mathrm{imid}_{4}$ na conformação do complexo. 


\section{Comparação entre os complexos}

Ao observar a densidade de estados dos complexos tetradentados no estado oxidado (Fig. $3.19)$, verificamos que o HOMO e o LUMO tem sempre o mesmo caráter: $\mathrm{d}_{x}{ }^{2}-y^{2}$ para o $C u$ e caráter $\sigma$ nos ligantes de $N$. A diferença de energia entre o HOMO e o LUMO é de 0.578 eV para o tetra-1 chegando a $0.767 \mathrm{eV}$ para o $\left[\mathrm{Cu}(\mathrm{imid})_{4}\right]^{2+}$. Já o gap $\pi-\pi *$ apresenta maiores modificações: o menor valor é para o ligante ftalocianina, que é bastante conjugado, com o valor de $1.4 \mathrm{eV}$. Logo após vem a porfirina $(2.1 \mathrm{eV})$ e o tetra-4 $(2.2 \mathrm{eV})$. Os maiores valores são para os sistemas $\left[C u(p y)_{4}\right]^{2+}(4.5 \mathrm{eV})$ e $\left[C u(\text { imid })_{4}\right]^{2+}(4.7 \mathrm{eV})$. O autovalor HOMO mais profundo em energia é o do tetra-5 com valor de -12.272 eV e o menos estável é o $\mathrm{Cu}(\mathrm{imid})_{4} \mathrm{com}-11.444 \mathrm{eV}$. Já o LUMO mais profundo é o do tetra-1 com valor de -11.663, já o mais acessível é o do $\mathrm{Cu}(\text { imid })_{4}$ com $-10.677 \mathrm{eV}$. Comparando a DOS dos complexos tridentados (Fig. 3.6) com os tetradentados (Fig. 3.19) observa-se que nos tetradentados não há a hibridização do HOMO devido aos centros reativos como o par isolado do $p z$ e o orbital $\pi$ do imid.

A DOS para o sistema com carga total $+1 e$ apresenta características diferenciadas em relação ao sistema com carga +2 e (Fig. 3.20). O HOMO tem a ocupação preenchida para o orbital com característica $d_{x^{2}-y^{2}}$ e sítios ligantes de $N$ (Fig. 3.17 c). Para os níveis ocupados mais profundos ocorrem maiores modificações: os quatro níveis abaixo, pertencentes ao $C u$, tornam-se não ligantes com mínima hibridização com o restante do ligante. O LUMO apresenta um orbital bastante complexo com contribuição não simétrica de orbitais $\pi$ do ligante e alguma contribuição dos orbitais $d$ do $C u$. Esta configuração eletrônica reflete na energia de ligação (que será apresentada na próxima seção). 


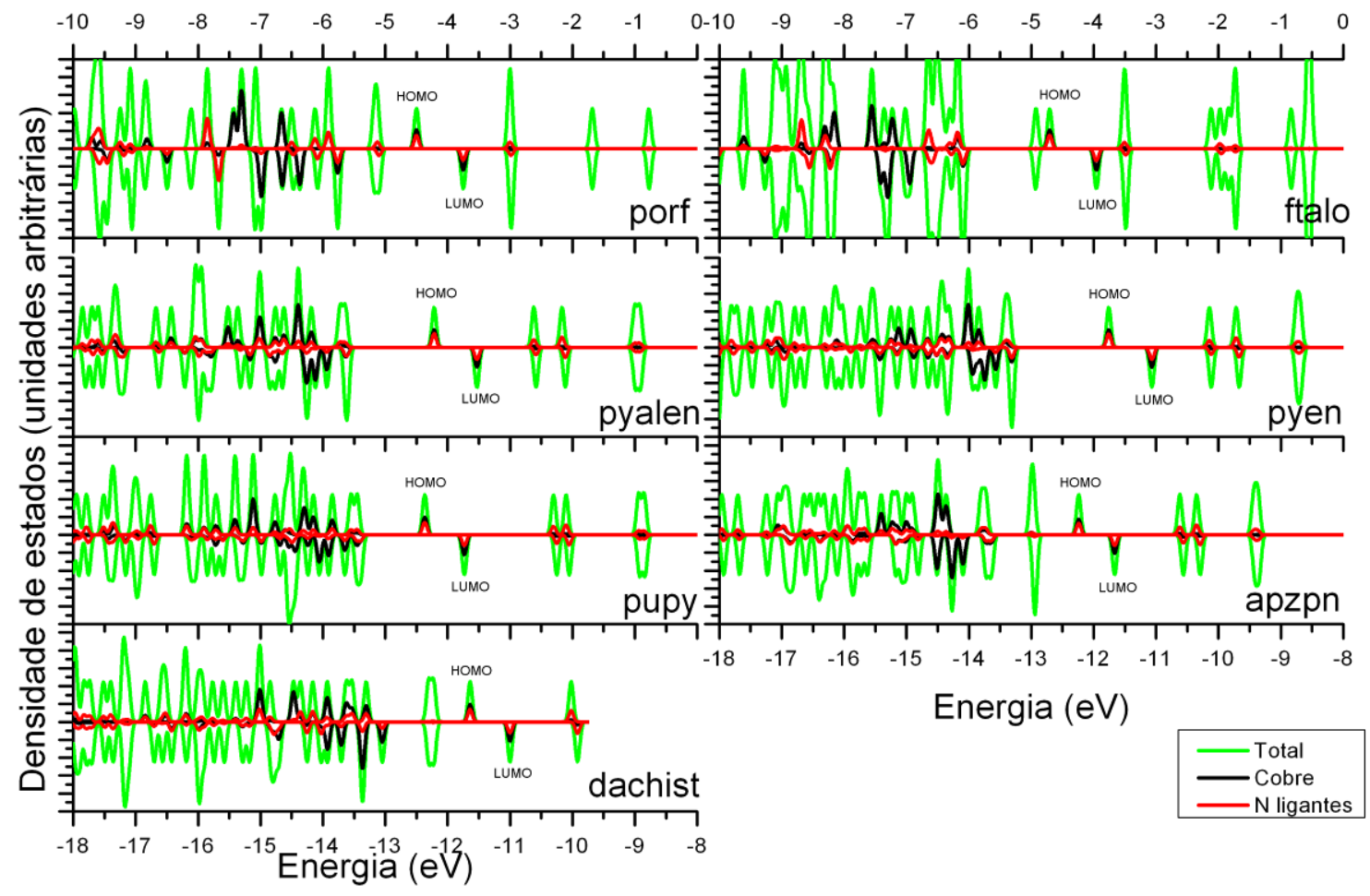

Figura 3.19: Densidade de estados (DOS) total e projetada nos sítios de $N$ ligantes e no $C u$ para o estado oxidado. A escala superior refere-se aos complexos [ $\mathrm{Cu}$ (porfirina)] e $[\mathrm{Cu}$ (ftalocianina $)]$ e a inferior aos demais complexos. 


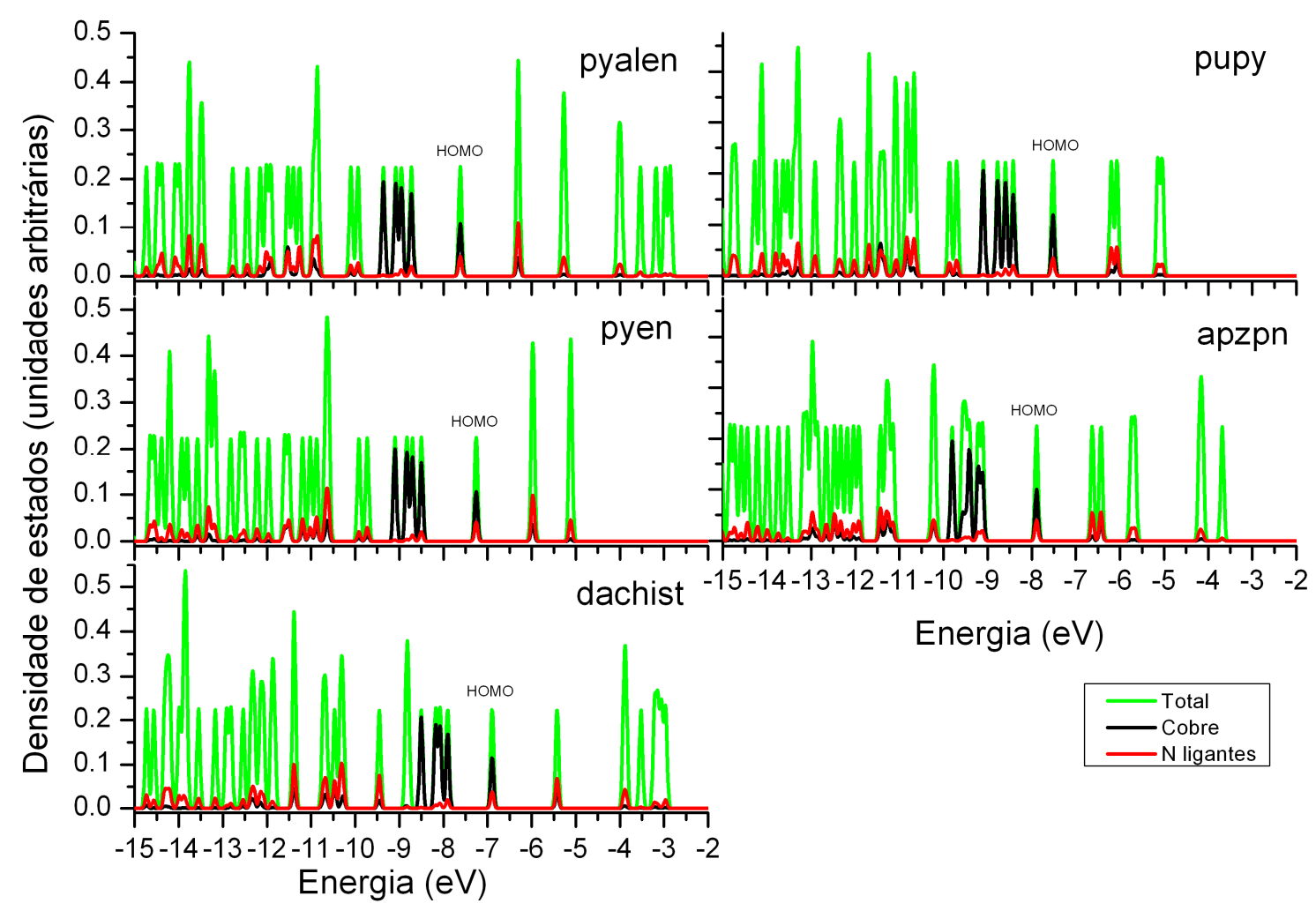

Figura 3.20: Densidade de estados (DOS) total e projetada nos sítios de $N$ ligantes e no $C u$ para o estado reduzido. 


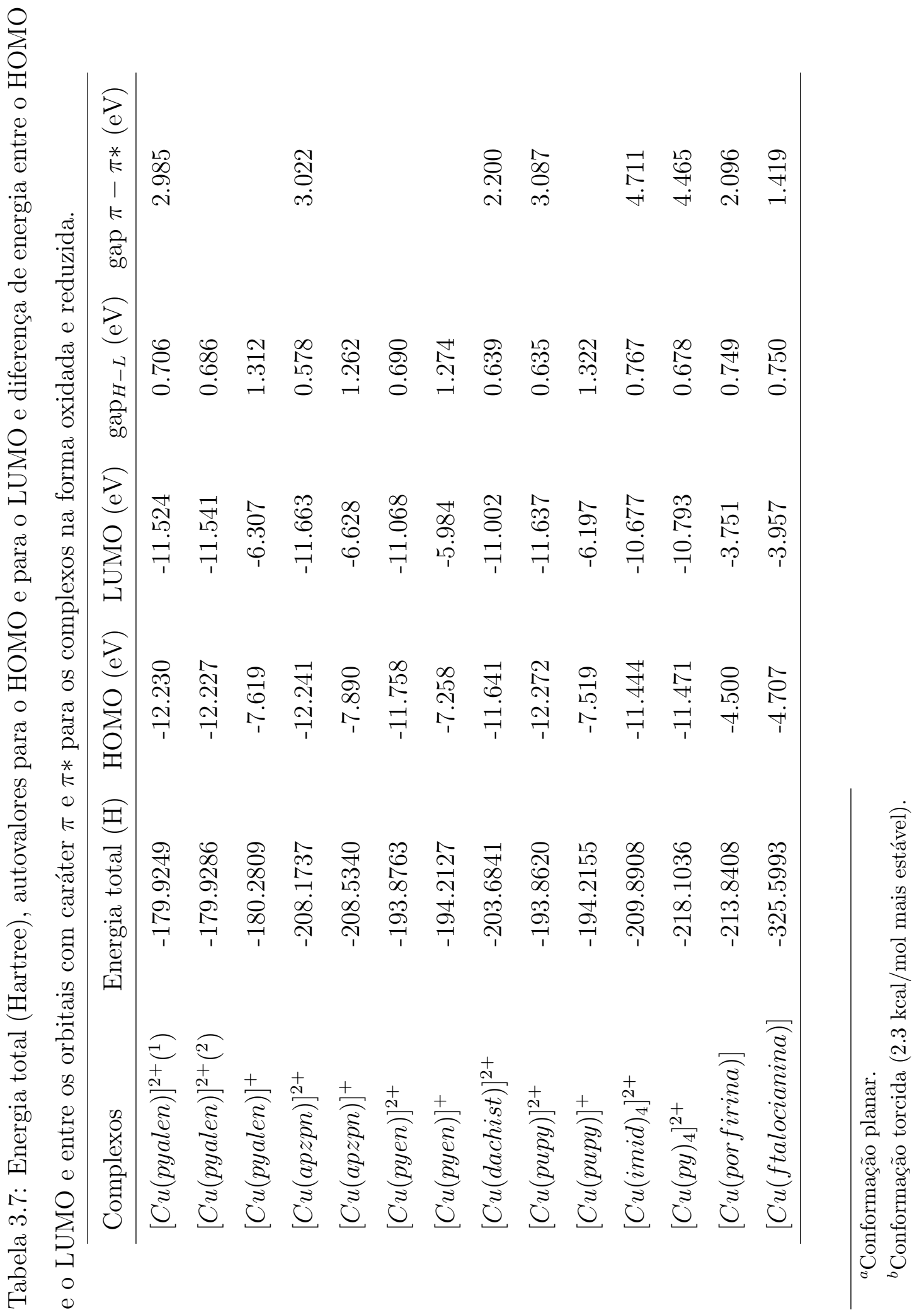




\subsubsection{Energia de Ligação}

Apresentamos na tabela 3.8 os valores para as energias de ligação e energias de deformação para alguns complexos da série dos tetradentados. Os complexos $\left[\mathrm{Cu}(\mathrm{imid})_{4}\right]^{2+}$ e tetra4 possuem a maior estabilização. Este fato é devido a presença dos grupos imidazólicos que tornam a distância Cu-L mínima e assim estabilizando o complexo (tabela 3.6). Estes resultados confirmam à alta afinidade do aminoácido histidina por $C u$ tanto nas metaloproteínas como um eficiente transportador e competidor por $C u$ em meio biológico [125]. O $\left[\mathrm{Cu}\left(\text { imid }_{4}\right]^{2+}\right.$, com quatro imidazóis, é $10 \mathrm{kcal} / \mathrm{mol}(0.44 \mathrm{eV})$ mais estável que o tetra-4 e $34 \mathrm{kcal} / \mathrm{mol}(1.48 \mathrm{eV})$ mais estável que o tetra-2. 
Tabela 3.8: Energia Total (Hartree), energia de deformação e energia de ligação para os complexos, ligantes (na conformação do complexo) e ligantes com as posições atômicas otimizadas (representado por 'OPT').

\begin{tabular}{lcll}
\hline Sistema & $\begin{array}{l}\text { Energia } \\
\text { Total }(\mathrm{H})\end{array}$ & $\begin{array}{l}\text { Edef } \\
(\mathrm{kcal} / \mathrm{mol})\end{array}$ & $\begin{array}{l}\text { Elig } \\
(\mathrm{kcal} / \mathrm{mol})\end{array}$ \\
\hline$[\mathrm{Cu}(\text { apzpn })]^{2+}$ & -208.1737 & 15.71 & -440.47 \\
apzpn & -157.3434 & & \\
apzpn OPT & -157.3685 & & -464.80 \\
{$[\mathrm{Cu}(\text { dachist })]^{2+}$} & -203.6841 & 31.10 & \\
dachist & -152.7905 & & -440.77 \\
dachist OPT & -152.8400 & & \\
{$[\mathrm{Cu}(\text { pyalen })]^{2+}$} & -179.9285 & 21.37 & \\
pyalen & -129.0887 & & -458.29 \\
pyalen OPT & -129.1228 & & -474.84 \\
{$\left[\mathrm{Cu}(\text { py })_{4}\right]^{2+}$} & -218.1036 & & \\
py & -41.8175 & & \\
{$\left[\mathrm{Cu}(\text { imid })_{4}\right]^{2+}$} & -209.8908 & & \\
imid & -39.7577 & &
\end{tabular}




\subsection{Série Oxindol}

Estudamos a série de complexos provenientes do radical isatina (Fig. 3.1 e) compostos estes também sintetizados nos laboratórios da Profa. Ana Maria Ferreira do IQUSP $[12,16]$. A isatina é um indol endógeno, ou seja, sintetizado pelo nosso organismo e apresenta uma série de propriedades farmacológicas como por exemplo: atividade antigripal, antimicrobiano, anticonvulsivo entre outras [126]. Estudos mostram que a combinação do ligante com metais aumenta a atividade farmacológica em questão [127]. Por ser um ligante endógeno, este composto pode facilitar a chamada ADME (absorção, distribuição, metabolismo e excreção) [128], sendo menos nocivo ao organismo. Estudamos os complexos $[C u(\text { isapn })]^{2+}$ (oxi-1), $\left[\mathrm{Cu}(\text { isaepy })_{2}\right]^{2+}$ (oxi-2), $[\mathrm{Cu}(\text { isaenim })]^{2+}$ (oxi-3) e $\left[\mathrm{Cu}(\text { enim }) \mathrm{H}_{2} \mathrm{O}\right]^{2+}$ (oxi-4) (Fig. 1.5). Em especial, os complexos com ligantes de isaepy e isapn mostraram acentuada atividade anti cancerígena atravessando a parede celular e atuando principalmente na mitocôndria e no DNA $[12,15]$ e assim induzindo a apoptose celular (morte celular programada). Esta etapa do trabalho foi realizada em colaboração com o Prof. Giovanni F. Caramoni e parte dos resultados aqui obtidos já estão publicados na Ref. [16] (anexo I). Investigamos também a interação de quadrupolo elétrico nuclear (interação hiperfina elétrica) através de cálculos de gradidente de campo elétrico (GCE) no núcleo dos ligantes $N$ e $O$ e também no íon $C u$. Estes resultados estão no Apêndice A.

\subsubsection{Estrutura dos complexos}

A presença do radical precursor isatina (Fig. 3.1 e) é a principal característica estrutural que os diferenciam dos demais ligantes. Este grupo torna o complexo mais plano, impedindo grandes deformações fora do plano como acontece com os tetradentados. Os complexos $\left[\mathrm{Cu}(\text { isaepy })_{2}\right]^{2+}$ e $[\mathrm{Cu}(\text { isapn })]^{2+}$ são os mais simétricos para esta série ${ }^{15}$. Para estes complexos foram realizados dois estudos para geometrias iniciais distintas: uma simétrica e outra torcida ou assimétrica. Nos dois casos a estrutura de menor energia total foi aquela com

\footnotetext{
${ }^{15}$ Estes complexos apresentam maior citotoxicidade e atividade apoptótica $[12,129]$.
} 
geometria mais simétrica. O ligante isaepy (Fig. 1.5) possui maior flexibilidade devido ao ligante epy (Fig. 3.1 b) comum aos ligantes tridentados apzepy e apyepy (Fig. 1.3). Experimentalmente observa-se a formação de espécies diméricas devido a torção das ligações $C 1-C 2$ e $C 2-N 2$ (semelhante a estrutura dos tridentados, Fig. $3.2 \mathrm{~b}$ e c). A forma dimérica e simétrica deste complexo ocorre quando cada um dos ligantes estão na conformação 'para cima' (cc) e 'para baixo' (cb) (Figs. 3.2). Além do ligante isatina os demais ligantes precursores são o pn (Fig. 3.1 h) para o oxi-1 e o en (fig. 3.1 f) para o oxi-3 e o oxi-4.

Realizamos estudos utilizando dois métodos diferentes: a base mista PAW e o funcional de troca e correlação PBE e também a base local TZVP e o funcional BP86. Ambos os métodos apresentaram ótima concordância estrutural com diferenças nas distâncias $\mathrm{Cu}$-Ligante $(\mathrm{Cu}$ L) menores do que $0.013 \AA$. Estes complexos apresentam distância de ligação Cu-L maiores em relação às demais séries devido à planaridade da isatina que mantém o ligante mais rígido (Tabela 3.9). A exceção é o ligante isaepy que apesar de ter maior flexibilidade, devido a impedimentos estéricos na forma dimérica, apresenta distâncias de 2.094 A. Este complexo apresenta a coordenação quadrado planar ligado a quatro sítios de $N$ e na quinta e sexta posições, mais alongadas, devido a distorção Jahn-Teller [3] coordenados à carbonila (Fig. $3.21)$.

\subsubsection{Estrutura Eletrônica}

A análise da densidade de estados (DOS) e dos orbitais de fronteira realizadas com o código computacional CP-PAW mostra a influência do grupo isatina para estes ligantes (Fig. 3.22). O oxi-1 apresenta inversão nos níveis ocupados em relação aos demais complexos estudados. Os orbitais HOMO e HOMO-1 tem caráter $\pi$ nas isatinas (Fig. 3.23) e o orbital $d$ do $C u$ $\left(\mathrm{d}_{x}{ }^{2}-y^{2}\right)$ está degenerado em energia com o HOMO (a aproximadamente $0.05 \mathrm{eV}$ ), embora não haja hibridização entre estes níveis. O $[$ Cu(isaenim $)]^{2+}$ apresenta o HOMO e o LUMO com caráter $\mathrm{d}_{x}{ }^{2}-y^{2}$ mas o HOMO está quase degenerado com o HOMO-1 (em $0.08 \mathrm{eV}$ ) com caráter $\pi$ nos sítios de $C$ e na carbonila $(=O)$ da isatina. O HOMO-2 tem o mesmo caráter 
a)

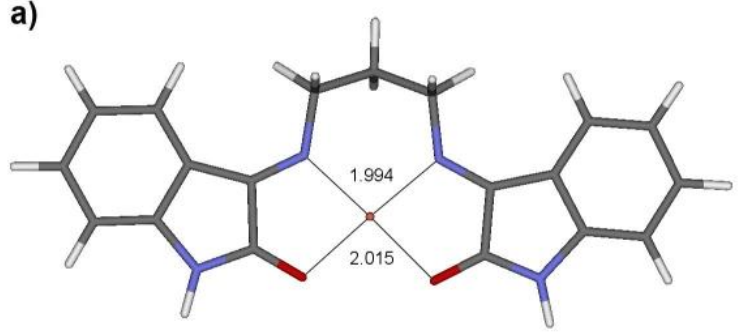

c)

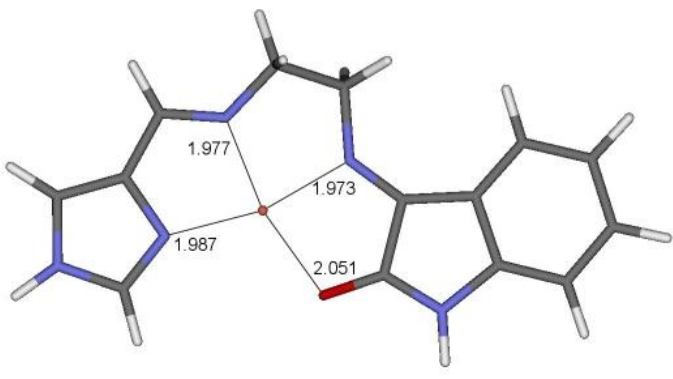

b)

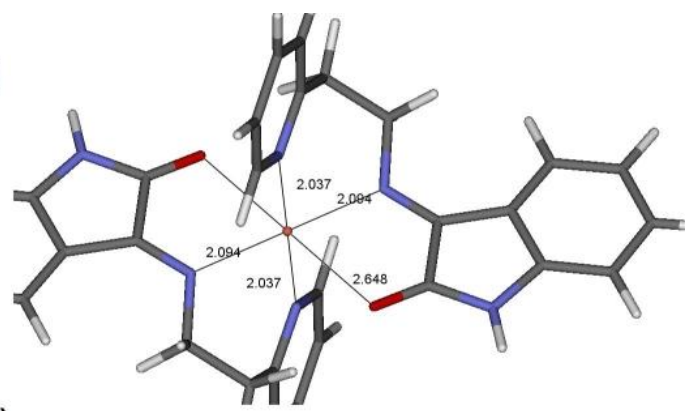

d)

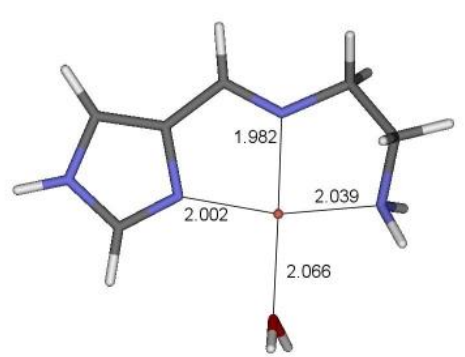

Figura 3.21: Representação dos complexos com as posições atômicas otimizadas obtidas com o CP-PAW para a) oxi-1; b) oxi-2; c) oxi-3; d) oxi-4. Distâncias de ligação $\mathrm{Cu}-\mathrm{L}$ em $\AA$.

$\pi$ mas com contribuição no $N$ ligante próximo a isatina. O HOMO-3 tem caráter $\pi$ no imidazol. $\mathrm{O}\left[\mathrm{Cu}(\text { isaepy })_{2}\right]^{2+}$ apresenta a torção do ligante em $90^{\circ}$, assim, esta quebra na conjugação torna os orbitais $\pi$ mais profundos em energia. Para o oxi-2 e o oxi-4 os orbitais HOMO e LUMO apresentam o mesmo caráter $\mathrm{d}_{x}{ }^{2}{ }_{-y}{ }^{2}$ e ligantes $\sigma$.

\subsubsection{Considerações sobre energia}

A tabela 3.10 apresenta os resultados de energia total para os complexos, os ligantes na conformação do complexo e os ligantes isolados com a geometria relaxada. Observa-se que o gap em energia HOMO-LUMO para os complexos são aproximadamente $0.65 \mathrm{eV}$ para o complexo oxi-1 e oxi-2 e de 0.75 eV para o oxi-3 e oxi-4. Já para o ligante otimizado o gap é de aproximadamente $2.5 \mathrm{eV}$. Apenas o complexo ligante enim apresenta um gap maior de $3.4 \mathrm{eV}$. O gap $\pi-\pi *$ dos complexos é menor para as estruturas com maior conjugação: oxi-1 $1.671 \mathrm{eV}$, oxi-3 $1.768 \mathrm{eV}$, oxi-2 $1.926 \mathrm{eV}$ e oxi-4 $3.316 \mathrm{eV}$. 
Tabela 3.9: Distâncias de Cu-L obtidas com os métodos: (funcional/base) CPPAW(PBE/PAW) e G03(BP86/TZVP) entre parênteses para os complexos $[C u(\text { isapn })]^{2+}$ (oxi-1), $\left[\mathrm{Cu}(\text { isaepy })_{2}\right]^{2+}$ (oxi-2), $[\mathrm{Cu}(\text { isaenim })]^{2+}$ (oxi-3) e $\left[\mathrm{Cu}(\text { enim }) \mathrm{H}_{2} \mathrm{O}\right]^{2+}$ (oxi-4).

\begin{tabular}{lccccc}
\hline Complexos & $\mathrm{Cu}-\mathrm{N}_{\text {hist }}$ & $\mathrm{Cu}-\mathrm{N}_{\text {Schiff }}$ & $\mathrm{Cu}^{-\mathrm{N}_{\text {Schiff }}}$ & $\mathrm{Cu}-\mathrm{NH}_{2}$ & $\mathrm{Cu}-\mathrm{O}$ \\
\hline oxi-1 & 1.983 & & & & 2.008 \\
& $(1.994)$ & & & $(2.015)$ \\
oxi-2 & 2.094 & & & 2.648 \\
oxi-3 & 1.974 & 1.972 & 1.963 & & 2.045 \\
& $(1.987)$ & $(1.977)$ & $(1.973)$ & & $(2.051)$ \\
oxi-4 & 1.989 & 1.977 & 2.033 & 2.069 & \\
& $(2.002)$ & $(1.982)$ & $(2.039)$ & $(2.037)$ & \\
\hline
\end{tabular}

Na tabela 3.11 apresentamos os valores para as energias de ligação e deformação. Estes complexos apresentam grande deformação devido à conformação do complexo que é mais planar e que no ligante isolado este se deforma a fim de evitar interação entre os pares isolados próximos. Os complexos da série dos oxindóis apresentam maior energia devido à planaridade na conformação do complexo. As energias de ligação são em torno de -420 a $475 \mathrm{kcal} / \mathrm{mol}^{16}$. Apenas o oxi-2 que apresenta características estruturais diferentes (dimérico, com seis sítios de coordenação e formando ligações de $\mathrm{H}$ entre os ligantes) possui energia de ligação maior que os demais complexos. Este complexo é $2.3 \mathrm{eV}$ mais estabilizado que o oxi-4.

\footnotetext{
${ }^{16}$ A fim de verificar a precisão dos estudos de energia de ligação, realizamos testes de convergência aumentando o corte em energia para as ondas planas em até 70 Ry e observamos que os valores se reduziram em apenas $\approx 0.4 \mathrm{kcal} / \mathrm{mol}$ mostrando que em 40 Ry o resultado já está adequadamente convergido.
} 
Tabela 3.10: Energia total, autovalores dos orbitais de fronteira e gap HOMO-LUMO para os complexos, para os ligantes na conformação do complexo e para os ligantes com a estrutura relaxada (OPT) obtidos com o código computacional CP-PAW. [Cu(isapn) $]^{2+}$ (oxi-1), $\left[\mathrm{Cu}(\text { isaepy })_{2}\right]^{2+}$ (oxi-2), $[\mathrm{Cu}(\text { isaenim })]^{2+}$ (oxi-3) e $\left[\mathrm{Cu}(\text { enim }) \mathrm{H}_{2} \mathrm{O}\right]^{2+}$ (oxi-4).

\begin{tabular}{|c|c|c|c|c|}
\hline & $\begin{array}{r}\text { Energia } \\
\text { Total }(\mathrm{H})\end{array}$ & $\begin{array}{r}\text { HOMO } \\
(\mathrm{eV})\end{array}$ & $\begin{array}{r}\text { LUMO } \\
(\mathrm{eV})\end{array}$ & $\begin{array}{r}g a p \\
(\mathrm{eV}) \\
\end{array}$ \\
\hline$[\mathrm{Cu}($ isapn $)] 2+$ & -242.3001 & -12.058 & -11.415 & 0.643 \\
\hline Isapn & -191.4688 & -4.908 & -3.008 & 1.900 \\
\hline isapn (OPT) & -191.5019 & -5.594 & -3.240 & 2.354 \\
\hline$[\mathrm{Cu}($ isaepy $) 2] 2+$ & -331.7822 & -10.434 & -9.768 & 0.666 \\
\hline isaepy 2 & -280.8683 & -4.264 & -2.844 & 1.420 \\
\hline isaepy & -140.4407 & -4.994 & -3.180 & 1.814 \\
\hline isaepy (OPT) & -140.4606 & -5.835 & -3.327 & 2.508 \\
\hline$[\mathrm{Cu}($ isaenim $)] 2+$ & -205.5783 & -12.189 & -11.447 & 0.742 \\
\hline isaenim & -154.7343 & -4.378 & -2.915 & 1.463 \\
\hline isaenim (OPT) & -154.7802 & -5.570 & -3.042 & 2.528 \\
\hline$[\mathrm{Cu}($ enim $) \mathrm{H} 2 \mathrm{O}] 2+$ & -148.8527 & -13.263 & -12.502 & 0.761 \\
\hline enim & -80.6806 & -4.456 & -1.707 & 2.749 \\
\hline enim (OPT) & -80.7049 & -5.166 & -1.729 & 3.437 \\
\hline $\mathrm{H} 2 \mathrm{O}$ & -17.3743 & -7.368 & -1.084 & 6.284 \\
\hline $\mathrm{Cu} 2+$ & -50.1033 & -29.368 & -29.111 & 0.257 \\
\hline
\end{tabular}




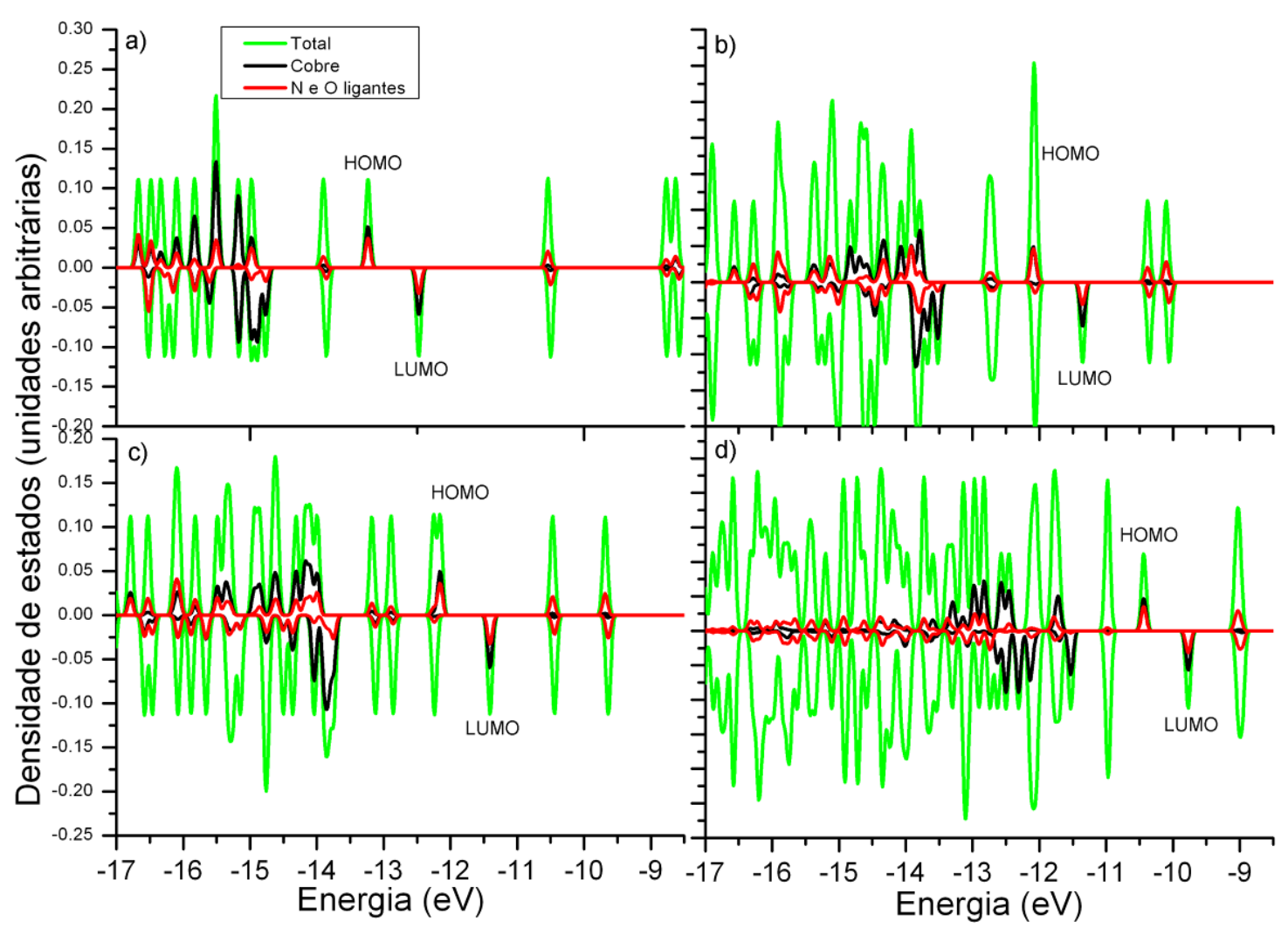

Figura 3.22: Densidade de estados (DOS) total e projetada nos sítios ligantes e no $C u$ para os complexos oxindóis. a) $\left[\mathrm{Cu}(\text { enim }) \mathrm{H}_{2} \mathrm{O}\right]^{2+}$; b) $\left.[\mathrm{Cu}(\text { isapn })]^{2+} ; \mathrm{c}\right)[\mathrm{Cu}(\text { isaenim })]^{2+}$;d) $\left[\mathrm{Cu}(\text { isaepy })_{2}\right]^{2+}$. 


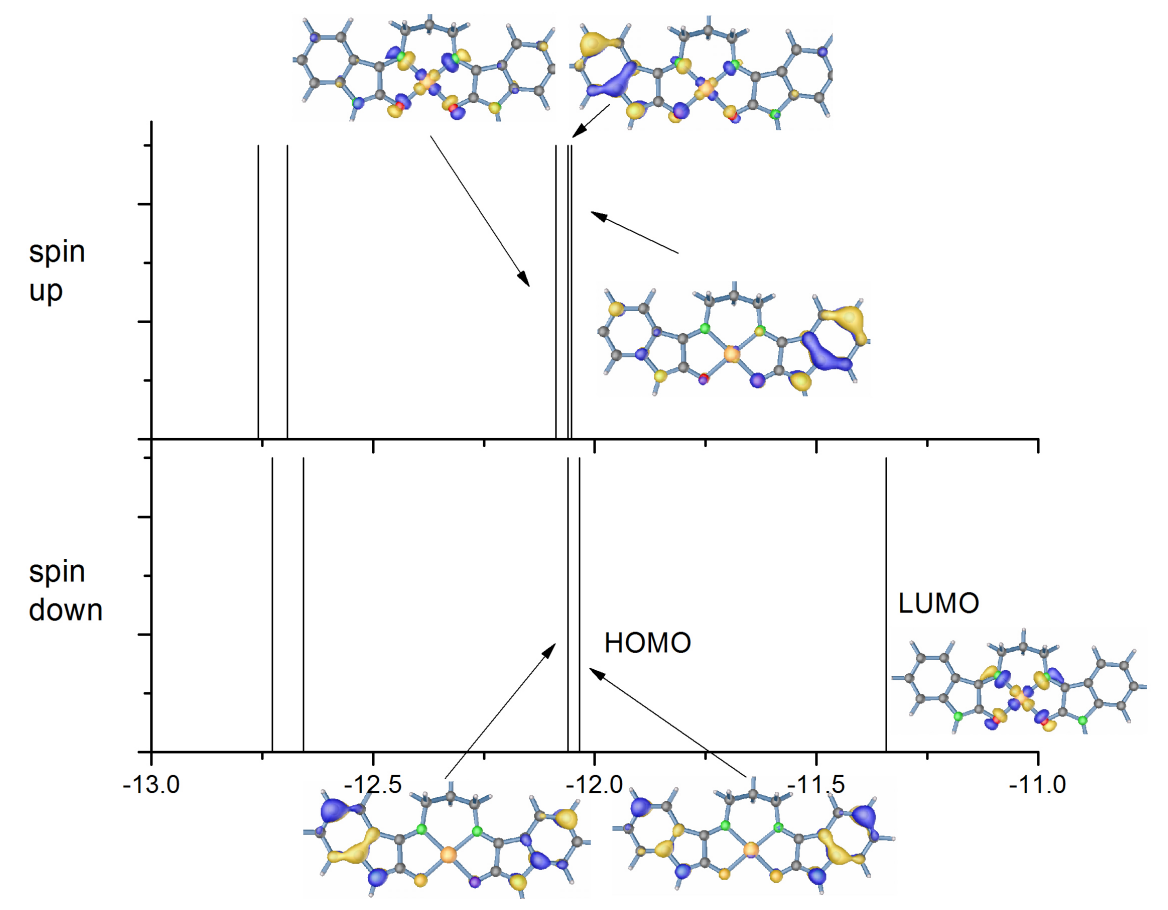

Figura 3.23: Representação dos níveis eletrônicos e dos orbitais de mais alta energia para o complexo oxi-1, $[\mathrm{Cu}(\text { isapn })]^{2+}$. 
Tabela 3.11: Energias de deformação $\left(\mathrm{E}_{\text {def }}\right)$ e energias de ligação $\left(\mathrm{E}_{\text {lig }}\right)$ para o PAW (funcional/base) PBE/PAW e para G03 BP86/TZVP (entre parênteses). [Cu(isapn) $]^{2+}$ (oxi-1), $\left[\mathrm{Cu}\left(\text { isaepy }_{2}\right]^{2+}\right.$ (oxi-2), $[\mathrm{Cu}(\text { isaenim })]^{2+}$ (oxi-3) e $\left[\mathrm{Cu}(\text { enim }) \mathrm{H}_{2} \mathrm{O}\right]^{2+}$ (oxi-4).

\begin{tabular}{|c|c|c|}
\hline & $\begin{array}{l}\mathrm{E}_{\text {def }} \\
(\mathrm{kcal} / \mathrm{mol})\end{array}$ & $\begin{array}{l}\mathrm{E}_{\text {lig }} \\
(\mathrm{kcal} / \mathrm{mol})\end{array}$ \\
\hline \multirow{2}{*}[\mathrm{Cu}(\text{isapn})]{$2+$} & 20.71 & -436.29 \\
\hline & $\begin{array}{l}(22.10) \\
24.91\end{array}$ & $\begin{array}{l}(-409.5) \\
-475.68\end{array}$ \\
\hline$[\mathrm{Cu}($ isaepy $) 2] 2+$ & $\begin{array}{l}(26.03) \\
28.80\end{array}$ & $\begin{array}{l}(-441.77) \\
-436.20\end{array}$ \\
\hline$[\mathrm{Cu}($ isaenim $)] 2+$ & $\begin{array}{l}(30.19) \\
15.25\end{array}$ & $\begin{array}{l}(-412.57) \\
-420.81\end{array}$ \\
\hline$[\mathrm{Cu}($ enim $) \mathrm{H} 2 \mathrm{O}] 2+$ & $(16.06)$ & $(-401.42)$ \\
\hline
\end{tabular}




\subsection{Estudo da proteína albumina}

\subsubsection{Sítio N-terminal da BSA e da HSA}

O sítio preferencial para o íon $C u^{2+}$ na proteína HSA/BSA é o N-terminal [32] e é aqui representado através dos três primeiros aminoácidos da sequência: a) HSA - Asp1 (ácido aspártico), Ala2 (alanina), His3 (histidina) e do nitrogênio N-terminal (Fig. 1.6); b) BSA - Asp1 (ácido aspártico), Thr2 (treonina), His3 (histidina) e do nitrogênio N-terminal. Ao realizar uma busca no repositório de proteínas ProteinDataBank (www.pdb.org) encontramos 55 estruturas cristalográficas para a HSA e nenhuma estrutura para a BSA ${ }^{17}$. Utilizamos no presente trabalho a estrutura obtida por difração de raios-X de identificação 1N5U [130]. Dentre as 55 proteínas esta é a de maior resolução (1.9 Å) e com apenas dois aminoácidos faltantes: o aspartato ou ácido aspártico da posição 1 (Asp1) e a leucina da posição $585\left(\right.$ Leu585) ${ }^{18}$. Estes aminoácidos são de difícil caracterização cristalográfica por se apresentarem na região externa da proteína e sofrerem maior vibração [130]. Como estamos interessados apenas no sítio N-terminal, adicionamos o aminoácidos Asp1, o nitrogênio do N-terminal e também os átomos de hidrogênio. Realizamos a relaxação estrutural destas estruturas inseridas manualmente. Para o pH fisiológico (7.4) o átomo de hidrogênio do grupamento carboxílico está ionizado apresentando carga negativa. Como consideramos o cobre com o estado de oxidação +2 a carga total atribuída ao sistema foi de $+1 e$.

O sítio N-terminal complexado com o íon cobre está na coordenação quadrado planar entre quatro átomos de $N$ conforme medidas de NMR e EPR [32]. Desta forma simulamos algumas possíveis conformações em que os quatro átomos de $N$ estivessem direcionados ao íon $C u$ formando assim uma estrutura mais próxima da medida. A figura 3.24 representa a estrutura após a total relaxação estrutural encontrada para o N-terminal da HSA e da BSA para esta conformação. As distâncias de ligação são maiores que as encontradas para as bases de Schiff devido ao maior tamanho do ligante que impede a compactação da estrutura.

\footnotetext{
${ }^{17}$ Data de acesso: julho de 2010.

${ }^{18}$ Observe que a ordem dos aminoácidos apresentada é dada pela estrutura primária da proteína.
} 
A energia de ligação para o mimético da HSA foi de $-530 \mathrm{kcal} / \mathrm{mol}$ e para a BSA foi de $-519.97 \mathrm{kcal} / \mathrm{mol}$. A energia de deformação para a HSA foi de 48.47 e para a BSA foi de $62.15 \mathrm{kcal} / \mathrm{mol}$. A energia de ligação do mimético do N-terminal é maior que a dos demais complexos estudados, isto porque, o ligante tem a carga formal negativa e portanto a carga total adotada no cálculo foi fixada em $+1 e$.

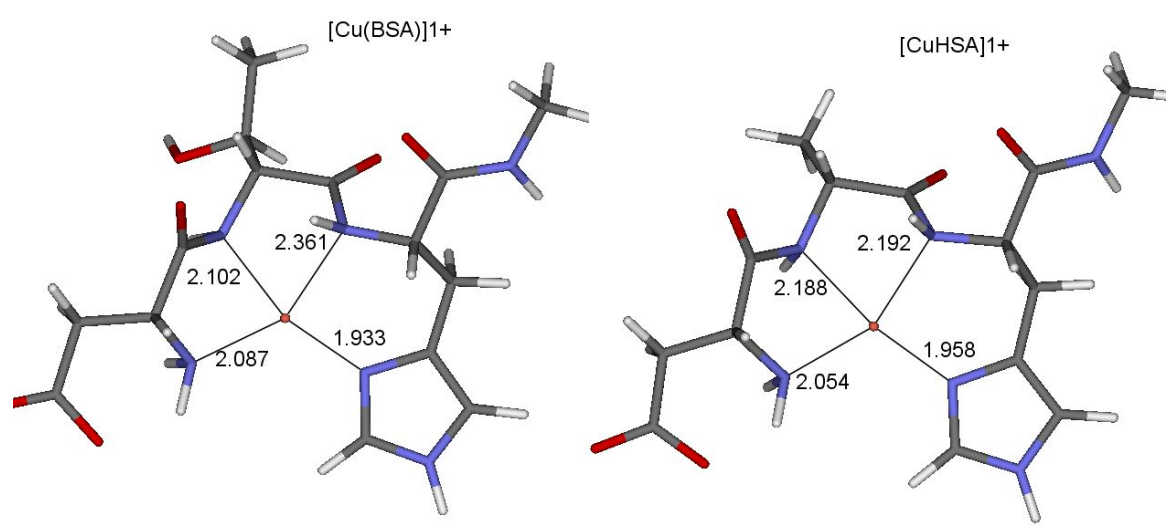

Figura 3.24: Representação das estruturas com as posições atômicas relaxadas para os sítios N-terminal da $[C u(B S A)]^{+}$e da $[C u(H S A)]^{+}$e as respectivas distâncias Cu-Ligante em $\AA$.

\subsection{Comparação entre os complexos}

Apresentamos agora a comparação entre todos os complexos estudados nas seções anteriores. Apresentamos também uma análise dos dois sítios principais de ligação conhecidos de $C u$ da proteína albumina humana (HSA) (Figs. 1.6 e 1.7).

\section{Análise Estrutural e Energética}

Ao comparar as distâncias de ligação $\mathrm{Cu}$-Ligante $(\mathrm{Cu}-\mathrm{L})$ de todos os complexos estudados (Fig. 3.25) observa-se que a distância média é de $2.009 \pm 0.1 \AA$. O ligante macrocíclico ftalocianina apresenta a menor distância média $(1.966 \AA$ ) e o ligante oxi-2 a maior distância 
média (equatorial): $2.066 \AA$. Ou seja, a variação máxima média é de apenas $\pm 0.1 \AA$ (Fig. 3.25) o que pode ser atribuído ao ligante se adequar ao raio iônico do metal ${ }^{19}$. Conforme esperado, as distâncias médias $\mathrm{Cu}-\mathrm{L}$ dos complexos com carga +1 e são maiores que aquelas com carga +2 e. Isto porque o sistema no estado oxidado apresenta o orbital $\mathrm{d}_{x}{ }^{2}-y^{2}$ com apenas um elétron e no estado reduzido este orbital está preenchido (por exemplo as densidades de estado da Figuras 3.17 para o $\left.[\mathrm{Cu}(\text { pyalen })]^{+n}\right)$. A única exceção a esta tendência foi para o complexo tetra-1 em que o sistema com carga +2 e apresentou a distância média maior que o cálculo com carga 1+e. Entretanto este complexo apresentou distâncias de ligação assimétricas diferentes de todos os outros complexos e, desta forma, será averiguado no futuro. Comparando as distâncias $\mathrm{Cu}-\mathrm{L}$ em cada complexo estas são em geral simétricas apresentando desvio padrão de $1 \%$ a $4 \%$. As menores distâncias de ligação $\mathrm{Cu}-\mathrm{N}$ são dos ligantes possuindo o heterociclo imid (1.935 ^ para o tri-1) e do ligante ftalocianina com (1.967 ̊). Já a maior distância de ligação foi $2.051 \AA$ para a cabonila do oxi-3 (Fig. 3.21).

Podemos correlacionar a cada classe de estrutura a tendência entre a distância média $\mathrm{Cu}$ L e a energia de ligação, ou seja, para a classe dos tridentados, tetradentados ou oxindóis, quanto mais estável é o complexo menor é a distância Cu-L. Já para os complexos no estado reduzido ( carga $+1 e$ ) a tendência é inversa, o composto é mais estável para maiores distâncias de ligação devido a maior repulsão eletrônica entre os pares isolados dos ligantes com os orbitais $d$ preenchidos do $C u$. Os resultados de energia de ligação podem ser reunidos em três grupos: a) o grupo formado pelos complexos tri-3 e oxi-4 com energia de ligação da ordem de $-420 \mathrm{kcal} / \mathrm{mol}$ (o tri-4 apresenta $E_{\text {lig }}$ intermediária em $-429 \mathrm{kcal} / \mathrm{mol}$ ); b) o tetra-4 com $E_{l i g}$ de $-460 \mathrm{kcal} / \mathrm{mol}$ e c) os demais complexos com $E_{l i g}$ de aproximadamente -440 kcal $/ \mathrm{mol}^{20}$. O tetra-4 é o complexo mais estável com $44 \mathrm{kcal} / \mathrm{mol}(1.9 \mathrm{eV})$ mais estável que o oxi-4. O tetra-4 possui dois grupos hist que apresentam grande flexibilidade ligados ao grupo imidazólico. A figura $3.26(d)$ mostra a torção deste ligante para manter o íon

\footnotetext{
${ }^{19} \mathrm{O}$ raio iônico do $\mathrm{Cu}^{2+}$ e $C u^{1+}$ são $0.72 \AA$ e $0.96 \AA$ respectivamente [131]

${ }^{20} \mathrm{Nesta}$ análise não consideramos o composto oxi-2 que possui dois ligantes e seis posições de coordenação com o $C u$.
} 
coordenado. Ao comparar a estrutura e a energética do tetra-4 com a atividade biológica medida $[17,108]$ este complexo é o menos reativo frente à degradação de biomoléculas como açúcares e proteína e também apresenta menor atividade redox ${ }^{21}$, ou seja, reduzida capacidade de formar e também inibir espécies radicalares [17,108]. A menor atividade biológica deste complexo pode estar relacionada à proteção do ligante ao íon $C u$ (que apresenta coordenação bastante distorcida com o ângulo de torção $N_{4}=45.2^{\circ}$ ) que o mantém mais estabilizado que os demais. Desta forma, uma possível explicação para a menor atividade biológica em relação aos demais complexos vem de fatores estéricos e energéticos [132].

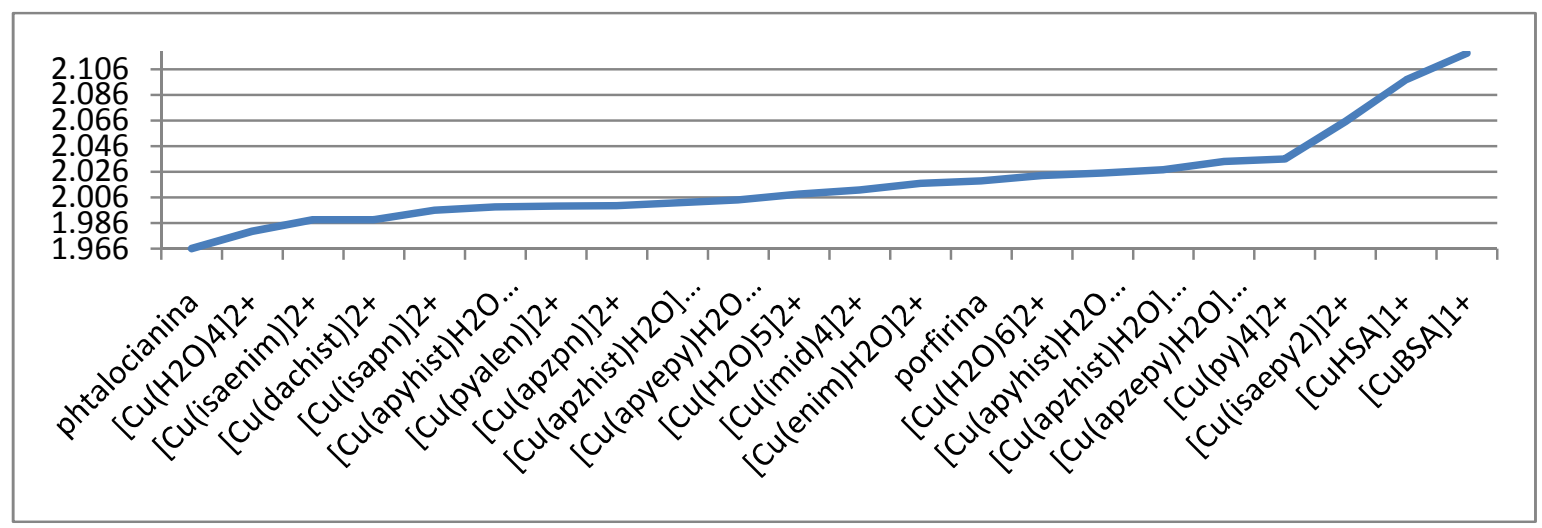

Figura 3.25: Representação gráfica das distâncias de ligação médias $(\mathrm{Cu}-\mathrm{L}) / 4$ para os complexos investigados em angstrons.

Há diversos estudos publicados que comparam a energia de ligação de metais com ligantes piridínicos $[118,133]$. Entretanto estes valores são dependentes da escolha do funcional de troca e correlação, apresentando significado apenas as diferenças entre as $\mathrm{E}_{\text {lig }}$ dos complexos. A ordem de grandeza da energia de ligação no presente trabalho está em bom acordo com as obtidas para outros complexos calculados (-369 kcal/mol para o funcional/base PW91/STO-TZP) [118]. Comparando este valor da literatura com a $E_{l i g}$ para complexo enim (sem H2O) obtivemos $-391 \mathrm{kcal} / \mathrm{mol}$ com o funcional BP86 e $-405 \mathrm{kcal} / \mathrm{mol}$ com o

\footnotetext{
${ }^{21} \mathrm{~A}$ atividade redox não está necessariamente relacionado ao potencial redox dos complexos [132].
} 
funcional PBE (Tabela 2 do anexo I). Estes valores não podem ser comparados diretamente com os valores experimentais de entalpia do complexo $(\Delta \mathrm{H})$, isto porque estamos considerando apenas os termos eletrônicos de ligação metal ligante não contabilizando as energias de solvatação e desolvatação. Entretanto, esta análise é importante para verificar as tendências relativas entre os diferentes ligantes e a chamada contribuição intrínseca, sem os efeitos do ambiente condensado [134].

\section{Comparação com as medidas experimentais da proteína albumina}

Como já foi citado na introdução, o equilíbrio químico competitivo entre os ligantes bases de Schiff e a albumina pelo íon $C u\left(\mathrm{~K}_{C u L}\right.$ tabela 1.1) indica a estabilidade do complexo [16]. Entretanto um dos complexos, o tri-1, tem o comportamento de transferir o íon $C u$ apenas para o sítio de menor afinidade que é o sítio da cis-34 [45]. Nesta etapa do trabalho vamos propor uma hipótese para tal comportamento baseado nos resultados estruturais e eletrônicos obtidos.

\section{(a) Fatores estéricos}

A figura 3.26 mostra o ângulo e a distância de 'abertura' para os complexos estudados. Este fator parece ter grande influência visto que há restrições estéricas para o acesso à cis34 [28] e até o presente momento tal interação só foi medida para a série dos tridentados. Os ligantes tridentados apresentam uma posição de coordenação livre para o íon $C u$, o que pode indicar também maior facilidade para interagir com o $S$ da cis-34. Desta forma, ligantes com maior ângulo de abertura e tridentados tem, em princípio, maior possibilidade de interagir. Os ligantes tetradentados apresentam maior impedimento já que o 'ângulo de abertura' é menor que $60^{\circ}$. Já para os tridentados o ângulo de abertura está entre 87 e $99^{\circ}$. A figura 3.26 também apresenta a 'distância de abertura' entre os átomos de $\mathrm{H}$ que é de $5.6 \AA$ no oxi-4 a $4.2 \AA$ no tri-2. O segundo fator, que indica a interação com a cis-34, é a planaridade do complexo. A cavidade em que se encontra a cis-34 é restrita, parecendo estar disponível 
apenas a complexos mais planos que consigam se intercalar a ela. Portanto complexos mais volumosos apresentam menor possibilidade de interagir (Fig. 3.26). Desta forma, todos os complexos da série dos tridentados e o oxi-4 possuem propriedades estruturais factíveis a tal interação. Entretanto, experimentalmente observam-se tendências de interação que não são explicadas através de fatores estruturais nem por fatores energéticos: o tri-1 interage apenas com a cis-34, os complexos tri-3 e tri-4 interagem nesta cavidade após saturar o sítio N-terminal (Fig. 1.8), o tri-2 não interage com a cis-34 e ainda não há evidências experimentais de que o oxi-4 interaja com a cis-34 após saturar o sítio N-terminal [16].

\section{(b) Fatores Eletrônicos}

Analisamos a influência dos orbitais mais energéticos nesta interação que repercute na polaridade dos grupos heterocíclicos e também no momento de dipolo. Os aminoácidos que circundam a cavidade (com acesso ao solvente) são em sua maioria polares (Fig. 3.28). A cavidade de acesso a cis-34 apresenta uma região com caráter apolar composta pelos seguintes aminoácidos ${ }^{22}$ : Phe27, Leu31, Pro35, Val40, Leu42 no primeiro segmento e Leu74, Val77, Ala78 e Leu80 na segunda sequência (Fig. 3.6). As figuras 3.6 e 3.28 mostram, em vermelho, as regiões compostas por estes aminoácidos (AA) formando uma 'bolsa' apolar ou hidrofóbica [28]. A segunda região da cavidade apresenta aminoácidos com resíduos polares como o Gln33, Thr83 e Tyr84 próximos a cis-34. Desta forma, o reconhecimento molecular do complexo neste sítio passa pelo 'casamento' do $C u$ com o $S$ da cis-34 e também do complexo como um todo com a cavidade $[135,136]$. A característica desta região da HSA é conhecida conforme a descrição da Ref. [28]: "O grupo tiol $(S H)$ está na borda entre um segmento helicoidal polar e uma área hidrofóbica (apolar) com um grupo tirosina (tyr84) próximo". Comparando o caráter da cavidade de acesso à cis-34 com a densidade de estados dos complexos da série dos tridentados (seção 3.2), verifica-se que os sítios polares são energeticamente mais acessíveis do que os sítios apolares (Fig. 3.7). Os ligantes apzepy e apzhist

\footnotetext{
${ }^{22} \mathrm{~A}$ estrutura dos vinte amino ácidos fundamentais ao corpo humano encontra-se no apêndice B.3.
} 
apresentam o par isolado da pirazina altamente energético, enquanto os ligantes com imidazol (apyhist e apzhist) apresentam o orbital com caráter $\pi$ também bastante energéticos. Já o tri-2, que não possui sítios polares externos a esfera de coordenação apresenta os orbitais de fronteira na coordenação com o $C u$.

Outro fator importante é o estudo do momento de dipolo dos complexos. A proteína albumina possui carga formal negativa em pH fisiológico [28] assim a interação destes complexos é facilitada pelo potencial eletrostático. O momento de dipolo pode guiar o composto para determinada região da proteína e este interagir em certa orientação espacial. A Figura 3.29 e a Tabela 3.12) mostram a orientação e o módulo do momento de dipolo para os complexos. O tri-4 e o oxi-3 apresentam maior módulo do momento de dipolo. Em relação a orientação do vetor, os complexos da série dos tridentados que interagem com a cis-34 apresentam uma orientação para a esquerda enquanto o tri-2 apresenta a orientação mais centralizada e para a direita (Fig. 3.29) que não se modificam ao considerar os diferentes mínimos estruturais.

Com estas informações temos como hipótese que os grupos reativos dos ligantes podem ter influência no ancoramento na região de interação e também pode haver o reconhecimento molecular do tri-1 na cavidade com o grupo polar (hist) de um lado e o grupo apolar (py) do outro. 
Tabela 3.12: Valores do módulo do momento de dipolo (em Debye) calculados para os complexos com o funcional/base BP86/TZVP.

\begin{tabular}{lc} 
Complexos & $\begin{array}{c}\text { Momento de } \\
\text { dipolo }(\mathrm{D})\end{array}$ \\
\hline$\left[\mathrm{Cu}(\text { apzhist }) \mathrm{H}_{2} \mathrm{O}\right]^{2+}$ & 4.31 \\
{$\left[\mathrm{Cu}(\text { apyhist }) \mathrm{H}_{2} \mathrm{O}\right]^{2+}$} & 2.85 \\
{$\left[\mathrm{Cu}(\text { apyepy }) \mathrm{H}_{2} \mathrm{O}\right]^{2+}$} & 1.87 \\
{$\left[\mathrm{Cu}(\text { apzepy }) \mathrm{H}_{2} \mathrm{O}\right]^{2+}$} & 2.49 \\
{$[\mathrm{Cu}(\text { apzpn })]^{2+}$} & 2.69 \\
{$[\mathrm{Cu}(\text { dachist })]^{2+}$} & 1.38 \\
{$[\mathrm{Cu}(\text { pyalen })]^{2+}$} & 0.57 \\
{$[\mathrm{Cu}(\text { pyen })]^{2+}$} & 0.51 \\
{$\left[\mathrm{Cu}(\text { enim }) \mathrm{H}_{2} \mathrm{O}\right]^{2+}$} & 2.28 \\
{$[\mathrm{Cu}(\text { isaenim })]^{2+}$} & 5.48 \\
$\mathrm{H}_{2} \mathrm{O}$ & 2.14 \\
$\mathrm{H}_{2} \mathrm{O}($ experimental $)$ & 1.85 \\
\hline
\end{tabular}


a)

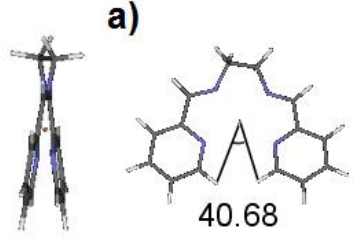

e)

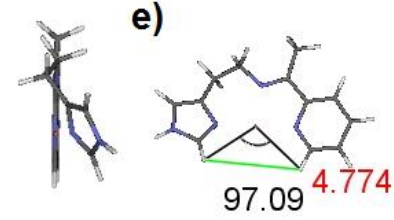

i)

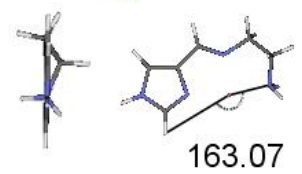

b)

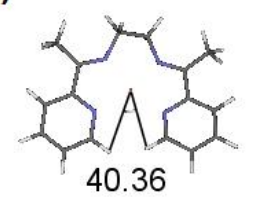

f)

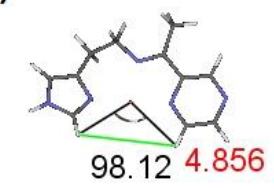

j)

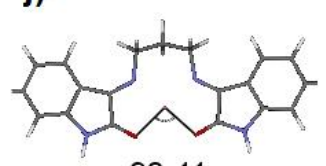

c)

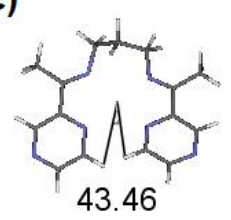

g)

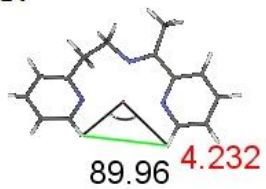

I)

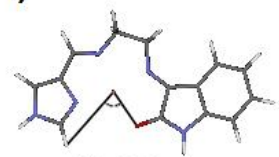

79.32

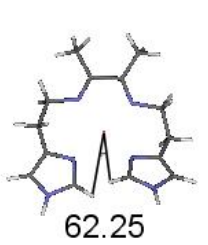

d)

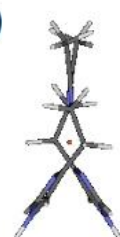

h)
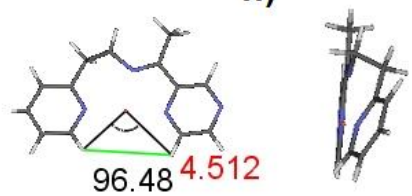

Figura 3.26: Representação dos complexos na vista frontal (e para alguns a vista lateral). 'Ângulo de abertura' e 'distância de abertura' (em A) para os complexos estudados. a) $\left.\left.\left.[\mathrm{Cu}(\text { pyalen })]^{2+} \mathrm{b}\right)[\mathrm{Cu}(\text { pyen })]^{2+} \mathrm{c}\right)[\mathrm{Cu}(\text { apzpn })]^{2+} \mathrm{d}\right)[\mathrm{Cu}(\text { dachist })]^{2+}$ e) $[\mathrm{Cu}(\text { apzhist }) H 2 O]^{2+}$ f) $[\mathrm{Cu}(\text { apyepy }) \mathrm{H} 2 \mathrm{O}]^{2+}$ g) $[\mathrm{Cu}(\text { apzepy }) \mathrm{H} 2 \mathrm{O}]^{2+}$ h) $[\mathrm{Cu}(\text { apyhist }) \mathrm{H} 2 \mathrm{O}]^{2+}$ i) $[\mathrm{Cu}(\text { enim }) \mathrm{H} 2 \mathrm{O}]^{2+}$ j) $[\mathrm{Cu}(\text { isaepy }) \mathrm{H} 2 \mathrm{O}]^{2+}$. 


\begin{tabular}{|c|c|c|c|c|c|c|c|}
\hline Sequência & Aminoácidos & Resíduo & $\begin{array}{l}\text { Estrutura } \\
\text { Secundária }\end{array}$ & Sequência & Aminoácidos & Resíduo & $\begin{array}{l}\text { Estrutura } \\
\text { Secundária }\end{array}$ \\
\hline PHE27 & Enilalanina & $\mathrm{CH}_{2}$ benz & Hélice & & & & \\
\hline ALA28 & Alanina & $\mathrm{CH}_{3}$ & Hélice & & & & \\
\hline GLN29 & Glutamina & $\left(\mathrm{CH}_{2}\right)_{2} \mathrm{CONH}_{2}$ & Hélice & & & & \\
\hline TYR30 & Tirosina & $\mathrm{CH}_{2}$-ty & Hélice & TYR84 & Tirosina & $\mathrm{CH}_{2}$-ty & Hélice \\
\hline LEU31 & Leucina & $\mathrm{CH}_{2} \mathrm{CH}\left(\mathrm{CH}_{3}\right)_{2}$ & Alça & THR83 & Treonina & $\mathrm{HCOH}-\mathrm{CH}_{3}$ & Hélice \\
\hline GLN32 & Glutamina & $\left(\mathrm{CH}_{2}\right)_{2} \mathrm{CONH}_{2}$ & Alça & GLU82 & Ảcido Glutâmico & $\left(\mathrm{CH}_{2}\right) \mathrm{COOH}$ & Hélice \\
\hline GLN33 & Glutamina & $\left(\mathrm{CH}_{2}\right)_{2} \mathrm{CONH}_{2}$ & Alça & ARG81 & Arginina & $\left(\mathrm{CH}_{2}\right)_{3} \mathrm{CNH}\left(\mathrm{NH}_{2}\right)_{2}$ & Hélice \\
\hline CYS34 & Cisteína & $\left(\mathrm{CH}_{2}\right) \mathrm{S}$ & Alça & LEU80 & Leucina & $\mathrm{CH}_{2} \mathrm{CH}\left(\mathrm{CH}_{3}\right)_{2}$ & Hélice \\
\hline PRO35 & Prolina & $\left(\mathrm{CH}_{2}\right)_{3}$ & Alça & THR79 & Treonina & $\mathrm{HCOH}-\mathrm{CH}_{3}$ & Alça \\
\hline GLU37 & Ácido Glutâmico & $\left(\mathrm{CH}_{2}\right)_{2} \mathrm{COOH}$ & Hélice & ALA78 & Alanina & $\mathrm{CH}_{3}$ & Alça \\
\hline ASP38 & Ácido Aspártico & $\left(\mathrm{CH}_{2}\right) \mathrm{COOH}$ & Hélice & VAL77 & Valina & $\mathrm{CH}(\mathrm{CH} 3)_{2}$ & Alça \\
\hline HIS39 & Histidina & $\mathrm{CH}_{2}$ hist & Hélice & THR76 & Treonina & $\mathrm{HCOH}-\mathrm{CH}_{3}$ & Alça \\
\hline VAL40 & Valina & $\mathrm{CH}(\mathrm{CH} 3)_{2}$ & Hélice & CYS75 & Cisteína & $\left(\mathrm{CH}_{2}\right) \mathrm{S}$ & Hélice \\
\hline LYS41 & Lisina & $\left(\mathrm{CH}_{2}\right)_{3} \mathrm{NH}_{3}$ & Hélice & LEU74 & Leucina & $\mathrm{CH}_{2} \mathrm{CH}\left(\mathrm{CH}_{3}\right)_{2}$ & Hélice \\
\hline LEU42 & eucina & $\mathrm{CH}_{2} \mathrm{CH}\left(\mathrm{CH}_{3}\right)_{2}$ & Hélice & LYS73 & Lisina & $\left(\mathrm{CH}_{2}\right)_{3} \mathrm{NH}_{3}$ & Hélice \\
\hline
\end{tabular}

Figura 3.27: Sequência dos aminoácidos mais relevantes constituintes da cavidade da próxima a cis-34. Em vermelho representamos os aminoácidos com resíduos de hidrocarbonetos apolares; em azul representamos os resíduos polares com sítios de $N$ e $O$; em amarelo o sítio da cis-34; em branco os resíduos que não estão orientados em direção a cavidade. A estrutura secundária indica a organização tridimensional na sequência polipeptídica: a) A hélice representa a conformação helicoidal entre os aminoácidos formado através de ligações de hidrogênio; b) A alça representa a conformação sem estrutura tridimensional definida, com maior flexibilidade, que nesta proteína interliga as diferentes hélices [46]. 

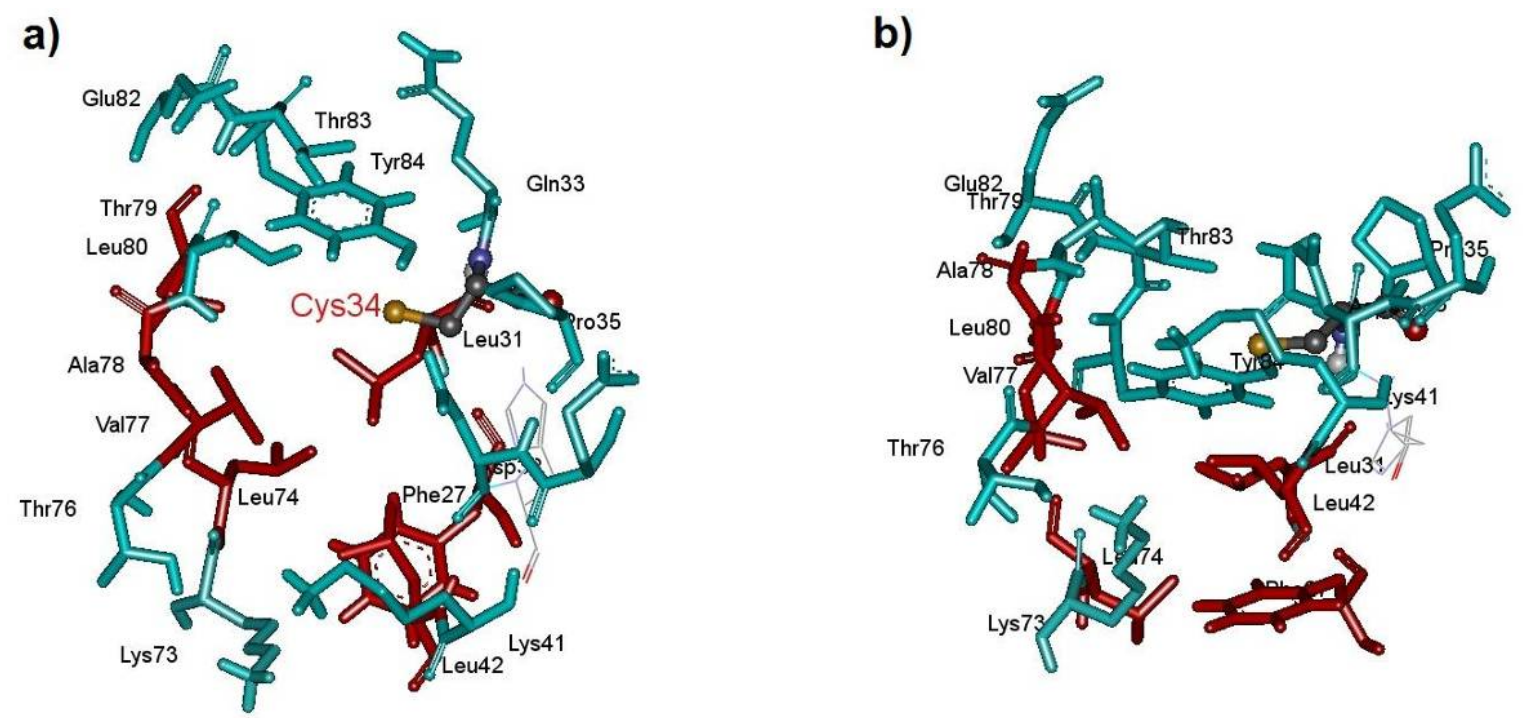

Figura 3.28: Representação esquemática dos aminoácidos constituintes da cavidade da cis-34 para a estrutura cristalográfica da proteína albumina [33]. Em vermelho os aminoácidos com os resíduos de hidrocarbonetos; em azul os resíduos polares com sítios de $N$ e $O$. 
a)
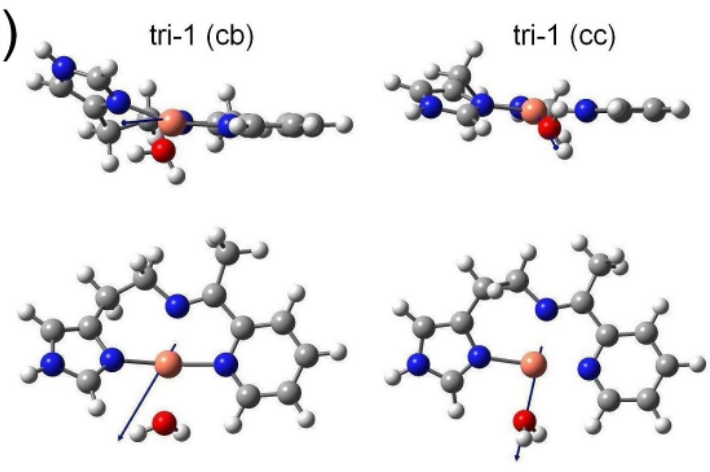

b)
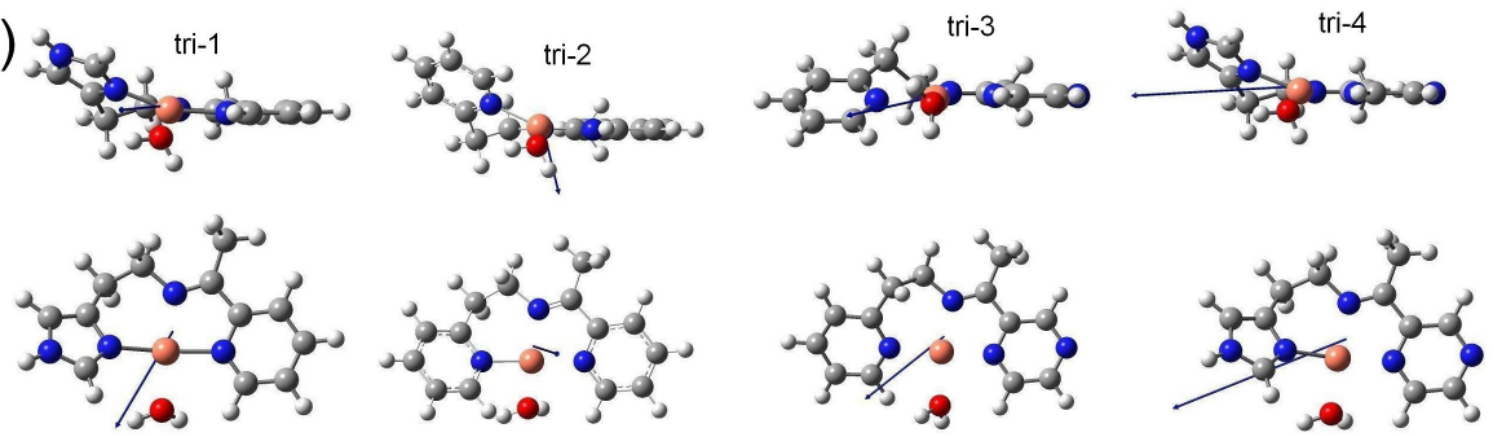

Figura 3.29: Representação esquemática do vetor momento de dipolo para os complexos tridentados. a) Orientação do vetor momento de dipolo em relação a conformação para baixo (cb) para cima (cc). b) Momento de dipolo para os complexos tri-1 a tri-4. 


\section{Capítulo 4}

\section{Estudo de bases modificadas de DNA}

Conforme já mencionado na introdução, este estudo tem como objetivo investigar a estabilidade da configuração ferromagnética em relação à antiferromagnética para as bases modificadas de DNA (hidroxipiridona) complexadas com cobre ([Hy-Cu-Hy]). Primeiramente faremos o estudo das bases isoladas metaladas sem a presença do backbone (Fig. 4.1). Na seção 4.1.1 faremos o estudo do estado de carga nas bases isoladas (metaladas) e na seção 4.1.2 o estudo do dímero com o backbone.

Como primeira etapa realizamos estudos do [Hy-Cu-Hy] comparando nossos resultados a outros trabalhos teóricos da literatura [64,65]. Estudamos o monômero (Fig. 4.1 a), o dímero (Fig. 4.1 b) e o tetrâmero (Fig. 4.1 c) utilizando diferentes configurações de spin. Todos os cálculos aqui apresentados foram realizados com o código computacional CP-PAW utilizando o corte em energia para as ondas planas de 40Ry e o funcional de troca e correlação PBE [88].

\subsection{Sistemas Estudados}

Para o monômero (Fig. 4.1 a) realizamos a completa relaxação estrutural com a carga total zero e estado de spin $1 / 2 \hbar$ (dubleto). A figura 4.2 apresenta a estrutura obtida após a 


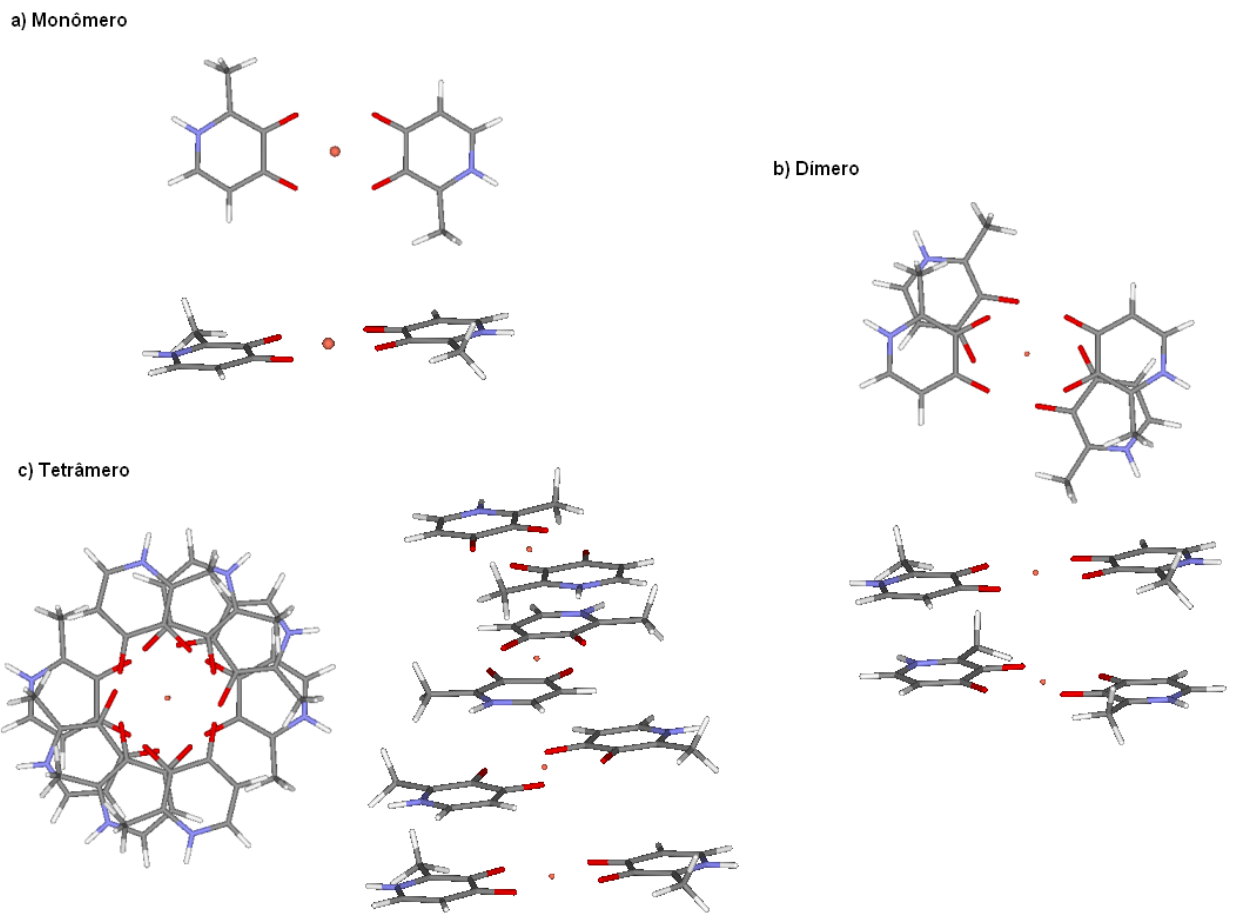

Figura 4.1: Representação esquemática para os sistemas estudados de $[\mathrm{Cu} \text { (hidroxipiridona) }]_{n}$ com vista superior e lateral: a) monômero $[\mathrm{Hy}-\mathrm{Cu}-\mathrm{Hy}]$; b) dímero $[\mathrm{Hy}-\mathrm{Cu}-\mathrm{Hy}]_{2}$; c) tetrâmero $[\mathrm{Hy}-\mathrm{Cu}-\mathrm{Hy}]_{4}$.

otimização de geometria para o monômero onde as distâncias de ligação $\mathrm{Cu}$-ligante $(\mathrm{Cu}-\mathrm{L})$ são 1.948 e 1.963 Å. A coordenação encontrada foi a quadrado planar. Realizamos alguns testes distorcendo a coordenação quadrado planar, evitando que o cálculo permanecesse em uma estrutura de mínimo local de energia mas nestes testes a geometria retornou a coordenação quadrado planar. No trabalho experimental de Tanaka et al [60] foi sugerido o arranjo de cinco bases modificadas empilhadas de forma que os átomos de $C u$ distam 3.7 $\AA$ entre si com uma rotação entre as bases de $36^{\circ}$. Com estas informações construímos o dímero e o tetrâmero (Fig. 4.1 b e c). Utilizamos a geometria obtida para o monômero em cada caso aqui estudado.

Apresentamos na tabela 4.1 os valores de energia total obtidas para o monômero e para o 


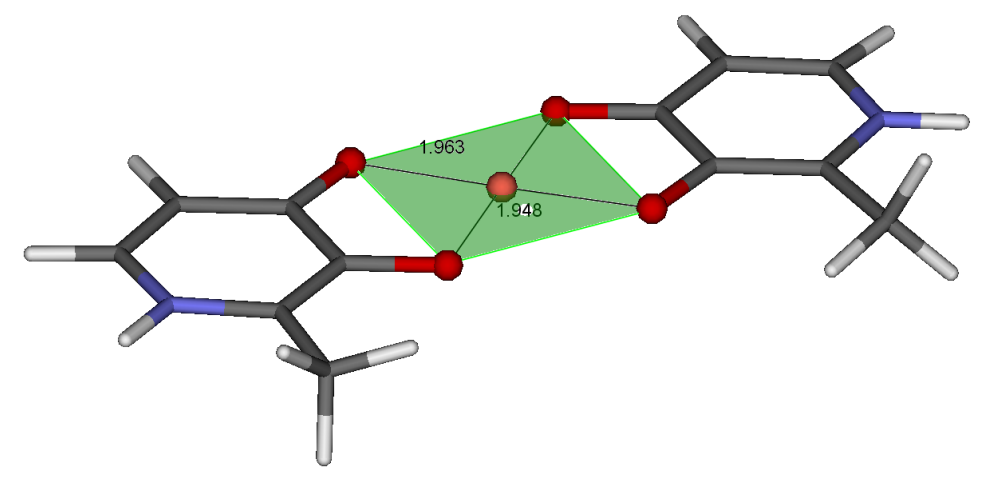

Figura 4.2: Representação esquemática do complexo [Hy-Cu-Hy] com total relaxação das posições atômicas. Em laranja o sítio de cobre e em vermelho os ligantes oxigênio. Coordenação $\mathrm{Cu}-\mathrm{L}$ quadrado planar e distâncias de ligação em angstrons.

dímero em diferentes configurações de spin. Podemos ver que a soma das energias totais dos cálculos de dois monômeros isolados é mais baixa do que a energia total do dímero em 0.6 eV. Os resultados de energia total para as projeções de spin 0 e $1 \hbar$ não favorecem nenhuma tendência particular de configuração magnética. Realizamos o estudo do tetrâmero a fim de verificar se um sistema maior poderia reproduzir a condição experimentalmente observada. A tabela 4.2 apresenta os resultados realizados para o tetrâmero para as configurações de spin 0,1 e $2 \hbar$. Podemos observar que todas as configurações de spin são degeneradas. Na tabela 4.3 apresentamos os momentos magnéticos locais $\left(\mathrm{m}_{l}\right)$ obtidos para os sítios de $C u$. As magnitudes são dadas pelas respectivas diferenças de ocupação $\left(\mathrm{n}_{u p}\right.$ e $\left.\mathrm{n}_{\text {down }}\right)$. Como se pode ver os $\mathrm{m}_{l}$ apresentam exatamente a mesma magnitude $(0.58 \mu \mathrm{B})$ em cada sítio de $C u$ e por este motivo representamos apenas seu 'sinal' através das flechas para baixo $(\downarrow)$ e para cima $(\uparrow)$. Estes resultados demonstram que as unidades em cada um dos planos são totalmente independentes e o empilhamento não introduz nenhum acoplamento magnético. As ocupações para os átomos de oxigênio seguem a mesma tendência dos íons $C u$ e se alinham paralelamente a estes. 


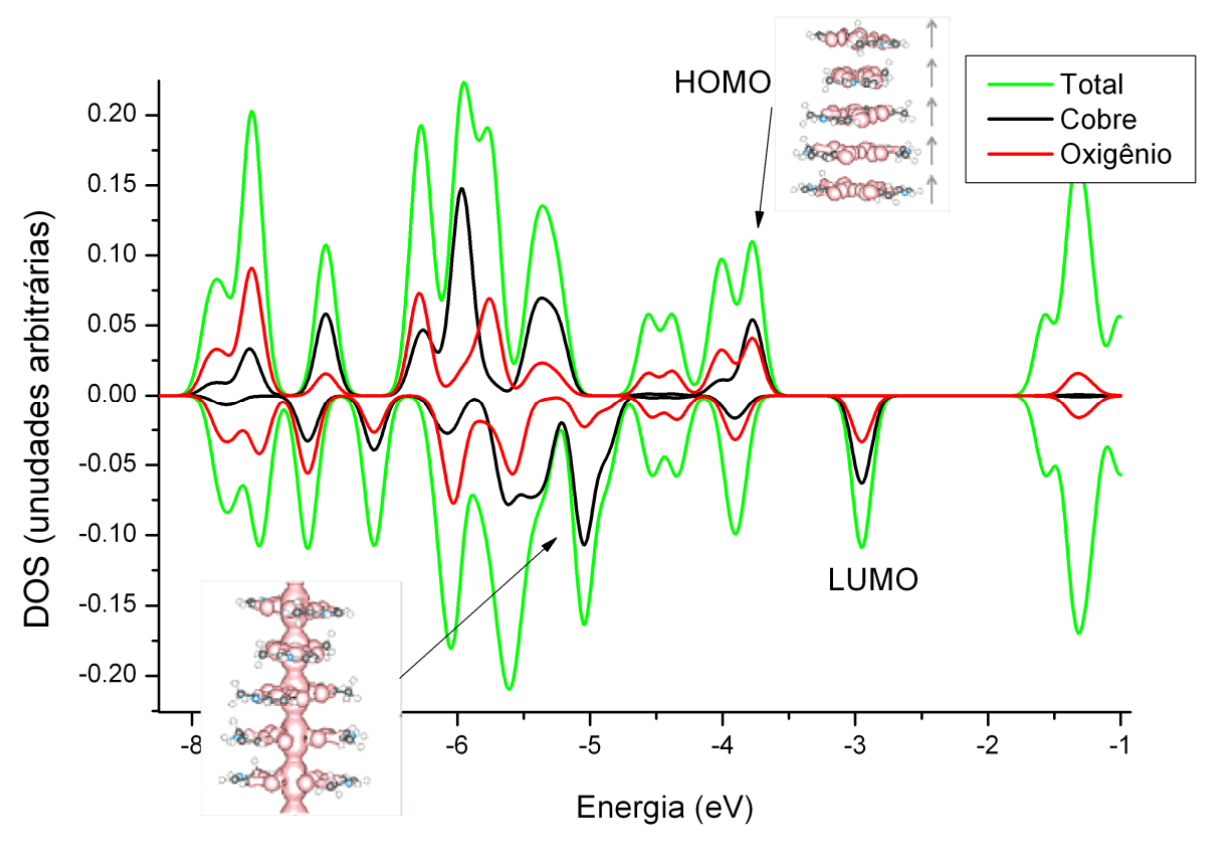

Figura 4.3: Densidade de estados (DOS) total e projetada nos sítios ligantes de oxigênio e no $\mathrm{Cu}$ para o tetrâmero de $[\mathrm{Hy}-\mathrm{Cu}-\mathrm{Hy}]_{4}$ com spin total $=2 \hbar$. Em destaque a representação dos orbitais HOMO e do orbital com caráter $\mathrm{d}_{z^{2}}$ (figura dos orbitais reproduzida da Ref. [64]. 
Tabela 4.1: Energia total (em Hartree) e diferença de energia gap HOMO-LUMO para o monômero $[\mathrm{Hy}-\mathrm{Cu}-\mathrm{Hy}]$ e para o dímero $[\mathrm{Hy}-\mathrm{Cu}-\mathrm{Hy}]_{2}$ em diferentes configurações de spin total.

\begin{tabular}{lcc}
\hline Sistema & Energia total $(\mathrm{H})$ & gap $(\mathrm{eV})$ \\
\hline Monômero (dubleto) & -212.12213 & 0.83 \\
Dímero (singleto) & -424.21989 & 0.78 \\
Dímero (tripleto) & -424.21987 & 0.78 \\
\hline
\end{tabular}

Tabela 4.2: Energia total para diferentes configurações de spin para o tetrâmero de [Hy-Cu$\mathrm{Hy}]_{4}$.

\begin{tabular}{llllll}
\hline Tetrâmero & & $\begin{array}{l}\text { Energia } \\
(\mathrm{H})\end{array}$ & $\begin{array}{l}\text { HOMO } \\
(\mathrm{eV})\end{array}$ & $\begin{array}{l}\text { LUMO } \\
(\mathrm{eV})\end{array}$ & gap $(\mathrm{eV})$ \\
\hline & Spin=0 & -848.36236 & -3.548 & -2.796 & 0.75 \\
& Spin=1 & -848.36235 & -3.426 & -2.796 & 0.63 \\
& Spin=2 & -848.36233 & -3.426 & -2.797 & 0.63 \\
\hline
\end{tabular}

Tabela 4.3: Número de ocupação por direção de spin $\left(\mathrm{n}_{u p}\right.$ e $\left.\mathrm{n}_{\text {down }}\right)$ projetada nos sítios de $C u$ nos estudos de spin total 0, 1 e $2 \hbar$ para o tetrâmero [Hy-Cu-Hy $]_{4}$ (Fig. 4.1c). As flechas para cima e para baixo indicam o sinal do momento magnético local $\left(\mathrm{m}_{l}\right)$ resultante.

\begin{tabular}{ccccccccccc}
\hline Sítio & 0.0 & $\hbar$ & & 1.0 & $\hbar$ & & $2.0 \hbar$ & & \\
& & $\mathrm{n}_{\text {up }}$ & $\mathrm{n}_{\text {down }}$ & & $\mathrm{n}_{\text {up }}$ & $\mathrm{n}_{\text {down }}$ & & $\mathrm{n}_{\text {up }}$ & $\mathrm{n}_{\text {down }}$ \\
& & & & & & & \\
$\mathrm{Cu} 01$ & 4.79 & -5.37 & $\downarrow$ & 4.79 & -5.37 & $\downarrow$ & 5.37 & -4.79 & $\uparrow$ \\
$\mathrm{Cu} 02$ & 5.37 & -4.79 & $\uparrow$ & 5.37 & -4.79 & $\uparrow$ & 5.37 & -4.79 & $\uparrow$ \\
$\mathrm{Cu} 03$ & 5.37 & -4.79 & $\uparrow$ & 5.37 & -4.79 & $\uparrow$ & 5.37 & -4.79 & $\uparrow$ \\
$\mathrm{Cu} 04$ & 4.79 & -5.37 & $\downarrow$ & 5.37 & -4.79 & $\uparrow$ & 5.37 & -4.79 & $\uparrow$ \\
\hline
\end{tabular}

A densidade de estados (Fig. 4.3) apresenta a hibridização dos orbitais do $C u$ com caráter $\mathrm{d}_{x^{2}-y^{2}}$ e caráter $\sigma$ nos sítios ligantes de $O$. Ou seja, o orbital possuindo elétron 
desemparelhado está no plano da base sem contribuição eletrônica perpendicular. O orbital com caráter $\mathrm{d}_{z^{2}}$ do $C u$, que poderia apresentar alguma interação eletrônica entre as unidades é duplamente ocupado e está a $1.2 \mathrm{eV}$ do HOMO.

Nossos resultados até aqui somente reproduziram (e bastante bem), o que já havia sido sugerido na literatura [64], além de calcular os $\mathrm{m}_{l}$, que ainda não havia sido feito. Numa tentativa de reproduzir o preferencial acoplamento ferromagnético experimentalmente observado, introduzimos em nossos cálculos os graus de liberdade de acoplamentos de spin não colineares [71]. Iniciamos assim os cálculos em diferentes configurações de spin, uma busca dentro deste sub-espaço. Entretanto, todos os cálculos resultaram nas mesmas conclusões obtidas para o caso colinear e por esse motivo não serão aqui apresentados.

\subsubsection{Estudo para diferentes estados de carga}

Realizamos então estudos para diferentes estados de carga e spin com o intuito de procurar modificações conformacionais que induzissem o comportamento magnético preferencial nestes sistemas. Retiramos um ou dois elétrons por base a fim de simular um possível efeito de polarização nas bases gerada pelo backbone. Estudamos nesta etapa o monômero e o dímero para as geometrias de coordenação $\mathrm{Cu}-\mathrm{L}$ quadrado planar e quadrado planar distorcida.

Para o monômero [Hy-Cu-Hy] consideramos os estados de carga $+1 e$, spin total 0 e $1 \hbar$ e também a carga +2 e com spin total $0.5 \hbar$. Em todas as configurações realizamos a completa relaxação das posições atômicas e os resultados de geometrias são apresentados na Fig. 4.4. No estudo com a configuração de carga $+1 e$ e spin $0 \hbar$ obtivemos a estrutura bastante distorcida com a distância de ligação metal ligante $(\mathrm{Cu}-\mathrm{L})$ abaixo dos demais resultados (Fig. 4.4 d). Desta forma esta configuração se mostrou com energia total mais alta e desprezamos este resultado. Nos demais casos verificamos que ao retirar elétron(s) do sistema a distância metal ligante se reduz (Fig. 4.4). O ângulo O-Cu-O permaneceu $\approx 85.4^{\circ} \mathrm{em}$ todos os casos. Os resultados obtidos com a carga total $+2 e$ distorce a base em relação a coordenação quadrado planar com ângulo de torção entre os quatro sítios ligantes de $O\left(\mathrm{O}_{4}\right)$ de $24.5^{\circ}$. 

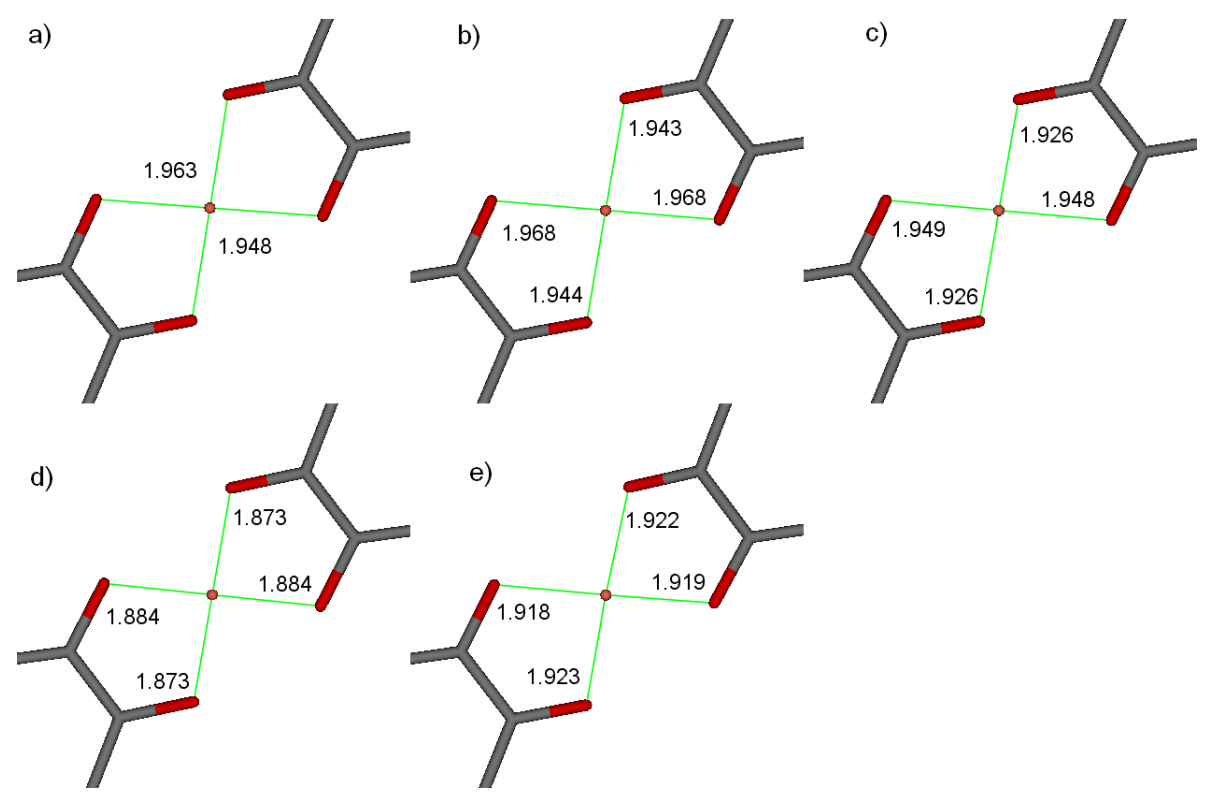

Figura 4.4: Distâncias de ligação metal ligantes para o monômero de [Hy-Cu-Hy] nas configurações geométricas, eletrônicas e de spin: a)cis, carga $0 e$, spin $0.5 \hbar$; b)trans, carga $0 e$, spin $0.5 \hbar$; c)trans, carga $1 e$, spin $1.0 \hbar$; d)trans carga $1 e$, spin $0.0 \hbar$; e)trans, carga $+2 e$, spin $0.5 \hbar$.

Apresentamos na Fig. 4.5 a DOS projetada nos ligantes e no átomo de $C u$ e os orbitais mais relevantes para o estado de carga 0 e, geometria quadrado planar e para a geometria distorcida (carga +2 e). Observa-se a aproximação dos estados de fronteira, quando comparamos o sistema neutro com o carregado positivamente. Para o sistema neutro tanto o HOMO quanto o LUMO tem caráter $\mathrm{d}_{x^{2}-y^{2}}$ e contribuição dos ligantes; por sua vez os orbitais HOMO-1 tem característica semelhante ao sistema carregado positivamente, isto é, característica $\mathrm{d}_{x z}$ e $\mathrm{d}_{y z}$ com contribuição $\pi$ dos sítios de $O$. Para o sistema carregado o HOMO e o LUMO apresentam característica $\pi$ dos ligantes e $\mathrm{d}_{x z}$ e $\mathrm{d}_{y z}$ do $C u$; os orbitais HOMO-1 apresentam característica $\mathrm{d}_{x 2-y 2}$ com contribuição dos ligantes e $\pi$ da piridona.

Na figura 4.6 a $e$ b apresentamos as diferenças nas densidades de $\operatorname{spin}\left(\Delta \rho=\rho_{\text {up }}-\rho_{\text {down }}\right)$ para o monômero neutro e carregado. Podemos ver que há uma concentração no plano 
Tabela 4.4: Auto-valores de energia HOMO e LUMO, gap de energia $\left(\mathrm{E}_{H O M O}-\mathrm{E}_{L U M O}\right)$ e cargas eletrônicas projetadas nos sítios de $C u$ e $O$ para as diferentes configurações de geometria, carga e spin.

\begin{tabular}{ccccccc}
\hline \multirow{2}{*}{ geometria } & $\begin{array}{c}\text { Carga } \\
\text { total }(\mathrm{e})\end{array}$ & $\begin{array}{c}\text { Spin } \\
\hbar\end{array}$ & $\begin{array}{c}\text { HOMO } \\
(\mathrm{eV})\end{array}$ & $\begin{array}{c}\text { LUMO } \\
(\mathrm{eV})\end{array}$ & $\begin{array}{c}\text { gap } \\
(\mathrm{eV})\end{array}$ & $\begin{array}{c}\text { Carga }(\mathrm{e}) \\
\mathrm{Cu} \mathrm{O} 1 \mathrm{O} 2\end{array}$ \\
\hline \multirow{2}{*}{ trans } & 0 & 0.5 & -4.239 & -3.416 & 0.82 & $0.7-0.5-0.6$ \\
cis & 0 & 0.5 & -4.192 & -3.370 & 0.82 & $0.7-0.5-0.5$ \\
trans & 1 & 0.0 & -8.542 & -8.180 & 0.36 & $0.7-0.4-0.5$ \\
trans & 1 & 1.0 & -8.543 & -8.105 & 0.44 & $0.7-0.4-0.5$ \\
trans & 2 & 0.5 & -12.603 & -12.212 & 0.39 & $0.7-0.4-0.4$ \\
\hline
\end{tabular}

para o sistema neutro, enquanto para o sistema carregado a densidade de spin está fora do plano. A tabela 4.5 apresenta os $\mathrm{m} l$ para os sistemas neutro e com carga +2 e. Observa-se a partir dos resultados apresentados a inversão do momento de spin quando o sistema é duplamente carregado, ao passo que a ocupação nos sítios ligantes mantém-se positiva. No sistema neutro a ocupação nos sítios ligantes são semelhantes em aproximadamente $0.09 \hbar$, enquanto no sistema carregado os sítios O2 e 03 aumentam a ocupação para $0.12 \hbar$ e os sítios $O 1$ e 04 diminuem a contribuição para $0.05 \hbar$ para a geometria distorcida.

Tabela 4.5: Momento magnético local $\left(\mathrm{m}_{l}\right)$ em unidades de $\hbar$ para os ligantes $O$ e para o $C u$ para o monômero neutro e carregado. Nomenclatura dos sítios segundo a Fig. 4.6 b.

\begin{tabular}{ccc}
\hline Sítios & $\mathrm{m}_{l}$ : Neutro & $\mathrm{m}_{l}$ : Carregado $(+2 e)$ \\
\hline $\mathrm{O}_{1}$ & 0.093 & 0.047 \\
$\mathrm{O}_{2}$ & 0.088 & 0.124 \\
$\mathrm{O}_{4}$ & 0.092 & 0.044 \\
$\mathrm{O}_{3}$ & 0.089 & 0.120 \\
$\mathrm{Cu} 1$ & 0.576 & -0.138 \\
\hline
\end{tabular}




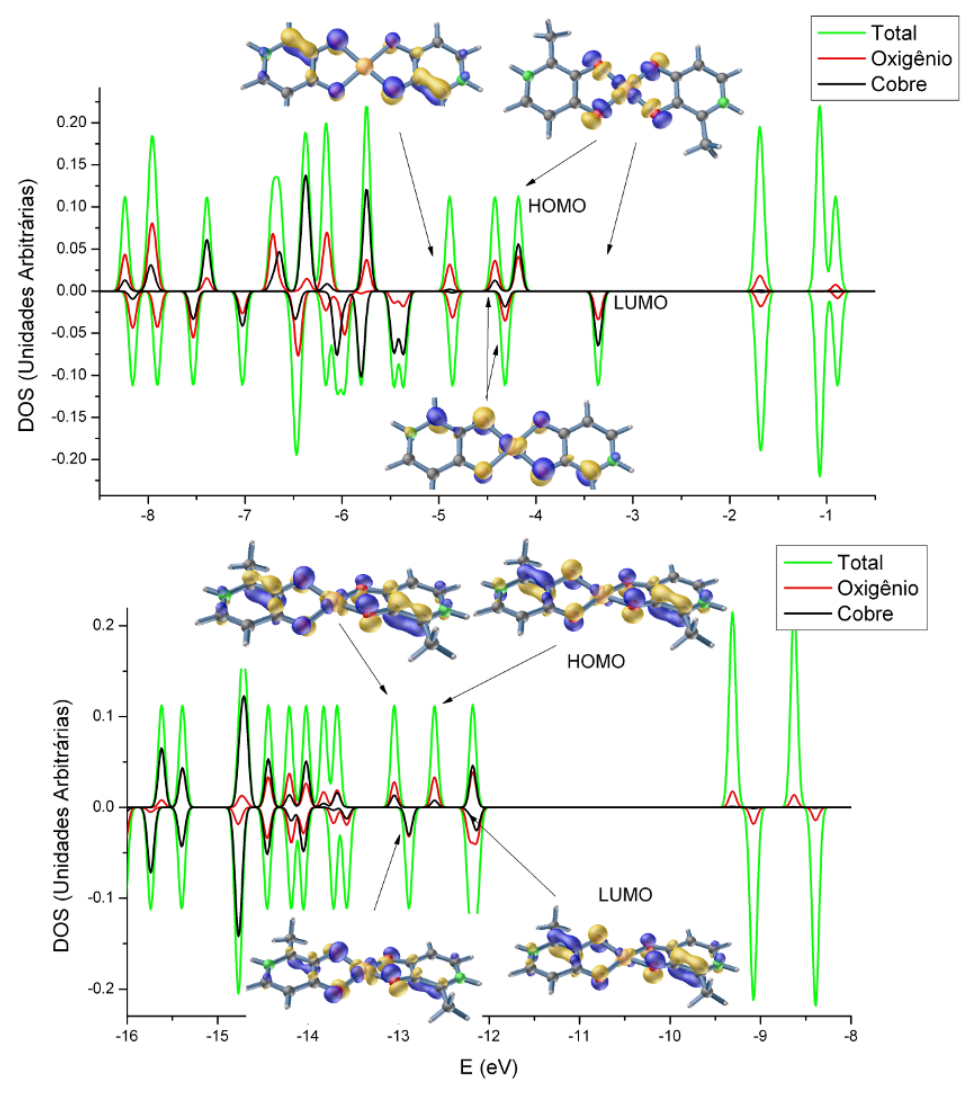

Figura 4.5: Densidade de estados total e projetada nos ligantes e no $C u$. Acima: coordenação

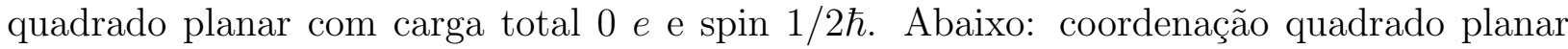
distorcida com carga +2 e e spin $1 / 2 \hbar$.

Realizamos também o estudo da interação magnética em função do estado de carga para dímero $[\mathrm{Hy}-\mathrm{Cu}-\mathrm{Hy}]_{2}$ (Fig. 4.1 b) levando em consideração os estados de carga 0, +2 e +4 e. Realizamos cálculos para as configurações de spin ferromagnética (spin total $1 \hbar$ ) e antiferromagnética (spin total $0 \hbar$ ). A geometria inicial foi obtida a partir das configurações quadrado planar e quadrado planar distorcida do monômero. Observa-se que para o sistema neutro a densidade de spins está no plano (como no monômero - Figs. 4.6 a e c) não havendo interação entre os planos e para o sistema carregado, novamente como no monômero, a densidade de spin sai do plano com grande contribuição $\pi$ nos ligantes $O$ (Figs. 4.6 b e d). 

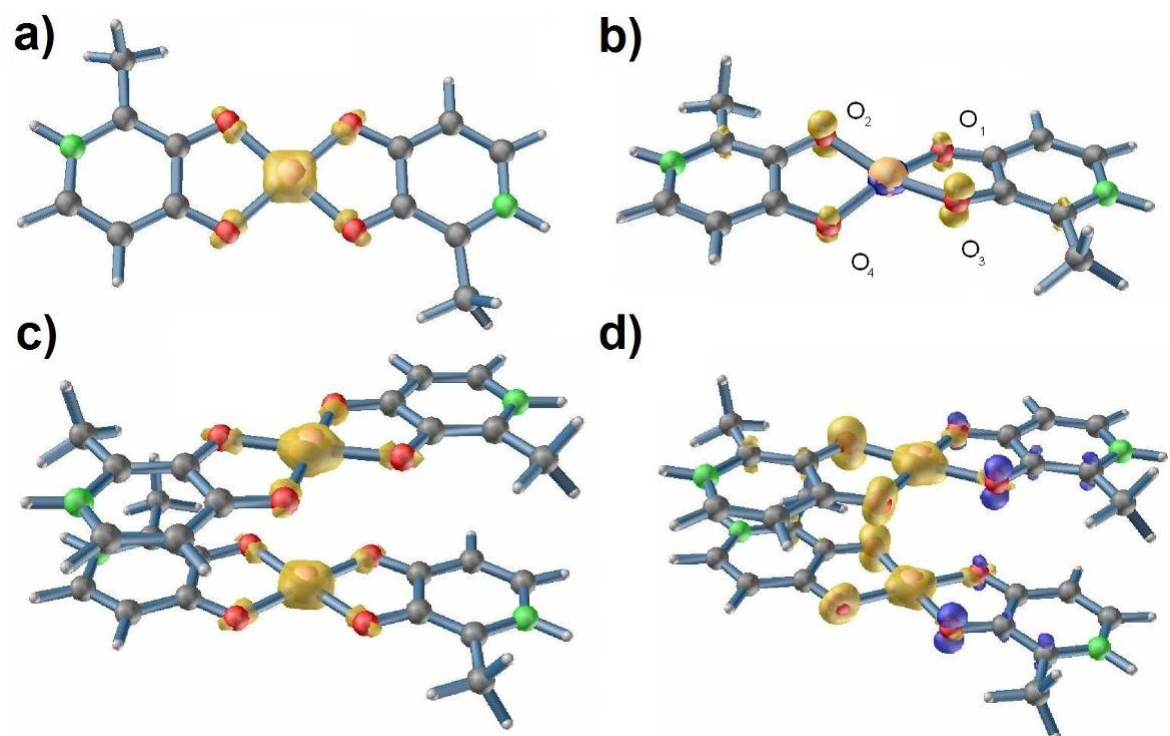

d)

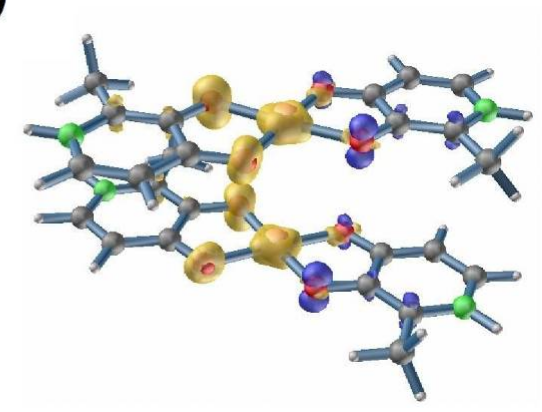

Figura 4.6: Diferença de densidade de spin $(\Delta \rho)$ para o a) $[\mathrm{Hy}-\mathrm{Cu}-\mathrm{Hy}]$; b) $[\mathrm{Hy}-\mathrm{Cu}-\mathrm{Hy}]^{2+}$; c) $\left.[\mathrm{Hy}-\mathrm{Cu}-\mathrm{Hy}]_{2} ; \mathrm{d}\right)[\mathrm{Hy}-\mathrm{Cu}-\mathrm{Hy}]_{2}^{4+}$.

As diferenças em energia com relação à coordenação e o estado de carga para o estado ferromagnético e antiferromagnético são apresentados na tabela 4.6. Vemos que no caso da estrutura planar com carga total +4 e o $\Delta \mathrm{E}$ é de $0.45 \mathrm{eV}$. Para a configuração planar com carga +2 e a diferença em energia diminui para $0.39 \mathrm{eV}$. Quando distorcemos a geometria esta diferença em energia chega a $0.1 \mathrm{eV}$. Observamos assim a importância do estado de carga na geometria e consequentemente para que ocorra o acoplamento ferromagnético.

Em resumo, pelos estudos apresentados nesta seção verificamos que a estabilização ferromagnética é verificada quando o sistema tem uma carga residual diferente de zero, o que gera distorções estruturais repercutindo na densidade de spin que "salta" para fora do plano entre as bases. 
Tabela 4.6: Diferença em energia total $(\Delta \mathrm{E})$ para as configurações ferromagnética e antiferromagnética para diferentes coordenações (quadrado planar e quadrado planar distorcida) e diferentes estados de cargas.

\begin{tabular}{lll}
\hline Geometria & Carga & $\Delta \mathrm{E}(\mathrm{eV})$ \\
\hline Quadrado Planar & $(e)$ & \\
Quadrado Planar & +4 & 0.45 \\
Quadrado Planar Dist. & +4 & 0.39 \\
Quadrado Planar & 0 & 0.11 \\
\hline
\end{tabular}

\subsubsection{Estudo do M-DNA com o backbone}

A primeira etapa para o estudo da inserção do backbone foi utilizar os resultados de raiox para o ligante hidroxipiridona isolado [54], isto é, sem a presença do íon Cu (Fig 1.12). Utilizamos esta estrutura como ponto de partida, retirando os dois átomos de $H$ da carbonila e adicionamos um íon $\mathrm{Cu}^{2+}$. Realizamos a completa relaxação estrutural. A figura 4.7 mostra o resultado final obtido onde as distâncias Cu-L são de $\approx 1.969$ e 1.944 A. Estas distâncias são semelhantes àquelas obtidas para as $[\mathrm{Hy}-\mathrm{Cu}-\mathrm{Hy}]$ com a carga 0 e. O ângulo diedral $\mathrm{O}_{4}$ no cristal foi de $41.6^{\circ}$ onde não havia a presença do íon $C u$ e no nosso estudo, com a adição do $C u$, foi de $12^{\circ 1}$.

A segunda etapa foi adicionar esta última estrutura relaxada (Fig. 4.7) em uma base natural de DNA. Utilizamos como modelo o cristal de DNA da estrutura 3IXN [137], fizemos o recorte do dímero saturando a ligação do backbone com átomos de $H$ e introduzimos dois cátions $\mathrm{Na}^{+}$a distância de $2.3 \AA$ dos sítios de $O$ da ligação fosfodiester [138]. Inserimos a estrutura otimizada do monômero de hydroxipiridona com o backbone (Fig. 4.7) na estrutura 3IXN. As bases de hidroxipiridona são maiores que as bases naturais de DNA, desta forma foi preciso afastar as ligações do backbone. Como estamos simulando apenas um dímero

\footnotetext{
${ }^{1}$ Não realizamos o estudo partindo da coordenação quadrado planar.
} 
de [M-DNA] interligado pelo backbone esta alteração no diâmetro da estrutura não gera restrições no sistema estudado. Realizamos os estudos com as configurações de spin 0 e $1 \hbar$ com total relaxação estrutural e também com um vínculo na distância $C u-C u$ de $3.6 \AA$.

A figura 4.8 apresenta os resultados obtidos para a configuração de spin $1 \hbar$. As distâncias $\mathrm{Cu}-\mathrm{L}$ são semelhantes das bases isoladas neutras sendo $\approx 1.963 \AA$ e $1.936 \AA$. A estrutura com total relaxação estrutural apresentou a distância $4.37 \AA$ o que indica que a presença das demais bases empilhadas são importantes para a estabilização, além do que neste estudo não há correções de van der Walls consideradas importantes para a estabilização deste sistema [139]. Desta forma consideramos os resultados para os cálculos com a restrição $C u-C u$ em 3.6 Å mais adequados. Nesta condição estrutural a configuração ferromagnética é $0.4 \mathrm{eV}$ mais estável que a antiferromagnética. O ângulo de torção é de $5.11^{\circ}$.

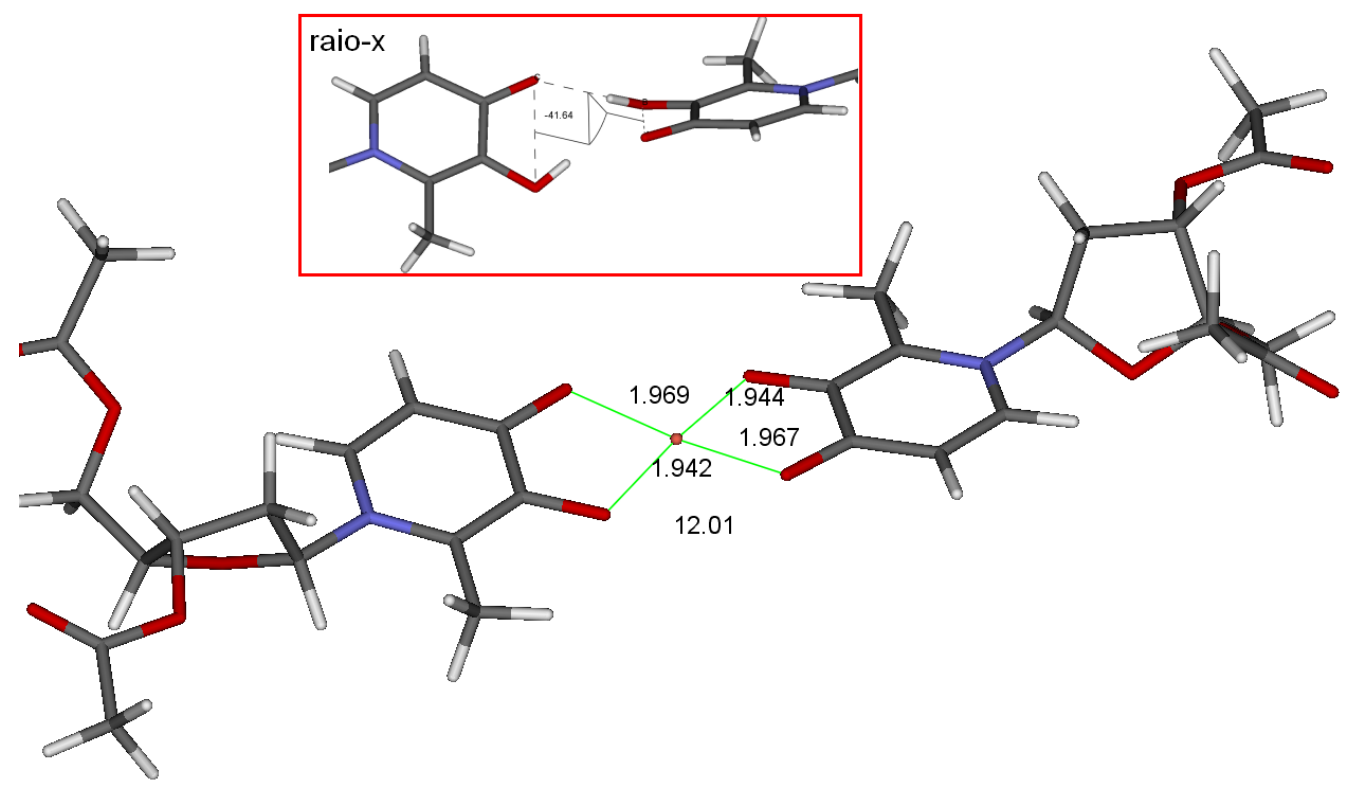

Figura 4.7: Representação da estrutura otimizada para o monômero ligado ao backbone com as distâncias de ligação $\mathrm{CuL}$ em $\AA$ e o ângulo diedral $\mathrm{O}_{4}$ de $12^{\circ}$. Em destaque o ângulo diedral da estrutura cristalográfica sem o íon $C u$. 


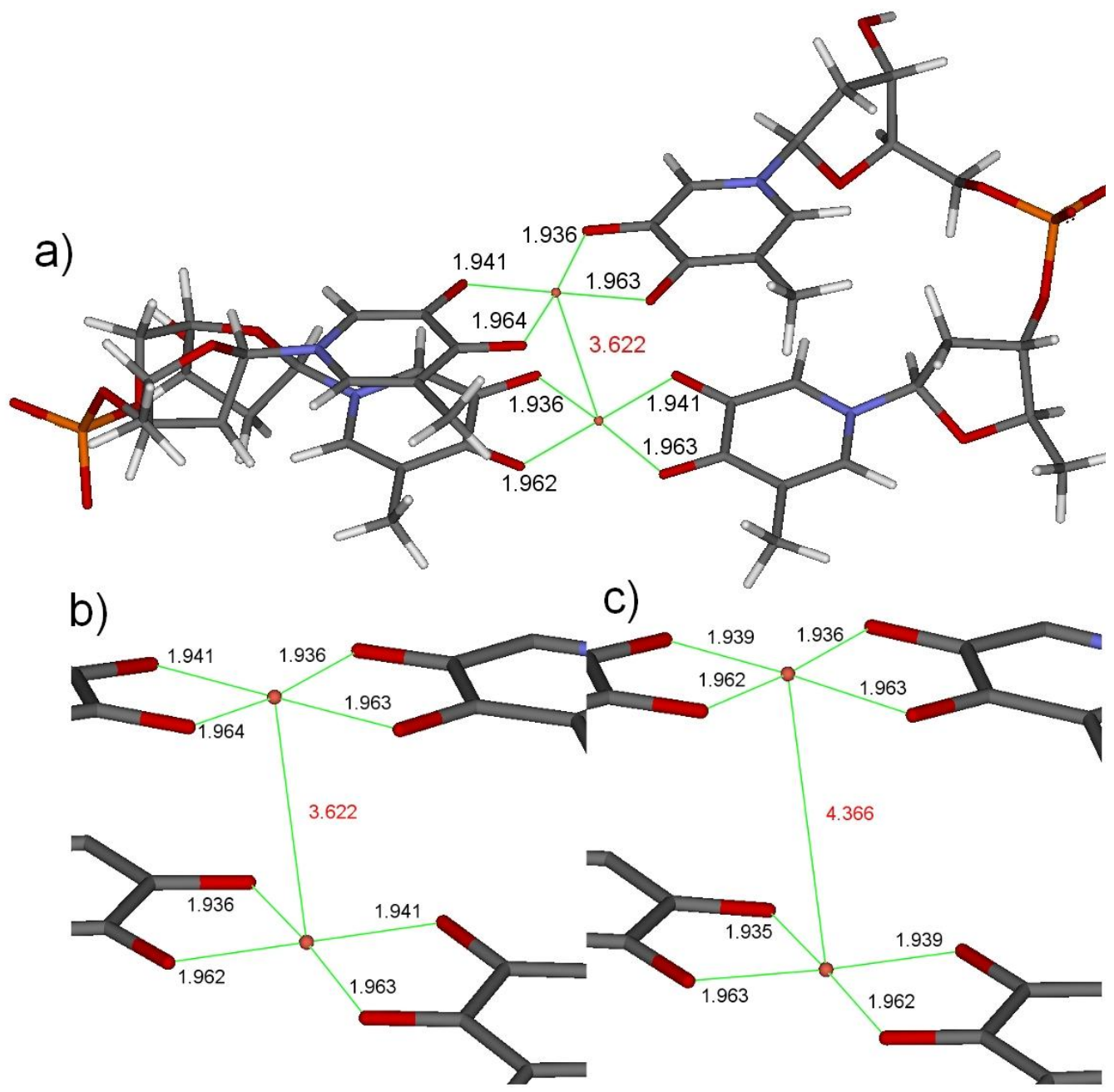

Figura 4.8: Estruturas do dímero interligado pelo backbone com spin total $1 \hbar$. a) Estrutura otimizada com o vínculo entre os sítios de $C u$ em $3.6 \AA$ b) Detalhe das distâncias de ligação Cu-L para o estudo com o vínculo entre os sítios de $C u$ em $3.6 \AA$ c) Detalhe das distâncias de ligação $\mathrm{Cu}-\mathrm{L}$ para o estudo com total relaxação estrutural. 


\section{Capítulo 5}

\section{Conclusões}

\section{Bases de Schiff e proteína albumina}

Neste trabalho realizamos um estudo sistemático de duas séries de bases de Schiff complexadas com $\mathrm{Cu}$ com potencial aplicação tecnológica e farmacológica. Com relação às propriedades estruturais encontramos que as distâncias Cu-L são semelhantes para os vários complexos estudados. Verifica-se a coordenação quadrado planar para dois oxindóis e com alguma distorção tetraédrica para os demais complexos com maior ângulo de torção de $28^{\circ}$. Mostramos, através da análise da energia de ligação Cu-L, que os complexos são estáveis (no vácuo, como aqui estudado) com variação de no máximo $1.9 \mathrm{eV}$ na série toda. Em particular, o complexo $[C u(\text { dachist })]^{2+}$ (tetra-4), apresentou maior energia de ligação, de forma que o ligante parece 'proteger' ou envolver o íon $C u$ mais eficientemente que os demais ligantes. Esta característica estrutural e energética pode estar relacionada à pequena atividade biológica (atividade SOD e geração de danos oxidativos) observada para este complexo.

No presente trabalho procuramos também elucidar o intrincado problema do equilíbrio competitivo entre as bases de Schiff e a proteína albumina pelo íon $C u$ procurando explicação a diferenciada característica do complexo $\left[\mathrm{Cu} \text { (apyhist) } \mathrm{H}_{2} \mathrm{O}\right]^{2+}$ (tri-1) que interage apenas com o sítio não específico da cis-34 por $C u$. Nossa hipótese inicial era de que haveria uma grande influência da coordenação $\mathrm{Cu}-\mathrm{L}$, sendo que o complexo apyhist poderia apre- 
sentar propriedades estruturas ou eletrônicas diferenciadas dos demais complexos como, por exemplo, ser bastante estável em uma conformação que favorecesse o estado reduzido e assim tivesse maior interação com o $S$ da cis-34. Porém as propriedades eletrônicas e estruturais aqui investigadas não foram capazes de responder esta questão. Propomos, então, uma outra explicação baseados em um conjunto de fatores para o comportamento diferenciado do tri-1. Verificamos que as características externas à esfera de coordenação parecem exercer maior influência neste tipo de interação. Entre as características observadas estão: a) o número de sítios de coordenação; b) as restrições estéricas do sítio da cis-34; c) a polaridade dos grupos do ligante. O complexo deve possuir estrutura mais planar e provavelmente necessite de um sítio de coordenação desimpedido para que o $C u$ interaja com o $S$ da cis-34. Os ligantes tridentados possibilitam um sítio de coordenação lábil na esfera de coordenação do cobre. Assim, compostos tetradentados apresentam maior impedimento o que deve reduzir as chances de interação. Outro fator importante diz respeito à estrutura eletrônica onde observamos que compostos com maior polaridade provavelmente possuem melhores condições de interação, passando assim a atuar algum mecanismo de 'ancoramento' na superfície da cavidade da proteína para que o $C u$ seja transferido. Desta forma as características eletrônicas da cavidade da cis-34 e do tri-1 com caráter polar/apolar pode se ajustar com numa espécie de reconhecimento molecular. Entretanto esta última hipótese aqui levantada requer para a sua confirmação, de um estudo de dinâmica molecular clássica que colocamos como perspectiva de trabalho futuro.

\section{M-DNA}

Neste trabalho realizamos estudos em bases modificadas de DNA (hidroxipiridona) complexadas com $C u$. Medidas por EPR e CD mostraram que o $C u$ se insere entre as bases modificadas e estes íons acoplam ferromagneticamente entre uma sequência de até cinco bases. As bases isoladas apresentam coordenação quadrado planar e não exibem acoplamento magnético sendo que a interação entre os planos das bases são magneticamente independentes. Ao 
retirar um elétron do sistema observamos a preferência pelo estado ferromagnético com a coordenação quadrado planar e ao retirar dois elétrons a preferência magnética ocorre com a quebra da simetria quadrado planar, quando os orbitais fora do plano passam a introduzir uma interação entre as bases empilhadas adjacentes. Ao adicionar o backbone, a estrutura ferromagnética relaxa em uma conformação quadrado planar com pequena distorção tetraédrica (com ângulo de torção $\mathrm{O}_{4}$ de $5.11^{\circ}$ ). Nos dois casos verificamos uma tendência de estabilidade para o acoplamento ferromagnético. 


\section{Apêndice A}

\section{Gradiente de Campo Elétrico no}

\section{Núcleo}

As interações hiperfinas ocorrem quando núcleos atômicos que possuem momentos elétricos e magnéticos interagem com campos elétricos e magnéticos internos do próprio átomo, molécula ou cristal. Estas interações geram um desdobramento na energia nuclear e podem ser detectadas por técnicas espectroscópicas [140]. Dentre as diversas interações hiperfinas destacamos a interação de quadrupolo elétrico nuclear (NQI), entre o momento de quadrupolo elétrico nuclear e o gradiente de campo elétrico no núcleo (GCE), que será estudada neste trabalho.

A técnica nuclear EPR é uma das mais utilizadas para o estudo do ambiente de coordenação do $\mathrm{Cu}^{2+}$. Entretanto, técnicas que fornecessem quantidades de quadrupolo nuclear de sítios próximos ao metal podem auxiliar na elucidação de determinada estrutura [141]. Temos como exemplo a molécula de imidazol, presente na histamina ou no aminoácido histidina, que é um dos ligantes biológicos encontrados na coordenação de sítios de proteínas com o $C u$ [112]. Não há resolução suficiente no espectro de EPR para determinar o ambiente químico do amino do imidazol [125]. Apesar do amino não estar diretamente coordenado com o metal, a sua vizinhança é sensível a presença deste metal mas seus parâmetros qua- 
drupolares elétricos nucleares podem ser obtido por técnicas como o ESEEM (Electron Spin Echo Envelope Modulation) [141]. Esta informação é importante para investigar a formação de ligações de hidrogênio neste sítio e também se uma ou mais moleculas de imidazol está coordenada com o $C u^{1}[90,125,142,143]$. Nesta seção estudamos a quantidade hiperfina gradiente de campo elétrico (GCE) os sítios de $N$ e de $O$ e também no $C u$.

Nesta seção apresentamos de forma bastante breve as bases teóricas do cálculo do GCE. Uma descrição mais aprofundada pode ser encontrada nas referências [140,144, 145]. A Hamiltoniana de interação de quadrupolo nuclear é dada por

$$
H_{Q}=-\frac{1}{6} \sum_{i} \sum_{j} \nabla_{i j} \mathbf{E} \int_{V n u} \rho_{R}(\mathbf{r})\left(3 x_{i} x_{j}-r^{2} \delta_{i j}\right) d^{3} r=-\frac{1}{6} \sum_{i j} V_{i j} Q_{i j}
$$

Onde $Q_{i j}$ é o tensor momento de quadrupolo elétrico nuclear

$$
Q_{i j}=\int_{V n u}\left(3 x_{i} x_{j}-r^{2} \delta_{i j}\right) \rho(\mathbf{r}) d^{3} r
$$

O tensor GCE é simétrico e dado por

$$
V_{i j}=\nabla_{i j} \mathbf{E}(0)=\frac{\partial^{2} V(0)}{\partial x_{i} \partial x_{j}}
$$

Os 9 elementos do tensor $(3 \times 3) V_{i j}$ são especificados por 6 elementos em uma matriz simétrica. Através de uma rotação do sistema de eixos, esta matriz pode ser diagonalizada, e

\footnotetext{
${ }^{1} \mathrm{O}$ uso de quantidades hiperfinas como o GCE pode ser útil para validar um 'corte' em estruturas modelo teóricas, no qual sabemos se o sítio de estudo está corretamente descrito se ao adicionarmos mais átomos o sítio ativo não modifica a estrutura eletrônica local.
} 
esta transformação leva ao chamado "sistema de eixos principais". A diagonalização produz apenas 3 elementos independentes (auto valores). No núcleo vale a equação de Laplace $\nabla^{2} V(\mathbf{r})=0$, ou $V_{x x}+V_{y y}+V_{z z}=0$. Portanto temos apenas dois elementos independentes, que chamaremos de GCE ou $V_{z z}$ que é a componente de maior módulo dentre os $V_{i i}$ e o parâmetro de assimetria $(\eta)$ dado por

$$
\eta=\frac{\left|V_{X X}-V_{Y Y}\right|}{\left|V_{Z Z}\right|}
$$

Note que $0 \leq \eta \leq 1$.

Fisicamente, a interpretação do tensor gradiente de campo elétrico $V_{i i}$ não é equivalente a um vetor convencional, mas podemos visualizar a direção de $V_{z z}$ (dado pelo autovetor correspondente) como aquele que informa a maior variação do campo elétrico (gradiente do campo elétrico). O parâmetro de assimetria relaciona o quanto uma distribuição de carga é simétrica. Seu valor varia de zero (totalmente simétrica) até um. Como exemplo podemos citar um sistema com simetria cilíndrica onde teremos $V_{x x}=V_{y y}$ assim $\eta=0$. Este cálculo necessita de expansões em ondas planas mais extensas (acima de 60Ry para a energia de corte em ondas planas) que para o cálculo, por exemplo, da geometria estrutural e da energia total. Isto porque o GCE é uma quantidade que depende sensivelmente da anisotropia da densidade de carga próxima a um dado núcleo [146].

\section{A.1 Cálculo do Gradiente de Campo Elétrico (GCE) no núcleo}

A tabela A.1 mostra os valores de GCE nos sítios de $N$ para os principais ligantes estudados: piridina, pirazina, imidazol e também para a amônia $\left(\mathrm{NH}_{3}\right)$. Os resultados obtidos para todos os ligantes estão em excelente concordância com os medidos. O módulo do tensor 
GCE $\left(V_{n n}\right)$ exibe quais são os grupos de orbitais mais reativos para cada molécula. Uma informação importante é a contribuição relativa do orbital não ligante de caráter $\sigma$ também chamado de 'par isolado' e da contribuição ' $\pi$ ' para cada sítio ligante de $N$. A direção da componente do tensor Vyy está perpendicular a molécula e terá o caráter $\pi$; o Vzz está alinhado na direção do 'par isolado'. O par isolado é o grupo orbital com maior GCE nos $N$, ou seja, apresenta a maior contribuição da variação direcional do campo elétrico neste sítio $^{2}$. Comparando o módulo do Vzz nos sítios de $\mathrm{N}$ dos ligantes $p y, p z$, imid e $\mathrm{NH}_{3}$, o Vzz é aproximadamente $20 \%$ maior o py e no pz. Outro dado importante é a contribuição dos orbitais com caráter $\pi$ perpendiculares ao plano da molécula: na py e na $p z$ a contribuição do Vyy é bastante relevante, sendo 70 a $75 \%$ do Vzz; enquanto no imid a contribuição é menor, sendo apenas 50\%. No imid o $\eta$ é quase zero, ou seja, apresenta simetria cilíndrica o que indica uma maior direcionalidade, enquanto no $p y$ e no $p z$ há uma distribuição entre a componente $\sigma$ e $\pi$.

\section{GCE para o complexo $\left[\mathrm{Cu}(\text { apyhist }) \mathrm{H}_{2} \mathrm{O}\right]^{2+}$}

Na tabela A.2 apresentamos os resultados para o GCE nos sítios de $N$ e $O$ e para o íon $\mathrm{Cu}$ para o complexo $\left[\mathrm{Cu}(\text { apyhist }) \mathrm{H}_{2} \mathrm{O}\right]^{2+}$ (tri-1). As três primeiras colunas representam o complexo em três geometrias de mínimo de energia: (i) coordenação quadrado planar com conformação para baixo (cb); (ii) coordenação quadrado planar distorcida com o conformação 'para cima' (cc) e (iii) com conformação para baixo (cb). O parâmetro de assimetria $(\eta)$ para o íon $C u$ é menor para a coordenação planar, no qual o Vzz é perpendicular ao plano dos ligantes. É interessante verificar a variação do $\eta$ de 0.05 até 0.77 com o posicionamento do ligante $\mathrm{H}_{2} \mathrm{O}$ entre as conformações (Fig. $3.2 \mathrm{~d} e$ e). Os valores de GCE para os ligantes não apresentam modificações significativas para as três conformações de mínimo estrutural. Comparando o GCE nos sítios de $N$ coordenados com o $C u$ e isolados observamos um grande

\footnotetext{
${ }^{2}$ Tomemos como exemplo o orbital $s$, perfeitamente esférico, este não apresenta direção preferencial de GCE. Já o orbital com caráter $\sigma$ apresenta uma direção preferencial de GCE, assim a direção de maior GCE (Vzz) é a direção do par isolado para um dos eixos principais do tensor.
} 
Tabela A.1: Valores experimentais e calculados com o CP-PAW de GCE nos sítios de $N$ para os ligantes piridina, pirazina, imidazol e $\mathrm{NH}_{3}$. Apresentamos também as componentes do tensor GCE $\left(V_{n n}\right)$ em $10^{21} \mathrm{~V} / \mathrm{m}^{2}$ calculados com o CP-PAW para a energia de corte de 90 Ry. $\nu_{Q}=e Q V_{z z} / h(\mathrm{MHz})$ onde $Q$ é o momento de quadrupolo elétrico nuclear para determinado sítio representado pela Eq. A.2.

\begin{tabular}{|c|c|c|c|c|c|c|}
\hline & GCE & $\begin{array}{l}\mathrm{N}_{P y} \\
{[147]}\end{array}$ & $\begin{array}{l}\mathrm{N}_{p z} \\
{[147]}\end{array}$ & $\begin{array}{l}\mathrm{N}_{\text {imid }} \\
{[90]}\end{array}$ & $\begin{array}{l}\mathrm{N}_{\text {amino }} \\
{[90]}\end{array}$ & $\begin{array}{l}\mathrm{N}_{N H_{3}} \\
{[148]}\end{array}$ \\
\hline \multirow[t]{2}{*}{ Experimental } & $\nu_{Q}$ & 4.91 & 5.30 & 4.032 & 2.537 & 4.089 \\
\hline & $\eta$ & 0.396 & 0.49 & 0.12 & 0.178 & \\
\hline \multirow[t]{5}{*}{ PAW } & $\nu_{Q}$ & 5.096 & 5.327 & 4.195 & 2.825 & \\
\hline & $\eta$ & 0.362 & 0.487 & 0.045 & 0.183 & \\
\hline & $\mathrm{Vzz}$ & -10.311 & -10.779 & -8.487 & 2.335 & \\
\hline & Vyy & 7.020 & 8.013 & 4.052 & -5.716 & \\
\hline & $\mathrm{Vxx}$ & 3.291 & 2.766 & 4.435 & 3.382 & \\
\hline
\end{tabular}

aumento do Vzz para o ligante isolado. Este aumento está relacionado a projeção dos orbitais não ligantes disponíveis no ligante isolado. Este efeito é visto também no $\eta$ do $\mathrm{N}_{S c h i f f}$ e do $\mathrm{N}_{\text {imid }}$ que diminuem. Entretanto, no $\mathrm{N}_{p} y$ o $\eta$ aumenta (como é observado com a molécula de $p y$ isolada) devido a grande contribuição do orbital $\pi$.

\section{GCE - Série Oxindol}

Realizamos o estudo do GCE nos sítios de $N$ e $O$ ligantes e no íon $C u$ para os complexos da série dos oxindóis (Tabela A.3). Estes complexos apresentam características estruturais e de coordenação distintas em relação ao tri-1. O Vzz no $C u$ para os complexos apresentam grande variação (maiores que $100 \%)^{3}$ Valores de $\eta$ mais simétricos (próximos a zero) parecem indicar

\footnotetext{
${ }^{3} \mathrm{O}$ cobre possui maiores possibilidades de coordenação visto que para o complexo tri-1 em conformações com diferenças de energia menores que $0.7 \mathrm{kcal} / \mathrm{mol}$ o $\mathrm{V}_{z z}$ varia em torno de $7 \%$ e o $\eta$ varre quase todo o
} 
Tabela A.2: GCE nos sítios de $\mathrm{N}$ e $\mathrm{O}$ ligantes e no $\mathrm{Cu}$ para o complexo $\left[\mathrm{Cu}(\text { apyhist }) \mathrm{H}_{2} \mathrm{O}\right]^{2+}$ (tri-1) e também para o ligante na geometria do complexo e para a geometria di ligante otimizada (OPT). Utilizamos a nomenclatura para os sítios conforme a Fig. 3.2. (i) coordenação quadrado planar (cb) Fig. 3.2 b e e; (ii) coordenação distorcida (cc) Fig. 3.2 c e d; (iii) coordenação distorcida (cb) Fig. 3.2 b e d. Vzz em $10^{21} \mathrm{~V} / \mathrm{m}^{2}$ e corte em energia de 90 Ry para os complexos e de 40 Ry para os ligantes.

\begin{tabular}{|c|c|c|c|c|c|c|}
\hline Sítio & & tri-1 (i) & tri-1 (ii) & tri-1 (iii) & apyhist (ii) & $\operatorname{apyhist}_{(\mathrm{OPT})}$ \\
\hline \multirow[t]{2}{*}{ Cobre } & $\mathrm{V}_{z z}$ & 5.741 & 6.090 & 5.687 & & \\
\hline & $\eta$ & 0.047 & 0.321 & 0.770 & & \\
\hline \multirow[t]{2}{*}{$\mathrm{O}_{\mathrm{H}_{2} \mathrm{O}}$} & $\mathrm{V}_{z z}$ & -17.452 & & -16.591 & & \\
\hline & $\eta$ & 0.571 & & 0.580 & & \\
\hline \multirow[t]{2}{*}{$N_{\text {Schiff }}$} & $\mathrm{V}_{z z}$ & -3.061 & -3.103 & -3.103 & -8.960 & -7.700 \\
\hline & $\eta$ & 0.582 & 0.509 & 0.610 & 0.206 & 0.213 \\
\hline \multirow[t]{2}{*}{$N_{i m i d}$} & $\mathrm{~V}_{z z}$ & 3.334 & 3.313 & 3.370 & -7.061 & -6.209 \\
\hline & $\eta$ & 0.562 & 0.520 & 0.610 & 0.106 & 0.059 \\
\hline \multirow[t]{2}{*}{$N_{p y}$} & $\mathrm{~V}_{z z}$ & -4.118 & -4.199 & -4.256 & -8.781 & -7.792 \\
\hline & $\eta$ & 0.193 & 0.188 & 0.200 & 0.276 & 0.463 \\
\hline \multirow[t]{2}{*}{$N_{\text {amino }}$} & $\mathrm{V}_{z z}$ & -4.410 & -4.389 & -4.449 & -4.661 & -4.619 \\
\hline & $\eta$ & 0.143 & 0.135 & 0.170 & 0.218 & 0.211 \\
\hline
\end{tabular}


para coordenações mais simétricas como a quadrado planar. Para os ligantes imínicos o Vzz varia em mais de 90\%. Para os ligantes de mesmo grupo funcional há maior concordância, embora exceções são encontradas como no caso do $\mathrm{N}_{\text {Schiff }}$ do complexo oxi-4 que é $20 \%$ menor que o Vzz do complexo oxi-3.

Para os ligantes $O$ o comportamento do Vzz é dependente da hibridização e da forma de coordenação com o cobre. $\mathrm{O}$ oxigênio do ligante $\mathrm{H}_{2} \mathrm{O}$ apresenta $\mathrm{Vzz} \approx-17.10^{21} \mathrm{~V} / \mathrm{m}^{2}$ (semelhante à série das piridinas e pirazinas). Na carbonila $(\mathrm{C}=\mathrm{O})$ com coordenação planar e estrutura semelhante apresenta valores da ordem de $9.10^{21} \mathrm{~V} / \mathrm{m}^{2}$ (complexos oxi-1 e oxi-3) e $\eta$ próximo a um. Já para o oxi-2 o Vzz é $30 \%$ maior, como esperado já que a carbonila está a maior distância do $C u$ devido a distorção Jahn Teller.

O complexo oxi-2 tem características bastante peculiares (Fig. 3.21 b). É o único composto com seis ligações com o átomo central e apresenta a geometria quadrado planar com distorção Jahn Teller voltada para os ligantes oxigênios. As distâncias entre os Cu-N são de 2.09 e $2.04 \AA$ e Cu-O de $2.65 \AA$. Este complexo apresenta o maior valor de Vzz para o $\mathrm{Cu}$ entre os complexos $\left(\mathrm{Vzz}=-7.23 .10^{21} \mathrm{~V} / \mathrm{m}^{2}\right)$ e a componente Vzz do tensor está orientado para o oxigênio da carbonila.

Não há, ainda, dados experimentais de GCE para os sítios das bases de Schiff estudados aqui. Comparando a ordem de grandeza dos resultados para os $N$ ligantes da metalo proteína azurina, que é coordenada através de dois resíduos de histidina e o $S$ da cisteína, verificamos que as estimativas são razoáveis ${ }^{4}$ já que os valores para os $\mathrm{N}$ do complexo (oxi-2) são $4.68 .10^{21} \mathrm{~V} / \mathrm{m}^{2}$ e para os iminos da azurina experimentalmente temos 5.1 a $5.4 .10^{21} \mathrm{~V} / \mathrm{m}^{2}$ $[149,150]$.

espectro de valores (de zero até um) (tabela A.2).

${ }^{4}$ Note que o sítio metálico de uma proteína está imerso em um ambiente químico próprio. 
Tabela A.3: GCE nos sítios ligantes e no $\mathrm{Cu}$ para o corte em ondas planas para $70 \mathrm{Ry}$. Vzz em $10^{21} \mathrm{~V} / \mathrm{m} 2$. [Cu(isapn) $] 2+$ (oxi-1), [Cu(isaepy) 2$] 2+$ (oxi-2), [Cu(isaenim) $] 2+$ (oxi-3), $[\mathrm{Cu}($ enim $) \mathrm{H} 2 \mathrm{O}] 2+($ oxi-4)

\begin{tabular}{|c|c|c|c|c|c|}
\hline & Sítios & oxi-1 & oxi-2 & oxi-3 & oxi-4 \\
\hline \multirow[t]{2}{*}{$\mathrm{Cu}$} & $\mathrm{V}_{z z}$ & -5.88 & -7.23 & 3.11 & 3.46 \\
\hline & $\eta$ & 0.11 & 0.25 & 0.63 & 0.43 \\
\hline \multirow[t]{2}{*}{$\mathrm{O}=\mathrm{O} / \mathrm{H}_{2} \mathrm{O}$} & $\mathrm{V}_{z z}$ & -8.94 & -13.35 & -9.73 & -17.38 \\
\hline & $\eta$ & 0.95 & 0.17 & 0.89 & 0.50 \\
\hline \multirow[t]{2}{*}{$\mathrm{N}_{\text {Schiff }}$} & $\mathrm{V}_{z z}$ & -3.49 & -4.68 & -3.89 & -2.85 \\
\hline & $\eta$ & 0.44 & 0.36 & 0.60 & $\begin{array}{r}0.82 \\
\text { (semi- } \\
\text { estrutura) }\end{array}$ \\
\hline \multirow{2}{*}{$\mathrm{N}_{\text {Schiff }}$} & $\mathrm{V}_{z z}$ & & & -3.74 & -4.60 \\
\hline & $\eta$ & & & 0.57 & 0.30 \\
\hline \multirow[t]{2}{*}{$\mathrm{N}_{i m i d}$} & $\mathrm{~V}_{z z}$ & & & 3.44 & 3.33 \\
\hline & $\eta$ & & & 0.97 & 0.85 \\
\hline \multirow[t]{2}{*}{$\mathrm{N}_{p y}$} & $\mathrm{~V}_{z z}$ & & -4.58 & & \\
\hline & $\eta$ & & 0.15 & & \\
\hline \multirow[t]{3}{*}{$N_{\text {amino }}$} & $\mathrm{V}_{z z}$ & & & -4.56 & -4.44 \\
\hline & $\eta$ & & & 0.22 & 0.26 \\
\hline & & & & (isatina) & \\
\hline \multirow[t]{2}{*}{$N_{\text {amino }}$} & $\mathrm{V}_{z z}$ & -6.74 & & -6.73 & \\
\hline & $\eta$ & 0.11 & & 0.11 & \\
\hline
\end{tabular}




\section{Apêndice B}

\section{B.1 Testes de Convergência}

Realizamos alguns testes de convergência para mais de um ponto $k$, para o tamanho da célula unitária e para a escolha da energia de "corte" (truncamento) para a expansão da base em ondas planas, com o objetivo de saber a partir de qual valor o incremento do número de ondas planas não alteraria os resultados [71]. O CP-PAW é um método de célula periódica repetida no espaço recíproco diferente das abordagens de espaço real como a do código Gaussian [72]. No CP-PAW o estudo de sistemas isolados, como uma molécula ou um "cluster" é realizado através de uma "super célula" que é repetida formando-se um cristal infinito. Para tanto, é necessário gerar uma célula unitária grande o suficiente para que as moléculas de células vizinhas não interajam entre si. Tanto na literatura quanto em nossos estudos apontam a necessidade de criar células unitárias com no mínimo 6 Å de vácuo [151]. Outra funcionalidade adotada no cálculo foi o uso do recurso de "cancelamento de imagens eletrostáticas" para anular as interações Coulombianas de longo alcance entre as moléculas e suas imagens periódicas [151]. Portanto alguns testes utilizando diferentes tamanhos de células unitárias foram realizados para verificar tal cancelamento. 


\section{Energia de corte e dispersão dos auto-valores}

Para o cálculo de molécula isolada espera-se que não haja interação entre as imagens periódicas e que não ocorra a dispersão nos auto-valores em relação às diferentes direções da célula unitária. Realizei o cálculo para o complexo tri-1 com até oito pontos k's para a célula unitária 15x20x11 Å. Verificamos que não houve dispersão dos auto-valores, portanto, o sistema estva devidamente isolado.

Outro teste realizado foi a escolha da energia de "corte" (truncamento) para a expansão da base em ondas planas. A expansão foi realizada para o corte de 40 Ry. Para os testes realizados com o complexo (tri-1) aumentamos a precisão do cálculo em até 90 Ry. Observamos que em 40 Ry a convergência está em $10^{-5} \mathrm{H}$ que já é o suficiente para o estudo da energética dos complexos.

\section{Teste de convergência para diferentes tamanhos de células unitárias}

O cálculo do gradiente de campo elétrico (GCE) no núcleo é um parâmetro bastante sensível a modificações estruturais e a convergência da densidade eletrônica [152]. Assim podemos utilizá-lo também como ferramenta de convergência de densidade eletrônica local. Realizamos desta forma estudos de GCE para o complexo tri-1 modificando o tamanho da célula unitária gradualmente nas direções x, y e z e verificamos os efeitos do GCE nos ligantes e no Cu. A tabela B.1 apresenta os resultados obtidos. Verifica-se que os valores de GCE são semelhantes com variações de 0.02 em unidades de $\mathrm{V}_{z z}{ }^{1}$ Desta forma a célula unitária adotada de 15x20x11 Å foi adequada para a análise dos complexos. Podemos também comparar a convergência da energia total em função do tamanho da célula unitária onde podemos notar que não há diferenças substanciais ao modificar a célula unitária.

\footnotetext{
${ }^{1}$ Realizamos a relaxação estrutural em cada um dos cálculos.
} 


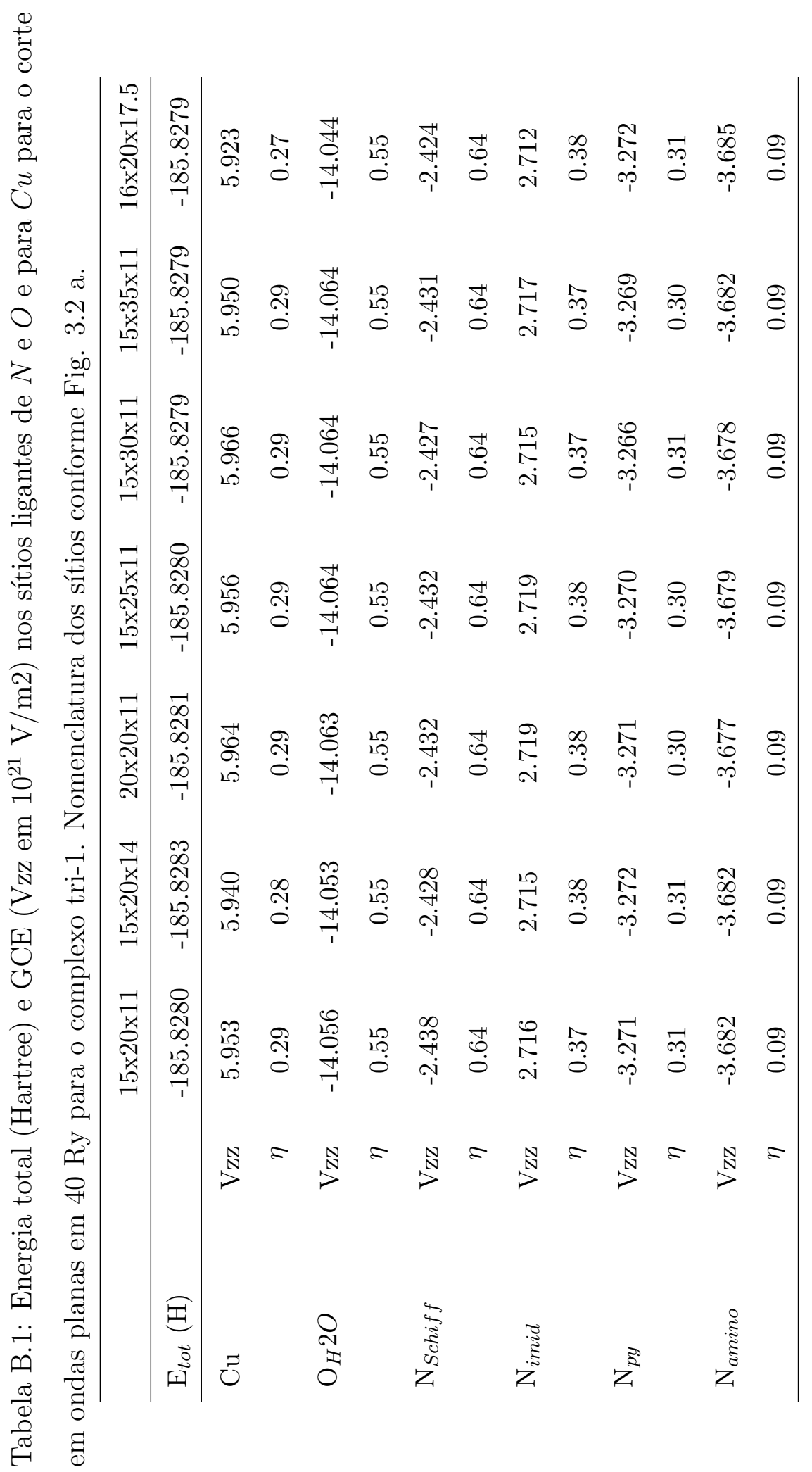




\section{B.2 Estudo dos complexos $\left[\mathrm{Cu}\left(\mathrm{H}_{2} \mathrm{O}\right)_{n}\right]^{2+}$}

Apresentamos os resultados para os complexos $\left[\mathrm{Cu}\left(\mathrm{H}_{2} \mathrm{O}\right)_{n}\right]^{2+}$ para as coordenações quadrado planar $(n=4)$, quadrado piramidal $(n=5)$ e octaédrica com distorção tetragonal $(n=6)$. A tabela B.2 apresenta a energia total, a energia de ligação $\mathrm{Cu}-\mathrm{L}$ e os autovalores HOMO e LUMO para os complexos. Comparando os valores de $\mathrm{E}_{l i g}$ calculados no presente trabalho com a Ref. [153], nossos resultados são em média $23 \mathrm{kcal} / \mathrm{mol}$ mais ligados que aqueles calculados com o funcional B3LYP e a base $6-311 G^{++}(d, p)$, entretanto a diferença de energia entre as diferentes coordenações apresentam variações pequenas de no máximo 2 $\mathrm{kcal} / \mathrm{mol}$, mostrando que apesar do uso de funcionais $\mathrm{E}_{x c}$ diferentes, as diferenças energéticas são semelhantes.

Tabela B.2: Energia de ligação, autovalores e gap de energia para os complexos $\left[\mathrm{Cu}(\mathrm{H} 2 \mathrm{O})_{n}\right]^{2+}$.

\begin{tabular}{lcccc}
\hline $\mathrm{E}_{\text {total }}(\mathrm{H})$ & $\begin{array}{c}\mathrm{E}_{\text {lig }} \\
(\mathrm{kcal} / \mathrm{mol})\end{array}$ & $\begin{array}{c}\text { HOMO } \\
(\mathrm{eV})\end{array}$ & $\begin{array}{c}\text { LUMO } \\
(\mathrm{eV})\end{array}$ \\
\hline & & & \\
{$\left[\mathrm{Cu}\left(\mathrm{H}_{2} \mathrm{O}\right)_{6}\right]^{2+}$} & -154.9549 & -380.26 & -14.93 & -14.458 \\
{$\left[\mathrm{Cu}\left(\mathrm{H}_{2} \mathrm{O}\right)_{5}\right]^{2+}$} & -137.5488 & -360.30 & -15.95 & -15.147 \\
{$\left[\mathrm{Cu}\left(\mathrm{H}_{2} \mathrm{O}\right)_{4}\right]^{2+}$} & -120.1336 & -334.63 & -16.86 & -15.909 \\
\hline
\end{tabular}




\section{B.3 Lista dos Aminoácidos}

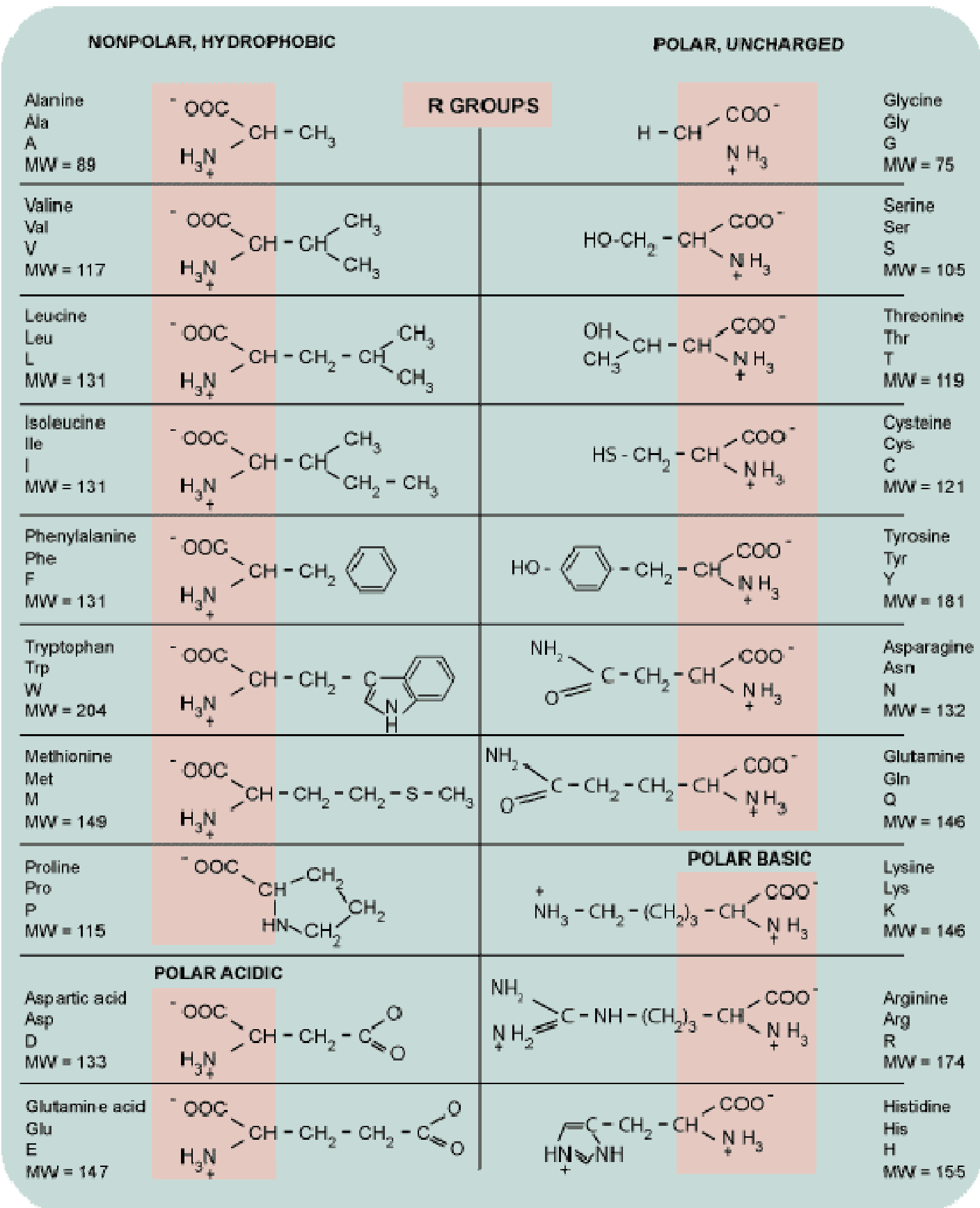

Figura B.1: Representação esquemática dos vinte aminoácidos presentes no ser humano [154]. 


\section{Lista de Publicações}

"Electric field gradient and electronic properties of crown thioether compound" F.C.D.A. Lima, R.R. Nascimento, M.B. Gonçalves, S. Cottenier, M.J. Caldas, H. M. Petrilli; Hyperfine Interactions aceito para publicação (2010).

"Spectroscopic Characterization of Schiff base-Copper Complexes Immobilized in Smectite Clay" P.M. Dias, L. Kinouti, V.R.L. Constantino, A.M.D.C. Ferreira, M.B. Gonçalves, R.R. Nascimento, H.M. Petrilli, M.J.Caldas R.C.G. Frem; Quimica Nova (no Prelo) 2010.

"Interactions of di-imine copper(II) complexes with albumin:competitive equilibria, promoted oxidative damage and DFT studies" M.A.A. Azzellini, M.P. Abbot, A.Machado, L.C.Garcia, G.F. Caramori, M.B. Gonçalves, H.M. Petrilli, A.M.D.C.Ferreira; Journal of the Brazilian Chemical Society, V. 21, n. 7 p. 1303, (2010).

"Oxindole-Schiff base copper(II) complexes interactions with human serum albumin: spectroscopic, oxidative damage, and computational studies" V.C. Silveira, G.F. Caramori, M.P. Aboott, M.B.Gonçalves, H.M. Petrilli, A.M.D.C. Ferreira; Journal of Inorganic Biochemistry, v. 103, p. 1331, (2009).

"Ab initio study of the EFG at the N sites in imidazole" M.B. Gonçalves, R.D. Felice, O.Kh. Poleshchuk, H.M. Petrilli Hyperfine Interactions; v. 181, p. 53, (2008). 
APÊNDICE B. 
Anexo I 
Anexo II 
Anexo III 


\section{Lista de Tabelas}

1.1 Medidas das constantes de estabilidade relativa $\left(\mathrm{K}_{C u L}\right)$ dos complexos listados na coluna 1 frente à albumina obtidas por CD $[10,16]$. A banda na região de $\lambda=564 \mathrm{~nm}$ indica a coordenação do íon $C u$ no sítio N-terminal. O erro experimental é \pm 1 . [38]. . . . . . . . . . . . . . . . . . . . . . . 15

3.1 Energia total em Hartree (H) para as conformações (cb) e (cc) e coordenações do tri-1. . . . . . . . . . . . . . . . . . . . . . . . . . . . . . .

3.2 Distâncias $\mathrm{Cu}$-ligante $(\mathrm{Cu}-\mathrm{L})$ onde o subscrito representa o grupo funcional pertencente ao sítio do $N$; ângulo de torção entre os sítios de $N$ e o $C u$ e o ângulo entre os ligantes $N$ (ângulo de abertura conforme apresentado na Fig. 3.3 c) para o complexo tri-1 calculado e para as estruturas cristalográficas. Entre parênteses a incerteza experimental e as conformações de mínimo estrutural $(\mathrm{cb})$ e $(\mathrm{cc}) \ldots \ldots \ldots \ldots \ldots$

3.3 Distâncias metal ligante, ângulo de abertura e de torção dos complexos tridentados estudados para os mínimos conformacionais $(c b)$ e $(c c)$ (conforme nomenclatura das Figs. 3.2 e 3.3) . . . . . . . . . . . .

3.4 Diferença em energia entre as conformações de mínimo local (cc) e (cb) para os dois mínimos locais e a energia de referência kT à temperatura ambiente.

3.5 Energias de deformação $\left(\mathrm{E}_{\text {def }}\right)$ e energia de ligação $\left(\mathrm{E}_{l i g}\right)$ para os complexos no estado oxidado e reduzido. 
3.6 Distâncias de ligação $(\mathrm{Cu}-\mathrm{L})$ onde $\mathrm{Cu}-\mathrm{N}_{e n}, \mathrm{Cu}-\mathrm{N}_{p n}, \mathrm{Cu}-\mathrm{N}_{p y / p z}$ e $\mathrm{Cu}-\mathrm{N}_{h i s t / p i r}$ representam os sítios de $N$ dos ligantes en, pn, py, pz, hist e pirrol respectivamente; Ângulo de torção $N_{4}$; Os valores entre parênteses são referentes aos dados cristalográficos para o ligante pupy [117]. (*) Ângulo de torção referente a estrutura dimérica. . . . . . . . . . . . . . . . . . . . .

3.7 Energia total (Hartree), autovalores para o HOMO e para o LUMO e diferença de energia entre o HOMO e o LUMO e entre os orbitais com caráter $\pi$ e $\pi *$ para os complexos na forma oxidada e reduzida. . . . . . . . . . . . . .

3.8 Energia Total (Hartree), energia de deformação e energia de ligação para os complexos, ligantes (na conformação do complexo) e ligantes com as posições atômicas otimizadas (representado por 'OPT'). . . . . . . . . . . .

3.9 Distâncias de Cu-L obtidas com os métodos: (funcional/base) CP-PAW(PBE/PAW) e G03(BP86/TZVP) entre parênteses para os complexos $[C u(\text { isapn })]^{2+}$ (oxi1), $\left[\mathrm{Cu}(\text { isaepy })_{2}\right]^{2+}$ (oxi-2), $[\mathrm{Cu}(\text { isaenim })]^{2+}$ (oxi-3) e $\left[\mathrm{Cu}(\text { enim }) \mathrm{H}_{2} \mathrm{O}\right]^{2+}$ (oxi-4). 79

3.10 Energia total, autovalores dos orbitais de fronteira e gap HOMO-LUMO para os complexos, para os ligantes na conformação do complexo e para os ligantes com a estrutura relaxada (OPT) obtidos com o código computacional CPPAW. $[C u(\text { isapn })]^{2+}$ (oxi-1), $\left[C u(\text { isaepy })_{2}\right]^{2+}$ (oxi-2), $[C u(\text { isaenim })]^{2+}$ (oxi-3) e $\left[\mathrm{Cu}(\text { enim }) \mathrm{H}_{2} \mathrm{O}\right]^{2+}($ oxi-4) . . . . . . . . . . . . . . . . . . 80

3.11 Energias de deformação $\left(\mathrm{E}_{\text {def }}\right)$ e energias de ligação $\left(\mathrm{E}_{l i g}\right)$ para o PAW (funcional/base) PBE/PAW e para G03 BP86/TZVP (entre parênteses). [Cu(isapn) $]^{2+}$ (oxi-1), $\left[\mathrm{Cu}(\text { isaepy })_{2}\right]^{2+}$ (oxi-2), $[\mathrm{Cu}(\text { isaenim })]^{2+}$ (oxi-3) e $\left[\mathrm{Cu}(\text { enim }) \mathrm{H}_{2} \mathrm{O}\right]^{2+}$

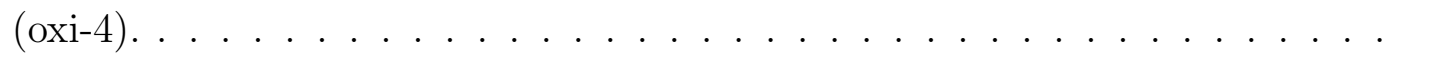

3.12 Valores do módulo do momento de dipolo (em Debye) calculados para os complexos com o funcional/base BP86/TZVP. . . . . . . . . . . . . 
4.1 Energia total (em Hartree) e diferença de energia gap HOMO-LUMO para o monômero $[\mathrm{Hy}-\mathrm{Cu}-\mathrm{Hy}]$ e para o dímero $[\mathrm{Hy}-\mathrm{Cu}-\mathrm{Hy}]_{2}$ em diferentes configurações de spin total. . . . . . . . . . . . . . . . . . . . 100

4.2 Energia total para diferentes configurações de spin para o tetrâmero de [Hy$\mathrm{Cu}-\mathrm{Hy}]_{4} \ldots \ldots \ldots \ldots \ldots$

4.3 Número de ocupação por direção de spin $\left(\mathrm{n}_{u p}\right.$ e $\left.\mathrm{n}_{\text {down }}\right)$ projetada nos sítios de $C u$ nos estudos de spin total 0,1 e $2 \hbar$ para o tetrâmero $[\mathrm{Hy}-\mathrm{Cu}-\mathrm{Hy}]_{4}$ (Fig. 4.1c). As flechas para cima e para baixo indicam o sinal do momento magnético local $\left(\mathrm{m}_{l}\right)$ resultante. . . . . . . . . . . . . . . . . 100

4.4 Auto-valores de energia HOMO e LUMO, gap de energia ( $\left.\mathrm{E}_{H O M O}-\mathrm{E}_{L U M O}\right)$ e cargas eletrônicas projetadas nos sítios de $\mathrm{Cu}$ e $\mathrm{O}$ para as diferentes configurações de geometria, carga e spin. . . . . . . . . . . . . . . . . . . . 103

4.5 Momento magnético local $\left(\mathrm{m}_{l}\right)$ em unidades de $\hbar$ para os ligantes $O$ e para o $C u$ para o monômero neutro e carregado. Nomenclatura dos sítios segundo a Fig. 4.6 b. . . . . . . . . . . . . . . . . . . . . 103

4.6 Diferença em energia total $(\Delta \mathrm{E})$ para as configurações ferromagnética e antiferromagnética para diferentes coordenações (quadrado planar e quadrado planar distorcida) e diferentes estados de cargas. . . . . . . . . . . . . . . . 106

A.1 Valores experimentais e calculados com o CP-PAW de GCE nos sítios de $N$ para os ligantes piridina, pirazina, imidazol e $\mathrm{NH}_{3}$. Apresentamos também as componentes do tensor GCE $\left(V_{n n}\right)$ em $10^{21} \mathrm{~V} / \mathrm{m}^{2}$ calculados com o CP-PAW para a energia de corte de 90 Ry. $\nu_{Q}=e Q V_{z z} / h(\mathrm{MHz})$ onde $Q$ é o momento de quadrupolo elétrico nuclear para determinado sítio representado pela Eq.

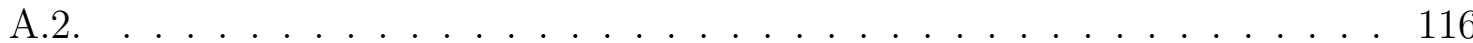


A.2 GCE nos sítios de $\mathrm{N}$ e $\mathrm{O}$ ligantes e no $\mathrm{Cu}$ para o complexo $\left[\mathrm{Cu}(\text { apyhist }) \mathrm{H}_{2} \mathrm{O}\right]^{2+}$ (tri-1) e também para o ligante na geometria do complexo e para a geometria di ligante otimizada (OPT). Utilizamos a nomenclatura para os sítios conforme a Fig. 3.2. (i) coordenação quadrado planar (cb) Fig. 3.2 b e e; (ii) coordenação distorcida (cc) Fig. 3.2 c e d; (iii) coordenação distorcida (cb) Fig. 3.2 b e d. Vzz em $10^{21} \mathrm{~V} / \mathrm{m}^{2}$ e corte em energia de 90 Ry para os complexos e de 40 Ry para os ligantes. . . . . . . . . . . . . . . . 117

A.3 GCE nos sítios ligantes e no $\mathrm{Cu}$ para o corte em ondas planas para 70 Ry. Vzz em $10^{21} \mathrm{~V} / \mathrm{m} 2$. [Cu(isapn) $] 2+$ (oxi-1), [Cu(isaepy) 2]2+ (oxi-2), $[\mathrm{Cu}($ isaenim $)] 2+($ oxi-3),$[\mathrm{Cu}($ enim $) \mathrm{H} 2 \mathrm{O}] 2+($ oxi-4) . . . . . . . . . . 119

B.1 Energia total (Hartree) e GCE (Vzz em $\left.10^{21} \mathrm{~V} / \mathrm{m} 2\right)$ nos sítios ligantes de $N$ e $O$ e para $C u$ para o corte em ondas planas em 40 Ry para o complexo tri-1. Nomenclatura dos sítios conforme Fig. 3.2 a. . . . . . . . . . . . . . . . . . . 122

B.2 Energia de ligação, autovalores e gap de energia para os complexos $\left[\mathrm{Cu}(\mathrm{H} 2 \mathrm{O})_{n}\right]^{2+} .123$ 


\section{Lista de Figuras}

1.1 a) Representação esquemática da estrutura básica das bases de Schiff. b) Exemplo da reação de um aldeído (ou cetona) e uma amina primária formando uma base de Schiff ou imina (figura reproduzida da referência [10]). . . . . .

1.2 Esquema das potenciais aplicações dos complexos de cobre estudados. Potenciais metalofármacos $[12,15]$; Ligantes competitivos por $\mathrm{Cu}$ em meio biológico [16, 17]; Catalisadores [18,19]; Miméticos de sítios ativos de metaloproteínas [20,21]; Complexos multinucleares com propriedades magnéticas e catlíticas $[19,22] \ldots \ldots \ldots \ldots \ldots \ldots \ldots \ldots \ldots \ldots \ldots \ldots \ldots \ldots \ldots \ldots \ldots \ldots \ldots$

1.3 Representação esquemática dos complexos de cobre da série das piridinas, pirazinas e histaminas tridentadas estudadas neste trabalho utilizando a mesma nomenclatura para designar os complexos e os ligantes (entre parênteses) introduzida na Ref. [10]. Na linha abaixo a nomenclatura simplificada empregada neste trabalho.

1.4 Representação esquemática dos complexos de cobre da série das piridinas, pirazinas e histaminas tetradentadas estudadas neste trabalho utilizando a mesma nomenclatura para designar os complexos e os ligantes (entre parênteses) introduzida na Ref. [17]. Na linha abaixo a nomenclatura simplificada empregada neste trabalho. . . . . . . . . . . . . . . . . . . 
1.5 Representação esquemática dos complexos de cobre da série dos oxindóis estudados neste trabalho utilizando a mesma nomenclatura para designar os complexos e os ligantes (entre parênteses) introduzida na Ref. [16]. Na linha abaixo a nomenclatura simplificada empregada neste trabalho. . . . . . . .

1.6 a) Representação artística da HSA (código PDB:1N5U) com o destaque das regiões do aminoácido cis-34 e dos aminoácidos do sítio N-terminal. b) Representação do sítio N-terminal constituído pelos três primeiros aminoácidos ASP1, ALA2 e HIS3 e parte do quarto resíduo (LYS4) da sequência poli-

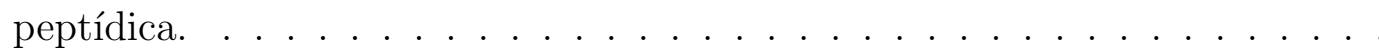

1.7 Representação dos aminoácidos constituintes da cavidade que permite o acesso ao aminoácido cis-34 da HSA (código pdb 1N5U). Representação artística da superfície de potencial eletrostático em três perspectivas diferentes da cavidade da cis-34.

1.8 Espectros de CD da titulação de HSA com os complexos: A) $\left[\mathrm{Cu}\left(\mathrm{H}_{2} \mathrm{O}\right)\right]^{2+}$; B) $\left[\mathrm{Cu}(\text { isaepy })_{2}\right]^{2+}$ (oxi-2); C) $\left[\mathrm{Cu}(\text { apzhist }) \mathrm{H}_{2} \mathrm{O}\right]^{2+}$ (tri-4); D) $\left[\mathrm{Cu}(\text { apzhist }) \mathrm{H}_{2} \mathrm{O}\right]^{2+}$ $\left(\right.$ tri-4) $+\mathrm{NEM}$; E) $\left[\mathrm{Cu}(\text { apyhist }) \mathrm{H}_{2} \mathrm{O}\right]^{2+}$ (tri-1); F) $\left[\mathrm{Cu} \text { (apyhist) } \mathrm{H}_{2} \mathrm{O}\right]^{2+}$ (tri1) $+\operatorname{NEM}[16,45] \ldots \ldots \ldots \ldots \ldots \ldots$

1.9 (a) Representação esquemática da estrutura do DNA e seus nucleotídeos: em destaque as ligações de hidrogênio entre as bases nitrogenadas adenina e timina (A-T) e guanina e citosina (G-C); detalhe da ligação fosfodiéster com o açúcar. (b) Bases nitrogenadas do DNA e do ácido ribonucleico (RNA) da família das purinas e das pirimidinas. (c) Detalhe do açúcar ribose (RNA) e deoxiribose (DNA). Numeração padronizada para o backbone onde a ligação fosfodiéster ocorre entre os carbonos $3^{\prime}$ e $5^{\prime}$. Figura reproduzida da referência

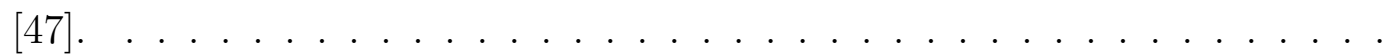

1.10 Representação esquemática de uma base modificada de DNA complexada com metal em uma sequência natural de DNA [59]. . . . . . . . . . . . . . . 
1.11 Representação da base modificada de hidroxipiridona (Hy) ligada ao açúcar deoxiribose determinada por difração de raios-X [54]; a distância $O-O$ é de $3.187 \AA$ e a $H-H$ de $2.447 \AA$.

1.12 (esquerda) Representação esquemática do experimento da complexação de cinco íons $\mathrm{Cu}^{2+}$ na estrutura de hidroxipiridona $[\mathrm{Hy}-\mathrm{Cu}-\mathrm{Hy}]_{5}$. (direita) Espectro de EPR indicando as modificações a cada inserção de $\mathrm{Cu}^{2+}$. Figura reproduzida da referência $[60] \ldots \ldots \ldots$. . . . . . . . . . . .

1.13 Representação esquemática da estrutura de bases modificadas de DNA complexada com cobre. a) monômero b) arranjo espacial separado a $3.7 \AA$ e $36^{\circ}$ de rotação entre os planos adjacentes c) Vista superior do pentâmero d) vista lateral do pentâmero. Figura reproduzida da Ref. [64]. . . . . . . . . . . . .

2.1 Representação esquemática de uma molécula diatômica. As regiões no interior das esferas $\Omega$ são chamadas de regiões 'aumentadas' augmentation, onde, devido ao forte potencial nuclear, a função de onda varia rapidamente. Fora das esferas temos a região intersticial com funções de onda mais suaves. . . .

2.2 Representação esquemática das três contribuições para a função total (AE) de um elétron. De cima para baixo: Função de onda AE, função de onda auxiliar, função de onda parcial e função de onda parcial auxiliar. A função de onda auxiliar é idêntica a total fora de $\Omega$, e a função de onda parcial é idêntica a total dentro de $\Omega$ (Figura retirada da referência [96]). . . . . . . .

3.1 Representação das estruturas precursoras: a) hist, possuindo o heterocíclo imidazol ou imid; b) epy, possuindo o heterocíclo piridina ou py; c) apy, possuindo o heterocíclo piridina ou py; d) apz, possuindo o heterocíclo pirazina ou $p z$; e) $i s a ; f) e n ; \mathrm{g}) d a c$; h) pn. Alguns átomos de $\mathrm{H}$ foram removidos para melhor visualização. Representação das cores: carbono (cinza), nitrogênio (azul), oxigênio (vermelho) e hidrogênio (branco). . . . . . . . . . . . . 
3.2 Representação do complexo tri-1 com as posições atômicas relaxadas para as duas conformações de mínimo estrutural encontradas. a) Nomenclatura para os átomos de $C$ e $N$; b) Representação da conformação 'para baixo' (cb); c) Representação da conformação 'para cima' (cc). d) Representação esquemática do plano que contém os átomos ligantes de $N$ com o sítio de $O$ (em vermelho) e o íon $C u$ abaixo deste plano (coordenação quadrado planar distorcida); e) Representação esquemática do plano que contém os átomos ligantes de $N$ com todos os sítios coplanares (coordenação quadrado planar). Representação das cores: carbono (cinza), nitrogênio (azul), oxigênio (vermelho), cobre (laranja) e hidrogênio (branco) . . . . . . . . . . . . . .

3.3 Representação dos resultados obtidos para o complexo tri-1 com a) conformação para baixo (cb); b) conformação para cima (cc); c) Ângulo de abertura entre N-N-N; d) Ângulo de torção entre N-N-Cu-N (direita). Distâncias de ligação em $\AA$.

3.4 Distâncias de ligação para as estruturas relaxadas para dois mínimos conformacionais obtidas com o PAW para o estado oxidado a) $\left[\mathrm{Cu}(\text { apyhist }) \mathrm{H}_{2} \mathrm{O}\right]^{2+}$ (tri-1) b) $\left[\mathrm{Cu}(\text { apzhist }) \mathrm{H}_{2} \mathrm{O}\right]^{2+}\left(\right.$ tri-4) c) $\left[\mathrm{Cu}(\text { apyepy }) \mathrm{H}_{2} \mathrm{O}\right]^{2+}\left(\right.$ tri-2) d) $\left[\mathrm{Cu}(\text { apyhist }) \mathrm{H}_{2} \mathrm{O}\right]^{2+}$ (tri-1) e) $\left[\mathrm{Cu}(\text { apzhist }) \mathrm{H}_{2} \mathrm{O}\right]^{2+}\left(\right.$ tri-4) f) $\left[\mathrm{Cu} \text { (apzepy) } \mathrm{H}_{2} \mathrm{O}\right]^{2+}$ (tri-3). Para o estado reduzido: g) $\left.\left.\left[\mathrm{Cu}(\text { apyhist }) \mathrm{H}_{2} \mathrm{O}\right]^{+} \mathrm{h}\right)\left[\mathrm{Cu}(\text { apzhist }) \mathrm{H}_{2} \mathrm{O}\right]^{+} \mathrm{i}\right)\left[\mathrm{Cu}(\text { apyepy }) \mathrm{H}_{2} \mathrm{O}\right]^{+} .50$

3.5 Representação dos complexos e seus ligantes isolados (em amarelo) após relaxação estrutural: a) tri-1; b) tri-2; c) tri-3; d) tri-4. . . . . . . . . . . . . . . 54

3.6 Densidade de estados (DOS) total e projetada nos sítios ligantes e no $C u$ para o complexos tridentados para os estados ocupados e desocupados de mais alta energia. a) tri-1, b) tri-2, c) tri-4 d) tri-3. . . . . . . . . . . . . . .

3.7 Densidade de estados (DOS) total e projetada nos sítios ligantes e no $C u$ para o complexos tridentados. Orbitais mais altos ocupados e o primeiro orbital desocupado (LUMO). a) tri-1, b) tri-2, c) tri-4 d) tri-3. . . . . . . . . . . . 
3.8 Representação esquemática dos complexos de cobre estudados da literatura. Na linha abaixo a nomenclatura simplificada empregada neste trabalho. . . . 59

3.9 Representação dos ligantes isolados com as posições atômicas relaxadas. a) pyalen; b) dachist em dois mínimos estruturais sobrepostos para as estruturas 'aberta' e 'fechada'; c) apzpn. . . . . . . . . . . . . . . . . . .

3.10 Representação esquemática para os complexos com as posições atômicas relaxadas no estado oxidado com as respectivas distâncias de ligação $\mathrm{Cu}-\mathrm{N}$ (em $\AA$ ): a) tetra-2 b) tetra-3 c) tetra-5 d) tetra-1 e) tetra-4 f) tetra-7 g) tetra-6.

3.11 Representação esquemática para os complexos com as posições atômicas relaxadas com carga total $1+e$ (estado reduzido) com as respectivas distâncias de ligação $\mathrm{Cu}-\mathrm{N}$ (em $\AA$ ): a) tetra-2 b) tetra-3 c) tetra-5 d) tetra-1 e) tetra-4.

3.12 Representação esquemática para os complexos com as posições atômicas relaxadas no estado oxidado com os respectivos ângulos de torção $N_{4}$ (em graus):

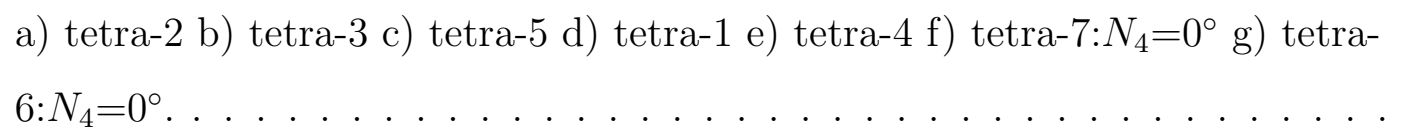

3.13 Representação esquemática para os complexos com as posições atômicas relaxadas com carga total $1+$ (estado reduzido) com os respectivos ângulos de torção $N_{4}$ (em graus): a) tetra-2 b) tetra-3 c) tetra-5 d) tetra-1 e) tetra-4. .

3.14 Representação do complexo tetra-2 em dois mínimos locais conformacionais.a) Torcido: ângulo de torção $N_{4}=17.60^{\circ}$. b) Plano: ângulo de torção $N_{4}=0.03^{\circ}$.

3.15 Representação esquemática para as simetrias $D_{4 h}$ e $D_{2 h}$ estudadas para os compostos tetra-8 $\left(\left[\mathrm{Cu}(\mathrm{py})_{4}\right]^{2+}\right)$ e tetra-9 $\left(\left[\mathrm{Cu}(\mathrm{imid})_{4}\right]^{2+}\right)$. . . . . . . .

3.16 Representação das estruturas relaxadas para o $\left[\mathrm{Cu}(\text { imid })_{4}\right]^{2+}$, tetra-9 (esquerda) e $\left[C u(p y)_{4}\right]^{2+}$, tetra-8 (direita) com as distâncias de ligação $\mathrm{Cu}-\mathrm{L}$ em

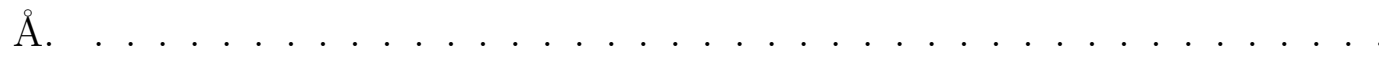


3.17 Densidade de estados (DOS) total e projetada nos ligantes $N$ e no íon $C u$ para o a) tetra-2 na conformação 'torcida' para o estado oxidado $[\mathrm{Cu}(\text { pyalen })]^{2+}$; b) conformação planar para o estado oxidado $[\mathrm{Cu}(\text { pyalen })]^{2+}$; c) conformação para o estado reduzido. $[\mathrm{Cu}(\text { pyalen })]^{+}$; d) conformação para o estado sem carga $[\mathrm{Cu}($ pyalen $)] \ldots \ldots \ldots \ldots \ldots$

3.18 Densidade de estados (DOS) total e projetada nos sítios de $N$ ligantes e no íon $C u$ para a) o complexo $\left[C u(p y)_{4}\right]^{2+}$; b) o ligante $p y_{4}$ na conformação do complexo; c) o complexo $\left[\mathrm{Cu}(\mathrm{imid})_{4}\right]^{2+}$; d) o ligante $\mathrm{imid}_{4}$ na conformação do complexo. . . . . . . . . . . . . . . . . . .

3.19 Densidade de estados (DOS) total e projetada nos sítios de $N$ ligantes e no $C u$ para o estado oxidado. A escala superior refere-se aos complexos $[\mathrm{Cu}$ (porfirina) $]$ e $[\mathrm{Cu}$ (ftalocianina) $]$ e a inferior aos demais complexos. . . . .

3.20 Densidade de estados (DOS) total e projetada nos sítios de $N$ ligantes e no $C u$ para o estado reduzido. . . . . . . . . . . . . . . .

3.21 Representação dos complexos com as posições atômicas otimizadas obtidas com o CP-PAW para a) oxi-1; b) oxi-2; c) oxi-3; d) oxi-4. Distâncias de ligação $\mathrm{Cu}-\mathrm{L}$ em $\AA$. . . . . . . . . . . . . . . . . . . . . . .

3.22 Densidade de estados (DOS) total e projetada nos sítios ligantes e no $C u$ para os complexos oxindóis. a) $\left[\mathrm{Cu}(\text { enim }) \mathrm{H}_{2} \mathrm{O}\right]^{2+}$; b) $[\mathrm{Cu}(\text { isapn })]^{2+}$;c) $[\mathrm{Cu}(\text { isaenim })]^{2+}$ ;d) $\left[\mathrm{Cu}(\text { isaepy })_{2}\right]^{2+} \ldots \ldots \ldots \ldots \ldots \ldots \ldots$. . . . . . . . . . . . . . . 81

3.23 Representação dos níveis eletrônicos e dos orbitais de mais alta energia para o complexo oxi-1, $[\mathrm{Cu}(\text { isapn })]^{2+} \ldots \ldots \ldots \ldots$

3.24 Representação das estruturas com as posições atômicas relaxadas para os sítios N-terminal da $[C u(B S A)]^{+}$e da $[C u(H S A)]^{+}$e as respectivas distâncias Cu-

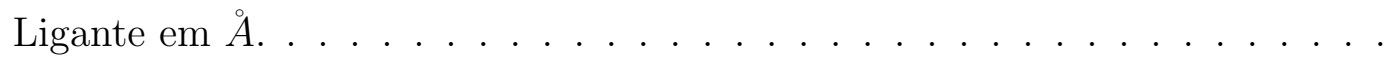

3.25 Representação gráfica das distâncias de ligação médias $(\mathrm{Cu}-\mathrm{L}) / 4$ para os complexos investigados em angstrons. 
3.26 Representação dos complexos na vista frontal (e para alguns a vista lateral). 'Ângulo de abertura' e 'distância de abertura' (em Å) para os complexos estudados. a) $[\mathrm{Cu}(\text { pyalen })]^{2+}$ b) $[\mathrm{Cu}(\text { pyen })]^{2+}$ c) $[\mathrm{Cu}(\text { apzpn })]^{2+}$ d) $[\mathrm{Cu}(\text { dachist })]^{2+}$ e) $\left.\left.\left.[\mathrm{Cu}(\text { apzhist }) \mathrm{H} 2 \mathrm{O}]^{2+} \mathrm{f}\right)[\mathrm{Cu}(\text { apyepy }) H 2 O]^{2+} \mathrm{g}\right)[\mathrm{Cu}(\text { apzepy }) H 2 O]^{2+} \mathrm{h}\right)$ $[\mathrm{Cu}(\text { apyhist }) \mathrm{H} 2 \mathrm{O}]^{2+}$ i) $\left.[\mathrm{Cu}(\text { enim }) \mathrm{H} 2 \mathrm{O}]^{2+} \mathrm{j}\right)[\mathrm{Cu}(\text { isaepy }) \mathrm{H} 2 \mathrm{O}]^{2+}$. . . . . . .

3.27 Sequência dos aminoácidos mais relevantes constituintes da cavidade da próxima a cis-34. Em vermelho representamos os aminoácidos com resíduos de hidrocarbonetos apolares; em azul representamos os resíduos polares com sítios de $N$ e $O$; em amarelo o sítio da cis-34; em branco os resíduos que não estão orientados em direção a cavidade. A estrutura secundária indica a organização tridimensional na sequência polipeptídica: a) A hélice representa a conformação helicoidal entre os aminoácidos formado através de ligações de hidrogênio; b) A alça representa a conformação sem estrutura tridimensional definida, com maior flexibilidade, que nesta proteína interliga as diferentes hélices $[46] \ldots \ldots \ldots \ldots \ldots \ldots \ldots \ldots \ldots \ldots \ldots \ldots \ldots \ldots \ldots \ldots$

3.28 Representação esquemática dos aminoácidos constituintes da cavidade da cis34 para a estrutura cristalográfica da proteína albumina [33]. Em vermelho os aminoácidos com os resíduos de hidrocarbonetos; em azul os resíduos polares com sítios de $N$ e $O \ldots \ldots \ldots \ldots \ldots$

3.29 Representação esquemática do vetor momento de dipolo para os complexos tridentados. a) Orientação do vetor momento de dipolo em relação a conformação para baixo (cb) para cima (cc). b) Momento de dipolo para os complexos tri-1 a tri-4. . . . . . . . . . . . . . . .

4.1 Representação esquemática para os sistemas estudados de $[\mathrm{Cu} \text { (hidroxipiridona) }]_{n}$ com vista superior e lateral: a) monômero $[\mathrm{Hy}-\mathrm{Cu}-\mathrm{Hy}]$; b) dímero $[\mathrm{Hy}-\mathrm{Cu}-$ $\mathrm{Hy}]_{2} ;$ c) tetrâmero $[\mathrm{Hy}-\mathrm{Cu}-\mathrm{Hy}]_{4} \ldots \ldots \ldots \ldots \ldots$ 
4.2 Representação esquemática do complexo [Hy-Cu-Hy] com total relaxação das posições atômicas. Em laranja o sítio de cobre e em vermelho os ligantes oxigênio. Coordenação Cu-L quadrado planar e distâncias de ligação em ang-

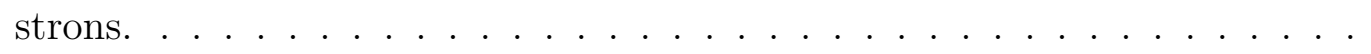

4.3 Densidade de estados (DOS) total e projetada nos sítios ligantes de oxigênio e no $\mathrm{Cu}$ para o tetrâmero de $[\mathrm{Hy}-\mathrm{Cu}-\mathrm{Hy}]_{4}$ com spin total $=2 \hbar$. Em destaque a representação dos orbitais $\mathrm{HOMO}$ e do orbital com caráter $\mathrm{d}_{z^{2}}$ (figura dos orbitais reproduzida da Ref. [64]. . . . . . . . . . . . . . .

4.4 Distâncias de ligação metal ligantes para o monômero de [Hy-Cu-Hy] nas configurações geométricas, eletrônicas e de spin: a)cis, carga $0 e$, spin $0.5 \hbar$; b)trans, carga $0 e$, spin $0.5 \hbar$; c)trans, carga $1 e$, spin $1.0 \hbar$; d)trans carga 1

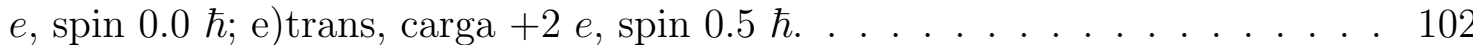

4.5 Densidade de estados total e projetada nos ligantes e no $C u$. Acima: coor-

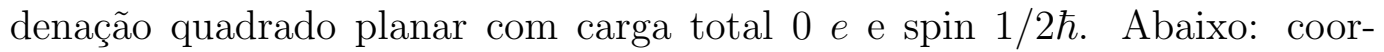
denação quadrado planar distorcida com carga +2 e e spin $1 / 2 \hbar$. . . . . . . 104

4.6 Diferença de densidade de $\operatorname{spin}(\Delta \rho)$ para o a) $[\mathrm{Hy}-\mathrm{Cu}-\mathrm{Hy}]$; b) $[\mathrm{Hy}-\mathrm{Cu}-\mathrm{Hy}]^{2+}$; c) $\left.[\mathrm{Hy}-\mathrm{Cu}-\mathrm{Hy}]_{2} ; \mathrm{d}\right)[\mathrm{Hy}-\mathrm{Cu}-\mathrm{Hy}]_{2}^{4+}$.

4.7 Representação da estrutura otimizada para o monômero ligado ao backbone com as distâncias de ligação $\mathrm{CuL}$ em $\AA$ e o ângulo diedral $\mathrm{O}_{4}$ de $12^{\circ}$. Em destaque o ângulo diedral da estrutura cristalográfica sem o íon $C u$. . . . . .

4.8 Estruturas do dímero interligado pelo backbone com spin total 1 . a) Estrutura otimizada com o vínculo entre os sítios de $C u$ em $3.6 \AA$ b) Detalhe das distâncias de ligação $\mathrm{Cu}-\mathrm{L}$ para o estudo com o vínculo entre os sítios de $C u$ em $3.6 \AA$ c) Detalhe das distâncias de ligação $\mathrm{Cu}-\mathrm{L}$ para o estudo com total relaxação estrutural.

B.1 Representação esquemática dos vinte aminoácidos presentes no ser humano $[154]$ 


\section{Referências Bibliográficas}

[1] James E. House. Inorganic Chemistry. Elsevier, Oxford, (2008).

[2] Shriver; Atkins. Atkins Química Inorgânica. Bookman, São Paulo, (2003).

[3] Catherine E. Housecroft and Alan G. Sharpe. Inorganic Chemistry. Pearson Second Edition, London, (2005).

[4] S. J. Lippard and J. M. Berg. Principles of Bioinorganic Chemistry. University Science Books, Mill Valley, (2006).

[5] Y. M. Kuo, B. Zhou, D. Cosco, and J. Gitschier. PNAS, 98, (2001).

[6] Wolfgang Kaim and Brigitte Schwederski. Bioinorganic Chemistry: Inorganic Elements in the Chemistry of Life. John Wiley and Sons, New York, (2005).

[7] M. R. Ciriolo, G. Rotilio, and L. Rossi. Cell. Mol. Life Sci., 60:1733, (2003).

[8] Yves Jean. Molecular Orbitals of Transition Metal Complexes. Oxford University Press, New York, (2005).

[9] James E. Huheey, Ellen A. Keiter, and Richard L. Keiter. Inorganic Chemistry: Principles of Structure and Reactivity (4th Edition). Harper Collins College Publishers, New York, (1993).

[10] Mariana Pedrinha Abbott. Modificações Oxidativas em proteínas em presença de complexos de cobre(II), :Tese de Doutorado IQUSP São Paulo, (2007). 
[11] P. L. Holland and W. B. Tolman. Coord. Chem. Rev., 190 192:855, (1999).

[12] V. C. da Silveira, J. S. Luz, C. C. Oliveira, I. Graziani, M. R. Ciriolo, and A. M. C. Ferreira. J. Inorg. Biochem., 102:1090, (2008).

[13] G. Cerchiaro, K. Aquilano, G. Filomeni, G. Rotilio, M. R. Ciriolo, and A. M. D. C. Ferreira. J. Inorg. Biochem., 99:1433, (2005).

[14] K. A. Koch, M. Marjorette, and D. J. Thiele. Chemistry and Biology, 4:549, (1997).

[15] G. Filomeni, S. Piccirillo, I. Graziani, S. Cardaci, A. M. D. C. Ferreira, G. R., and M. R.Ciriolo. Carcinogenesis, 30:1115, (2009).

[16] V. C. da Silveira, G. F. Caramori, M. P. Abbott, M. B. Gonçalves, H. M. Petrilli, and Ana Maria da Costa Ferreira. J. Inorg. BioChem., 103:1331, (2009).

[17] M. A. de A. Azzellini, M. P. Abbott, A. Machado, M. T. M. Miranda, L. C. Garcia, G. F. Caramori, M. B. Gonçalves, H. M. Petrilli, and A. M. D. C. Ferreira. J. Braz. Chem. Soc, 21:1303, (2010).

[18] W. A. Alves, G. Cerchiaro, A. Paduan-Filho, D. M. Tomazela, M. N. Eberlin, and A. M. D. C. Ferreira. Inorganica Chimica Acta, 358:3581 3591, (2005).

[19] W. A. Alves, I. O. Matos, P. M. Takahashi, E. L. Bastos, H. Martinho, J. G. Ferreira, C. C. Silva, R. H. de A. Santos, A. Paduan Filho, and A. M. D. C. Ferreira. Eur. J. Inorg. Chem., 15:2219, (2009).

[20] A. M. D. C. Ferreira, M. L. P D. Santos, E. M Pereira, M. O. Damasceno, and W. A. Alves. An. Acad. Bras. Ciênc., 1:72, (2000).

[21] M. L. P. dos Santos, A. F. Alario, A. S. Mangrich, and A. M. D. C. Ferreira. Journal of Inorganic Biochemistry, 71:71, (1998). 
[22] W. A. Alves, R. H. de A. Santos, A. P. Filho, C. C. Becerra, A. C. Borin, and A. M. D. C. Ferreira. Inorganica Chimica Acta, 357:2269, (2004).

[23] Giselle Cerchiaro. Reatividade e Implicações em Processos Biológicos de Complexos Iminicos de Cobre(II), :Tese de Doutorado IQUSP São Paulo, (2005).

[24] W. A. Alves, A. C. SantAna, M. P. Abbott, P. H. de Mello, H. Martinho, R. H. A. Santos, J. G. Ferreira, M. L. A. Temperini, A. Paduan-Filho, and A. M. D. C. Ferreira. Science of Advanced Materials, 2:173, (2010).

[25] J. Ghuman. J. Mol. Biol., 38:353, (2005).

[26] T. Peters Jr. Advances in Protein Chemistry, 37:161, (1985).

[27] D. C. Carter and X. Ho Joseph. Adv. Protein Chem., 45:153, (1994).

[28] Theodore Peters Jr. All about Albumin Biochemistry, Genetics, and Medical Applications. Academic Press (Elsevier), New York, (1992).

[29] A. G. Bearn and H. G. Kukel. PTOC. Sot. Exp. Biol. Med., 88:44, (1954).

[30] Y. Zhang and D.E. Wilcox. J. Biol. Inorg. Chem., 7:327, (2002).

[31] S. J. Lau, T. P. A. Kruck, and B. Sarkar. J. Biol. Chem., 249:5878, (1974).

[32] J. P. Laussac and B. Sarkar. Biochem., 23:2832, (1984).

[33] D. C. Carter, X. M. He, S. H. Munson, P. D. Twigg, K. M. Gernert, M. B. Broom, and T. Y. Miller. Science, 244:1195, (1989).

[34] P. Gizzi, B. Henry, P. Rubini, and E. Wenger S. Giroux. J. Inorg. Biochem., 99:1182, (2005).

[35] S. de Silva, R. M. de Silva, and K. M. N; de Silva. Journal of Molecular Structure (Theochem), 711:73, (2004). 
[36] B. R. Kima and H. T. Kim. Journal of Molecular Structure: Theochem, 868:109, (2008).

[37] J. N. Zvimba and G. E. Jackson. Polyhedron, 26:2395, (2007).

[38] W. Bal, J. Christodoulou, P.J. Sadler, and A. Tucker. J. Inorg. Biochem, 70:33, (1998).

[39] K. Oettl and R. E. Stauber. British Journal of Pharmacology, 151:580, (2007).

[40] M.Rozga, M. Sokolowska, A. M. Protas, and W. Bal. J. Biol. Inorg. Chem., 12:913, (2007).

[41] P.J. Sadler, A. Tucker, and J.H. Viles. Eur. J. Biochem, 220:193, (1994).

[42] W. Bal, J. Christodoulou, P.J. Sadler, and A. Tucker. J. Inorg. Biochem, 70:22, (1998).

[43] M. Valko, H. Morris, M. Mazur, J. Telser, E.J.L. McInnes, and F.E. Mabbs. J. Phys. Chem. B, 103:5591, (1999).

[44] M. Rózga, M. Sokolowska, A.M. Protas, and W. Bal. J. Biol. Inorg. Chem., 12:913, (2007).

[45] M. A. A. Azzellini, M. P. A. A. Machado, M. T. M. Miranda, and A. M. C. Ferreira. Comunicação privada, .

[46] D. L. Nelson and M. N. Cox. Lehninger, Principles of Biochemistry. 3rd Ed. Worth Publishing, New York, (2000).

[47] J. M. Berg, J. L. Tymoczko, and L. Stryer. Biochemistry. W H Freeman, New York, (2002).

[48] R. Di Felice and D. Porath. Springer DNA Based Nanoelectronic, , (2006).

[49] D. D. Eley and D. I. Spivery. Trans. Faraday Soc, 58:411, (1962). 
[50] M. Taniguchi and T. Kawai. Physica E, 33:1, (2006).

[51] K. Tanaka, M. K. G. Schlegel, L. O. Essen, and E. Meggers. J. Am. Chem. Soc., 130:8158, (2008).

[52] M. K. Schlegel, L. O. Essen, and E. Meggers. J. Am. Chem. Soc., 130:8158, (2008).

[53] J. Sponer, P. Jureka, and P. Hobza. J. Am. Chem. Soc., 126:10142, (2004).

[54] K. Tanaka, A. Tengeiji, T. Kato, N. Toyama, M. Shiro, and M. Shionoya. J. Am. Chem. Soc., 124:12494, (2002).

[55] E.B. Starikov, J.P. Lewis, and S. Tanaka. Modern Methods for Theoretical Physical Chemistry of Biopolymers, :Elsevier, (2006).

[56] A. Rakitin, P. Aich, C. Papadopoulos, Yu. Kobzar, A. S. Vedeneev, J. S. Lee, and J. M. Xu. Phys. Rev. Lett., 86:3670, (2001).

[57] S. S. Alexandre, J. M. Soler, L. Seijo, and F. Zamora. Phys. Rev. B, 73:205112, (2006).

[58] R. Di Felice, A. Calzolari, and H. Zhang. Nanotechnology, 15:1256, (2004).

[59] K. Tanaka and M. Shionoya. J. Org. Chem., 64:5002, (1999).

[60] K. Tanaka, A. Tengeiji, T. Kato N. Toyama, and M. Shionoya. Science, 299:1212, (2003).

[61] G. Brancolini and R. Di Felice. J. Phys. Chem. B, 112:14281, (2008).

[62] G. H. Clever and T. Carell. Angew. Chem. Int. Ed., 46:250, (2007).

[63] K. Tanaka, G. H. Clever, Y. Takezawa, C. Kaul, M. Shionoya, and T. Carell. Nature Nanotechnology, 1:190, (2006).

[64] H. Y. Zhang, A. Calzolari, and R. di Felice. J. Phys. Chem. B, 109:15345, (2005). 
[65] S. S. Mallajosyula and S. K. Pati. Phys. Rev. Lett., 98:136601, (2007).

[66] T. Matsui, H. Miyachi, T. Sato, Y. Shigeta, and K. Hirao. J. Phys. Chem. B, 112:16960, (2008).

[67] Y. Nakanishi, Y. Kitagawa, Y. Shigeta, T. Saito, T. Matsui, H. Miyachi, T. Kawakami, M. Okumura, and K. Yamaguchi. Polyhedron, 28:1945, (2009).

[68] F. L. Gervasio, P. Carloni, and M. Parrinello. Phys. ReV. Lett., 89:108102, (2002).

[69] S. S. Mallajosyula and S. K. Pati. Angew. Chem. Int. Ed., 48:4977, (2009).

[70] W. Kohn. Rev. Mod. Phys., 71:1253, (1999).

[71] P. E. Blöchl. Phys. Rev. B, 50:17953, (1994).

[72] M.J. Frisch et al. Gaussian 03 Revision A.1, :Gaussian Inc. Pittsburgh PA, (2003).

[73] R. Car and M. Parrinello. Phys. Rev. Lett., 55:2493, (1985).

[74] J. D. M. Viana, A. Fazzio, and S. Canuto. Teoria Quântica de Moléculas e Sólidos. Livraria da Física, Sao Paulo, (2004).

[75] P. Hohenberg and W. Kohn. Phy. Rev., 136:864, (1964).

[76] W. Kohn and L. J. Sham. Phy. Rev., 140:1133, (1965).

[77] K. Capelle. Braz. J. Phys., 36:1318, (2006).

[78] C. J. Cramer and D. G. Truhlar. Phys. Chem. Chem. Phys., 11:10757, (2009).

[79] B. F. Ghermana and C. J. Cramer. Coord. Chem. Rev., 253:723, (2009).

[80] Wolfram Koch and Max C. Holthausen. A Chemist's Guide to Density Functional Theory. Wiley-VCH Verlag GmbH, Germany, (2001).

[81] V.I. Anisimov, J. Zaanen, and O.K. Andersen. Phys. Rev. B, 44:943, (1991). 
[82] H. Vázquez, P. Jelínek, M. Brandbyge, and F. Flores A.P. Jauho. Appl Phys A, 95:257, (2009).

[83] R. K. Szilagyi, M. Metz, and E. I. Solomon. J. Phys. Chem. A, 106 (12):2994, (2002).

[84] A. D. Becke. Phys. Rev. A, 38:3098, (1988).

[85] J. P. Perdew. Electronic Structure of Solids. ed. P. Ziesche and H. Eschrig, Akademie Verlag, Berlin, (1991).

[86] G. Artur. Dissertação de Mestrado, :Accurate redox potentials of transition metal complexes calculated using density functional theory and electrostatics, (2008).

[87] J. Poater, M. Sola, A. Rimola, L. Rodriguez-Santiago, and M. Sodupe. J. Phys. Chem. A, 108:6072, (2004).

[88] J.P. Perdew, K. Burke, and M. Ernzerhof. Phys. Rev. Lett., 77:3865, (1996).

[89] J. P. Perdew. Phys. Rev. B, 33:8822, (1986).

[90] Marcos Brown Gonçalves. Efeitos de estado sólido e ligações de hidrogênio sobre o gradiente de campo elétrico no núcleo no imidazol, Dissertação de Mestrado, (2006).

[91] D. J. Singh. Planewaves, pseudopotentials, and the LAPW method. Kluwer Academic Publishers, Boston, (1994).

[92] N. W. Ashcroft and N. D. Mermin. Solid State Physics Vol.5. Saunders College Publishing, Fort Worth, (1976).

[93] Hans Martin Senn. "Transition metal catalysed hydroamination od alkenes: theoretical studies using ab initio molecular dynamics" Tese de Doutorado, , (2001).

[94] J.C. Phillips and L. Kleinman. Phys. Rev., 116:287, (1959).

[95] P. Blöchl. www.arxiv.org/abs/cond mat/0201015, , (2002). 
[96] Andrei Huamantinco. "Estudo da superfície Au(111) e da adsorção de 'Ch IND.3 S' em Au(111) através do método PAW" Tese de Mestrado, , (2003).

[97] M. A. Santos, L. Y. A. Dávila, H. M. Petrilli, R. B. Capaz, and M. J. Caldas. J. Comp. Chem., 27:217, (2005).

[98] Attila Szabo and Neil S. Ostlund. Modern Quantum Chemistry: Introduction to Advanced Electronic Structure Theory.

[99] E. R. Davidson and D. Feller. Chem.Rev., 86:661, (1988).

[100] David B. Cook. Handbook of Computational Quantum Chemistry. Oxford University Press, New York, (1998).

[101] James B. Foresman and Eleen Frisch. Exploring Chemistry With Electronic Structure Methods: A Guide to Using Gaussian. Gaussian, Inc, Pittsburg, PA, (1994).

[102] A. Schafer, H. Horn, and R. Ahlrichs. J. Chem. Phys., 97:2571, (1992).

[103] A. Schafer, C. Huber, and R. Ahlrichs. J. Chem. Phys., 100:5829, (1994).

[104] K. P. Jensen, B. O. Roos, and U. Ryde. J Chem Phys., 126:14103, (2007).

[105] B. T. O. Holt, M. A. Vance, L. M. Mirica, D. E. Heppner, T. D. P. Stack, and E. I. Solomon. J. Am. Chem. Soc., 131:6421, (2009).

[106] M. C. Payne, M. P. Teter, D. C. Allan, T. A. Arias, and J. D. Joannopoulos. Rev. Mod. Phys., 64:1045, (1992).

[107] G. Pastore, E. Smargiassi, and F. Buda. Phy. Rev. A, 44:6334, (1991).

[108] M. A. de A. Azzellini, I. A. Bagatin, and A. M. D. C. Ferreira. Redox Report, 11:25, (2006). 
[109] Catherine E. Housecroft and Alan G. Sharpe. Chemistry An Introduction to Organic, Inorganic and Physical Chemistry. Pearson Second Edition, London, (2005).

[110] A. M. D.C. Ferreira, H. E. Toma, and A. C. Massabni. Química Nova, 7:9, (1984).

[111] R. D. Nelson Jr., D. R. Lide, and A. A. Maryott. www.nist.gov/data/nsrds/NSRDSNBS-10.pdf, :data de acesso: outubro 2010, (1967).

[112] E.M. Fielden, G. Rotilio, and R. Lontie (Ed.). Copper Proteins and Copper Enzymes. CRC Press in Boca Raton, (1984).

[113] S.F. Boys and F. Bernardi. Mol. Phys., 19:553, (1970).

[114] P. M. Dias, L. Kinouti, V. R.L. Constantino, M. B. Gonçalves, R. R. do Nascimento, H. M. Petrilli, M. Caldas, R. C. G. Frem, and A. M.D.C. Ferreira. Quimica Nova, , (aceito para publicação).

[115] M. L. P. Santos, I. A. Bagatin, E. M. Pereira, and A. M. D. C. Ferreira. J. Chem. Soc., Dalton Trans., :838, (2001).

[116] M.A. Bizeto, W. A. Alves, C. A. S. Barbosa, A.M.D.C. Ferreira, and V. R. L. Constantino. Inorg. Chem., 45:6214, (2006).

[117] J. Muller, Dieter Schubl, C. M. Mossmer, J. Strahle, and U. Weser. J. of Inorg Biochem., 75:63, (1999).

[118] L. Puskar, H. Cox, A. Goren, G. D. C. A., and A. J. Stace. Faraday Discuss., 124:259, (2003).

[119] X. Lu, K. W. Hipps, X. D. Wang, and U. Mazur. J. Am. Chem. Soc., 118:7197, (1996).

[120] N. Marom, O. Hod, G. E. Scuseria, and L. Kronik. J. of Chem. Phys, 128:164107, (2008). 
[121] N. Aratani and A. Osuka. Handbook of Porphyrin Science, , (2010).

[122] F. Evangelista, V. Carravetta, G. Stefani, B. Jansik, S. Stranges, and A. Ruocco. J. Chem. Phys., 126:124709, (2007).

[123] M. S. Liao and S. Scheiner. J Comput Chem, 23:1391, (2002).

[124] F. Evangelista, V. Carravetta, G. Stefani, B. Jansik, M. Alagia, S. Stranges, and A. Ruocco. J. of Chem. Phys, 126:124709, (2007).

[125] P. Deschamps, P.P. Kulkarni, M. Gautam-Basak, and B. Sarkar. Coord. Chem. Rev., 249:895, (2005).

[126] G. Cerchiaro and A. M. D. C. Ferreira. J. Braz. Chem. Soc., 17:1473, (2006).

[127] Nick Hadjiliadis and Einar Sletten. Metal Complex DNA Interactions. John Wiley and Sons, Ltd., Londres, (2009).

[128] Terry P. Kenakin. A Pharmacology Primer. Theory, Applications and Methods. Academic Press, New York, (2006).

[129] G. Filomeni, G. Cerchiaro, A.M.D.C. Ferreira, A. De Martino, J.Z. Pedersen, G. Rotilio, and M.R. Ciriolo. J. Biol. Chem., 282:12010, (2007).

[130] M. Wardell, Z. Wang, J.X. Ho, J. Robert, F. Ruker, and J. D.C. Carter. Biochem. Biophys. Res.Commun., 291:813, (2002).

[131] G. W. Neilson. J. Phys. C: Solid State Phys, 15:L233, (1982).

[132] C. G. Palivan, V. Balasubramanian, and B. A. Goodman. Eur. J. Inorg. Chem., :4634, (2009).

[133] S. Del Piero, P. Di Bernardo, R. Fedele, A. Melchior, P. Polese, and M. Tolazzi. Eur. J. Inorg. Chem., :3738, (2006). 
[134] J. Sponer, Leszczynski J, and P. Hobza. Biopolymers, 61:3, (2002).

[135] A.J. Stewart, C.A. Blindauer, S. Berezenko, D. Sleep, D. Tooth, and P.J. Sadler. FEBS Journal, 272:53, (2005).

[136] M.T.N. Petersen, P.H. Jonson, and S.B. Petersen. Prot. Eng., 12:535, (1999).

[137] S. Venkadesh, P.K. Mandal, and N. Gautham. :código pdb: 3IXN, www.rcsb.org data de acesso 12/2010.

[138] A.M.J.J. Bonvin. Eur. Biophys. J., 29:57, (2000).

[139] J. Rezac and P. Hobza. Chem. Eur. J., 13:2983, (2007).

[140] Gunter Schatz and Alois Weidinger. Nuclear Condensed Matter Physics. John Wiley and Sons, Chichester, England, (1996).

[141] Y. Deligiannakis, M. Louloudi, and N. Hadjiliadis. Coordination Chemistry Reviews, 204:1, (2000).

[142] Y. P. Ginotra and P. P. Kulkarni. Inorg. Chem., 48:7000, (2009).

[143] M. B. Gonçalves, R. Di Felice, O. Kh. Poleshchuk, and H. M. Petrilli. Hyperfine Interactions, 181:53, (2008).

[144] T. P. Das and E. L. Han. Nuclear Quadrupole Resonance Spectroscopy. Academic Press, New York, (1958).

[145] W. Witthuhn and W. Engel. Topics in Current Physics Hyperfine Interactions of Radioactive Nuclei. Springer Verlag, Berlin, 1983.

[146] Helena Maria Petrilli. "Metodo de calculo do gradiente de campo eletrico no nucleo para sistemas sem simetria” Tese de Doutorado, , (1989).

[147] W. C. Bailey. Chem. Phys., 252:57, (2000). 
[148] S.G.Kukolich. J.Chem.Phys, 49:5523, (1968).

[149] J. W. A. Coremans, O. G. Poluektov, E. J. J. Groenen, G. W. Canters, H. Nar, and A. Messerschmidt. J. Am. Chem. Soc., 118:12141, (1996).

[150] J. W. A. Coremans, O. G. Poluektov, E. J. J. Groenen, G. W. Canters, H. Nar, and A. Messerschmidt. J. Am. Chem. Soc., 119:4726, (1997).

[151] P E. Blöchl. J. Chem Phys, 103:7422, (1995).

[152] L. A. Errico, M. Renteria, and H. M. Petrilli. Physica B, 31, (2006).

[153] V. S. Bryantsev, M. S. Diallo, A. C. T. van Duin, and W. A. Goddard. J. Phys. Chem. A, 112:9104, (2008).

[154] http://biotech.matcmadison.edu. :data de acesso outubro de 2010. 